\title{
Improvement of maize-based foods in Sub-Saharan Africa
}

$=$

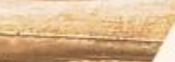

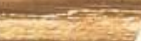

trimasy

$\sqrt{2-15}$

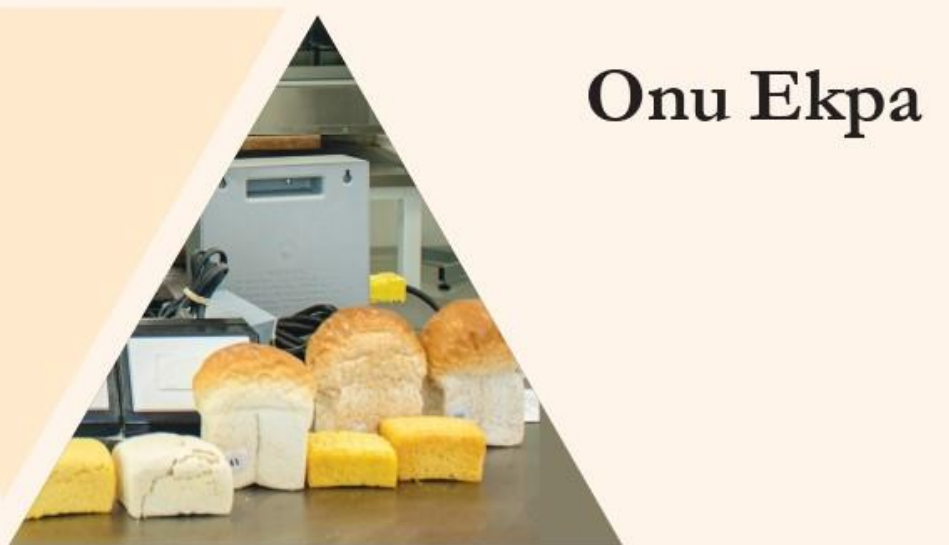




\section{Propositions}

1. Disconnection between maize breeders and end users is very costly. (this thesis)

2. Gluten-free bread can be made from maize using sourdough technology. (this thesis)

3. Humankind is coded to multiply beyond its limit but the efforts of both the "wizards and prophets" distinguishes our fate from Oostvaardersplassen's red deer.

4. Homo sapiens will become extinct in the futuristic world of the designer baby.

5. Your ghost continues writing in the middle of the night.

6. Storytelling gives science its soul.

Propositions belonging to the thesis, entitled

\section{Improvement of maize-based foods in Sub-Saharan Africa}

Onu Ekpa

Wageningen, 28th August 2020. 
Improvement of maize-based foods in Sub-Saharan Africa

Onu Ekpa 


\section{Thesis committee}

\section{Promotor}

Prof. Dr V. Fogliano

Professor of Food Quality and Design

Wageningen University \& Research

\section{Co-promotor}

Dr A. R. Linnemann

Associate professor, Food Quality and Design Group

Wageningen University \& Research

\section{Other members}

Prof. Dr R. Ruben, Wageningen University \& Research

Prof. Dr E. Vittadini, University of Camerino, Italy

Prof. Dr M.J. Kropff, International Maize and Wheat Improvement Centre (CIMMYT), Mexico City, Mexico

Dr E.F. Talsma, Wageningen University \& Research

This research was conducted under the auspices of the Graduate School VLAG (Advanced Studies in Food Technology, Agrobiotechnology, Nutrition and Health Sciences) 
Improvement of maize-based foods in Sub-Saharan Africa

\section{Onu Ekpa}

\section{Thesis}

submitted in fulfilment of the requirements for the degree of doctor at Wageningen University by the authority of the Rector Magnificus

Prof. Dr A.P.J. Mol, in the presence of the

Thesis Committee appointed by the Academic Board

to be defended in public

on Friday 28 August 2020

at 4 p.m. in the Aula. 
Onu Ekpa

Improvement of maize-based foods in Sub-Saharan Africa, 227 pages.

$\mathrm{PhD}$ thesis, Wageningen University, Wageningen, the Netherlands (2020)

With references, with summary in English

ISBN: 978-94-6395-440-2

DOI: https://doi.org/10.18174/525331 
Table of contents

Chapter $1 \quad$ General introduction and thesis outline 9

Chapter 2 Sub-Saharan African maize-based foods - processing 27

practices, challenges and opportunities

Chapter 3 Sub-Saharan African maize-based foods: Technological

71

perspectives to increase the food and nutrition security

impacts of maize breeding programmes

Chapter 4 Identification of the volatile profiles of 22 traditional and

newly bred maize varieties and their porridges by PTR-

QiTOF-MS and HS-SPME/GC-MS

Chapter 5 Carotenoid stability and aroma retention during the post-

125

harvest storage of biofortified maize

Chapter 6 Genotype selection influences the quality of gluten-free

bread from maize

Chapter 7 Influence of exopolysaccharides produced by lactic acid

bacteria on the quality of maize bread

Chapter 8 General discussion

General Summary

Acknowledgement

About the Author

List of publications 



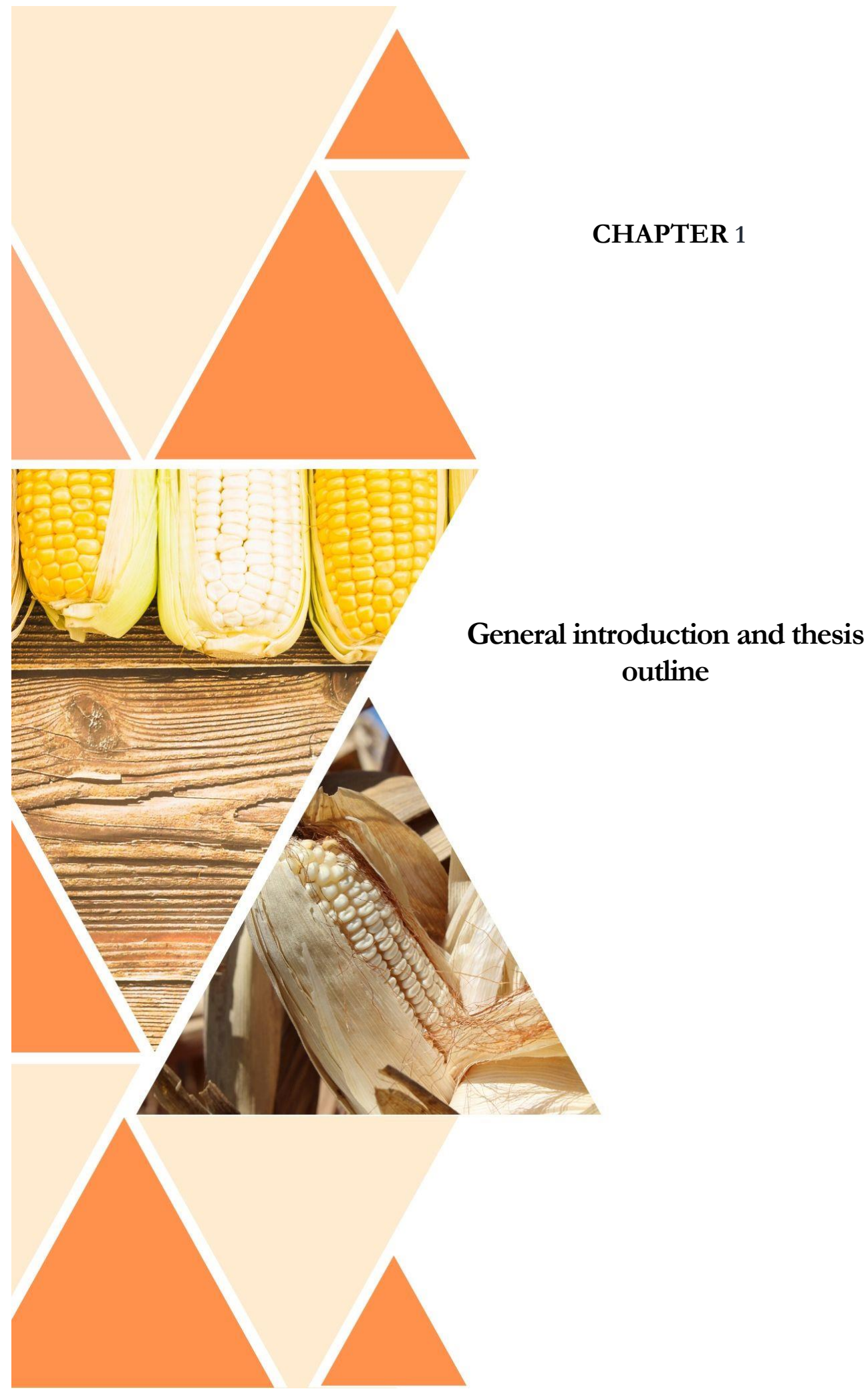




\subsection{Trends in cereal production and consumption in Africa}

The predominant cereal crops in Africa are maize, rice, wheat, sorghum and millet, with maize contributing $45 \%$ of the cereal production and mostly being used as food [1-3], (Figure 1.1). In 2018, worldwide maize production was 1,074 million tonnes (MT), with the United States, China, Brazil and Mexico producing 34.4\% (370 MT), 20.7\% (223 MT), $8.3 \%$ (90 MT) and 2.4\% (26 MT), respectively. [3] Africa as a whole produces $8 \%$ (84 MT) of the total world production. South Africa and Nigeria are the largest producing countries in Africa, with an average production of 15 MT and 11 MT, respectively; together these countries account for 31\% of Africa's maize production. ${ }^{33}$ Despite the huge production of maize in the United States and China, merely 34 and 18 $\mathrm{g} /$ person/day, respectively, is consumed as food in these countries. The per capita consumption of maize in Sub-Saharan Africa (SSA) is an average of $130 \mathrm{~g} /$ day, with values varying extensively. For instance, inhabitants of Lesotho consume 449 g/person/day, Malawians (359 g), Zambians (307 g), Zimbabweans (297 g) and South Africans $(271 \mathrm{~g}) .{ }^{[2]}$ These figures signify the paramount importance of maize in the daily diet of Africans. Africa uses more than $80 \%$ of its maize production as food, contrary to other regions where maize is mostly reserved for animal feed, biofuel and industrial uses. $[1,4,5]$
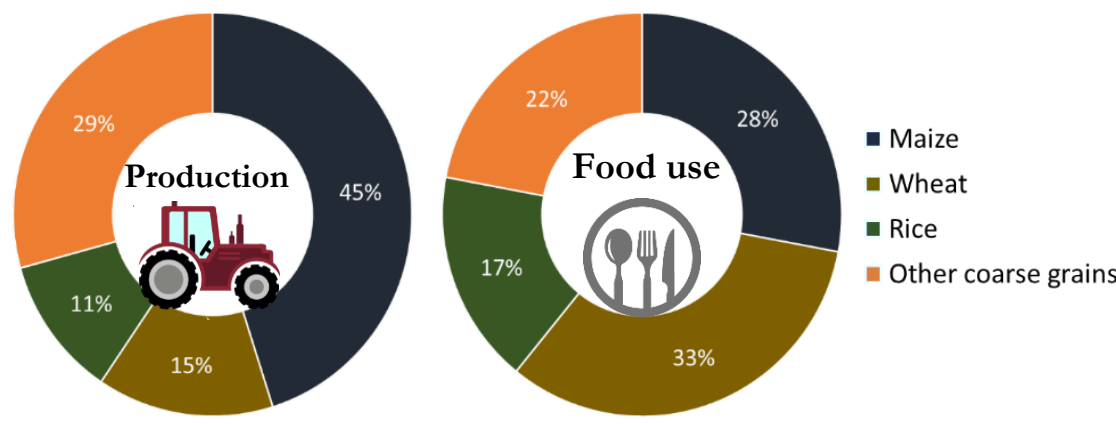

Figure 1.1: Africa's cereal production and food use. Adapted from OECD-FAO Agricultural Outlook 2018.

The asymmetry in the production and food use of cereals in Africa needs a change to avert an impending food security crisis. For instance, production of wheat (Figure 1.2 chart A) is low but wheat remains the predominantly consumed cereal, mainly for bakery use, pasta and noodles (Figure 1.2 - chart B). SSA produces $1.0 \%$ of world wheat production and $23.7 \%$ of Africa's production. ${ }^{[6]}$ As the agro-ecological conditions in SSA are generally unsuitable for wheat production, African countries depend on importation to cater for the ever-rising drive for food produced from crops not sufficiently grown locally. This unsustainable trend, if left unchecked, will continue to 
hurt the economy and possibly trigger food crises - not ruling out uprising and riots as observed in Mozambique, Sudan, Zimbabwe and during the popular "Arab spring". Import dependent staple crop economy often prompt supply issues and high price volatility causing food insecurity and driving social unrest. The trend raises the need to find solutions to issues related to poor shelf life, poor baking properties, food safety, a decrease of nutritional value and sensory properties of maize (and other resilient and climate-smart indigenous crops) for baked foods, particularly bread making.

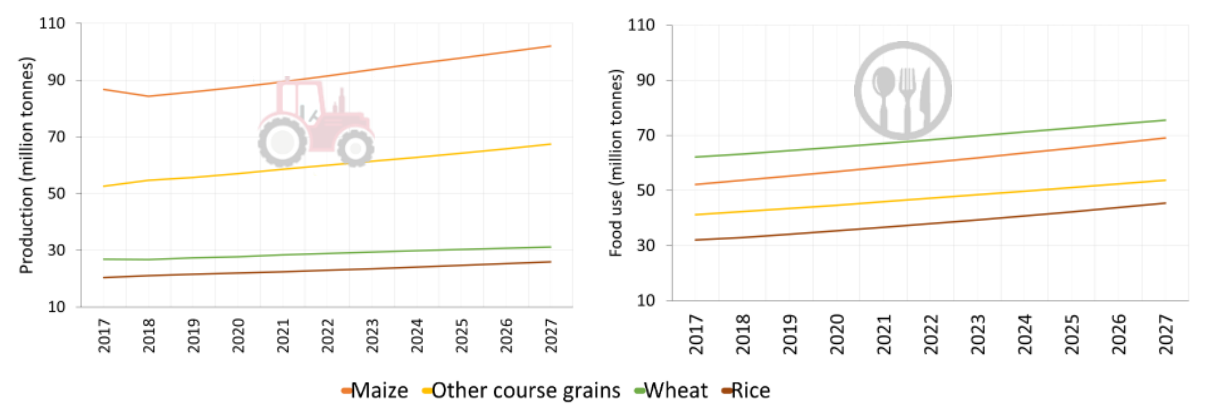

Figure 1.2: Projected cereal production (chart A) and food use (chart B) in SSA.

Adapted from OECD-FAO Agricultural Outlook 2018.

Maize is an integral part of the daily diet of many Africans, serving as a significant source of energy and protein, albeit heavy reliance can result in malnutrition due to natural deficiencies of some nutrients or losses during post-harvest handling. This buttresses the need for continued investigation of feasible ways to improve the nutritional values of maize foods, enhance maize food diversity as well as encourage acceptance of nutrient-dense varieties, which is the overarching aim of this thesis - improvement of maizebased foods in Sub-Saharan Africa.

\subsection{Contribution of maize to the daily diet of Africans}

\subsubsection{Caloric intake}

Cereals account for about $80 \%$ of the total caloric intake in Africa, with maize as the major contributor. Maize contributes as much as $55 \%$ of the total energy consumption in Lesotho, $50 \%$ in Zambia, 49\% in Malawi, 40\% in Zimbabwe and 31\% in Kenya. ${ }^{22,7]}$ The presented consumption data are based on average national figures. Region-specific data could show higher diversity; for example, in Chongwe district of Zambia, maize contributes for at least $75 \%$ to the total energy intake ${ }^{8]}$ and a vast multicultural country like Nigeria could even show a wider diversity. Maize supplies on average $363 \mathrm{kcal} / 100$ $\mathrm{g}$ [7,9]; less than $200 \mathrm{~g} / \mathrm{capita} /$ day of maize is needed to meet the $130 \mathrm{~g}$ Recommended Dietary Allowance (RDA) for carbohydrates. ${ }^{[10]}$ People in some countries in SSA are now consuming far more than this amount. Therefore, in these countries, assorted 
energy sources in the meal are needed, rather than an increase in maize consumption. According to the OECD agricultural projection 2018 - 2027, Africa will experience a continuous rise (1.5 - 2.5\% per annum) in the production of legumes, meat, fish and dairy products. ${ }^{[3]}$ This demonstrates the available potential for food diversification to address malnutrition or hidden hunger that may result from over-reliance on maize meal.

\subsubsection{Protein and essential amino acids}

Maize accounts for more than $30 \%$ of the total daily protein intake in Kenya, Lesotho, Malawi, Zambia, Zimbabwe and Swaziland. [2] Since the protein in maize is poor in essential amino acids (e.g. lysine and tryptophan), people who highly depend on maize for their nutrition may incur problems associated with protein deficiencies. [11] This is particularly relevant since the available protein can be lost during traditional processing. ${ }^{[12]}$ However, quality protein maize (QPM) has higher amounts of lysine and tryptophan due to an about $50 \%$ reduction in the level of zein.[13]

Assuming an average maize intake of $130 \mathrm{~g} /$ person/day [2] in Africa and an 80\% nutrient retention after cooking, both adults and children are not able to meet the RDA for protein through maize intake, see Table 1.1. A child (1-2 yr.) can derive all the needed amino acids from quality protein maize (QPM) except for lysine (i.e. an additional intake of $43 \mathrm{~g}$ per day is needed to meet the lysine requirement), while only threonine and leucine can be sufficiently derived from conventional maize. An adult is not able to meet the daily dietary requirement for protein and all essential amino acids (e.g. an adult requires an impossibly high additional intake of $775 \mathrm{~g}$ of conventional maize or $543 \mathrm{~g}$ QPM to meet the daily requirement for lysine). Although protein and amino dietary requirements cannot be achieved by either the normal and QPM varieties, it is obvious that a lower quantity of protein from maize is needed when other quality protein staple crops are available.[13] 
Table 1.1: Estimated daily intake (g) from common and quality protein maize (QPM) to meet the protein and essential amino acid requirements of a $70 \mathrm{~kg}$ adult and $12 \mathrm{~kg}$ child.

\begin{tabular}{|c|c|c|c|c|c|c|c|}
\hline Maize type & Protein & Trp & Thr & Lys & Leu & Ile & Val \\
\hline Common $(100 \mathrm{~g})^{\text {a }}$ & 9.0 & 0.07 & 0.30 & 0.29 & 1.32 & 0.31 & 0.39 \\
\hline QPM (100 g) a & 9.8 & 0.09 & 0.38 & 0.39 & 0.96 & 0.34 & 0.54 \\
\hline \multicolumn{8}{|c|}{ Recommended Dietary Allowance (g/kg-bw/day) ${ }^{\mathrm{b}}$} \\
\hline Adult (70 kg) & 46.2 & 0.28 & 1.05 & 2.10 & 2.73 & 1.40 & 1.82 \\
\hline child (1-2) yrs, $12 \mathrm{~kg}$ & 10.3 & 0.08 & 0.28 & 0.54 & 0.65 & 0.32 & 0.43 \\
\hline \multicolumn{8}{|c|}{ Intake balance sheet: g maize /person/day to meet $\mathrm{RDA}^{\mathrm{c}, \mathrm{d}}$} \\
\hline Adult (common) & -512 & -370 & -308 & -775 & -129 & -435 & -453 \\
\hline Adult (QPM) & -459 & -259 & -215 & -543 & -224 & -385 & -294 \\
\hline Child (common) & -13 & -7 & +15 & -103 & +69 & -1 & -8 \\
\hline Child (QPM) & -2 & +23 & +39 & -43 & +46 & +11 & +29 \\
\hline \multicolumn{8}{|c|}{$\begin{array}{l}\text { Authors' calculations based on the following sources: } \\
\text { a Data derived from Qi } \text { et al. }{ }^{[14]} \text {, Prasanna } \text { et al. }{ }^{[15]} \text { and Mbuya } \text { et al. }{ }^{[16]} \\
\text { b Recommendations provided by WHO }{ }^{[17]} \text { and Schönfeldt } \text { et al. } .^{13]} \\
\text { c Calculated quantity of additional maize required to meet RDA, assuming an average maize intake of } 130 \\
\text { g/person/day in Africa (without information on the complete meal). The negative sign indicates an intake deficit while } \\
\text { a positive sign indicates a surplus. } \\
\text { d Assumed protein and amino acid retention of } 80 \% \text { after cooking. }{ }^{[18]}\end{array}$} \\
\hline
\end{tabular}

\subsubsection{Vitamin A}

White maize, which unfortunately contains insignificant retinol activity, is usually preferred in most parts of Africa where vitamin A deficiency prevails. ${ }^{[19]}$ Vitamin A deficiency is still rampant in Africa. ${ }^{[20]}$ Vitamin A deficiency results in preventable vision loss, poor growth, and immune weakness, which increases the risk of infections and premature death. ${ }^{21,22]}$ Provitamin A (i.e. $\alpha$-carotene, $\beta$-carotene and $\beta$-cryptoxanthin) and non-provitamin $A$ (i.e. zeaxanthin and lutein with no vitamin $A$ activity) carotenoids are found mainly in yellow maize in different proportions, i.e. from high to low - lutein $>$ zeaxanthin $>\beta$-carotene $>\beta$-cryptoxanthin $>\alpha$ - carotene (Table 1.2). Bioconversion of dietary carotenoids to vitamin A was established at $12 \mu \mathrm{g} \beta$-carotene, and $24 \mu \mathrm{g} \alpha$ carotene or $\beta$-cryptoxanthin equivalent to $1 \mu \mathrm{g}$ retinol activity. ${ }^{[2]}$ However, the bioconversion rate is influenced by the food matrix, food processing, differences in individual genetic variability and the amount of fat in the diet. Processing activities could also denaturalize carotenoids, which have consequences on the bioavailability. About $40 \%$ of $\beta$-carotene could be lost during traditional processing of maize-based foods due to the removal of pericarp and germ. ${ }^{[23]}$ Muzhingi et al. [24] found that the conversion factor of yellow maize $\beta$-carotene to $1 \mu \mathrm{g}$ retinol by weight is $3.2 \pm 1.5$, Li et al. [25] found $6.5 \pm 3.5 \mu \mathrm{g} \beta$-carotene and Gannon et al. ${ }^{20]}$ calculated $10.4 \mu \mathrm{g} \beta$-carotene for $\beta$ carotene-biofortified maize. This signifies that the $\beta$-carotene in yellow-orange maize is an efficacious source of vitamin A.[20] 
The amount of carotenoids in maize is genetically improved through conventional breeding by exploiting the naturally occurring variation in provitamin A carotenoid concentrations.[26] In breeding programmes between 2012 - 2018, more than 30 provitamin A enriched maize varieties were released in SSA.[26-29] Aside from breeding efforts, identification of the most effective provitamin A maize-based food matrix, suitable traditional processing and storage methods could have a significant impact on meeting the target for carotenoids in maize for vitamin A deficient populations. The overall nutritional contribution of provitamin A maize could be significantly reduced by the loss of carotenoids along the value chain. Understanding the parameters necessary for optimal handling of provitamin A biofortified maize, to enable better acceptance and higher impact on the target population is needed. Therefore, a better understanding of critical postharvest parameters to prevent vitamin A degradation during storage under tropical conditions is a crucial study area.

Table 1.2: Major carotenoids in maize

\begin{tabular}{|l|c|c|}
\hline \multirow{2}{*}{ Carotenoids } & Conventional maize & \multicolumn{1}{|c|}{$\begin{array}{c}\text { Biofortified maize } \\
(\text { orange) }\end{array}$} \\
\cline { 2 - 3 } & \multicolumn{2}{|c|}{ min.- max. $(\boldsymbol{\mu g} / \mathbf{g})$} \\
\hline Lutein & $1.3-32.3$ & $0.9-14.1$ \\
\hline Zeaxanthin & $0.4-34.9$ & $1.2-37.5$ \\
\hline $\boldsymbol{\beta}$ - cryptoxanthin & $0.0-6.1$ & $0.7-8.8$ \\
\hline $\boldsymbol{\beta}$ - carotene & $0.0-7.6$ & $1.3-13.0$ \\
\hline $\boldsymbol{\alpha}$ - carotene & $0.0-2.3$ & - \\
\hline
\end{tabular}

${ }^{a}$ Data adapted from Ortiz-Monasterio $e$ t al. ${ }^{[23]}$ : carotenoids in over 1000 tropical maize genotypes identified at CIMMYT, - not determined. ${ }^{\mathrm{b}}$ Data adapted from Muzhingi et al. ${ }^{[28]}$, Pillay et al. ${ }^{[30]}$ and Cabrera-Soto et al. [31]

\subsubsection{Mineral intake and the influence of the anti-nutrient phytate}

In most countries in Africa, maize plays a critical role in the total zinc and iron intake, i.e. more than $10 \%$ of the zinc and iron supply in about 24 countries is derived from maize. [2] In fact, in Zambia, Zimbabwe, Lesotho and Malawi more than $50 \%$ of total zinc supply is from maize consumption. Furthermore, with the advent of maize biofortified with zinc, which contains up to $34 \mu \mathrm{g}$ zinc/g (normal maize contains 20 $\mu \mathrm{g}$ zinc/g grain), these countries and many more can meet the daily requirement for zinc for adults and even exceed the requirement for children. With the relatively high genetic diversity of zinc in maize (mean $20 \pm 5$, range $15-47 \mu \mathrm{g} / \mathrm{g}$ ), further improvements of maize through biofortification is achievable.[23] Though the known genetic diversity in iron contents in maize is low (mean 25, range $11-39 \mu \mathrm{g} / \mathrm{g}$ ) [23], improvement through further identification of genetic diversity in iron levels, multiple aleurone traits, and exploration of the latest genome editing techniques seem promising as measures to help alleviate anaemia and associated problems.[32] 
Although the increase in the mineral contents of maize is of great importance, their use for normal body functions, i.e. bioavailability, is limited due to the presence of antinutrients such as phytate. A substantial increase in micronutrient bioavailability has been reported after traditional processing, e.g. fermentation and lime-cooking, as well as due to the use of low phytic acid bred maize and transgenic bred maize containing Aspergillus phyA (encoding phytase). [32] Maize accounts for 39.4\% of the total phytate supply in SSA, with eastern and southern Africa having the largest burden (Table 1.4). A complete reduction of phytate intake from maize through processing and breeding programmes could achieve a decrease of $20-60 \%$ in the overall phytate intake, with huge consequences for mineral bioavailability.

Table 1.3: Estimated mineral intake of an adult (31-50 yr.) and a child (1-3 yr.) from the current maize consumption rate

\begin{tabular}{|l|l|l|l|l|l|l|}
\hline & Ca & Cu & Fe & Mg & Se & Zn \\
\hline Maize (mg/100 g) $)^{\mathbf{a}}$ & 6.5 & 0.21 & 3.7 & 121 & 0.0019 & 1.8 \\
\hline \multicolumn{7}{|c|}{ Recommended Dietary Allowance (mg /day) } \\
\hline Adult (31-50 yr) & 1000 & 0.90 & $18^{*}$ & 420 & 0.06 & $11^{*}$ \\
\hline Child (1-3 yr) & 700 & 0.34 & 7 & 80 & 0.02 & 3 \\
\hline Intake Balance Sheet (i.e. amount of maize g/person/day needed to complete \\
RDA), d \\
\hline Adult (31-50 yr) & -19101 & -406 & -478 & -304 & -3488 & -634 \\
\hline Child (1-3 yr) & -13332 & -72 & -106 & +47 & -1186 & -78 \\
\hline
\end{tabular}

Authors' calculations based on the following resources:

aData averaged from Stadlmayr et al. [1], USDA [7] and Lukmanji et al. [33]

${ }^{\mathrm{b}}$ Recommendations provided by WHO [34]

c Calculated quantity of additional maize required to meet RDA, assuming an average maize intake of 130 $\mathrm{g} /$ person/day in Africa. The negative sign indicates intake deficit while positive indicates a surplus.

d Assumed retention of after cooking. [18,35]*Maximum RDA value for male or female was taken. 
Table 1.4: Estimated phytate intake (in \%) from maize consumption (g/capita/day) in Africa

\begin{tabular}{|l|c|c|c|c|}
\hline & $\begin{array}{c}\text { Maize } \\
\text { intake }\end{array}$ & $\begin{array}{c}\text { Phytate supply } \\
\text { by all foods }\end{array}$ & $\begin{array}{c}\text { Phytate intake } \\
\text { maize }\end{array}$ & $\begin{array}{c}\text { Phytate intake } \\
\text { from maize }\end{array}$ \\
\hline $\begin{array}{l}\text { Eastern } \\
\text { Africa }\end{array}$ & 156.1 & 2798 & 1169.5 & 41.8 \\
\hline $\begin{array}{l}\text { Middle } \\
\text { Africa }\end{array}$ & 87.3 & 1840 & 653.5 & 35.5 \\
\hline $\begin{array}{l}\text { Southern } \\
\text { Africa }\end{array}$ & 263.3 & 3254 & 1971.8 & 60.6 \\
\hline $\begin{array}{l}\text { Western } \\
\text { Africa }\end{array}$ & 76.8 & 2923 & 575.1 & 19.7 \\
\hline $\begin{array}{l}\text { Grand } \\
\text { Total }\end{array}$ & 134.9 & 2703.8 & 1092.5 & 39.4 \\
\hline
\end{tabular}

Authors' calculations based on the following resources:

*Average phytate per $100 \mathrm{~g}$ maize is $749 \mathrm{mg} .{ }^{[36,37]}$

* Maize supply, three-year average - 2009,2010 and 2011

*Data for phytate supply was derived from Joy et al. [38]

\subsection{Adoption of nutritionally improved maize varieties}

In response to the incessant malnutrition in developing countries, maize breeding programmes have given ample attention to improving the nutritional composition, for instance, a better protein quality by increased lysine and tryptophan, higher levels of minerals like iron and zinc, and increased vitamins such as in biofortified provitamin A maize. ${ }^{26,39,40]}$ Despite the agronomic competitiveness of the nutritionally improved varieties, the crops have a low adoption rate in Africa, for reasons ranging from grain colour to sensory perception. ${ }^{[41]}$ Conventional maize usually consumed in Africa is deficient in two essential amino acids, namely lysine and tryptophan - indispensable amino acids required for proper human physiological function and development. QPM has been bred to have twice the amount of these amino acids but the adoption rate in Africa remains abysmally low. White maize, which contains no retinol activity, remains the preferred in most parts of Africa where vitamin A deficiency is prevalent. ${ }^{[19]} \mathrm{A}$ similar fate befalls all improved varieties of maize meant to solve one nutrition problem or the other. Obviously, a lasting solution to the nutritional challenges of SSA has no general remedy but requires a holistic chain approach.

\subsection{Sensory profile of improved maize varieties}

In theory, if the flavour of the biofortified and improved varieties is not significantly altered by breeding and agronomic activities, their adoption and use for improvement of the nutritional status of the target group is likely to be successful. This is because biofortification tends to solve undernutrition problems without changing traditional ways of food processing and consumption. However, in the quest to unravel the reason for low adoption of the improved varieties, most attention has been given to research 
about consumer sensory evaluation using affective testing, e.g. using "like and dislike" questionnaires. Comparative analytical testing of the flavour profile of the different maize genotypes and the foods derived from them has not been executed, whereas the flavour profile is likely to be connected to consumer preferences. To complement and validate the current affective consumer studies on the improved varieties, critical laboratory assessments of the flavour profiles are needed to identify the deviations from the preferred traditional African maize varieties and also to determine the impact of deterioration due to storage under tropical conditions. Comparative tests are required since available sensory analyses appear to be very subjective and largely different in the vast swathes of Africa. The research on flavour analysis of different varieties present in Africa is necessary because one of the reasons for the dismissal of yellow maize was attributed to organoleptic properties, e.g. some respondents claim to hate the smell and taste of yellow maize-based foods. $[19,42-45]$

Deterioration of the volatile composition of maize during storage is likely, hence the analysis of volatiles associated with rancidity or off-odour is a worthy research area. For instance, the production of hexanal has been associated with rancidity of food products. ${ }^{[46,47]}$ Therefore, tracking the production of hexanal can help to set parameters to prevent off-odour and possibly help maize breeders to improve the crop for slower odour deterioration.

\subsection{Finding alternative to wheat-bread for SSA}

Several food technological options to improve the quality of maize-based foods in SSA require further research but should be attuned to users' needs and preferences. This implies the need for an assessment of the most relevant food processing practices as well as a proper understanding of consumer preferences with respect to different maizebased foods. In SSA, maize is used in a wide array of traditional food products. However, making bread from maize flour remains a technological challenge. ${ }^{[48]}$ With the large-scale urbanization and shift in preference for fast food, the demand for bread has increased in SSA. The population is caught up in need for food produced from wheat, a crop not sufficiently grown locally. To achieve food self-sufficiency and security in SSA, an alternative to wheat flour for bread making is needed. This has been acknowledged by many African countries, especially in West Africa, where over the years policies have pressed towards the incorporation of local ingredients to make composite flour for bakery use.[49] Since SSA produces nearly enough maize to meet domestic demands (Figure 1.1 and 1.2), improvement of maize flour functional properties could enhance its use for bread making, thereby reducing the dependence on wheat importation and even promoting the use of other indigenous crops. Maize, being the most cultivated crop in Africa, is the best alternative to wheat. However, it lacks 
functional gluten, the protein responsible for the favourable viscoelastic properties needed to achieve the desirable loaf quality attributes - volume and softness. Usually, to mimic the overall quality of wheat bread - flavour, texture properties, appearance and shelf-life - the addition of bread improvers such as hydrocolloids is required.[48] Unfortunately, the use of commercial hydrocolloids and other enhancers can substantially increase the cost of bread, which counters the original value proposition maize bread tends to offer. Therefore, there is a need to improve maize bread quality using existing traditional maize processing methods across the world, especially in SSA.

\subsection{Affordable methods for improving functional and nutritional quality of maize bread}

Methods such as nixtamalization (a Mesoamerican technique), pre-gelatinization, malting, fermentation (sourdough technique), screening for genotypes with improved baking performance and the addition of local ingredients such as soy protein could play a significant role in improving the quality of maize bread without significantly raising the cost. ${ }^{[50-52]}$ These methods are common in Africa, except for the nixtamalization technique. Nixtamalization is a method of cooking maize grains in lime (usually calcium hydroxide - slaked lime) to convert it to a more edible and digestible product as well as improve dough rheology.[53]

Screening for diversity of maize genotypes (hybrids and landraces) for bread-making performance has recently been reported to be an area of interest for gluten-free bread. ${ }^{[54]}$ Apart from deriving maize with improved bread-making performance, conservation of maize landraces would be encouraged. The growing introduction of hybrid maize varieties (typically unsuitable for bread making) has led to an increasing loss of maize landraces in the past two decades. ${ }^{[54]}$ This tendency increases the loss of genetic diversity and has partly contributed to the shift of most local communities to the use of wheat for bread in spite of affordability and availability issues. A recent assessment of the genomic properties of maize shows that the differences in the reported properties were associated with environmental factors rather than the intrinsic nature of the landraces. ${ }^{[5]}$ Presently, knowledge on the diversity of maize landraces in Mexico and SSA for breadmaking performance is lacking. Mexico is where maize was first domesticated before it spread to the rest of the world and to date around 60 maize landraces are still grown in the country.[55] These maize varieties could create opportunities in maize bread production, especially for the benefit of regions like SSA. Interestingly, maize landraces in Mexico are grown under a wide diversity of environmental conditions, i.e. altitude, temperature and water availability, indicating robustness to adapt and thrive in different regions. ${ }^{[55]}$ Besides, available studies reiterate the need to continue to exploit maize germplasm variability for bakery applications. ${ }^{[52,54-56]}$ 
Cereal-associated lactic acid bacteria (LAB) are known to produce exopolysaccharides (EPS), an extracellular secreted microbial polysaccharide that is known to improve the viscoelastic properties of dough for gluten-free bread making. ${ }^{[57]}$ Since fermentation is a common practice in Africa, research on the potential of in-situ synthesis of EPS in sourdough bread seems promising. In addition, EPS confers beneficial health effects such as improving gut health, immunomodulation bioactivity, anti-tumour and anticarcinogenic activity. ${ }^{[58,59]}$ Bacteria such as Weissella confusa, Lactobacillus reuteri and Leuconostoc mesenteroides have been reported to produce EPS, especially dextran, without strong acid production. The polymer is widely used in the food industry to increase the viscosity of sourdough to derive bread with increased loaf volume, crumb softness, freshness and improved mouthfeel.[60-63] This implies that through selection of existing EPS producing LAB in traditional food for starter culture, sourdough technology could be an affordable method for producing bread from maize in Sub-Saharan Africa.

\subsection{Overall objective}

The overall objective of this $\mathrm{PhD}$ thesis was to assess appropriate technology (i.e. suitable for adoption by maize users in local communities) to improve the nutritional quality as well as enhance diversification of maize-based foods in Sub-Saharan Africa, in order to contribute to the fight against malnutrition and socioeconomic issues in the region.

To do this, the following specific research objectives were identified:

- Assess maize-based food processing and consumption patterns and establish the objectives to meet processors' and consumers' needs and preferences.

- Determine the volatile profiles of the most commonly used maize varieties in SSA and their respective porridges.

- Evaluate carotenoid stability and volatile organic compound changes during maize storage in different packaging materials and conditions.

- Screen for maize genotypes to obtain maize flour suitable for making glutenfree bread.

- Enhance the functional properties of maize flour using readily available local techniques such as fermentation.

The specific research questions to address the identified objectives are presented in Figure 1.3.

\subsubsection{Thesis outline}

This general introduction provides information about the trends in maize production and consumption along with further analysis of the nutritional contribution of the crop 
to the daily diet of Africans. Research areas to encourage adoption of nutritionally improved maize varieties, as well as increase maize food diversity were elaborated. Chapter 2 focuses on the assessment of maize-based food processing and consumption patterns, while Chapter 3 further establishes the objectives to meet the needs and preferences of maize processors and consumers (Figure 1.3). The knowledge from both chapters led to the prioritization of a study on the volatile organic compounds in maize, which resulted in the analysis of 22 maize varieties commonly used in Africa as reported in chapter 4. Subsequently, it was concluded that volatile and provitamin A deterioration during storage under tropical conditions could be a major issue in the improved maize varieties. Therefore, in chapter 5, deterioration of carotenoids and volatile organic compounds of biofortified provitamin A maize is discussed on the basis of understanding the parameters to preserve the flavour and nutritional quality of the crop under tropical conditions and postharvest handling.

Chapter 6 presents research on the use of maize landraces, hybrids and thermoalkaline processed flour for bread making. Subsequently, in Chapter 7, the functional properties of sourdough produced from EPS secreting bacteria strains was studied. This was on the basis of making maize bread to reduce Africa's dependence on importation of wheat and to ameliorate the present incessant price fluctuation of bread across the continent. Finally, chapter 8 presents the general discussion of the major findings, analysis of the opportunities abound in Africa's maize value chain, future perspectives and concluding remarks. 


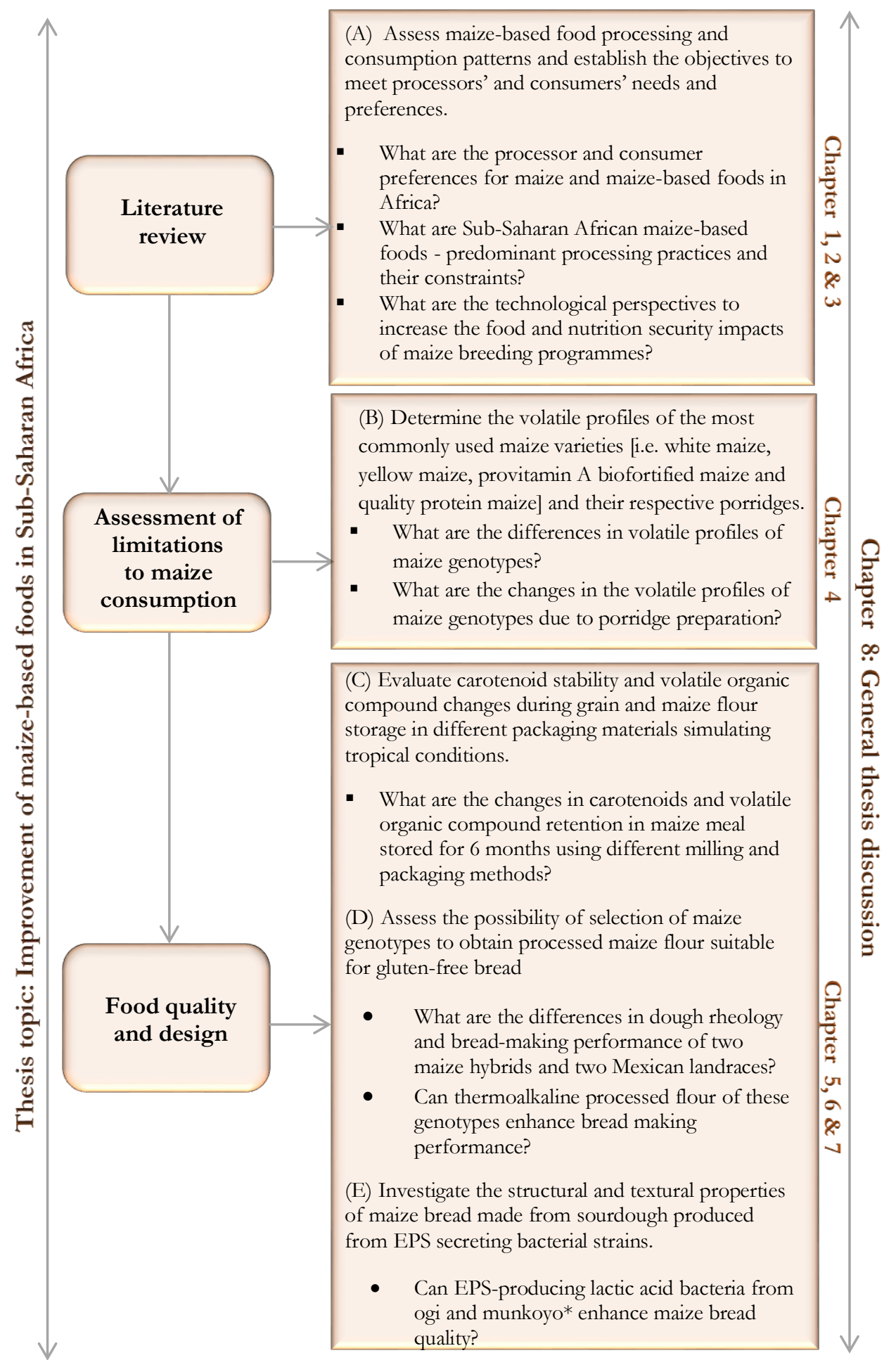

Figure 1.3: Schematic overview of thesis outline. * Ogi is traditional fermented maize-based food usually consumed as porridge in Western Africa; munkoyo is a cereal-based traditional fermented beverage in Zambia. 


\section{References}

1. USDA-FAS. Food supply and distribution 2016 [Available from: https://apps.fas.usda.gov/psdonline/psdQuery.aspx.

2. FAOSTAT. Food balance sheet 2016 [Available from: http:// faostat.fao.org/site/345/default.aspx.

3. OECD-FAO. World cereal projections", in OECD-FAO Agricultural Outlook 2018-2027. OECD Publishing, Paris; 2018.

4. Byerlee D, Heisey P. Evolution of the African maize economy. Africa's Emerging Maize Revolution. (No. 338.17315096 BYE. CIMMYT); 1997.

5. Shindano J. Functional properties of white maize meal stored under tropical conditions: Ghent University; 2007.

6. FAO. "FAOSTAT", FAO, Rome. http:// faostat.fao.org. (Accessed 19 March 2020). 2018.

7. USDA. USDA Nutrient Database. 2016.

8. Chomba E, Westcott CM, Westcott JE, Mpabalwani EM, Krebs NF, Patinkin ZW, et al. Zinc absorption from biofortified maize meets the requirements of young rural Zambian children. The Journal of nutrition. 2015;145(3):514-9.

9. Stadlmayr B, Charrondiere UR, Addy P, Samb B, Enujiugha VN, Bayili RG, et al. Composition of selected foods from West Africa. Food and Agriculture Organization, Rome. 2010:13-4.

10. Otten JJ, Hellwig JP, Meyers LD. Dietary reference intakes: the essential guide to nutrient requirements: National Academies Press; 2006.

11. TWumasi-Afriyie S, Friesen D, Pixley K. Quality protein maize: Progress and prospects. Plant Breed Rev. 2011;34:83.

12. Hotz C, Gibson RS. Traditional food-processing and preparation practices to enhance the bioavailability of micronutrients in plant-based diets. The Journal of nutrition. 2007;137(4):1097-100.

13. Schönfeldt HC, Hall NG. Dietary protein quality and malnutrition in Africa. British Journal of Nutrition. 2012;108(S2):S69-S76.

14. Qi GH, Diao Q-Y, Tu Y, Wu S-G, Zhang S-H, editors. Nutritional evaluation and utilization of quality protein maize (QPM) in animal feed. FAO expert consultation and workshop, Bangkok, Thailand; 2004.

15. Prasanna B, Vasal S, Kassahun B, Singh N. Quality protein maize. 2001.

16. Mbuya K, Nkongolo K, Kalonji-Mbuyi A. Nutritional analysis of quality protein maize varieties selected for agronomic characteristics in a breeding program. International Journal of Plant Breeding and Genetics. 2011;5(4):317-27.

17. WHO. Protein and amino acid requirements in human nutrition. World health organization technical report series. 2007(935):1.

18. Oyarekua M, Eleyinmi A. Comparative evaluation of the nutritional quality of corn, sorghum and millet ogi prepared by a modified traditional technique. Journal of Food Agriculture and environment. 2004;2:94-9.

19. Khumalo TP, Schönfeldt HC, Vermeulen H. Consumer acceptability and perceptions of maize meal in Giyani, South Africa. Development Southern Africa. 2011;28(2):271-81. 
20. Gannon B, Kaliwile C, Arscott SA, Schmaelzle S, Chileshe J, Kalungwana N, et al. Biofortified orange maize is as efficacious as a vitamin A supplement in Zambian children even in the presence of high liver reserves of vitamin A: a community-based, randomized placebo-controlled trial. The American journal of clinical nutrition. 2014;100(6):1541-50.

21. WHO. Global prevalence of vitamin A deficiency in populations at risk 1995-2005: WHO global database on vitamin A deficiency. 2009.

22. Trumbo P, Yates AA, Schlicker S, Poos M. Dietary reference intakes: vitamin A, vitamin K, arsenic, boron, chromium, copper, iodine, iron, manganese, molybdenum, nickel, silicon, vanadium, and zinc. Journal of the American Dietetic Association. 2001;101(3):294-301.

23. Ortiz-Monasterio J, Palacios-Rojas N, Meng E, Pixley K, Trethowan R, Pena R. Enhancing the mineral and vitamin content of wheat and maize through plant breeding. Journal of Cereal Science. 2007;46(3):293-307.

24. Muzhingi T, Gadaga TH, Siwela AH, Grusak MA, Russell RM, Tang G. Yellow maize with high $\beta$-carotene is an effective source of vitamin $A$ in healthy Zimbabwean men. The American journal of clinical nutrition. 2011;94(2):510-9.

25. Li S, Nugroho A, Rocheford T, White WS. Vitamin A equivalence of the $\beta$-carotene in $\beta$ carotene-biofortified maize porridge consumed by women. The American journal of clinical nutrition. 2010;92(5):1105-12.

26. Menkir A, Maziya-Dixon B, Mengesha W, Rocheford T, Alamu EO. Accruing genetic gain in pro-vitamin A enrichment from harnessing diverse maize germplasm. Euphytica. 2017;213(5):105.

27. Saltzman A, Birol E, Bouis HE, Boy E, De Moura FF, Islam Y, et al. Biofortification: progress toward a more nourishing future. Global Food Security. 2013;2(1):9-17.

28. Muzhingi T, Palacios-Rojas N, Miranda A, Cabrera ML, Yeum KJ, Tang G. Genetic variation of carotenoids, vitamin $\mathrm{E}$ and phenolic compounds in Provitamin A biofortified maize. Journal of the Science of Food and Agriculture. 2017;97(3):793-801.

29. Saltzman A, Birol E, Oparinde A, Andersson MS, Asare-Marfo D, Diressie MT, et al. Availability, production, and consumption of crops biofortified by plant breeding: current evidence and future potential. Annals of the New York Academy of Sciences. 2017;1390(1):104-14.

30. Pillay K, Siwela M, Derera J, Veldman FJ. Provitamin A carotenoids in biofortified maize and their retention during processing and preparation of South African maize foods. Journal of food science and technology. 2014;51(4):634-44.

31. Cabrera-Soto L, Pixley KV, Rosales-Nolasco A, Galicia-Flores LA, Palacios-Rojas N. Carotenoid and tocochromanol profiles during kernel development make consumption of biofortified "fresh" maize an option to improve micronutrient nutrition. Journal of agricultural and food chemistry. 2018;66(36):9391-8.

32. Drakakaki G, Marcel S, Glahn RP, Lund EK, Pariagh S, Fischer R, et al. Endospermspecific co-expression of recombinant soybean ferritin and Aspergillus phytase in maize results in significant increases in the levels of bioavailable iron. Plant molecular biology. 2005;59(6):869-80.

33. Lukmanji Z, Hertzmark E, Mlingi N, Assey V, Ndossi G, Fawzi W. Tanzania food composition tables. MUHAS-TFNC, HSPH, Dar es Salaam Tanzania. 2008. 
34. WHO. Vitamin and mineral requirements in human nutrition: report of a joint FAO/WHO expert consultation, Bangkok, Thailand, 21-30 September 1998: World Health Organization; 2004.

35. Adeniji AO, Potter nN. Properties of OGI powders made from normal, fortified and Opaque-2 corn. Journal of Food Science. 1978;43(5):1571-4.

36. Mitchikpe ECS, Dossa RA, Ategbo E-AD, van Raaij JM, Hulshof PJ, Kok FJ. The supply of bioavailable iron and zinc may be affected by phytate in Beninese children. Journal of food composition and analysis. 2008;21(1):17-25.

37. Egli I, Davidsson L, Juillerat M, Barclay D, Hurrell R. The Influence of Soaking and Germination on the Phytase Activity and Phytic Acid Content of Grains and Seeds Potentially Useful for Complementary Feedin. Journal of Food Science. 2002;67(9):3484-8.

38. Joy EJ, Ander EL, Young SD, Black CR, Watts MJ, Chilimba AD, et al. Dietary mineral supplies in Africa. Physiologia plantarum. 2014;151(3):208-29.

39. Bänziger M, Long J. The potential for increasing the iron and zinc density of maize through plant-breeding. Food and Nutrition Bulletin. 2000;21(4):397-400.

40. Chaudhary DP, Kumar D, Verma R, Langyan S, Sangwan S. Nutritional Quality of Maize. Maize: Nutrition Dynamics and Novel Uses: Springer; 2014. p. 135-40.

41. Ekpa O, Palacios-Rojas N, Kruseman G, Fogliano V, Linnemann AR. Sub-Saharan African maize-based foods: Technological perspectives to increase the food and nutrition security impacts of maize breeding programmes. Global Food Security. 2018;17:48-56.

42. Pillay K, Derera J, Siwela M, Veldman FJ. Consumer acceptance of yellow, provitamin Abiofortified maize in KwaZulu-Natal: original research. South African Journal of Clinical Nutrition. 2011;24(4):186-91.

43. De Groote H, Kimenju SC. Consumer preferences for maize products in urban Kenya. Food and nutrition bulletin. 2012;33(2):99-110.

44. Stevens R, Winter-Nelson A. Consumer acceptance of provitamin A-biofortified maize in Maputo, Mozambique. Food Policy. 2008;33(4):341-51.

45. Muzhingi T, Langyintuo AS, Malaba LC, Banziger M. Consumer acceptability of yellow maize products in Zimbabwe. Food Policy. 2008;33(4):352-61.

46. Pastorelli S, Torri L, Rodriguez A, Valzacchi S, Limbo S, Simoneau C. Solid-phase microextraction (SPME-GC) and sensors as rapid methods for monitoring lipid oxidation in nuts. Food additives and contaminants. 2007;24(11):1219-25.

47. Azarbad MH, Jeleń H. Determination of hexanal—an indicator of lipid oxidation by static headspace gas chromatography (SHS-GC) in fat-rich food matrices. Food analytical methods. 2015;8(7):1727-33.

48. Matos ME, Rosell CM. Understanding gluten-free dough for reaching breads with physical quality and nutritional balance. Journal of the Science of Food and Agriculture. 2015;95(4):653-61.

49. Abass A, Awoyale W, Alenkhe B, Malu N, Asiru B, Manyong V, et al. Can food technology innovation change the status of a food security crop? A review of cassava transformation into "bread" in Africa. Food Reviews International. 2018;34(1):87-102.

50. Nkhabutlane P. An investigation of Basotho culinary practices and consumer acceptance of Basotho traditional bread 2014. 
51. Hager A-S, Wolter A, Czerny M, Bez J, Zannini E, Arendt EK, et al. Investigation of product quality, sensory profile and ultrastructure of breads made from a range of commercial gluten-free flours compared to their wheat counterparts. European Food Research and Technology. 2012;235(2):333-44.

52. Brites C, Trigo MJ, Santos C, Collar C, Rosell CM. Maize-based gluten-free bread: influence of processing parameters on sensory and instrumental quality. Food and Bioprocess Technology. 2010;3(5):707-15.

53. Santiago-Ramos D, de Dios Figueroa-Cárdenas J, Mariscal-Moreno RM, Escalante-Aburto A, Ponce-García N, Véles-Medina JJ. Physical and chemical changes undergone by pericarp and endosperm during corn nixtamalization-A review. Journal of Cereal Science. 2018;81:108-17.

54. Garzón R, Rosell CM, Malvar RA, Revilla P. Diversity among maize populations from Spain and the United States for dough rheology and gluten-free breadmaking performance. International journal of food science \& technology. 2017;52(4):1000-8.

55. Arteaga MC, Moreno-Letelier A, Mastretta-Yanes A, Vázquez-Lobo A, Breña-Ochoa A, Moreno-Estrada A, et al. Genomic variation in recently collected maize landraces from Mexico. Genomics Data. 2016;7:38-45.

56. Vázquez-Carrillo G, García-Lara S, Salinas-Moreno Y, Bergvinson DJ, Palacios-Rojas N. Grain and tortilla quality in landraces and improved maize grown in the highlands of Mexico. Plant Foods for Human Nutrition. 2011;66(2):203-8.

57. Galle S, Schwab C, Dal Bello F, Coffey A, Gänzle MG, Arendt EK. Influence of in-situ synthesized exopolysaccharides on the quality of gluten-free sorghum sourdough bread. International journal of food microbiology. 2012;155(3):105-12.

58. Ruas-Madiedo P. Methods for the screening, isolation, and characterization of exopolysaccharides produced by lactic acid bacteria. J Dairy Sci. 2005;88:853-66.

59. Adesulu-Dahunsi A, Sanni A, Jeyaram K. Production, characterization and in vitro antioxidant activities of exopolysaccharide from Weissella cibaria GA44. LW'T. 2018;87:432-42.

60. Katina K, Maina NH, Juvonen R, Flander L, Johansson L, Virkki L, et al. In situ production and analysis of Weissella confusa dextran in wheat sourdough. Food microbiology. 2009;26(7):734-43.

61. Lacaze G, Wick M, Cappelle S. Emerging fermentation technologies: development of novel sourdoughs. Food Microbiology. 2007;24(2):155-60.

62. Kajala I, Mäkelä J, Coda R, Shukla S, Shi Q, Maina NH, et al. Rye bran as fermentation matrix boosts in situ dextran production by Weissella confusa compared to wheat bran. Applied microbiology and biotechnology. 2016;100(8):3499-510.

63. Schwab C, Mastrangelo M, Corsetti A, Gänzle M. Formation of oligosaccharides and polysaccharides by Lactobacillus reuteri LTH5448 and Weissella cibaria 10M in sorghum sourdoughs. Cereal Chemistry. 2008;85(5):679-84. 


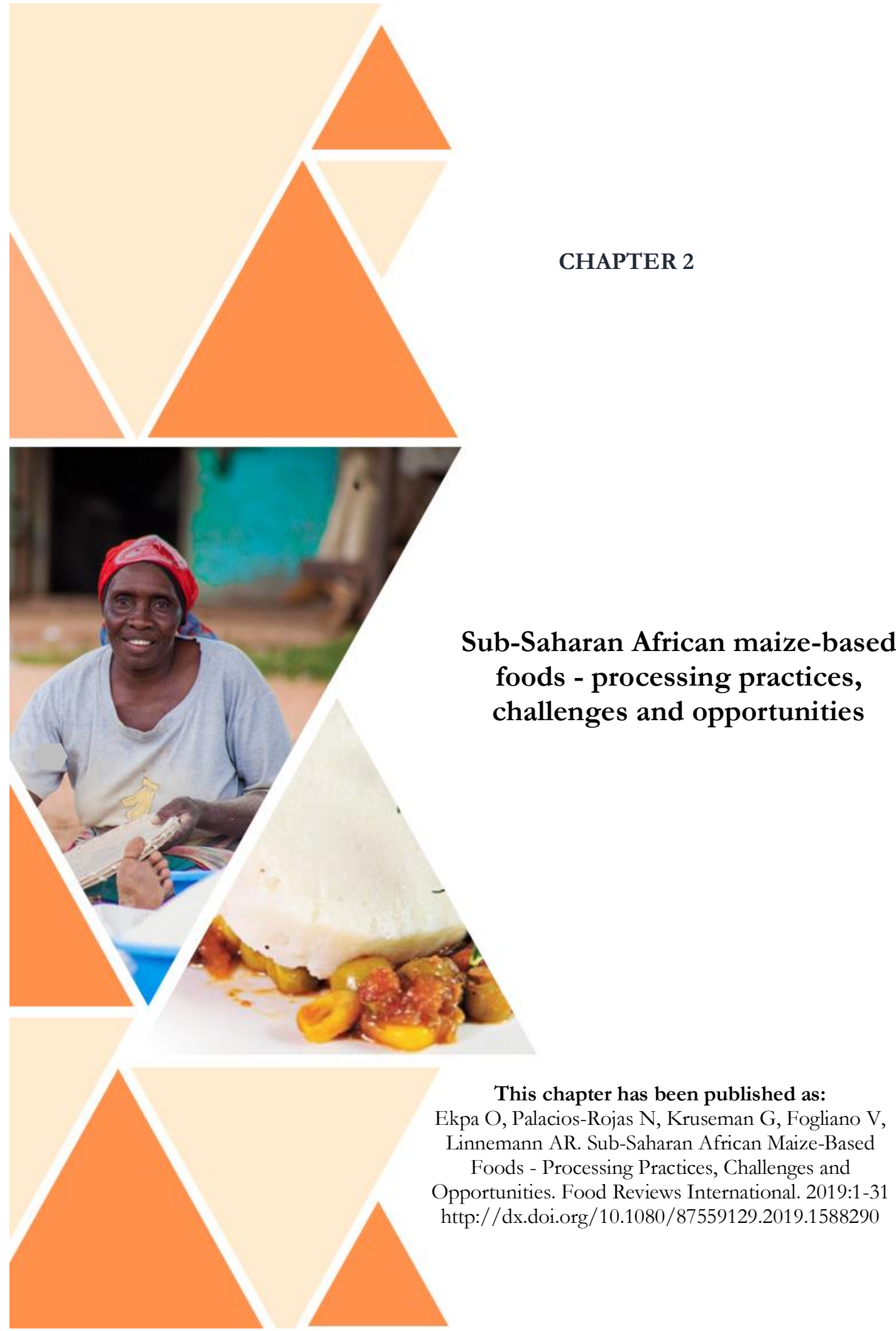




\begin{abstract}
In vast swathes of Sub-Saharan Africa, maize is the staple food with consumption of up to $450 \mathrm{~g} /$ person/day. Additionally, maize is used as a weaning food for infants as well as for special ceremonies, caring for the sick, aged and pregnant women. Malnutrition persists in regions with heavy maize consumption, partly due to compositional maize characteristics, nutrient loss during processing and consumer preferences. This paper reviews the traditional uses and processing of maize, opportunities and necessary improvements to ensure (micro)nutrient security. Better use of maize can enhance its contribution to meeting the dietary needs and livelihood of Africa's growing populace.
\end{abstract}

Keywords: Maize; maize-based foods; Sub-Saharan Africa; maize processing; maize consumption; maize opportunities 


\subsection{Introduction}

Maize (Zea mays) accounts for $40 \%$ of the cereal production in Sub-Saharan Africa (SSA), where more than $80 \%$ is used as food.[7] The crop provides at least $30 \%$ of the total calorie intake of people in Sub-Saharan Africa. ${ }^{[23]}$ Maize is consumed as a staple in the African region where intake ranges from 52 to $450 \mathrm{~g} /$ person/day and in the Latin American where it varies from 50 to $267 \mathrm{~g} /$ person/day. [7, 29] Maize is also considered an important source of nutraceuticals known to enhance health and prevent diseases, including phenolics, carotenoids (yellow maize), anthocyanins (blue maize), phlobaphenes (red maize), insoluble and soluble dietary fibre and polar and nonpolar lipids.[30-32]

Maize can be consumed in several forms: green maize roasted or boiled, steamed products, porridges, beverages, bread, and snacks.[29] Maize-based foods are available in Africa with each country having different processing methods, food products and forms of consumption. ${ }^{[33]}$ Sometimes differences in maize food processing and consumption patterns within the same socio-cultural group exist to communicate individual cultural identity and social class. ${ }^{[34]}$

Compositional features of maize and local processing techniques affect the nutritional content and bioavailability of nutrients. For instance, the pericarp and germ of maize are usually sieved out as chaff in the preparation of most traditional foods, leading to loss of a large portion of proteins, lipids, minerals and vitamins that are present in those kernel structures. Therefore, in addition to the intrinsic nutritional deficiencies of maize, i.e., low lysine and tryptophan, and the presence of an anti-nutrient like phytate, a high amount of nutrients (20-50\%) can be lost during maize processing in general.[29] This may contribute to malnutrition in regions where maize is a staple crop and diet diversification is very limited. Efforts to improve the nutritional quality of maize have mainly focused on breeding, by developing biofortified maize with higher protein quality or higher content of provitamin A or zinc. ${ }^{[3]}$ However, the possibility to improve nutrient security by acting on home-based and street vendor processing and formulation aspects have been largely neglected.

Comprehensive maize food reviews by Nuss et al. [23], Suri et al. [36] and Ranum et al. [29] focused on global perspectives while this paper specifically targets Africa, especially Sub-Saharan Africa (SSA), where the population is most in danger of malnutrition and where there is a high rate of maize consumption and untapped opportunities in the value chain. The current paper reviews the most important maize-based foods in Africa and their respective traditional processing techniques, and discusses the constraints of traditional processing and opportunities to improve the nutritional quality and use of 
maize. The population in Africa is projected to double between 2010 and 2050, with increasing urbanization. To ensure both food and nutrition security, a thorough understanding of the nutritional aspects of traditional processing techniques and identification of important opportunities present on the dynamic continent are crucial.

\subsubsection{Traditional food uses of maize in Africa}

Maize is commonly consumed as immature or matured whole kernel (i.e., boiled or roasted), freshly ground or parched ground into grits and flour for the production of different kinds of traditional products. Milling is traditionally done through stone grinders (now obsolete), mortar and pestle, steel plate mills, and increasingly by the power-driven hammer mill.[5, 37] Light dishes are habitually served as a breakfast, while thick dishes are served as lunch or as dinner and others are reserved for special ceremonies, rituals or caring for ill or aged people, pregnant women or infants. ${ }^{[5,34]}$ Consumer preference for maize in Africa is changing as many recipes use it in a combination with other grains such as wheat, sorghum, millet, barley and legumes/nuts. However, despite the recent trends, maize remains a major contributor to the daily diet of Africans. Different categories of maize-based foods are discussed in the following sections.

\subsubsection{Maize-based foods: whole maize cob and kernel}

Consumption of green maize is a significant part of the whole maize food intake in Africa. To prepare fresh maize foods, the ears are harvested in the milky to the doughy stage (i.e., three to five weeks after silking), boiled in water, steamed, or roasted and eaten with herbs, spices, condiments and vegetables depending on the socio-cultural group. ${ }^{[38]}$ At the milky stage, kernels are high in sugar content and quantities of other nutrients may be lower than at harvest maturity. ${ }^{[39]}$ Street vendors sell boiled and roasted maize at many places in the major maize-producing countries and it is a common snack for children at schools. ${ }^{[38,40]}$ During harvest season, roasted and boiled maize is eaten on a daily basis by more than $50 \%$ of the people in Nigeria ${ }^{[40]}$ and in Zimbabwe, $48 \%$ consume boiled / roasted maize at least once a day.[6]

Freshly harvested maize is cooked or boiled in salted water until the kernels are soft, while roasting is through hot charcoal over a wire gauze, beside a fire or in hot ashes until the maize turns brownish; both types are eaten on the cob with all kinds of spices and vegetables. The charcoal gives the kernels a unique odour and flavour. Boiling is usually with the husk to denote freshness and to retain nutrients and flavour. On the contrary, roasting with the husk is not practised as it results in decreased sensory attributes such as poor aroma, chewiness, poor taste and appearance. ${ }^{[38]}$ Apart from the fresh maize eaten on the cob, it can be shelled into the constituent kernels for different 
dishes. Usually, the kernels are spiced and cooked with legumes or vegetables (Table 2.1). In Kenya, $17 \%$ and $23 \%$ of consumers prefer githeri (maize cooked with beans) as 1 st choice lunch and dinner, respectively.[5] A similar maize food known as mutakura is consumed at least once a day by $40 \%$ Zimbabweans. ${ }^{[6]}$ The attributes of green whole cob and kernel maize that are preferred by consumers have not been defined clearly for African consumers. However, freshness seems to be crucial. ${ }^{[5]}$ Harvest time and variety have a significant effect on physical properties of maize; very mature maize (27-34 DAP) is not suitable to prepare roasted or boiled green maize foods. ${ }^{[38]}$ Generally, green maize attributes of interest are soft endosperm, soft or thin hull, sweet taste and not easily burst/pop or burn during roasting. [3, 5, 38, 41] Green maize is a very important form of maize consumption during harvest season in Africa. ${ }^{[38]}$ Canning of green maize provides an opportunity to make it available all year round and reduce the chance of mycotoxin contamination, which is common to on-farm drying and storage of matured maize, thereby giving farmers more market opportunities.

In East, West, and Central Africa, whole dried grain is commonly cooked with alkaline rock salt (popularly known as kaun or akanwu or trona or magadi) or white wood ash, which reduces cooking time, improves digestibility, increases the viscosity of soup, and acts as flavour enhancer, preservative and tenderizer.[42] Akanwu is a crystal-like (bi)carbonate salt that is naturally present in many parts of Africa. ${ }^{[43]}$ The traditional use of akanwu in Africa, which is comparable to the lime-cooking process (nixtamalization) in Mexico, has not been well studied yet. In Mexico, more than 300 foods are produced by processing methods that include nixtamalization, the most common one being the tortilla.[42] This processing method for maize is not known in Africa; from about 1500 onwards the continent has connected to maize that originates from America through its agronomy but not through its processing technology.

Nixtamalization provides nutritional benefits (Figure 2.1), including: 1) reduction in pellagra disease risk, due to the improved niacin bioavailability, 2) increasing calcium intake due to its absorption by the kernels during the steeping process with calcium hydroxide, 3) supply of dietary fiber by increasing the content of resistant starch in the food products, 4) significantly reducing mycotoxin levels in kernels by removal of pericarp, and 5) reducing levels of phytic acid, an inhibitor of iron and zinc bioavailability. $[30,44]$ Nixtamalization is reported to be effective in reducing mycotoxin contamination in maize through a combination of extraction and hydrolysis. ${ }^{[45,46]}$ This method can be combined with traditional processing techniques in Africa to mitigate aflatoxin contamination, which remains a grave concern and hinders efforts to attain food and nutrition security. The ancient technology of nixtamalization is simple and 
cheap, thus conditions to promote its use in Africa should be assessed to enhance the nutritional quality of maize-based foods.

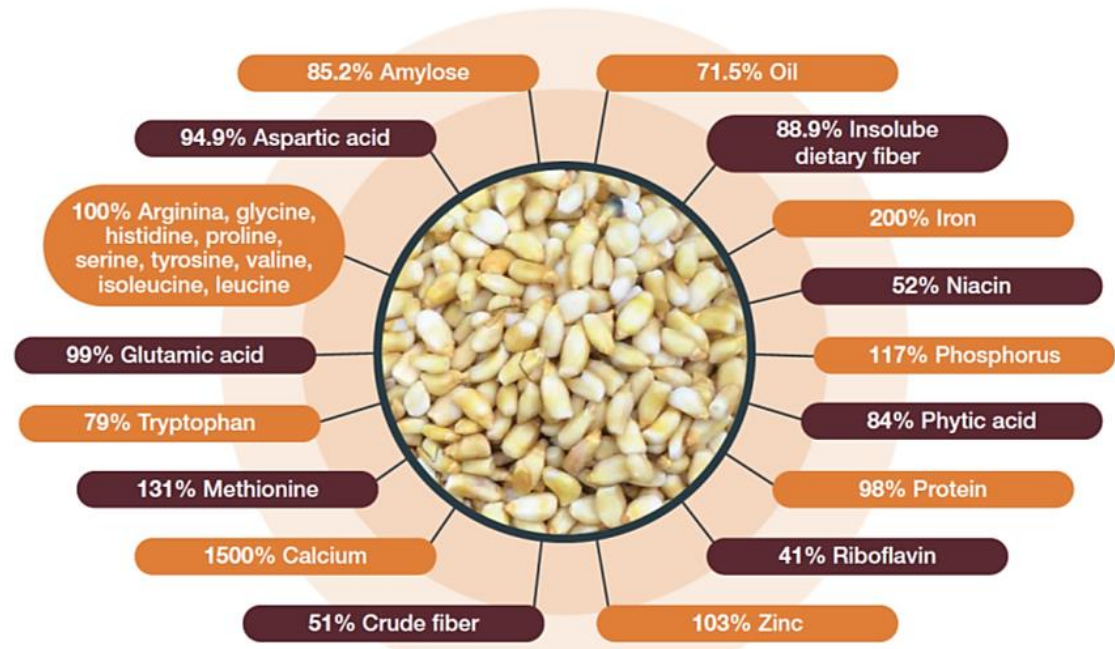

Figure 2.1: An overview of compound retention in nixtamalized maize. The increase in mineral composition along with decrease in anti-nutrient as well as high retention of amino acid is beneficial to the fight against the rampant hidden hunger. 


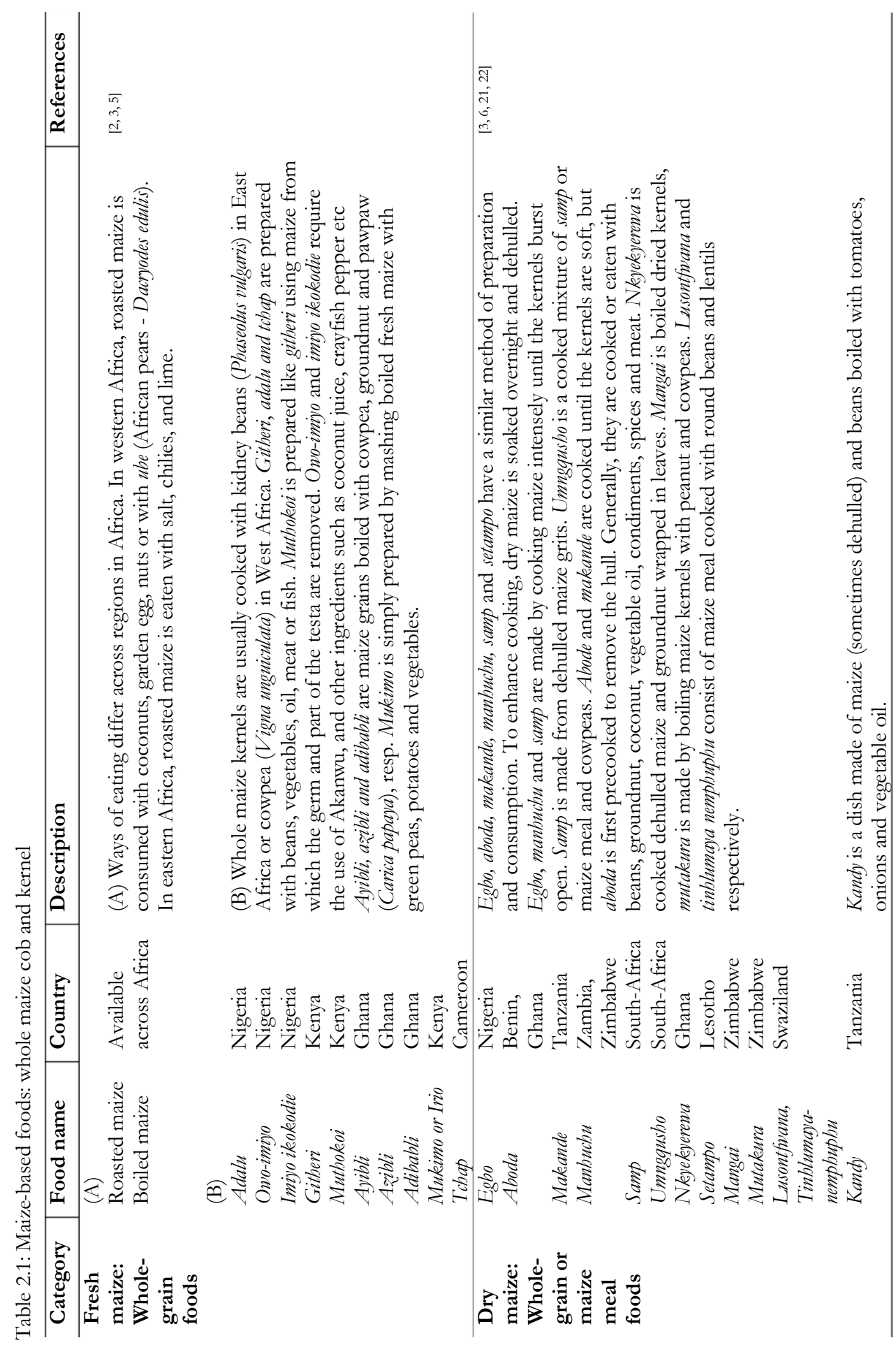




\subsubsection{Local wet-ground maize foods}

Wet-ground maize foods are produced by steeping maize kernels and grinding or pounding with ingredients such as vegetables, herbs, spices, legumes and nuts. The foods can also be produced from maize flour or the usually imported canned maize when fresh maize is not available. The term wet-ground used in this study should not be confused with wet milling, i.e., separation of maize into constituent parts or extraction of components such as oil and protein. ${ }^{[47]}$ Wet milling is typically an industrial process, and hence not a home-based or traditional processing method in Africa. Examples of wet-ground foods are shown in Table 2.2. The grinding of whole grains to form wet-ground foods ensures optimum utilization of the kernel due to the inclusion of all parts as against many maize-based foods that require dehulling and other refining processes.

An important attribute of these foods in West Africa is the method of packaging before or after steaming; the foods are wrapped in leaves of different plants. The type of leaves used for packaging imparts a special flavour to the food, which is the preferred quality attribute among the different socio-cultural groups. Moreover, the leaves used for food wrapping were observed to be protein-rich and contain essential oils, antioxidants and antimicrobial agents that can prevent food spoilage and leaching of nutrients. [48] Leaves of banana, cocoyam, bamboo, uma, cassava and maize husk are commonly used for wrapping foods in Africa. However, considering the possible cyanogenic potential of cassava leaves (i.e., 5-20 times that of the roots), proper selection and treatment are required to avoid exposure above the safety limit, i.e., $10 \mathrm{ppm}$. ${ }^{[4]}$ The indigenous custom of using cassava leaves for wrapping foods such as egble or madadi and kenkey is still common among the Ewe tribe in Ghana. ${ }^{[50]}$ The scarcity of wrapping leaves in urban environments cause urban dwellers to use empty cans, foil and cellophane or polyethene (nylon) bags instead. The use of such materials could result in migration of poisonous chemicals (i.e., dioxin, bisphenol A and heavy metals ) into the food. [51] 


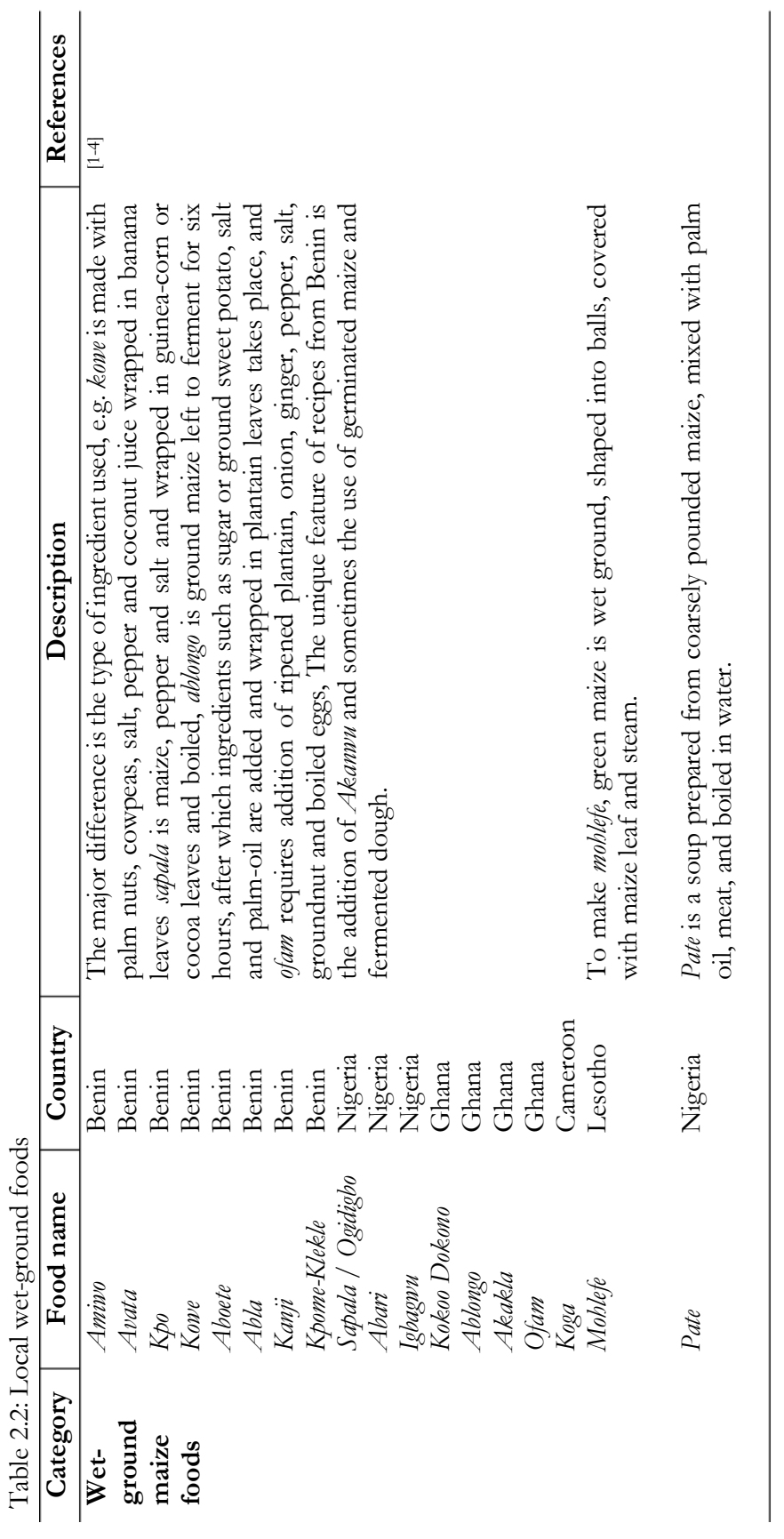




\subsubsection{Maize-based bread and snacks}

Maize mixed with ingredients (e.g., groundnut, salt, sugar, egg, spices and vegetables) is used to produce different kinds of snacks and bread (Table 2.3), which are usually consumed in between meals and sometimes as the main meal. Unlike Mexico and Central America with different kinds of bread and snacks that can serve as a main meal, ${ }^{[42]}$ only a few are found in Africa. However, northern African countries such as Egypt have different kinds of maize bread that serve as main meal, included in this paper to serve as an example (Table 2.3). The reduced use of maize in bread production is due to the unavailability of local technology, dominance of substitute grains (e.g. wheat), susceptibility to staling, storability issues (e.g., lipid in maize is more than two times higher than in wheat so relatively it becomes rancid faster during storage) and a lack of functional gluten, which is needed to produce an elastic dough and bread with characteristic light and spongy properties. ${ }^{30,52]}$ To minimize rancidity issues, heat treatment is used to inactivate lipase; local users commonly grind maize for short-term use and in some communities, maize bread is eaten during winter months. In general, the higher the proportion of polar lipid, the better the baking properties (e.g., increase in loaf volume); the ratio of polar to nonpolar lipid in cereal flour decreases in the order wheat $>$ rye $>$ maize. ${ }^{[53]}$

Maize bread has a low volume and a heavy, dry, fibrous and brittle crumb with a relatively strong malty and fermented flavour. ${ }^{[52]}$ At times, in local communities, water is sprinkled on it, after which it is covered with a cloth to keep it fresh. In most cases, maize bread contains wheat flour as a source of gluten. One of the outstanding properties of wheat is its ability to provide a viscoelastic dough that can hold and retain air to form a spongy structure. Maize does not have this ability due to the absence of gluten, thus making bread production difficult. Gluten-free bread has poor texture and flavour, a short shelf-life, low volume and stales rapidly.[54] The functional properties, commercial and nutritional value of maize flours can be improved by inclusion of protein from decorticated and defatted flours of crops like peanut, sesame seed, sunflower seed, soybeans, cowpea, melon seed, winged bean, bambara groundnut, chick pea, lentil seed, shea nut and sweet potato flour. Traditional Indian foods, such as dosai or $i d l i$, use fermentation of the mixture of rice and a legume to produce a gluten-like paste. ${ }^{[55]}$ A non-wheat based composite flour with the ratio of sweet potato flour $40 \%$, maize starch $40 \%$, soybean flour $19.5 \%$ and xanthan gum $0.5 \%$ was observed to yield acceptable bread.[56] In another study, addition of $2 \%$ hydrocolloid hydroxypropyl methylcellulose (HPMC) significantly improved the quality of maize bread, mimicking wheat bread qualities.[57] With the use of appropriate additives - hydrocolloids, emulsifiers and binding agents and suitable flour milling properties, the viscoelastic and sensory properties can be improved. Furthermore, pre-gelatinized cereal flour and 
composite flour made by inclusion of malted grains have been shown to improve dough and bread qualities. ${ }^{[52,58,59]}$ Composite flour made from pre-gelatinized starch or alkaline treated maize exhibit improved rheological properties that support bread making. Similarly, flours derived from sourdough made by fermentation using selected multiple strains of microorganisms have been shown to improve maize bread quality.[60] Acidification of the sourdough during fermentation (mainly by lactic acid bacteria) or through addition of lactic/acetic acid improves the swelling or water binding properties of starch and the functionality of zein (maize prolamin) to enhance loaf volume and crumb structure of gluten-free bread.[61] Sourdough improves nutritional quality, i.e. increases mineral bioavailability due to a lower phytate content. Likewise, the low $\mathrm{pH}$ helps to improve the shelf-life of bread.[60]

Popcorn, as a snack, is found all over Africa due to the introduction of locally fabricated popping technologies and the growing acceptance of the product at cinemas, amusement parks, schools and during travelling. ${ }^{62]}$ Though affordable foreign and local popcorn machines are now available, popcorn is traditionally prepared using a clay pot or metal dishes. There are different kinds of popcorn-like snacks common in Africa (e.g., roasted maize kernels of any variety with salt/sweetener and roasted popcorn with salt or sweetener - honey or sugar). Though popcorn production still strongly relies on the importation, it is a crucial opportunity in the maize value chain capable of improving the livelihood of street vendors. Generally, consumers prefer popcorn with a soft texture and free from hulls, while the processors prefer high storability, unbroken pericarp and a high popping volume. ${ }^{[62]}$ Ingredients such as fat, sugar and salt are usually added to enhance the flavour of popcorn. Other maize-based snacks are listed in Table 2.3. In general, a mildly sour and sweet taste, crispy and brown edge colour are desirable for maize-based snacks.[63]

To supplement the low nutritional value of maize-based snacks, protein-rich legumes and nuts such as soybean, cowpea and groundnut are usually included in the recipe. For instance, kokoro, a common crispy maize snack was observed to have a 54-68\% higher protein content due to the inclusion of $30 \%$ soybean or groundnut in the recipe. 


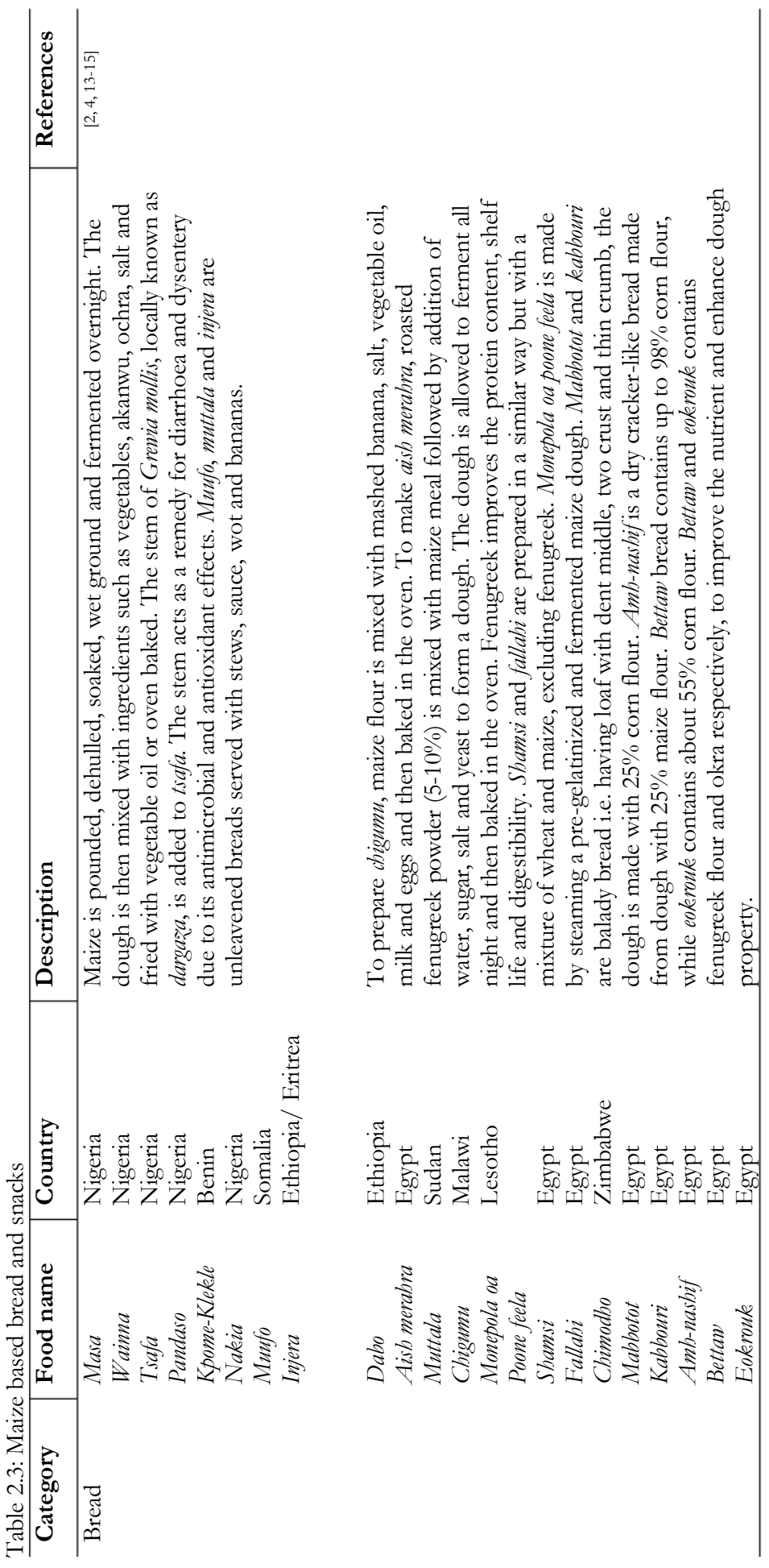




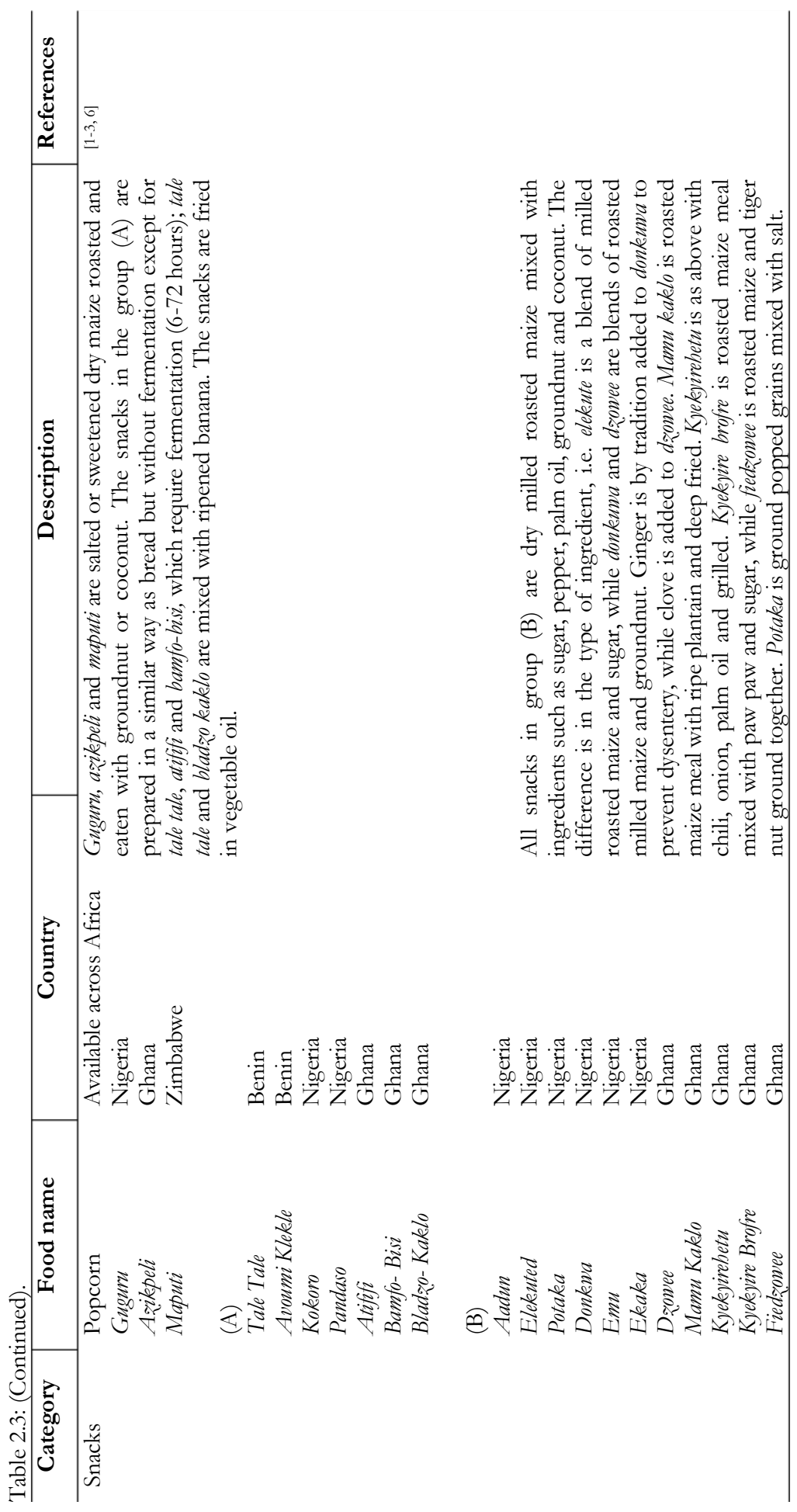




\subsubsection{Maize sourdough and dumplings}

Maize sourdough is an uncooked thick fermented cake that is pressed, shaped and ready to use in other dishes like maize dumplings, porridges, snacks, bread and beverages [9, ${ }^{64]}$ (Table 2.4). Maize sourdough is most common in West Africa. For instance, more than half of the total maize production in Nigeria is used for ogi.[9] Maize dumplings, such as kenkey, are consumed twice or more often per week by $26-58 \%$ of Ghanaians.[65] Traditional preparation of sourdough and dough dumplings is labour intensive and time-consuming (4-6 days); consumers mostly buy such foods from street vendors. Technological improvements, such as a temperature increase, the use of drymilled maize and pure starter cultures, have shown positive results in reducing preparation time and facilitating industrial processes. ${ }^{[66]}$ Maize sourdough can be derived from either fresh or dried maize. However, dried maize is preferred for its higher starch content and retention of the accustomed flavour. ${ }^{[9]}$ Traditional preparation of maize sourdough in Africa follows a similar process. Dry maize is soaked for $24-36 \mathrm{~h}$; the peak of water uptake is attained at $36 \mathrm{~h}$. The time of water saturation can be reduced to $8 \mathrm{~h}$ by increasing the soaking temperature to $60^{\circ} \mathrm{C}$ or using crushed maize kernels. ${ }^{[66]}$ The soaked kernels are drained, then milled to a slurry and sieved to remove the chaff, followed by dewatering, kneading to dough and fermentation for 1-3 days at room temperature $\left(25-32^{\circ} \mathrm{C}\right) .[9,67]$, see Figure 2.2. The chaff removed during the sieving process is fed to animals or reserved as a base for the preparation of other foods such as amala (i.e., a thick cassava or yam flour food in Nigeria, having a dough-like consistency). Aside from the inherent characteristics of maize, the amount of chaff separated by sieving depends on the nature of the milling technology. Plate mills are commonly used for wet grinding; the sharpness of the plate and the number of milling rounds minimize the chaff yield. ${ }^{[9,37]}$ The use of plate mills has been reported to increase the iron content in dry and wet milled maize by $78-89 \%$ and $199 \%$, respectively, due to the wear and tear of the grinding metal plate. The increase was suggested to be an enrichment, but the bioavailability of the extra iron was not established.[37]

Traditional sourdough production uses spontaneous fermentation, which is uncontrolled. Sometimes backslopping is used to achieve a consistent and faster fermentation. ${ }^{[64]}$ The microorganisms involved in natural maize food fermentation in Africa have been well elucidated in the literature. ${ }^{[68-73]}$ The addition of commercially available yeasts as starter culture and the use of backslopping to speed up the fermentation, improve flavour, nutrient and functional properties of fermented food is common in both rural and urban areas in Africa, showing the possibility of adoption of pure microbial starter cultures (optimized mixtures of microorganisms) for traditional maize fermentation, if made available. Since fermentation is an age-old, acceptable food processing method in Africa and used for many foods, a sustainable increase in 
production, commercial and nutritional value of food products can be achieved by optimizing the composition of starter cultures for fermentation. Several biotechnological methods have been developed over the years as a substitute for the costly chemical synthesis of amino acids and vitamins used for fortification. [74-76] For instance, to improve protein quantity and quality of ogi (maize sourdough), microbial in situ fortification or bio-enrichment, such as the use of high lysine or methionine producing mutant microorganisms, have been used successfully to significantly increase essential amino acids. ${ }^{77,78]}$ Sybesma et al. ${ }^{776]}$ isolated spontaneous mutants of Lactococcus lactis able to overproduce both folic acid (B11) and riboflavin (B2) during food fermentation. Vitamin overproducing microorganisms such as A. gossypii, C. famata, B. subtilis, $P$. freudenreichii and $L b$. plantarum have been identified and isolated. ${ }^{[7]}$ Aside from increasing the amount of nutrients, decreasing the amount of anti-nutrients such as phytate is crucial for malnourished societies. Therefore, in the selection of microorganisms for starter cultures, it is important to also consider those able to overproduce the enzyme phytase, because phytate remains a major factor limiting mineral (iron and zinc) bioavailability; deficiencies of both minerals remain a major public health concern in SSA. Starter cultures containing phytase-active microorganisms will help to degrade phytate and improve mineral bioavailability. [79]

The major variations in sourdough production in Africa are the extent and conditions of fermentation, which determine the degree of sourness/acidity, flavour and physical properties such as colour and texture. ${ }^{[67]}$ The degree of sourness of a dough depends on the type of end product and the preference of the respective socio-cultural groups. For instance, relatively sour dough $(\mathrm{pH} 3.8-4.2$ and acidity 1.2-1.4\%) is used for the preparation of eko and akassa, while less sourness is used for thin porridges such as koko.[67] Furthermore, the most desirable attributes of kenkey are a mild sourness, fruity odour, clear white colour and non-sticky texture, which can be achieved by a reduction of fermentation time, modification of inoculant (i.e., using bacteria and yeast starter cultures with higher yeast concentrations to give the desired fruity taste), dehulling the maize, and adjusting the sourdough puree consistency before cooking, respectively. ${ }_{[}^{[3]}$ The moisture content of maize dough ranges from 45\% (amo and mawe) to 55\% (ogi). [3, 9] The high moisture content predisposes it to microbial deterioration. In home-based processing, it is therefore left in source liquor with a steady change of water. The commercial dough is spray dried in the industry to increase stability; drum drying has been reported to be harmful to the heat sensitive components, e.g. amino acids. [80] Sourdough commonly used for making porridge is mainly sold in the wet form, having a short shelf life because of continued fermentation. The current development trends in SSA require a better supply of easily accessible and shelf-stable maize-based foods. Controlled drying methods can be used to reduce the moisture content (below 12\%) to 
enhance storability and ease of distribution. ${ }^{[9]}$ This form of fermented flour can be reconstituted to make paste needed for porridge. It can also serve as an ingredient in other products where consumers desire a sour or fermented flavour, e.g. in Western Africa food and beverages. 


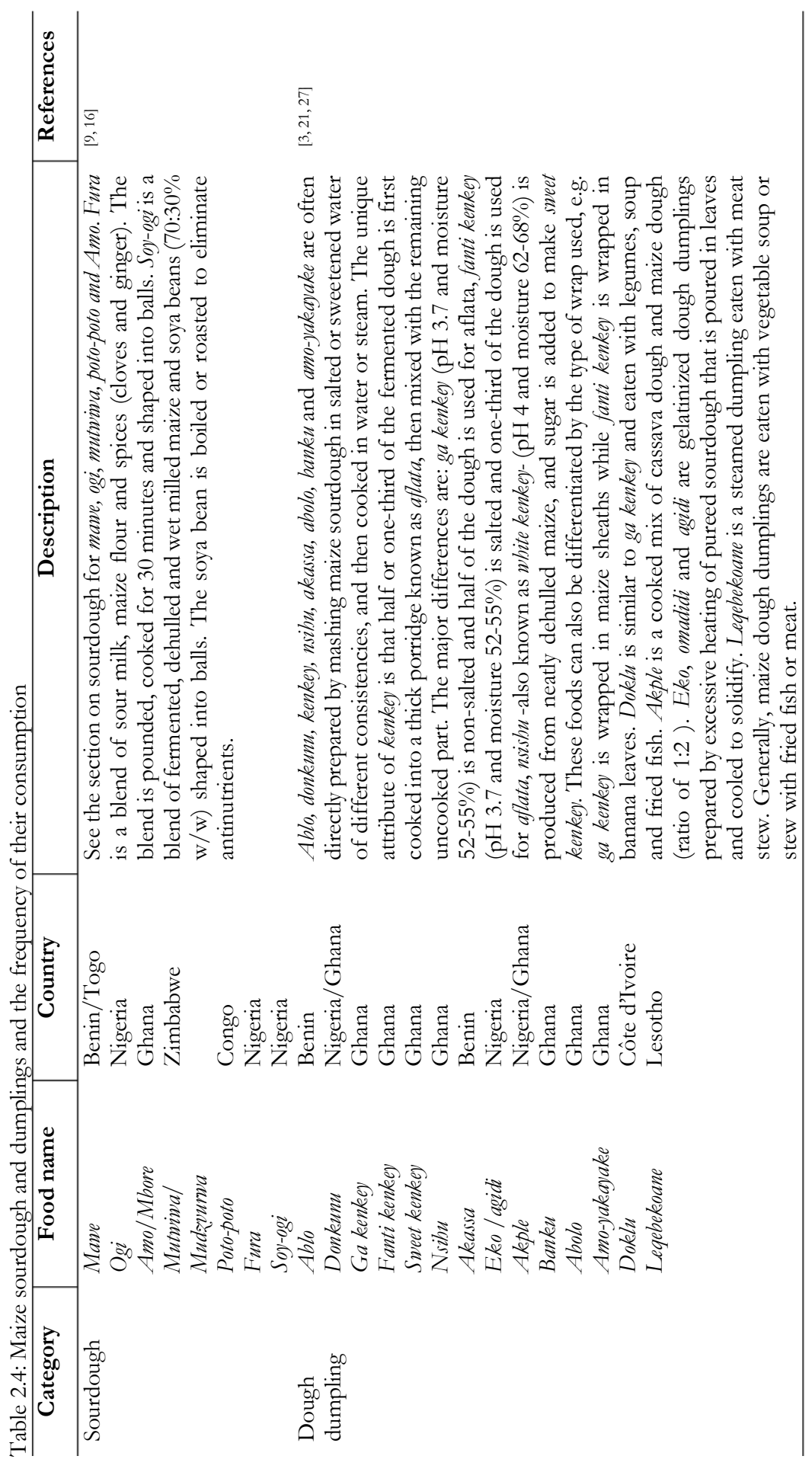




\subsubsection{Maize-based porridges}

Maize porridge is simply a dish made by cooking milled maize or sourdough in water and stirring until thickened. In most parts of Africa, maize porridge is consumed in different consistencies, namely as breakfast when thin or as lunch/dinner when thick. For instance, $46 \%$ of consumers in Kenya prefer thin porridge (uji) as breakfast while $67-71 \%$ prefer thick porridge (ugali) as lunch/dinner. ${ }^{[5]}$ For economic reasons, the thick porridge is at times eaten as breakfast to withstand hunger all through the day due to its high energy density. ${ }^{[34]}$ In fact, ugali in Kenya is synonymous to 'strength' and in Tanzania, it is termed the 'real food'.[34] Ugali is consumed 5-7 times a week by $64 \%$ of the Tanzanians, ${ }^{[81]}$ and a similar pattern of consumption is common across Eastern/Southern Africa.[6] The ratio of flour to water, flour particle size, the method of preparation, the degree of starch gelatinization and enzymatic hydrolysis, the rate of maize meal extraction and sometimes the inclusion of other ingredients determine the consistency of the porridge. Porridges can be classified based on consistency or texture; i.e., ogi and koko are thin porridges with a water content over $90 \%$ whereas ugali is a thick or stiff porridge with less than $70 \%$ water and tuwo-masara is a soft porridge with an intermediate thickness. ${ }^{[28]}$ Thick maize porridges in Eastern, Western and Southern Africa have 33\%, 22\% and 20\% total solids, respectively.[28, 82] As shown in Table 2.6, not all porridges are fermented. Hence, they can be classified on that basis as well. In Eastern Africa, the main maize flour preparation is for porridges (mostly unfermented).[5, ${ }^{34]}$ This is also true for Western Africa, except that maize porridges are mostly derived from soaked maize or fermented dough. ${ }^{[1]}$

In general, fermentation is not a common practice for thick maize porridge in Africa (except in countries like Nigeria, Benin and Ghana); it is largely used for thin porridges. ${ }^{[28]}$ West Africans preserve the traditional porridge processing; i.e., preparation of soaked wet ground maize or sourdough followed by cooking in water, Figure 2.2. Nche et al. ${ }^{[83]}$ \& Teniola et al. ${ }^{84]}$ attempted to accelerate traditional porridge preparation by using maize flour instead of the usually soaked kernels as starting material. They observed a decrease in processing time from 6 days to 24 hours but produced porridge with an inferior and undesirable textural quality, namely poor pasting properties and flow behaviour. This clarifies the significance of the soaking step in the production of West African maize dishes. Sourdough from steeped whole maize gives a more preferred aroma, taste, smoothness, and better pasting and setback viscosities than dehulled steeped maize and fermented maize flour. ${ }^{[84]}$ Bolade ${ }^{[85]}$ observed the lowest pasting temperature (i.e., faster gelatinization) in flour produced from soaked maize, possibly due to the breakdown of the matrix around the starch granule. 
The most popular maize porridges in Eastern and Southern Africa are the thick textured foods known as ugali/nsima/sadza, all of which are derived primarily from unfermented dry milled maize generally with no ingredient added but with differences in thickness and maize meal type. For example, nsima from Malawi and Zambia is relatively soft compared to sadza from Zimbabwe and ugali from Kenya, Tanzania, Rwanda and Uganda. Properties such as moldability and mouthfeel are most desirable in thick porridges. ${ }^{[28,85]}$ While the urban areas depend on ready-made flours (i.e., packaged maize meal from the industrial mill), the rural areas sort and clean maize then mill at home or in a local mill that generally uses a hammer mill. The classification of maize meal can be based on colour, extraction rate, particle size and the type of maize kernel texture used, i.e. soft (dent) or hard (flint) endosperm. ${ }^{[86]}$ For instance, three types of maize meal are found in Africa: whole maize meal, dehulled maize meal and dehulled \& degermed maize meal, see Table 2.5. Although the preparation of refined maize flour is laborious and results in excessive loss of nutrients, it is the most preferred quality for the preparation of ugali/nsima, and it is perceived as "rich people" food. Unrefined flour such as dona (whole kernel maize flour) is classified as "food for the poor" in some communities. ${ }^{34]}$ The soaking process and a fine particle size of maize flour enhance water absorption, pasting properties, starch breakdown, cohesiveness, bulk density, taste and appearance.[28] Similarly, degermed maize flour was observed to require 10 times less energy and less time to cook as well as having a longer shelf life compared to whole maize flour. In a survey in urban Kenya, 64\% of refined maize meal consumers indicated ease of cooking as the major reason for purchasing this type of flour. ${ }^{[87]}$ From a nutritional point of view, dehulling, removal of maize germ, several rounds of soaking and drying during maize refinement indeed result in high nutrient losses. ${ }^{[36,88]}$ Ashanti and nsibu kenkey, usually made from degermed flour, were confirmed to have low mineral contents; ${ }^{[89]}$ up to $20 \%$ protein and more than half of the vitamins and minerals could be lost during maize meal refinement. The nutrient lost from the industrial meal may be replenished through exogenous fortification but this is unlikely for the majority of meals processed at home. Therefore, children depending on ingestion of foods produced from refined flours might have nutrient deficiencies.

About $70 \%$ of thin porridge consumers are infants, but the low dry matter content (5$10 \mathrm{~g} / 100 \mathrm{ml}$ ) makes it nutritionally inadequate. For instance, maize pap in Nigeria was reported to contain $0.5 \%$ protein and $1 \%$ fat; thin porridge provides an energy density of less than $0.40 \mathrm{Kcal} / \mathrm{ml}$, which is much lower than breastmilk $(0.68 \mathrm{Kcal} / \mathrm{ml}) .{ }^{90}$, 91] The energy, protein density and protein quality can be improved by using, for instance, quality protein maize with addition of legumes and sprouted maize to achieve a viscosity favourable for infant foods. ${ }^{[64]}$ To correct for the essential amino acids deficient in maize, a soybean enriched sourdough known as soy-ogi and weanimix was developed.[92] 
Soy-ogi was compared to nine commercial weaning foods and found to be relatively low cost and nutritionally adequate. Other maize - legume/nut (groundnut, melon, bambara groundnut and cowpea) combinations tested were found to be superior to any available single protein source. ${ }^{[2-95]}$ However, the acceptability of legumes in weaning food might be low due to problems associated with difficulties in digestion and the flavour when it is not properly processed. ${ }^{96]}$ The acceptability test carried out on soy-ogi showed that $66 \%$ preferred the usual ogi. [96] However, kenkey enriched with cowpea showed high acceptability by consumers. ${ }^{95]}$ A substantial improvement in the nutritional composition of sourdough has been reported from the addition of vegetables, leaves and fruits (e.g., okra seed, ${ }^{[97]}$ mango mesocarp, ${ }^{[98]}$ Moringa oleifera leaves, ${ }^{[9]}$ and pawpaw (Carica papaya) fruit).[100] In an unconventional approach, Cirina forda (an edible insect) and maize dough were blended to achieve a significant improvement in the protein, minerals, amino acid and fatty acid contents.[101] Information on home-based production or use of legume/nut supplemented maize food is scanty. However, Bankole ${ }^{[11]}$ reported that $49 \%$ of ogi consumers were aware that the food can be fortified with fruits and legumes but adoption was only $5.8 \%$, namely with soybean $(2.9 \%)$, groundnut $(1.9 \%)$ and cowpea (1\%). 
Table 2.5: Major maize meal types and nutrient composition

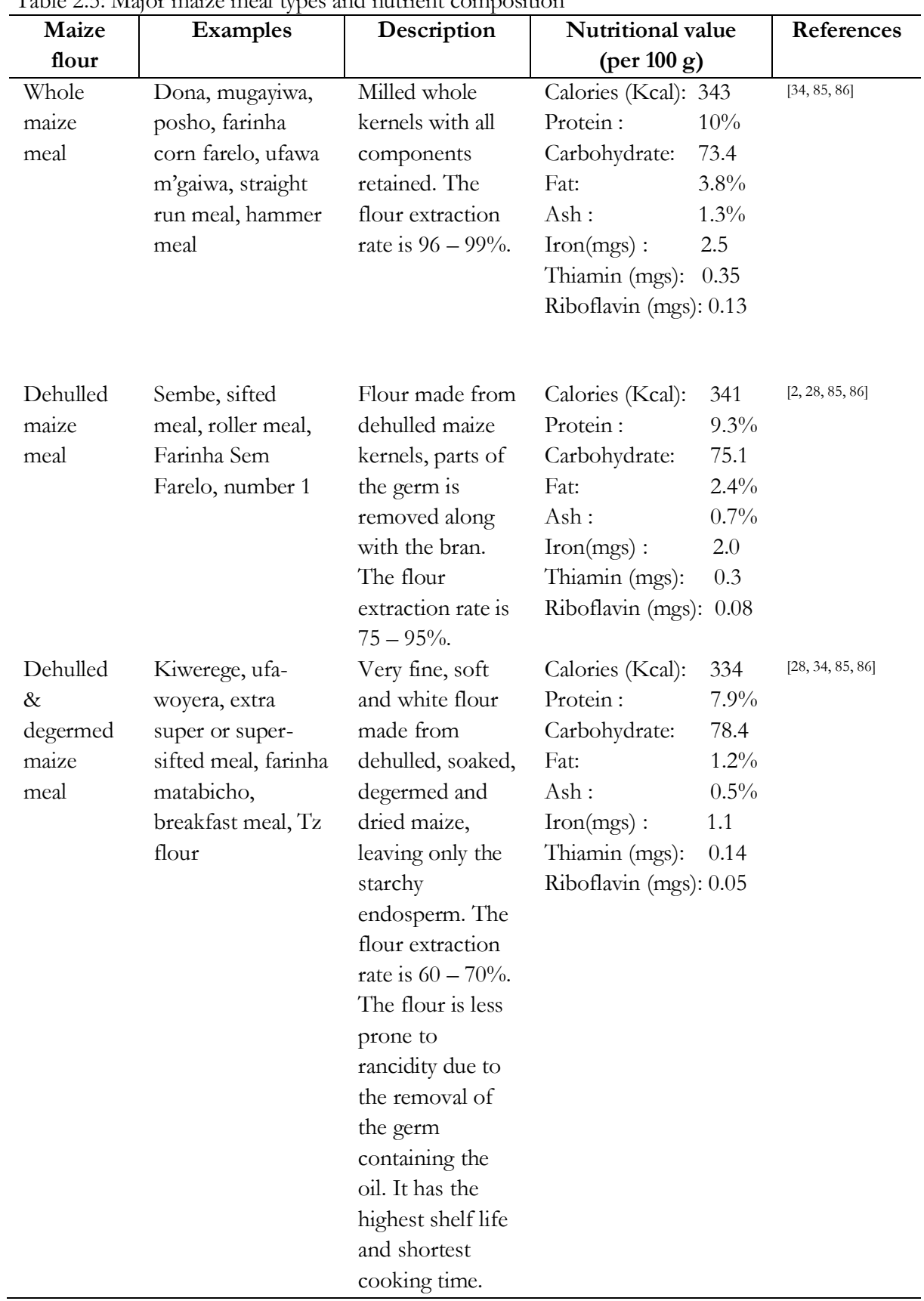




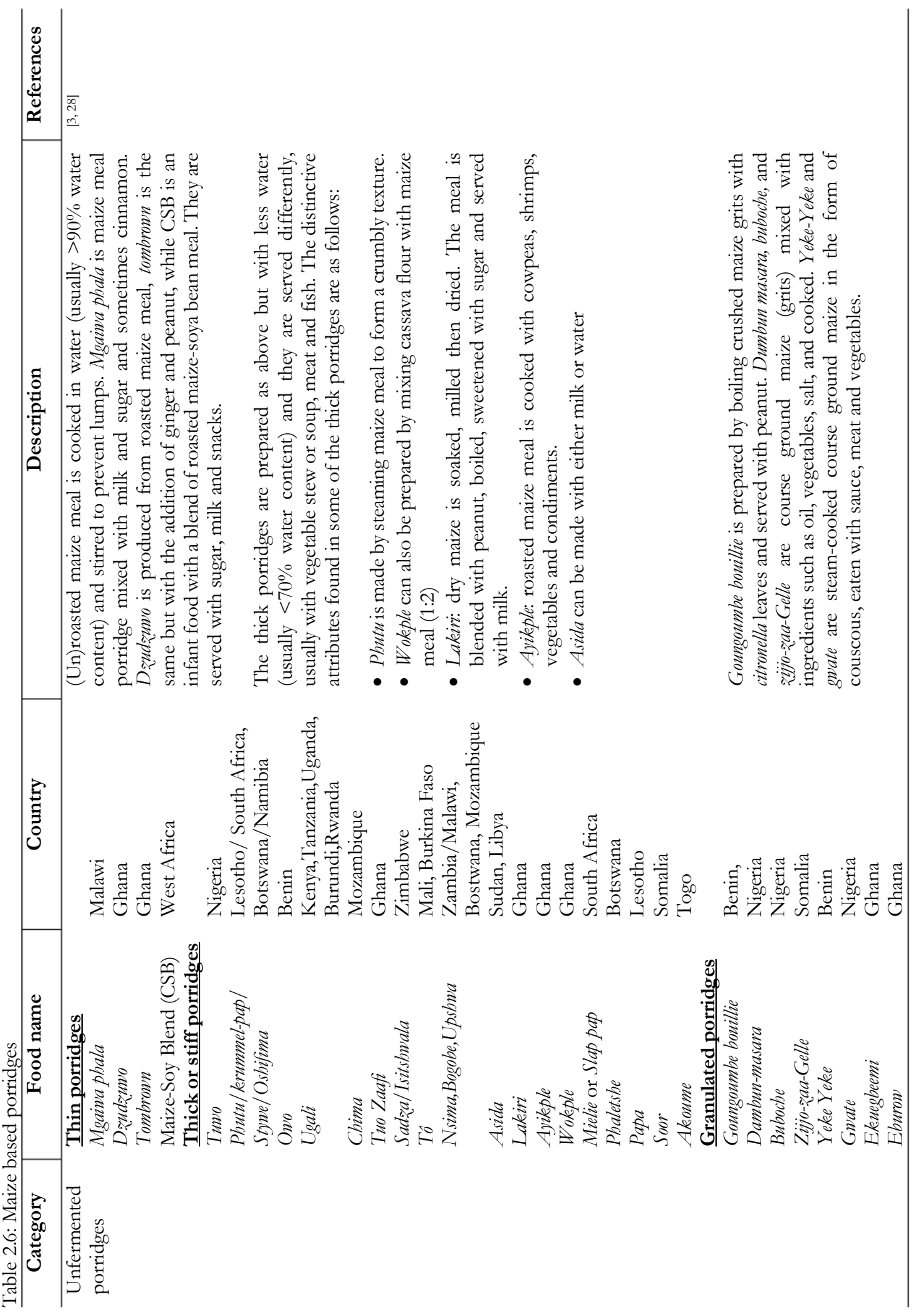




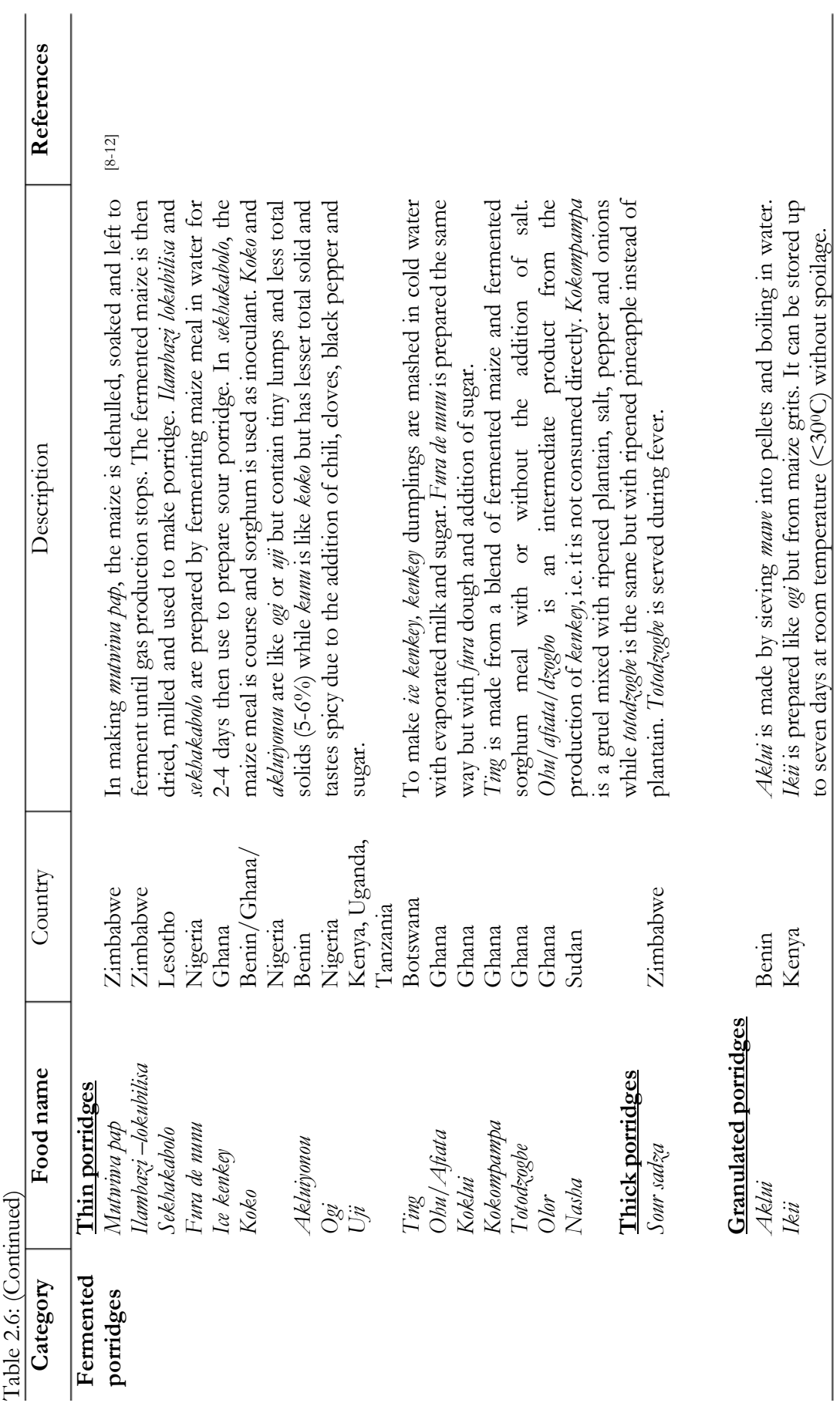




\subsubsection{Maize based beverages}

The use of locally available cereal-based beverages is common practice in Africa, serving as a well-accepted alternative to industrial brews or drinks. They consist of alcoholic and nonalcoholic beverages such as akpan in Benin,[1] kunu zaki in Nigeria,[18] togwa in Tanzania, ${ }^{[19]}$ see Table 2.7. The non-alcoholic beverages serve as thirst-quenchers and energizers. Akpan from maize is consumed 2-3 times a week by $34 \%$ of the Beninese.[102] The type of technology used and the preference for cereal grains for making beverages depend on the product, socio-cultural group and consumer preference. Gaffa et al. [18] reported that in the production of kunu in Northern Nigeria, 33\% prefer millet and 20\% maize while $36 \%$ of all the respondents prefer to combine grains. Likewise, $49 \%$ of cheka producers in Ethiopia uses a mixture of cereals; exclusive use of maize is believed to yield a too sour product. ${ }^{[103]}$ Most beverages are derived from combinations of maize with other grains (e.g., wheat, barley, millet, sorghum, legumes).[18, 104] Traditional methods of beverage production (soaking, germination, wet grinding, sieving, and fermentation) are preferred in Africa, Figure 2.2. The mechanism of these methods in producing the desired quality attributes has been well studied. Soaking softens the texture of the grain, triggers germination and activates endogenous enzymes such as amylases, proteases and lipases, which release sugar, amino acids and fatty acids, respectively; these are essential for the fermentation process. ${ }^{[11]}$ Phytase is also activated during soaking and degrades phytate.[105] Though mainly the endogenous amylase produces fermentable sugars, which serve as energy for the fermenting organism, some molds and lactic acid bacteria are also capable of producing amylolytic enzymes for starch hydrolysis.[106]

An alcoholic beverage is obtained using a malting process followed by fermentation, primarily by lactic acid bacteria (LAB; predominantly the genera - Lactobacillus, Lactococcus, Leuconostoc and Pediococcus), yeast (e.g., Saccharomyces), and fungi (e.g., Aspergillus), while nonalcoholic beverages basically use soaking and a slight fermentation. ${ }^{[18]}$ The preparation of nonalcoholic beverages involves soaking (sometimes with malting), grinding followed by filtration and overnight fermentation. The fermented filtrate is boiled and sweetened or salted. ${ }^{[18]}$ In a nonalcoholic beverage such as munkoyo, the alcohol content is less than $0.5 \%$ but can increase to more than $2.5 \%$ with continued fermentation, thereby turning it into an alcoholic beverage. ${ }^{[17]}$ This practice is not unusual since most traditional beverages are consumed while they are actively fermenting. Prolonged fermentation could also result in a bitter taste, off-odour and spoilage.[107] Many adults in Zambia drink an average of one-litre munkoyo per day.[108] Non-alcoholic beverages are cherished for their sweet and slightly sour taste, smooth texture, low acidity and characteristic local aroma. The type of ingredient gives each beverage its desired local flavour. Ingredients such as ginger, clove, red pepper, 
black pepper and tamarind (Dialium guineense L.) fruits are used for kunu zaki,,$^{[18]}$ ripened plantain and pepper are added to bladzodidiwo, ${ }^{[3]}$ see Table 2.7.

Traditional alcoholic beverages account for the highest percentage of alcohol consumption in Africa, possibly because of its cultural connotations (e.g., regular use in traditional ceremonies) and low cost. In Zambia, for instance, in the Copperbelt as well as in Southern Province, farmers drink more than 60 litres of chibuku per year.[108] Depending on the season, sorghum, millet, and maize beer contributes $6-12 \%$ of adult calories intake in countries like Burkina, Gambia, Guinea-Bissau, Togo, Cameroon, Sudan, Burundi, Rwanda, Kenya, Tanzania, Botswana, Lesotho, Swaziland, Malawi, and Zambia.[9] The preparation of the alcoholic beverage entails soaking maize for 2-3 days or for 5 to $7 \mathrm{~h}$ in warm water of $60-70^{\circ} \mathrm{C}$ (commonly maize serve as starchy adjunct while grains such as wheat, sorghum and millet are malted), followed by draining and leaving the grain to germinate in a well-aerated container covered with leaves or cloth. The germinated maize is wet ground, boiled, cooled and filtered. The filtrate is allowed to ferment until the desired sour flavour is obtained and then boiled to a concentrate. ${ }^{[17}$, 109] The beverage contains lactic acid, alcohol, sugar, and amino acids, which have an antimicrobial effect on pathogens, such as Campylobacter, Salmonella, Shigella and E. coli. $[110]$

In both alcoholic and nonalcoholic beverages, local starch liquefaction agents are often added, e.g. Rhynchosia heterophylla for munkoyo; Cadaba farinosa, malted rice/sorghum and sweet potato extract for kunu zaki; malted millet flour for togwa and wheat flour and/or sorghum malt for mahewu. ${ }^{[17-19,111]}$ These ingredients contain amylolytic enzymes, which break down large starch molecules into substrate for fermentation and result in the characteristic beverage with a low viscosity and relative density. A bittering and antimicrobial agent such as the gesho plant (Rhamnus prinoides) is added to tella drink in Ethiopia. Similarly, wood ash can be added to neutralize the excessive acid in the drink. ${ }^{[12]}$ The alcohol content of local beverages is unstandardized and varies widely within the same locality and sometimes even for the same type of production; e.g., pito is 3\%, tella is $2-4 \%$ and busaa is $2-4 \% .{ }^{[73,109]}$ The variation can be ascribed to differences in spontaneous fermentation or starter culture, the concentration of liquefaction agent, the duration of the fermentation, the homogeneity of the filtrate and whether or not distillation takes place.

Studies on beverages in Africa usually neglect their health-supporting potential. For instance, sour liquor such as the one derived from ogi production has been reported to possess probiotic and antimicrobial effects. ${ }^{[113]}$ In fact, maize sourdough solutions were observed to be as effective as WHO/UNICEF oral rehydration salts (ORS) for 
treatment of children having diarrhoea and abdominal discomfort. ${ }^{[14]}$ The sour liquor has long been effectively used in local communities for managing acute diarrhoea in children and for soaking or dilution of local herbal medicines, especially in rural areas where they may not have access to medical facilities. The production and packaging of sour liquor is inexpensive (fully derived from a liquid waste stream) and culturally accepted in most communities, especially in West Africa. To the best of our knowledge, it is only used at household level and not commercialized in any form. Similarly, microorganisms extracted from sourdough in traditional African foods have shown to exhibit probiotic properties.[113,115] However, heat treatment during cooking destroys the predominant lactic acid bacteria present, and therefore nullifies all probiotic effects. To use the probiotic potential of the sourdough, it could be positioned as an uncooked beverage drink like pozol in Mexico and sobia in Saudi Arabia. Pozol and sobia are refreshing beverages made from suspensions of fermented dough in water and consumed cold; [116] similar to the consumption of ice kenkey (in Ghana) and fura de nunu (in Nigeria). 


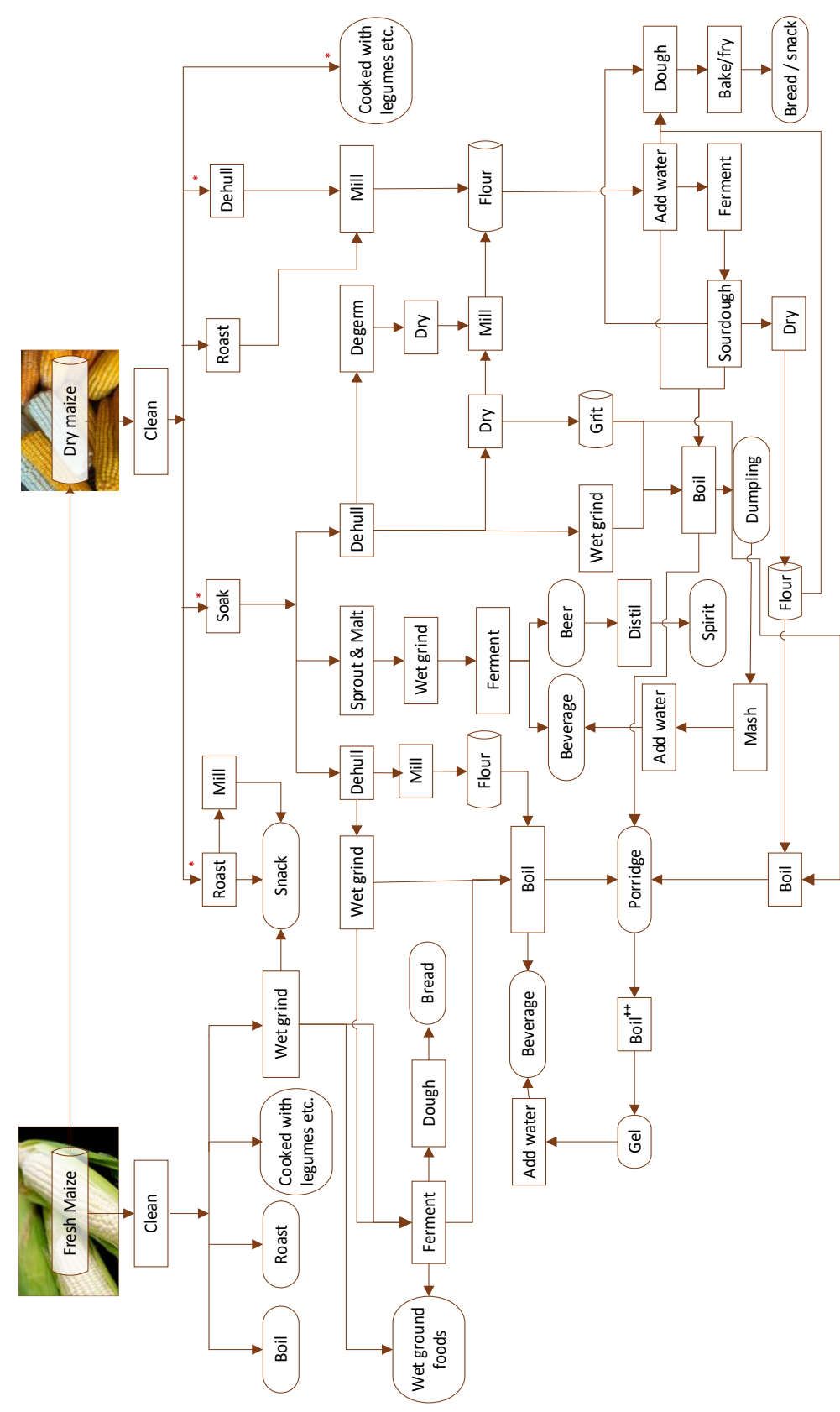

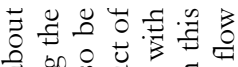
茪

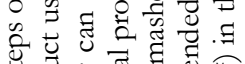

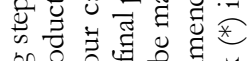

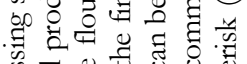

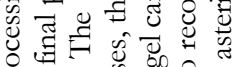

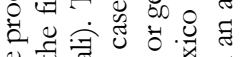
‡ُ 䒘.

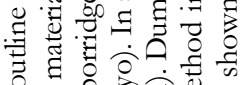

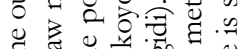

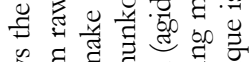

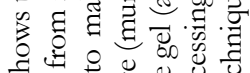

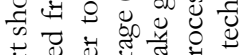

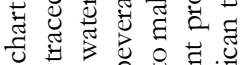

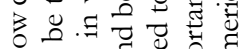

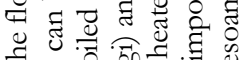
F.

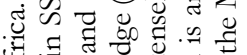

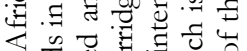
$\exists \begin{aligned} & 0 \\ & 0 \\ & 0\end{aligned}$ bo

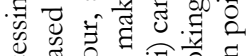
ช 웅

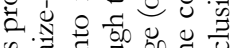
\% 크.

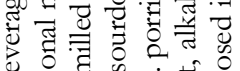

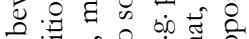

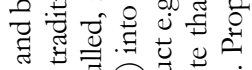

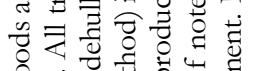

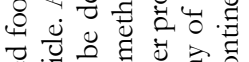
प्य

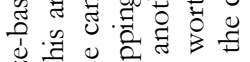
i⿱ चี

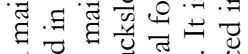

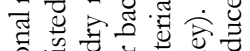

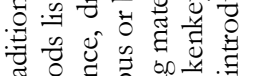

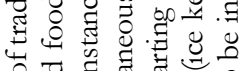

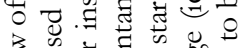

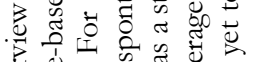
苟.

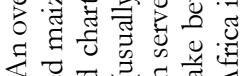

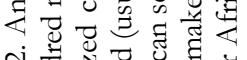

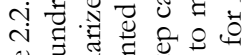

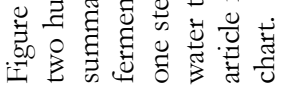




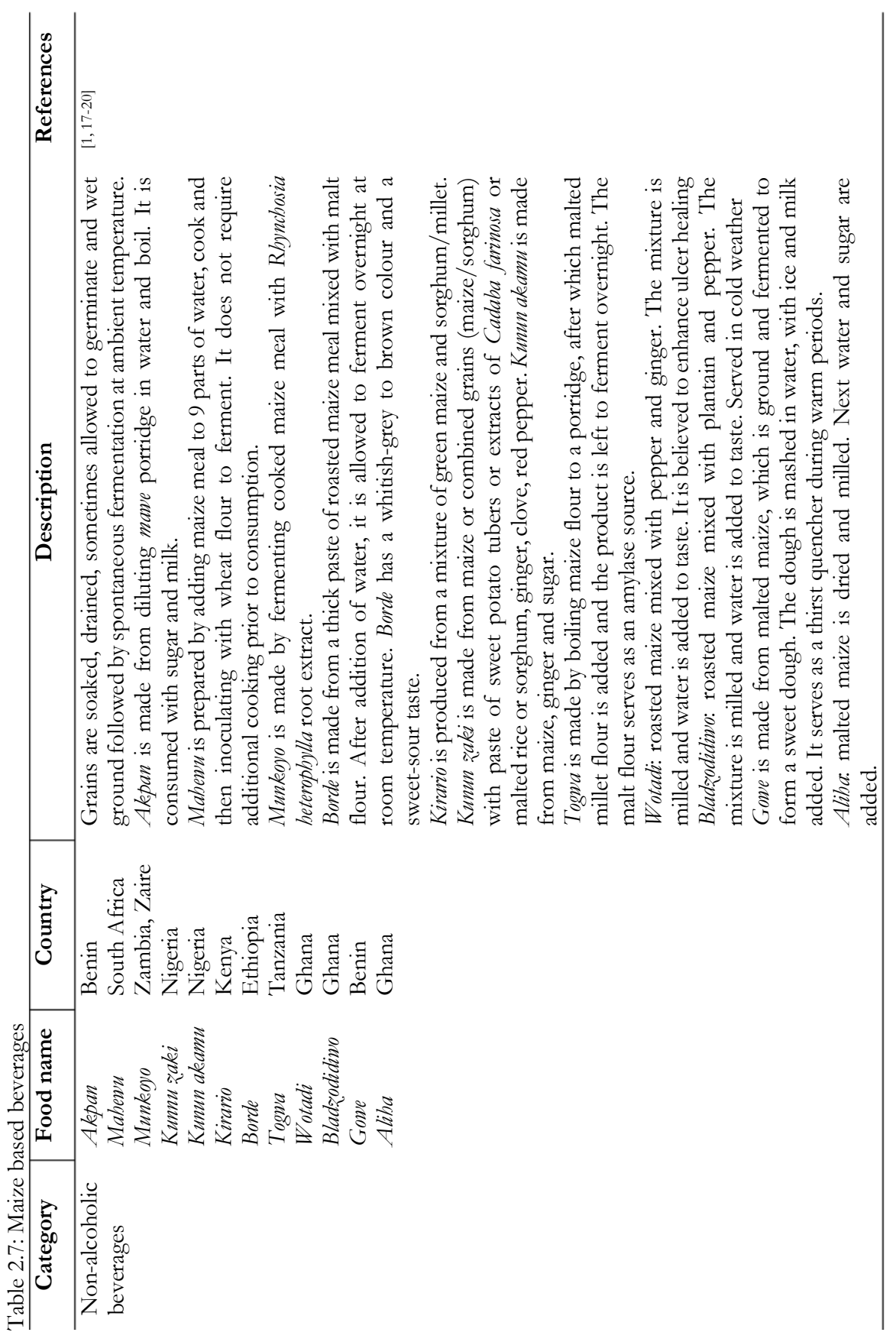




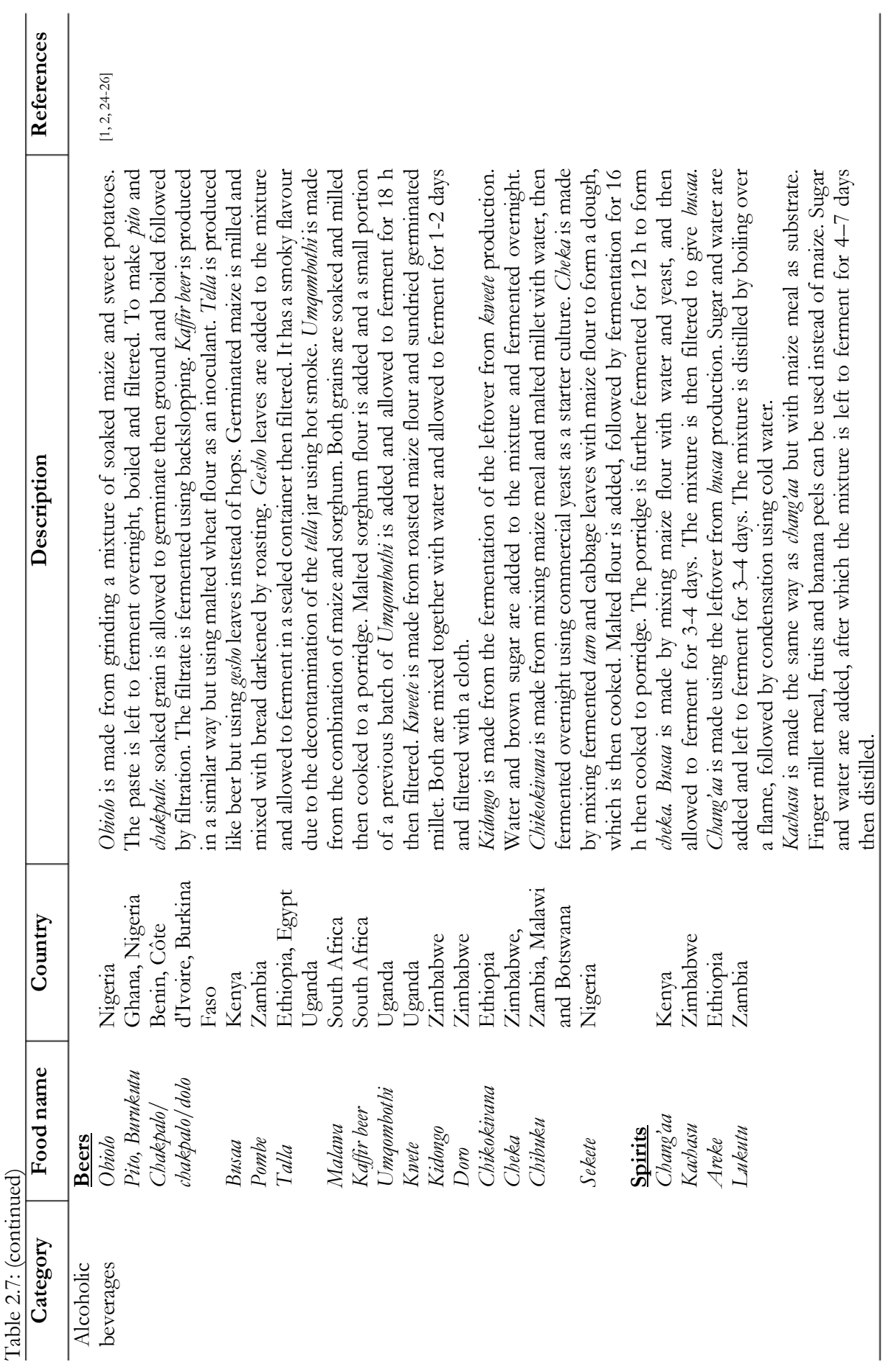




\subsubsection{General evaluation of maize value chains and opportunities}

Maize-based street food production serves as a major avenue for consumption of maize in Sub-Saharan Africa. An increase in patronage of street food has been recorded in Africa in the past two decades, consequent to urbanization (movement of people into towns in pursuit of opportunities - 'greener pastures'), which usually leaves a large number of the immigrants jobless. As a result, many embark on street food vending for livelihood. Likewise, the demand for street food increased because city-dwellers spend most time at work or commuting. Thus they prefer to buy convenient, fast, easily accessible and inexpensive food. ${ }^{[3]}$ This trend will continue since the population of Africa is expected to double, with urbanization levels rapidly expanding to more than half. A large portion of street foods in Africa is maize-based, for instance banku (a cooked fermented corn dough) is $44 \%$ of the menu list of street food vendors in Ghana. ${ }^{[17]}$ Therefore, it is important to pay more attention to maize-based street food vending as a means of increasing maize utilization and creating opportunities through a value chain approach. The long list of maize-based foods in the previous sections presents many opportunities that can benefit street vending, help to lift many people out of poverty as well as improve nutrition, especially for women (and their children), who are the predominant stakeholder. Other opportunities in maize value chains are presented in Figure 2.3.

To ensure food and nutrition security, value chains of major staple crops like maize have to become more efficient and diversified, thereby creating inclusiveness and innovations to feed the current and future population. Although value creation is often viewed exclusively in monetary terms, non-monetary value creation (enhancing quality, safety, sensory properties, food diversity, as well as the nutritional value of the end product) is critical to ameliorating the current poor performance and untapped potential of staple crops. Value addition of staple crops has been long neglected or received little attention over the years resulting in loss of foreign exchange and employment opportunities and contributing to prevailing malnutrition. Although this study emphasizes opportunities for street food vendors, upscaling food production by small and large scale enterprises is also highly feasible and to be encouraged. 


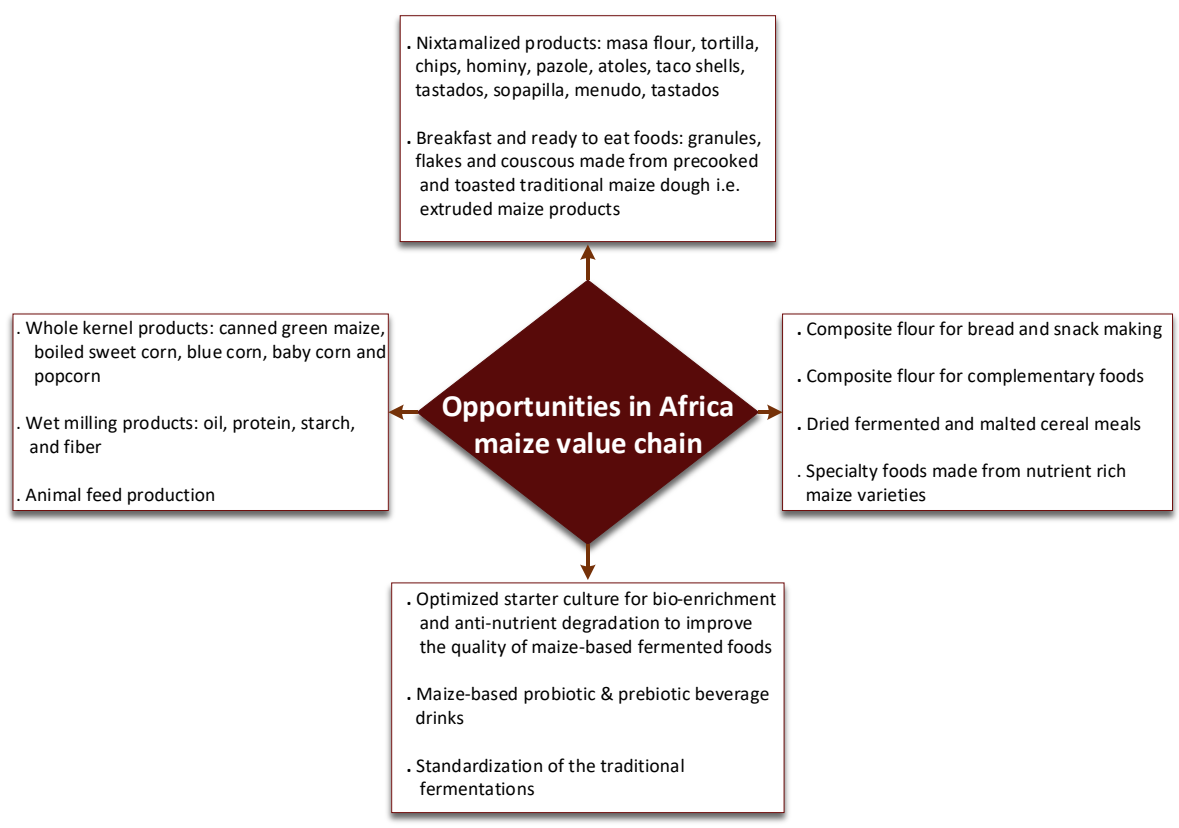

Figure 2.3: Framework of opportunities in Africa's maize value. Nixtamalization technique in Mexico generates about 300 products (Natalia et al., 2016). The vast amount of product from this technique coupled with its nutritional and food safety benefits shows that it could make a significant impact in Africa and can serve as a driver for the nutrient-dense varieties currently having low adoption. The close similarity of this technique with the examples of the traditional processing methods in Africa shows a strong possibility for incorporation and acceptance. Green maize and popcorn currently not sufficiently grown in the country are a huge gap of opportunities to be filled. And since fermentation is a critical processing step in Africa, local bio-enriched techniques can generate nutrient-rich products and probiotics/prebiotics from maize. The underutilization of maize for breakfast meal and composite flour could be overturned to drive the acceptance of improved maize varieties. 


\subsubsection{Effects of traditional maize processing on nutritional quality}

Traditional maize processing has been used for centuries to improve food quality functionality, texture, flavour, shelf life, safety and nutritional value. Processing methods include roasting, smoking, dehulling, drying, soaking, malting and fermentation. Maize-based foods are often characterized by a low nutritional quality as a result of the removal of some kernel structures like pericarp or germ, damage due to processing and/or the natural nutritional deficiencies of the grain. ${ }^{[93]}$ Besides, the presence of antinutrients, like phytate in maize, decreases the bioavailability of the minerals. Studies on the effects of maize processing on nutritional quality are scarce in Africa, and in many cases the available studies have contrasting results. ${ }^{[77,118]}$

In general, traditional processing in Africa involves uncontrolled drying, removal of the bran and sometimes the germ, either intentionally or not, and also excessive washing of grits, decanting of soaked or fermented water and sieving out chaff, all of which can result in loss of nutrients. ${ }^{[36]}$ Maize starch derived from sediments in water or repeated rounds of draining is normally used in the preparation of traditional foods, e.g. ogi. This infers that the nutrients in the supernatant are discarded. Improved nutrient retention was reported in modified sourdough processing methods such as in the use of a pure starter culture, reuse of steep water and a proper milling and sieving method to minimize loss of maize germ and other components. ${ }^{[119,120]}$ In addition to the impact of these mechanical processes, other treatments such as heating may result in denaturation of the heat sensitive components like proteins and possibly, crosslinking of amino acids to form lanthionine or lysinoalanine or Maillard browning products. ${ }^{[121]}$ Maize-based foods serve as weaning food for infants and staple foods for adults. Consequently, understanding the nutrient retention and the amount available for body functions as a result of maize processing is critical to optimize maize use.

\subsubsection{Effect of processing on anti-nutrient - phytic acid}

Phytic acid (PA) negatively influences the bioavailability of minerals due to the high chelating ability of its reactive groups with positively charged cations such as $\mathrm{Fe} 2+$, $\mathrm{Zn} 2+, \mathrm{Ca} 2+$ and $\mathrm{Mg} 2+$ to form insoluble metal-phytate complexes. ${ }^{[22]}$ Breakdown of PA can occur by 1) an endogenous enzyme (e.g., phytase in maize), 2) an exogenous enzyme (e.g., biotechnologically produced phytase or addition of crops with high phytase activity like wheat), 3) intestinal mucosal phytase, 4) microbial (e.g., bacteria, fungi, yeast) phytase released during fermentation or digestion in the gut, and 5) processing activities (e.g., boiling, roasting, milling etc.).[123, 124] As the mucosal phytase activity in humans is very low (i.e., 1000-fold lower than that of alkaline phosphatase), its role in the breakdown of PA is negligible. ${ }^{125]}$ 
Traditional processing and preparation methods, such as drying, milling, soaking, heating/roasting, cooking (e.g., with water or an alkaline solution), sprouting or malting and fermentation can degrade phytic acid (PA) to enhance the bioavailability of nutrients. $[44,124,126]$ The efficiency of these methods in reducing PA can be influenced by its location in the maize kernel.[127] About $90 \%$ of PA is located in the maize germ. This is the same structure where $26 \%$ of the kernel protein, $78 \%$ of the kernel minerals and $83 \%$ of the total kernel lipids are present. ${ }^{[111]}$ Thus the removal of the germ where PA is concentrated, deprives consumers of essential nutrients. An efficient maize processing method needs to optimize the reduction of PA to its lowest phosphorylated form (<IP3), and thus maintain a maximum amount of nutrients.[127] Breakdown of PA increases downstream processing, i.e. from raw maize to finished product; hence, it is important to systematically combine different processing methods to achieve a significant reduction of PA.[127]

All forms of heat treatment have a positive impact on PA degradation at different rates. The degradation is higher in fresh maize than in dried maize. ${ }^{[124]}$ Heat treatments such as boiling, cooking in hot powdered charcoal, roasting in sand and roasting on charcoal of fresh maize resulted in PA losses of 18.1, 29.2, 46.7 and 15 - 41.9\%, respectively, while a much lower reduction was observed in dried maize. For example, boiling in water and roasting in sand resulted in 19 and 24 - 37\% PA reductions, respectively.[122, 124] Milling or pounding exposes PA to enzymatic hydrolysis, thermal degradation, and faster absorption. For instance, a 47 - 51\% PA reduction was observed in soaked pounded maize, with a much higher reduction in finer flour. ${ }^{[105,128]}$ Reduction of PA during soaking is largely due to diffusion of water-soluble PA (e.g., $\mathrm{Na}, \mathrm{K}$, or $\mathrm{Mg}$ phytate), which can then be drained out.[127] Approximately $90 \%$ of PA in maize is soluble in water, ${ }^{[129]}$ which makes soaking a reliable method for reducing PA. The soaking of grain also results in activation of endogenous phytases, which break down PA.[130] In general, the extent of PA reduction during soaking depends on the level of granulation of maize, $\mathrm{pH}$, variety (i.e., hardness of the endosperm and hull) and duration. ${ }^{[126]}$ Amoa et al. ${ }^{[89]}$ observed a 5.9\% phytate reduction (with an additional 1.9\% in steeping water) in samples from Ghana while $2.2 \%$ was reported for samples from Malawian maize. Other researchers, Greffeuille et al. ${ }^{[37]}$ and Mitchikpe et al. ${ }^{[128]}$ reported 3 - 14\% PA reduction during soaking of maize grains.

The use of unmalted maize flour as a starting material for traditional maize-based food processing deprives the processor of the PA breakdown ability of sprouting since it requires whole maize. This can be mitigated by adding sprouted maize flour since it contains endogenous phytase. ${ }^{[127]}$ However, Amoa et al. ${ }^{[89]}$ observed that addition of wheat flour is more efficient than malted maize flour. The addition of $1 \%$ wheat flour 
during the production of kenkey resulted in a $99 \%$ phytate reduction after $36 \mathrm{~h}$ of fermentation. ${ }^{\left[{ }^{[9]}\right.}$ Wheat has a phytase activity of $1565(\mathrm{U} / \mathrm{kg})$ compared to $24(\mathrm{U} / \mathrm{kg})$ in maize; the addition of wheat flour increased the phytase concentration thereby causing phytate breakdown. ${ }^{[131]}$ The sprouting process significantly increases phytase activity (more than 80\%) in maize along with a decrease in PA. Egli et al. ${ }^{[126]}$ and Mitchikpe et al. ${ }^{128]}$ reported a 9 - 74\% PA reduction after maize sprouted for $48 \mathrm{~h}-72 \mathrm{~h}$. The PA reduction reported from sprouted maize is not sufficient to influence mineral bioavailability but it is an important step to complement successive degradation processes. ${ }^{[127]}$

The reduction of PA during fermentation of maize is possibly due to the growth of microorganisms rather than by the endogenous enzyme because normal maize has a low phytase activity.[132] An enzyme activity of up to $3 \mathrm{IU} / \mathrm{g}$ of maize seed has been reported in a transgenic maize line containing Aspergillus phyA (encoding phytase), with about $95 \%$ degradation of the endogenous PA in a maize flour paste. [133] Microorganisms break down PA through the production of microbial phytase. The enzyme hydrolyzes PA into myoinositol and inorganic phosphate through the intermediate myoinositol phosphates (i.e., IP1 to IP5).[105, 130, 134] Amoa et al. [89] observed $16.9 \%$ and $2.7 \%$ phytate reductions during the production of kenkey from Ghanaian and Malawian maize, respectively. Similarly, Hotz et al. ${ }^{[105]}$ reported a $12 \%$ reduction of phytate during spontaneous fermentation and a 39\% reduction using a starter culture. A larger reduction was observed after the addition of malted maize flour. Microbial phytase is released from the natural microorganisms on maize or starter cultures. The production and activity of phytase are influenced by $\mathrm{pH}$, temperature, species, available nutrients, and the presence of inhibiting agents. ${ }^{[123,130]}$ Optimum degradation of PA requires an understanding of the constituent microorganisms and the released microbial phytase since different phytase sources show differences in heat stability and $\mathrm{pH}$ optimum. Most bacteria and fungi produce phytase at an optimum $\mathrm{pH}$ range between 5.0 and 7.0; the released phytase is active at a $\mathrm{pH}$ optimum between 4.5 and 5.5 for fungi and 6.5 to 7.5 for bacteria. ${ }^{[123]}$ Similarly, most microorganisms produce phytase at an optimum temperature ranging from 25 to $37^{\circ} \mathrm{C}$; the released phytase is active at a temperature between 25 to $80^{\circ} \mathrm{C} .[123,130]$ Stability of microbial phytase decreases as $\mathrm{pH}$ drops below 4.5 and increases above 7.5.[134] The $\mathrm{pH}$ of the maize food ranges from an average of 6.5 (initial) to 3.1 (final product), with the temperature at an average of $28^{\circ} \mathrm{C}$. Lactobacillus plantarum, which is the most predominant LAB in fermented maize-based foods and has the highest phytase activity, was found to produce phytase with a single $\mathrm{pH}$ optimum of 5.5 , and to be inactive at $\mathrm{pH}<3.5 />6.5$. Therefore, to achieve the optimum degradation of $\mathrm{PA}$, fermentation processes need to be maintained at conditions that favor the activity of the predominant microbial phytase. ${ }^{[37]}$ 


\section{Conclusion}

The traditional uses of maize, especially for snacks, drinks and bread, in African countries are limited when compared to Mexico and Central America, where maize originates. Given the right technology, maize variety, process and awareness, many high potential maize foods localized in some communities can be scaled up across the continent and beyond. The introduction of local processing technologies or techniques, like nixtamalization, at both household and commercial level, would enhance the use of maize to meet consumer needs and preferences, and reduce nutrient wastages. Rapid population growth and urbanization in combination with increased disposable income is bound to induce dietary change. If dietary change follows comparable patterns as elsewhere in the world, this implies more reliance on semi-processed and processed foods. Promoting processing techniques that will reduce nutrient loss and make food preparation more convenient for consumers can enable enhanced food and nutrition security.

Traditional fermented foods will continue to gain acceptance in SSA; research into technologies to improve nutritional properties, shelf life and baking properties is necessary. Studies on more effective ways to enhance the nutritional quality of maizebased foods through blending with the commonly available nutrient-rich crops, vegetables and possibly through microbial fortification (e.g., fermentation with high amino acid secreting microorganisms) and other novel approaches should be encouraged. Advanced knowledge in biotechnology could be applied to develop microorganisms that can be used in fermentation to enhance nutritional components and quality of maize-based foods. Additionally, there is a need to embark on research to improve the bioavailability of essential nutrients as influenced by the maize food matrix and the different traditional processing methods.

\section{Acknowledgements}

This work was supported by the CGIAR research program (CRP) on MAIZE agri-food systems. The CGIAR Research Program MAIZE receives W1 \& W2 support from the governments of Australia, Belgium, Canada, China, France, India, Japan, Korea, Mexico, Netherlands, New Zealand, Norway, Sweden, Switzerland, U.K., and U.S., as well as the World Bank. The contents and opinions expressed herein are those of the authors and do not necessarily reflect the views of the associated and/or supporting institutions. The usual disclaimer applies. 


\section{References}

1. Nago M, Hounhouigan D. La transformation alimentaire traditionnelle des céréales au Bénin. CERNA, FSA/UAC1998. p. 152.

2. van Eijnatten CLM. Towards the improvement of maize in Nigeria [(Doctoral dissertation)]: Wageningen, The Netherlands; 1965.

3. Dovlo F. Maize in the Ghanaian diet. The Home Scientist. 1973;2(3):13-29.

4. Nkhabutlane P. An investigation of Basotho culinary practices and consumer acceptance of Basotho traditional bread 2014.

5. De Groote H, Kimenju SC. Consumer preferences for maize products in urban Kenya. Food and nutrition bulletin. 2012;33(2):99-110.

6. Muzhingi T, Langyintuo AS, Malaba LC, Banziger M. Consumer acceptability of yellow maize products in Zimbabwe. Food Policy. 2008;33(4):352-61.

7. FAOSTAT. Food balance sheet 2016 [Available from: http://faostat.fao.org/site/345/default.aspx.

8. Gadaga T, Mutukumira A, Narvhus J, Feresu S. A review of traditional fermented foods and beverages of Zimbabwe. International journal of food microbiology. 1999;53(1):1-11.

9. Steinkraus K. Industrialization of indigenous fermented foods, revised and expanded: CRC Press; 2004.

10. Gadaga TH, Lehohla M, Ntuli V. Traditional fermented foods of Lesotho. The Journal of Microbiology, Biotechnology and Food Sciences. 2013;2(6):2387.

11. Marras S, AgBendech M. STREET FOOD IN URBAN GHANA. Food and Agriculture Organization of the United Nations (FAO). 2016.

12. Kalui C, Mathara J, Kutima P, Kiiyukia C, Wongo L. Partial characterisation and identification of lactic acid bacteria involved in production of ikii: a traditional fermented maize porridge by the Kamba in Kenya. Journal of Tropical Microbiology and Biotechnology. 2008;4(1):3-15.

13. Mphwanthe G, Kalimbira AA, Geresomo NC. Consumption and wastage of home-fortified maize flour products in northern Malawi. South African Journal of Clinical Nutrition. 2015;29(1):23-6.

14. Redhead J, Boelen M. Utilization of Tropical Foods: Cereals: Food \& Agriculture Org.; 1989.

15. Iskander FY, Davis KR, Ashour H, Hassan HF. Aluminium content of Egyptian breads. Food chemistry. 1990;35(3):197-208.

16. Jideani V, Danladi I. Instrumental and sensory textural properties of fura made from different cereal grains. International Journal of food properties. 2005;8(1):49-59.

17. Zulu R, Dillon V, Owens J. Munkoyo beverage, a traditional Zambian fermented maize gruel using Rhynchosia root as amylase source. International journal of food microbiology. 1997;34(3):249-58.

18. Gaffa T, Jideani I, Nkama I. Traditional production, consumption and storage of Kunu-a non alcoholic cereal beverage. Plant Foods for Human Nutrition. 2002;57(1):73-81.

19. Oi Y, Kitabatake N. Chemical composition of an East African traditional beverage, togwa. Journal of agricultural and food chemistry. 2003;51(24):7024-8.

20. Seiuml NB, Kayodé A, Dalodé-Vieira G, Baba-Moussa L, Kotchoni S, Hounhouigan D. Improvement of the traditional technology for the production of gow, a sour and sweet beverage from Benin. African Journal of Food Science. 2011;5(15):806-13.

21. Osseo-Asare F. Food Culture in Sub-Saharan Africa: Greenwood Publishing Group; 2005.

22. Ohna IL. Food, Culture and Livelihood in Malinzanga Village, Tanzania [M.Sc. thesis]2007. 
23. Nuss ET, Tanumihardjo SA. Maize: a paramount staple crop in the context of global nutrition. Comprehensive reviews in food science and food safety. 2010;9(4):417-36.

24. Lee M, Regu M, Seleshe S. Uniqueness of Ethiopian traditional alcoholic beverage of plant origin, tella. Journal of Ethnic Foods. 2015;2(3):110-4.

25. Aka S, Konan G, Fokou G, Dje KM, Bassirou B. Review on African traditional cereal beverages. Am J Res Comm. 2014;2(5):103-53.

26. Mwesigye PK, Okurut TO. A survey of the production and consumption of traditional alcoholic beverages in Uganda. Process Biochemistry. 1995;30(6):497-501.

27. Assohoun MC, Djeni TN, Koussémon-Camara M, Brou K. Effect of Fermentation Process on Nutritional Composition and Aflatoxins Concentration of Doklu, a Fermented Maize Based Food. Food and Nutrition Sciences. 2013;4(11):1120.

28. Onyango C. Physical properties of dry-milled maize meals and their relationship with the texture of stiff and thin porridge. African Journal of Food Science. 2014;8(8):435-43.

29. Ranum P, Peña-Rosas JP, Garcia-Casal MN. Global maize production, utilization, and consumption. Annals of the New York Academy of Sciences. 2014;1312(1):105-12.

30. Serna-Saldivar SO. Cereal Grains: Properties, Processing, and Nutritional Attributes: CRC Press; 2016.

31. Hernández-Quintero JdD, Rosales-Nolasco A, Molina-Macedo A, Miranda-Piliado A, Willcox M, Hernández-Casillas JM, et al. Cuantificación de antocianinas mediante espectroscopía de infrarrojo cercano y cromatografía líquida en maíces pigmentados. Revista Fitotecnia Mexicana. 2017;40(2).

32. Zilić S, Serpen A, Ak1llioglu Gl, Gokmen V, Vančetović J. Phenolic compounds, carotenoids, anthocyanins, and antioxidant capacity of colored maize (Zea mays L.) kernels. Journal of Agricultural and food chemistry. 2012;60(5):1224-31.

33. Mensah JO, Aidoo R, Teye AN. Analysis of street food consumption across various income groups in the Kumasi Metropolis of Ghana. International Review of Management and Business Research. 2013;2(4):951.

34. Ohna I, Kaarhus R, Kinabo J. No meal without ugali? Social significance of food and consumption in a Tanzanian village. Culture, Agriculture, Food and Environment. 2012;34(1):3-14.

35. Bouis HE, Saltzman A. Improving nutrition through biofortification: A review of evidence from HarvestPlus, 2003 through 2016. Global Food Security. 2017;12:49-58.

36. Suri DJ, Tanumihardjo SA. Effects of Different Processing Methods on the Micronutrient and Phytochemical Contents of Maize: From A to Z. Comprehensive Reviews in Food Science and Food Safety. 2016;15(5):912-26.

37. Greffeuille V, Kayodé AP, Icard-Vernière C, Gnimadi M, Rochette I, Mouquet-Rivier C. Changes in iron, zinc and chelating agents during traditional African processing of maize: effect of iron contamination on bioaccessibility. Food chemistry. 2011;126(4):1800-7.

38. Alamu O, Maziya-Dixon B, Olaofe O, Menkir A. Varietal and harvesting time effects on physical characteristics and sensory properties of roasted fresh yellow maize hybrids. IOSR Journal of Applied Chemistry (IOSR-JAC). 2015;8(2):55-63.

39. Alamu OE, Menkir A, Maziya-Dixon B, Olaofe O. Effects of husk and harvest time on carotenoid content and acceptability of roasted fresh cobs of orange maize hybrids. Food science \& nutrition. 2014;2(6):811-20. 
40. Olayiwola I, Oganah B, Onabanjo O, Oguntona C, Popoola A, Sanni S, et al. Consumption Pattern Of Maize Based Dishes In Four Agro-Ecological Zones Of Nigeria. Journal of Agricultural Science and Environment. 2016;12(2):45-61.

41. Iken J, Amusa N. Review: Maize research and production in Nigeria. African Journal of Biotechnology. 2004;3(6):302-7.

42. Palacios-Rojas N, Vázquez G, Rodriguez ME, Carvajal M, Molina A, Rosales-Nolasco A, et al. Lime cooking process: nixtamalization from Mexico to the world. 2016.

43. Uzogara SG, Morton ID, Daniel JW. Changes in some antinutrients of cowpeas (Vigna unguiculata) processed with 'kanwa'alkaline salt. Plant foods for human nutrition. 1990;40(4):249-58.

44. Bressani R, Turcios J, De Ruiz A. Nixtamalization effects on the contents of phytic acid, calcium, iron and zinc in the whole grain, endosperm and germ of maize. Food science and technology international. 2002;8(2):81-6.

45. Voss K, Ryu D, Jackson L, Riley R, Gelineau-van Waes J. Reduction of fumonisin toxicity by extrusion and nixtamalization (alkaline cooking). Journal of agricultural and food chemistry. 2017;65(33):7088-96.

46. Elias-Orozco R, Castellanos-Nava A, Gaytan-Martinez M, Figueroa-Cárdenas J, Loarca-Pina G. Comparison of nixtamalization and extrusion processes for a reduction in aflatoxin content. Food Additives \& Contaminants. 2002;19(9):878-85.

47. White PJ, Johnson LA. Corn: chemistry and technology: American Association of Cereal Chemists; 2003.

48. Li R, Hu H-B, Li X-F, Zhang P, Xu Y-K, Yang J-J, et al. Essential oils composition and bioactivities of two species leaves used as packaging materials in Xishuangbanna, China. Food Control. 2015;51:9-14.

49. Bokanga M, editor Processing of cassava leaves for human consumption. International Workshop on Cassava Safety 375; 1994.

50. Kordylas JM. Processing and preservation of tropical and subtropical foods: Macmillan; 1990.

51. Proietti I, Frazzoli C, Mantovani A. Identification and management of toxicological hazards of street foods in developing countries. Food and chemical toxicology. 2014;63:143-52.

52. Nkhabutlane P, du Rand GE, de Kock HL. Quality characterization of wheat, maize and sorghum steamed breads from Lesotho. Journal of the Science of Food and Agriculture. 2014;94(10):2104-17.

53. MacRitchie F. Flour lipids and their effects in baking. Journal of the Science of Food and Agriculture. 1977;28(1):53-8.

54. Kohajdová Z, Karovicova J, Schmidt S. Significance of emulsifiers and hydrocolloids in bakery industry. Acta Chimica Slovaca. 2009;2(1):46-61.

55. Kataria R. Development of maize and rice based gluten free food products: CCSHAU; 2014.

56. Julianti E, Rusmarilin H, Yusraini E. Functional and rheological properties of composite flour from sweet potato, maize, soybean and xanthan gum. Journal of the Saudi Society of Agricultural Sciences. 2017;16(2):171-7.

57. Schober TJ, Bean SR, Boyle DL, Park S-H. Improved viscoelastic zein-starch doughs for leavened gluten-free breads: Their rheology and microstructure. Journal of Cereal Science. 2008;48(3):755-67.

58. Brites C, Trigo MJ, Santos C, Collar C, Rosell CM. Maize-based gluten-free bread: influence of processing parameters on sensory and instrumental quality. Food and Bioprocess Technology. 2010;3(5):707-15. 
59. Watanabe M, Maeda T, Tsukahara K, Kayahara H, Morita N. Application of pregerminated brown rice for breadmaking. Cereal Chemistry. 2004;81(4):450-5.

60. Falade AT, Buys EM, Taylor JR. Effect of Different Non-Wheat Bread Making Methods on the Quality of Maize Bread. Journal of Food Technology. 2017;15(1):1-6.

61. Sly AC, Taylor J, Taylor JR. Improvement of zein dough characteristics using dilute organic acids. Journal of Cereal Science. 2014;60(1):157-63.

62. Iken J, Amusa N. Consumer acceptability of seventeen popcorn maize (Zea mays L.) varieties in Nigeria. African Journal of Agricultural Research. 2010;5(5):405-7.

63. Uzor-Peters P, Arisa N, Lawrence C, Osondu N, Adelaja A. Effect of partially defatted soybeans or groundnut cake flours on proximate and sensory characteristics of kokoro. African Journal of Food Science. 2008;2(8):098-101.

64. Nout MR. Rich nutrition from the poorest-Cereal fermentations in Africa and Asia. Food Microbiology. 2009;26(7):685-92.

65. Haleegoah J, Ruivenkamp G, Essegbey G, Frempong G, Jongerden J. Street-Vended Local Food Systems Actors Perceptions on Safety in Urban Ghana: The Case of Hausa Koko, Waakye and Ga Kenkey. Advances in Applied Sociology. 2015;5(04):134.

66. Nout M, Kok B, Vela E, Nche P, Rombouts F. Acceleration of the fermentation of kenkey, an indigenous fermented maize food of Ghana. Food research international. 1995;28(6):599604.

67. Hounhouigan D, Nout M, Nago C, Houben J, Rombouts F. Changes in the physico-chemical properties of maize during natural fermentation of mawe. Journal of Cereal Science. 1993;17(3):291-300.

68. Adegbehingbe K. Fermented sprouted and unsprouted maize for Ogi production. Int J Adv Res. 2013;1(10):428-34.

69. Katongole JN. The microbial succession in indigenous fermented maize products: University of the Free State; 2008.

70. Oyeyiola G. Microbiological and biochemical changes during the fermentation of maize (Zea mays) grains formasa production. World Journal of Microbiology and Biotechnology. 1990;6(2):171-7.

71. Achi OK, Ukwuru M. Cereal-Based Fermented Foods of Africa as Functional Foods. International Journal of Microbiology and Application. 2015;2(4):71-83.

72. Blandino A, Al-Aseeri M, Pandiella S, Cantero D, Webb C. Cereal-based fermented foods and beverages. Food research international. 2003;36(6):527-43.

73. Nout M. Microbiological aspects of the traditional manufacture of Bussa, a Kenyan opaque maize beer. Chemie, Mikrobiologie, Technologie der Lebensmittel= Food chemistry, microbiology, technology. 1980.

74. Burgess CM, Smid EJ, van Sinderen D. Bacterial vitamin B2, B11 and B12 overproduction: an overview. International journal of food microbiology. 2009;133(1-2):1-7.

75. Adebawo O, Ruiz-Barba JL, Warner PJ, Oguntimein GB. Regulation of aspartokinase in Lactobacillus plantarum. Journal of applied microbiology. 1997;82(2):191-6.

76. Sybesma W, Burgess C, Starrenburg M, van Sinderen D, Hugenholtz J. Multivitamin production in Lactococcus lactis using metabolic engineering. Metabolic engineering. 2004;6(2):109-15.

77. Adebawo O, Akingbala J, Ruiz-Barba JL, Osilesi O. Utilization of high lysine-producing strains of Lactobacillus plantarum as starter culture for nutritional improvement of ogi. World Journal of Microbiology and Biotechnology. 2000;16(5):451-5. 
78. Odunfa S, Adeniran S, Teniola O, Nordstrom J. Evaluation of lysine and methionine production in some lactobacilli and yeasts from Ogi. International journal of food microbiology. 2001;63(1):159-63.

79. Hellström AM, Vázques-Juárez R, Svanberg U, Andlid TA. Biodiversity and phytase capacity of yeasts isolated from Tanzanian togwa. International journal of food microbiology. 2010;136(3):352-8.

80. Nche P, Nout M, Rombouts F. The effects of processing on the availability of lysine in kenkey, a Ghanaian fermented maize food. International journal of food sciences and nutrition. 1995;46(3):241-6.

81. Muhihi A, Gimbi D, Njelekela M, Shemaghembe E, Mwambene K, Chiwanga F, et al. Consumption and acceptability of whole grain staples for lowering markers of diabetes risk among overweight and obese Tanzanian adults. Globalization and health. 2013;9(1):1.

82. Bolade MK, Adeyemi IA, Ogunsua AO. Influence of particle size fractions on the physicochemical properties of maize flour and textural characteristics of a maize-based nonfermented food gel. International journal of food science \& technology. 2009;44(3):64655 .

83. Nche P, Odamtten G, Nout M, Rombouts F. Dry milling and accelerated fermentation of maize for industrial production of kenkey, a Ghanaian cereal food. Journal of cereal science. 1994;20(3):291-8.

84. Teniola O, Odunfa S. The effects of processing methods on the levels of lysine, methionine and the general acceptability of ogi processed using starter cultures. International journal of food microbiology. 2001;63(1):1-9.

85. Bolade MK. Effect of flour production methods on the yield, physicochemical properties of maize flour and rheological characteristics of a maize-based non-fermented food dumpling. African Journal of Food Science. 2009;3(10):288-98.

86. Jayne TS, Rubey L, Tschirley DL, Mukumbu M, Chisvo M, Santos AP, et al. Effects of market reform on access to food by low-income households: evidence from four countries in eastern and southern Africa. Michigan State University, Department of Agricultural, Food, and Resource Economics; 1996.

87. Mukumbu M, Jayne TS. Urban maize meal consumption patterns: Strategies for improving food access for vulnerable urban households in Kenya: Productive Sector Growth and Environment Division, Office of Sustainable Development, Bureau for Africa, US Agency for International Development; 1995.

88. Ongol MP, Niyonzima E, Gisanura I, Vasanthakaalam H. Effect of germination and fermentation on nutrients in maize flour. Pakistan Journal of Food Sciences. 2013;23(4):183-8.

89. Amoa B, Muller H. Studies on kenkey with particular reference to calcium and phytic acid. Cereal chem. 1979;53:365-75.

90. Mensah P, Tomkins A. Household-level technologies to improve the availability and preparation of adequate and safe complementary foods. Food and Nutrition Bulletin. 2003;24(1):104-25.

91. Bankole MO. Consumer's Knowledge, Attitude, Usage and Storage Pattern of Ogi-A Fermented Cereal Gruel in South West, Nigeria. Food and Public Health. 2015;5(3):77-83.

92. Lartey A, Manu A, Brown KH, Peerson JM, Dewey KG. A randomized, community-based trial of the effects of improved, centrally processed complementary foods on growth and micronutrient status of Ghanaian infants from 6 to 12 mo of age. The American journal of clinical nutrition. 1999;70(3):391-404. 
93. Onofiok N, Nnanyelugo D. Weaning foods in West Africa: Nutritional problems and possible solutions. Food and Nutrition Bulletin. 1998;19(1):27-33.

94. Oyarekua M. Evaluation of the nutritional and microbiological status of co-fermented cereals/cowpea 'OGI'. Agriculture and Biology Journal of North America. 2011;2(1):61-73.

95. Nche P, Nout M, Rombouts F. The effect of cowpea supplementation on the quality of kenkey, a traditional Ghanaian fermented maize food. Journal of cereal science. 1994;19(2):191-7.

96. Oluwamukomi M, Eleyinmi A, Enujiugha V. Effect of soy supplementation and its stage of inclusion on the quality of ogi-a fermented maize meal. Food chemistry. 2005;91(4):651-7.

97. Aminigo E, Akingbala J. Nutritive composition and sensory properties of ogi fortified with okra seed meal. 2004.

98. Badifu G, Ilochi J, Dutse J, Akpapunam M. Use of mango mesocarp flour to enrich the provitamin A content of a complementary food blend of maize and soya bean flours for porridge. Food and Nutrition Bulletin. 2000;21(3):316-22.

99. Abioye F, MO A. Proximate composition and sensory properties of moringa fortified maizeogi. Nutrition \& Food Sciences. 2015.

100. Ajani OO. Improvement of Nutritive Value of Sorghum-Ogi Fortified with Pawpaw (Carica papaya L). Fruit, Vegetable and Cereal Science and Biotechnology. 2010;4(1):98-101.

101. Adeoti O, Elutilo O, Babalola J, Jimoh K, Azeez L, Rafiu K. Proximate, Mineral, Amino Acid and Fatty Acid Compositions of Maize Tuwo-Cirina Forda Flour Blends. . Greener Journal of Biological Sciences. 2013;3(4):165-71.

102. Sacca C, Adinsi L, Anihouvi V, Akissoe N, Dalode G, Mestres C, et al. Production, consumption, and quality attributes of Akpan-a yoghurt-like cereal product from West Africa. Food Chain. 2012;2(2):207-20.

103. Worku BB, Woldegiorgis AZ, Gemeda HF. Indigenous Processing Methods of Cheka: A Traditional Fermented Beverage in Southwestern Ethiopia. J Food Process Technol. 2015;7(540):2.

104. Louw A, Geyser M, Troskie G, van der Merwe M, Scheltema N, Nicholson R. Determining the factors that limit agro-processing development in the maize milling industry in rural areas in South Africa. Report by Markets and Economics Research center (MERC) for the National Agricultural marketing centre (NAMC), South Africa. 2010.

105. Hotz C, Gibson RS. Assessment of home-based processing methods to reduce the phytate content and phytate/zinc molar ratio of white maize (Zea mays). Journal of Agricultural and Food Chemistry. 2001;49(2):692-8.

106. Olukoya D, Ebigwei S, Olasupo N, Ogunjimi A. Production of DogiK: an improved Ogi (Nigerian fermented weaning food) with potentials for use in diarrhoea control. Journal of Tropical Pediatrics. 1994;40(2):108-13.

107. Oi Y, Kitabatake N. Analysis of the carbohydrates in an East African traditional beverage, togwa. Journal of agricultural and food chemistry. 2003;51(24):7029-33.

108. Malaisse F. How to live and survive in Zambezian open forest (Miombo ecoregion): Presses agronomiques de Gembloux; 2010.

109. Haard N, Odunfa S, Lee C, Quintero-Ram'1rez R, Lorence-Quinones A, Wacher-Radarte C. Fermented cereals: A global perspective. . ISBN 92-5-104296-9; 1999.

110. Simango C, Rukure G. Survival of bacterial enteric pathogens in traditional fermented foods. Journal of applied bacteriology. 1992;73(1):37-40. 
111. Arendt EK, Zannini E. Cereal grains for the food and beverage industries: Elsevier, Cambridge, UK 2013.

112. Berhanu A. Microbial profile of Tellaand the role of gesho (Rhamnus prinoides) as bittering and antimicrobial agent in traditional Tella (Beer) production. 2013.

113. Adebolu T, Olodun A, Ihunweze B. Evaluation of ogi liquor from different grains for antibacterial activities against some common diarrhoeal bacteria in Southwest Nigeria. African Journal of Biotechnology. 2007;6(9).

114. Yartey J, Nkrumah F, Hori H, Harrison K, Armar D. Clinical trial of fermented maize-based oral rehydration solution in the management of acute diarrhoea in children. Annals of tropical paediatrics. 1995;15(1):61-8.

115. Enujiugha VN, Badejo AA. Probiotic potentials of cereal-based beverages. Critical reviews in food science and nutrition. 2017;57(4):790-804.

116. Wacher C, Cañas A, Bárzana E, Lappe P, Ulloa M, Owens JD. Microbiology of Indian and Mestizo pozol fermentations. Food Microbiology. 2000;17(3):251-6.

117. Ackah M, Gyamfi E, Anim A, Osei J, Hansen J, Agyemang O. Socio-economic profile, knowledge of hygiene and food safety practices among street-food vendors in some parts of Accra-Ghana. Internet journal of food safety. 2011;13:191-7.

118. Nwokoro O, Chukwu BC. Studies on Akamu, a traditional fermented maize food. Revista Chilena de Nutrición. 2012;39(4).

119. Ijabadeniyi A, Adebolu T. The effect of processing methods on the nutritional properties of ogi produced from three maize varieties. J Food Agric Environ. 2005;3:108-9.

120. Oyarekua M, Eleyinmi A. Comparative evaluation of the nutritional quality of corn, sorghum and millet ogi prepared by a modified traditional technique. Journal of Food Agriculture and environment. 2004;2:94-9.

121. Rutherfurd SM, Moughan PJ. Development of a novel bioassay for determining the available lysine contents of foods and feedstuffs. Nutrition research reviews. 2007;20(01):3-16.

122. Oboh G, Ademiluyi AO, Akindahunsi AA. The effect of roasting on the nutritional and antioxidant properties of yellow and white maize varieties. International journal of food science \& technology. 2010;45(6):1236-42.

123. Vohra A, Satyanarayana T. Phytases: microbial sources, production, purification, and potential biotechnological applications. Critical reviews in biotechnology. 2003;23(1):29-60.

124. Khan N, Zaman R, Elahi M. Effect of heat treatments on the phytic acid content of maize products. Journal of the Science of Food and Agriculture. 1991;54(1):153-6.

125. Iqbal T, Lewis K, Cooper B. Phytase activity in the human and rat small intestine. Gut. 1994;35(9):1233-6.

126. Egli I, Davidsson L, Juillerat M, Barclay D, Hurrell R. The Influence of Soaking and Germination on the Phytase Activity and Phytic Acid Content of Grains and Seeds Potentially Useful for Complementary Feedin. Journal of Food Science. 2002;67(9):3484-8.

127. Hotz C, Gibson RS. Traditional food-processing and preparation practices to enhance the bioavailability of micronutrients in plant-based diets. The Journal of nutrition. 2007;137(4):1097-100.

128. Mitchikpe ECS, Dossa RA, Ategbo E-AD, van Raaij JM, Hulshof PJ, Kok FJ. The supply of bioavailable iron and zinc may be affected by phytate in Beninese children. Journal of food composition and analysis. 2008;21(1):17-25.

129. De Boland AR, Garner GB, O'Dell BL. Identification and properties of phytate in cereal grains and oilseed products. Journal of Agricultural and Food Chemistry. 1975;23(6):1186-9. 
130. Gupta RK, Gangoliya SS, Singh NK. Reduction of phytic acid and enhancement of bioavailable micronutrients in food grains. Journal of food science and technology. 2015;52(2):676-84.

131. Godoy S, Chicco C, Meschy F, Requena F. Phytic phosphorus and phytase activity of animal feed ingredients. Interciencia. 2005;30(1):24-8.

132. Proulx AK, Reddy MB. Fermentation and lactic acid addition enhance iron bioavailability of maize. Journal of agricultural and food chemistry. 2007;55(7):2749-54.

133. Drakakaki G, Marcel S, Glahn RP, Lund EK, Pariagh S, Fischer R, et al. Endosperm-specific co-expression of recombinant soybean ferritin and Aspergillus phytase in maize results in significant increases in the levels of bioavailable iron. Plant molecular biology. 2005;59(6):86980.

134. Nakamura Y, Fukuhara H, Sano K. Secreted phytase activities of yeasts. Bioscience, biotechnology, and biochemistry. 2000;64(4):841-4. 



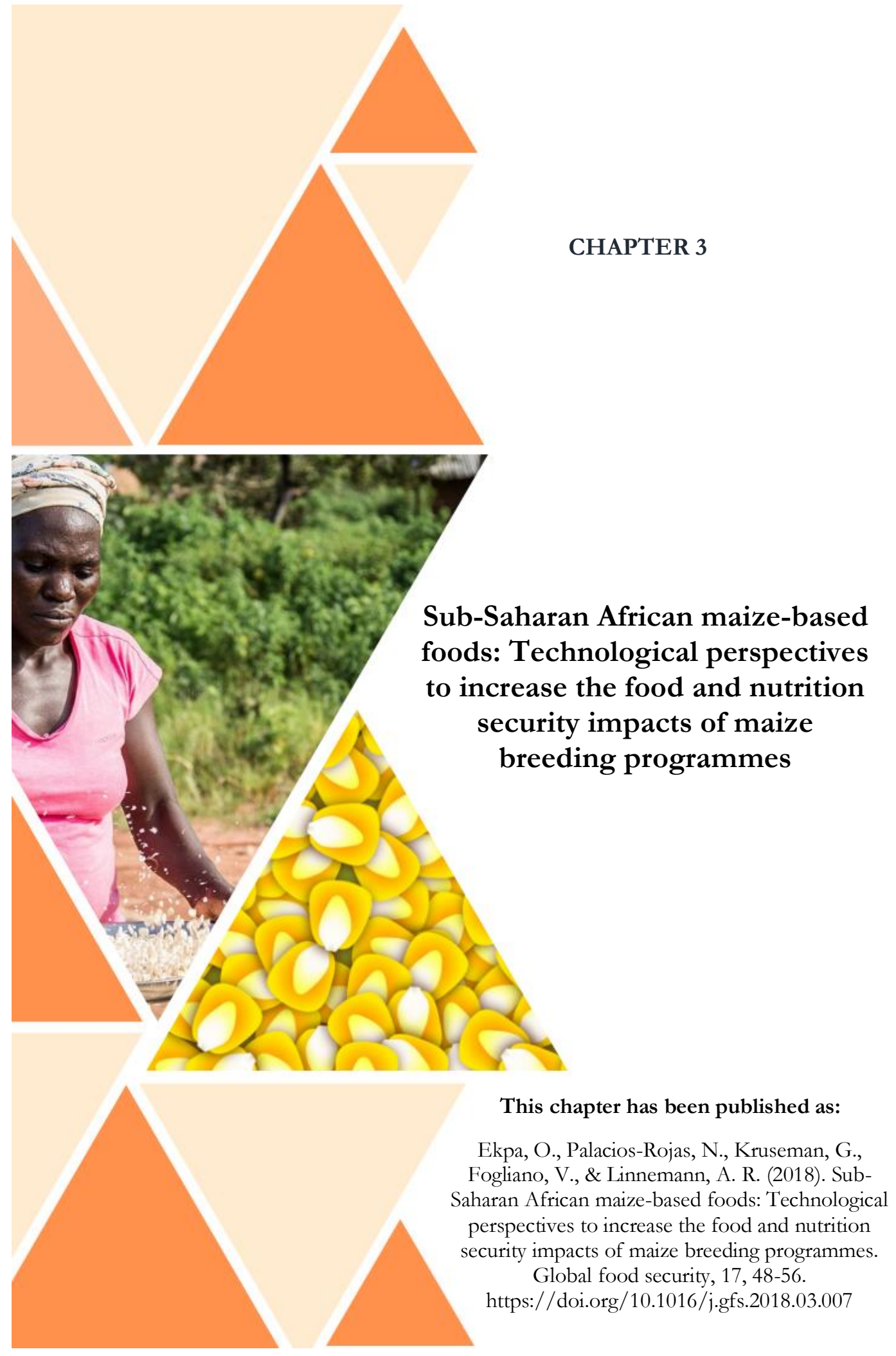




\begin{abstract}
The demand for maize in Sub-Saharan Africa will triple by 2050 due to rapid population growth, while challenges from climate change will threaten agricultural productivity. Most maize breeding programmes have focused on improving agronomic properties and have paid relatively little attention to postharvest qualities, thus missing important opportunities to increase the contribution to food and nutrition security. This paper considers current and potential food uses of maize in Africa and proposes six objectives to enhance the contribution of maize breeding programmes to food and nutrition security: (1) enhance nutrient density; (2) enhance suitability for use in bread and snacks; (3) improve characteristics for consumption as green maize; (4) improve characteristics that enhance the efficiency of local processing; (5) reduce waste by maximising useful product yield and minimising nutrient losses; (6) reduce the anti-nutrient content of grain.
\end{abstract}

Keywords: Maize; Maize-based food; Maize breeding; Maize value chain; Consumer preferences; Sub-Saharan Africa 


\subsubsection{Introduction}

The growing availability of staple foods in Sub-Saharan Africa (SSA) since the 1990s has substantially reduced the prevalence of undernutrition. [1] Staple foods in SSA are characterized by high carbohydrate content but are low in other food nutrient components like protein, vitamins and minerals. ${ }^{2]}$ One of the major staple crops in SSA is maize, which is consumed in many forms including infant foods, snacks and main dishes. Populations in regions with heavy maize consumption may suffer malnutrition due to natural deficiencies or low quantities of some nutrients in maize, limitations of the maize food matrix, presence of anti-nutrients, physical loss or chemical damage to the nutritional composition during post-harvest handling and limited alignment of maize breeding programmes with preferences of end-users, i.e., maize processors and consumers. [2] Preferences for maize and maize-based foods differ across Africa, thus implying that general solutions are not feasible for the diverse and dynamic continent. [3] Research and development (R\&D) policies in Africa generally emphasise improving agronomic properties such as yield and tolerance to abiotic and biotic stresses. In contrast, understanding characteristics such as taste, colour, nutritional value and suitability for use in preparing local or novel dishes seldom receives the attention it deserves. ${ }^{[4]}$

The ultimate measure of the success of maize breeding efforts is the demand and adoption of their new varieties by end-users. Breeders develop new varieties based on product profiles, which are a list of traits and characteristics that must be achieved in the new variety for it to succeed. More than one product profile is needed to define the needs of all clients, including processors and consumers. An adequate understanding of the needs of maize users, and integrating this understanding into product profiles targeted by breeding programmes across SSA will help to properly harness research resources, increase adoption of novel maize varieties, improve nutrition and meet the needs of traditional and modern food processes. Between 2010 and 2050 the population of Africa is expected to double, with urbanization levels changing from one third to more than half. Once food security is assured, consumers will increasingly demand quality traits. Maize food uses can be expanded to support the rural/urban transition by offering more nutritious food products and enhancing processing efficiency. This is critical because to date various maize varieties with improved agronomic traits are facing challenges along the value chain, such as differences in organoleptic preferences and processing requirements of users, limiting the utilisation of the crop for food. $[5,6]$ Strategies based on maize breeding and improved processing methods that hinge on a critical understanding of users' preferences and nutritional needs could help people meet their daily dietary requirements, and position breeding programmes in developing countries for greater impact. 
This paper examines the preferences and needs of maize users in SSA and suggests traits that maize breeding programmes might include in their portfolio to further increase the impact of new varieties on food and nutrition security. The research did not consider the specific needs of each country in SSA; instead, it focused on what is characteristic for two major maize production and consumption regions, i.e. Western and Eastern/Southern Africa, where maize is a staple food. Likewise, the research did not take into account the ease or difficulty of incorporating these traits into new varieties but identified some possible quality trait targets and the current methods for measurement. The review serves as a foundation for further work to meet users' needs and improve maize value chains.

\subsubsection{Categories of maize-based foods}

In general, we can distinguish six categories of maize-based foods in Africa, namely: whole-maize foods, wet-ground maize foods, snacks and bread, maize sourdough and dumplings, porridges and beverages. Examples of maize-based foods are summarised in Table 3.1; a comprehensive list of maize-based foods, their descriptions and frequency of consumption can be found in Ekpa et al. [7].

Table 3.1: Examples of maize-based foods in Africa

\begin{tabular}{|c|c|c|}
\hline $\begin{array}{l}\text { Food } \\
\text { category }\end{array}$ & $\begin{array}{l}\text { Major processing } \\
\text { steps }\end{array}$ & Examples \\
\hline $\begin{array}{l}\text { Whole- } \\
\text { grain } \\
\text { foods }\end{array}$ & $\begin{array}{l}\text { Cooking, steaming, } \\
\text { roasting }\end{array}$ & $\begin{array}{l}\text { Adalu, egbo (Nigeria); githeri, muthokoi (Kenya); aboda } \\
\text { (Benin); ayibli, nkyekyerewa, adibabli (Ghana); kandy, } \\
\text { makande (Tanzania); mangai, mutakura (Zimbabwe); } \\
\text { lusontfwana, tinhlumaya- nemphuphu (Swaziland); } \\
\text { setampo (Lesotho); umngqusho, samp (South Africa); } \\
\text { corn tchap (Cameroon); roasted \& boiled maize (across } \\
\text { Africa) }\end{array}$ \\
\hline $\begin{array}{l}\text { Wet- } \\
\text { ground } \\
\text { maize } \\
\text { foods }\end{array}$ & $\begin{array}{l}\text { Wet grinding, } \\
\text { steaming }\end{array}$ & $\begin{array}{l}\text { Amiwo, abla (Benin); sapala, abari (Nigeria); akakla, ofam } \\
\text { (Ghana); koga (Cameroon); mohlefe (Lesotho); shamsi, } \\
\text { fallahi (Egypt); Maputi (Zimbabwe) }\end{array}$ \\
\hline $\begin{array}{l}\text { Bread and } \\
\text { snacks }\end{array}$ & $\begin{array}{l}\text { Fermentation, baking, } \\
\text { frying and roasted }\end{array}$ & $\begin{array}{l}\text { Masa, donkwa (Nigeria); kpome-klekle, tale (Benin); } \\
\text { dzowee, mamu kaklo (Ghana); injera, dabo (Ethiopia); } \\
\text { muufo (Somalia); Monepola oa Poone feela (Lesotho); } \\
\text { chigumu (Malawi); Chimodho (Zimbabwe); Popcorn (all } \\
\text { over Africa) }\end{array}$ \\
\hline $\begin{array}{l}\text { Sourdough } \\
\text { and } \\
\text { dumplings }\end{array}$ & $\begin{array}{l}\text { Soaking, } \\
\text { fermentation, } \\
\text { steaming and cooking }\end{array}$ & $\begin{array}{l}\text { Ogi, donkunu (Nigeria); amo, kenkey (Ghana); poto-poto, } \\
\text { mawe, akassa (Benin); mutwiwa (Zimbabwe); doklu (Côte } \\
\text { d'Ivoire ); leqebekoane (Lesotho) }\end{array}$ \\
\hline
\end{tabular}




\begin{tabular}{|c|c|c|}
\hline \multirow[t]{2}{*}{ Porridges } & $\begin{array}{l}\text { Unfermented: } \\
\text { Milling, cooking }\end{array}$ & $\begin{array}{l}\text { Mgaiwa phala (Malawi), tombrown, tuo zaafi (Ghana); } \\
\text { phutu (South Africa); ugali (Kenya); sadza (Zimbabwe); tô } \\
\text { (Mali); nsima (Zambia); Asida (Sudan); tuwo (Nigeria); } \\
\text { papa (Lesotho); owo, yeke (Benin); soor (Somalia) }\end{array}$ \\
\hline & $\begin{array}{l}\text { Fermented: Soaking, } \\
\text { Fermentation, } \\
\text { cooking }\end{array}$ & $\begin{array}{l}\text { Mutwiwa pap, sour sadza (Zimbabwe); afiata, koko, ice } \\
\text { kenkey (Ghana); uji, ikii (Kenya); aklui (Benin); ting } \\
\text { (Botswana) }\end{array}$ \\
\hline \multirow[t]{2}{*}{ Beverages } & $\begin{array}{l}\text { Non-alcoholic: } \\
\text { Milling, soaking, } \\
\text { Cooking }\end{array}$ & $\begin{array}{l}\text { Akpan (Benin); mahewu (South Africa); munkoyo } \\
\text { (Zambia, Zaire); kunnu zaki (Nigeria); kirario (Kenya); } \\
\text { borde (Ethiopia); togwa (Tanzania) }\end{array}$ \\
\hline & $\begin{array}{l}\text { Alcoholic: } \\
\text { Germination, } \\
\text { Fermentation }\end{array}$ & $\begin{array}{l}\text { Obiolo, pito (Nigeria); busaa, chang'aa (Kenya); pombe, } \\
\text { chibuku (Zambia); talla, cheka (Ethiopia); malawa, } \\
\text { kidongo (Uganda); doro, chikokivana, kachasu } \\
\text { (Zimbabwe); kaffir beer, umqombothi (South Africa). }\end{array}$ \\
\hline
\end{tabular}

\subsubsection{Maize preferences for food in Africa}

Flint, dent, pop-maize (popcorn), waxy, sweet and floury maize types of diverse colours, sizes and shapes are commercially grown for human consumption around the world. Grain colour is an important selection criterion for users in Africa, where white is generally preferred over yellow. Although $90 \%$ of globally produced maize is yellow, white maize predominates in Africa with over $90 \%$ of the total maize crop; it also accounts for more than $30 \%$ of global white maize production. $[8,9]$

Yellow maize is in increasing demand for animal feed because it gives a deep yellow colouration to egg yolks, poultry skin and animal fat, which consumers attribute to healthiness and freshness. ${ }^{[10,11]}$ Human consumption of yellow maize in Africa may continuously decline as animal feed use rises. For instance, in South Africa, the commercial yellow maize area (mostly for feed) is expected to increase by $1.4 \%$ per annum while the white maize area decreases by $1.5 \%$ per annum. ${ }^{12,13]}$ In a survey conducted by Pillay et al. ${ }^{[14]}$, some respondents indicated that they only see yellow maize in shops that sell animal feed, not human food; for that reason, it is only for animals. This issue is outside the scope of the current study, which focuses on maize for human food from a food technological and consumer point of view. Information about trends in maize for animal feed in Africa can be found in Rosegrant et al. ${ }^{[13]}$ and Smale et al. [3].

The predominance of white maize for food production may be traced to many cultural valuations or social status (prestige) considerations: "white is superior" or "the whiter the better": the influence of indigenous competitive staple crops; government policies; organoleptic differences; a desire for the brightly coloured finished products; and 
familiarity (i.e. people are used to eating white maize).[2, 5, 8, 9, 14, 15] The association of yellow maize with food aid that was poorly handled or stored during transport and importation, resulting in an unacceptable taste, has been reported to have negatively influenced its acceptance as food.[14] The choice of colour could be customarily driven by indigenous competitive or substitute staple crops. For instance, in the eastern region of Nigeria where gari (fermented cassava flakes) is commonly prepared with palm oil, which appears yellowish, people prefer yellow maize, e.g. for making akamu porridge. In the western part of the country, where finished products made from cassava are white, people prefer white maize, e.g. for making ogi porridge.

In Eastern Africa, yellow maize is rarely found in Kenyan markets; only $26 \%$ of people would consider buying yellow maize at the same price as white maize.[16] Consumers need an average price discount of 37\% in Kenya, 30-40\% in Mozambique and 10\% in Zimbabwe to accept yellow maize instead of white. ${ }^{[16]}$ The perception differs among age groups; preschool children in rural South Africa showed a preference for yellow maize over white maize-based food products, while older groups preferred the white maize-based foods.[14] The rejection of yellow maize has been attributed to a dislike for the colour and to organoleptic or sensory properties, e.g. some respondents have shown a dislike for the smell and taste of yellow maize-based foods. $[8,14,16,17]$ However, when nutritional information was provided, while promoting orange provitamin A biofortified maize in Zambia, the consumers preferred and were willing to pay a premium for orange maize varieties. ${ }^{[18]}$ The differences in maize flavour (aroma and taste) are often elucidated by affective consumer sensory studies, which usually conclude that there are no significant differences. However, farmers in Malawi, Zambia and Zimbabwe have been reported to prefer growing local landraces due to their taste, even when hybrid maize has better yield.[19,20] Likewise, Hebinck et al. ${ }^{[4]}$ found that farmers in Luoland (Kenya), preferred the taste of local maize to the taste of available hybrids. Determination of the relationship between the available sensory data and instrumental measurements of the volatile profiles would help to understand the differences in flavour between and among hybrids, open-pollinated varieties (OPVs), local landraces, nutrient-dense varieties and the different colour types. The profile of volatile organic compounds (VOC) in maize varieties can be characterized using Proton Transfer Reaction -Time of Flight - Mass Spectrometry (PTR-ToF-MS), a direct and noninvasive technique for performing high-resolution measurements. ${ }^{21]}$ Though the equipment has high sensitivity, resolution and speed, it is costly for national breeding programmes and requires trained personnel. As experienced in the development of biofortified crops, one of the challenges faced by breeders is the availability of highthroughput, reliable and cost-efficient analytical methodologies that can be applied to enable rapid and accurate analysis of traits with high heritability. [22] 
Both dent and flint white maize grains are used for making food products in Africa. The difference between these two types is in the distribution of areas in the endosperm with different starch granules density. In the hard corneous endosperm starch granules are tightly packed while in the soft floury endosperm, granules are less dense. Thus in flint kernels, the hard endosperm comprises most of the grain and forms a cap over the germ, while in dent maize, the hard endosperm is on the sides of the kernel, partially surrounding the germ. ${ }^{[23]}$ Flint maize is commonly used as "green maize" (roasted or boiled) and, as opposed to most other maize food types, green maize consumption is without colour partiality by users. [24] In Western Africa, consumers have a preference for soft endosperm varieties because they are easier to steep and mill, and yield finer products. ${ }^{25]}$ This is reasonable because maize foods from the region are largely prepared with whole maize as starting material rather than with maize flour. In a morphological characterization of maize varieties in Nigeria, Anthony ${ }^{[10]}$ found $48 \%$ dent, $14 \%$ floury, 14\% flint, 13\% waxy and 6\% sweet maize. In Eastern and Southern Africa, 57\% and $85 \%$ of maize varieties released $(1966-98)$ by public and private breeding programmes, respectively, were dent varieties.[26] However, the substantial reliance of these regions on refined maize flour (e.g. for preparing 'ufa woyera', a local refined flour used to make nsima), drives the popularity of flintier maize varieties since the germ and bran can be easily separated by tampering with water.[27, 28] For instance, the hard endosperm account for $89 \%$ and $79 \%$ of maize grains found in Malawi and Tanzania, respectively, due to its suitability for making the preferred food types. ${ }^{[26]}$ Despite the consumer preference for flint maize in Malawi, most maize breeding and commercialization have been focused on semi-flint and dent varieties. ${ }^{[28]}$ The relatively low post-harvest losses of flint compared to dent varieties during traditional storage are the reason for their preference in parts of Africa. The most widely adopted modern maize variety (H614 hybrid) in Kenya is semi flint, and about $25 \%$ of the modern varieties in Zambia and Zimbabwe also have an intermediate grain texture.[29] Grain texture and pasting properties (starch content, composition and distribution) are crucial for food preparation. One of the main reasons that farmers in Luoland (Kenya) distance themselves from hybrid maize is that the women, who are generally the cooks at home, believe that it takes twice as much hybrid maize as compared to the local maize to make porridge, i.e. it gives a much 'lighter' ugali. ${ }^{4,28]}$ In general, as local communities transit from basic processing methods (e.g. pounding with stone or mortar) to mechanised methods (e.g. hammer mills and roller mills) and degerminated maize, their maize kernel characteristics like hardness, proportion of kernel structures (germ, endosperm, pericarp) and kernel size may also change. 
As shown in Fig. 3.1, the selection of maize varieties for food in Africa usually starts with grain colour. This is followed by grain texture and food properties, which are the core determinants of the processing and preparation attributes, storability, appearance, palatability, and product yield. These qualities are considered prior to agronomic characteristics during the long-term adoption of new varieties in local communities in Africa. $[20,25,27]$ An excellent agronomic performance does not guarantee adoption for consumption. [4] Participatory varietal selection and plant breeding play a significant role in the adoption of improved varieties. Farmers and end-users tend to adopt varieties they handpicked based on their own set of criteria and preferences. [30] Modern maize varieties have an adoption rate of about 50\% in Sub-Saharan Africa, i.e. $44 \%$ and $66 \%$ in Eastern/Southern Africa and Western/Central Africa, respectively.[29] Greater alignment with the product quality demands of various actors, i.e., processors (who are informed by food technologists, among others) and consumers, in the maize value chain can enhance the adoption and value of new maize varieties.

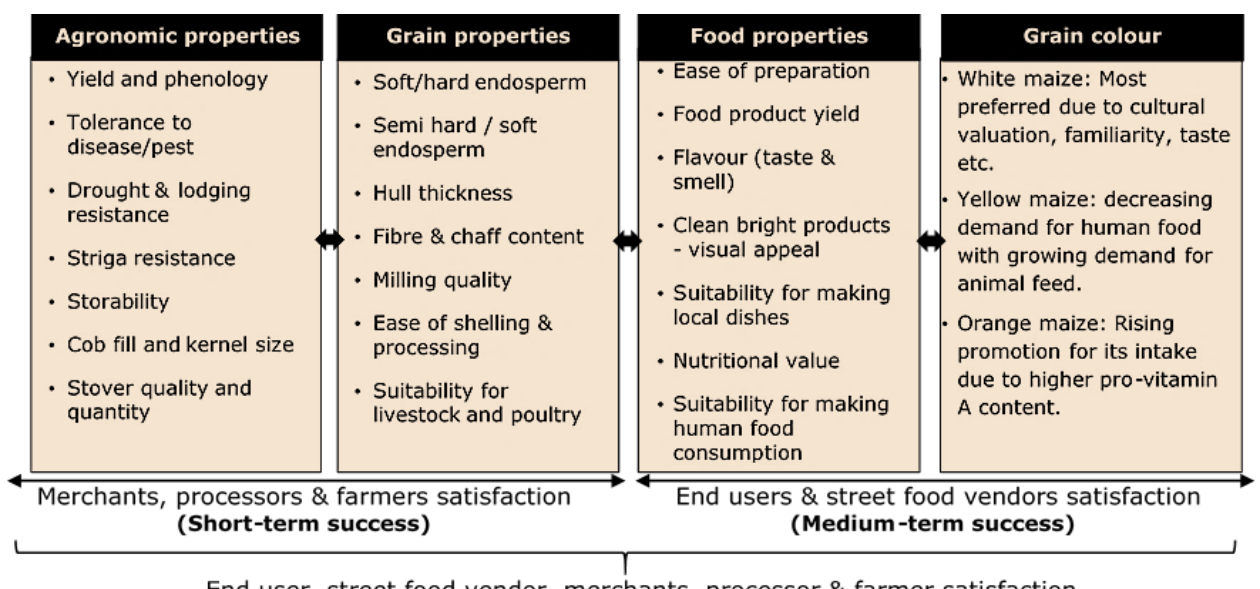

End user, street food vendor, merchants, processor \& farmer satisfaction

(Long-term \& sustainable success)

Figure 3.1: Factors driving the success of maize breeding program in Africa

The medium-term drivers of maize acceptance for food in Africa are associated with the interest of end users and street food vendors. Success in agronomic properties (farmers satisfaction) which fail to satisfy postharvest qualities, normally result in short-term success, if any. In Africa, end users and food vendors' interest starts with grain colour in which white maize is preferred. This is followed by food properties such as suitability of maize for making traditional dishes and sensory attributes, and the processors are keen about the type of grain texture depending on the available technology. Only a holistic breeding approach which ensures agronomically sound maize varieties matches consumer preferences can lead to a successful maize breeding programme. 


\subsubsection{Maize breeding for end-user's preferences and nutritional enhancement}

Identification of maize quality attributes that are important to processors and consumers is crucial for breeders to select the most suitable germplasm from a demand perspective while ensuring grain yield and tolerance to biotic and abiotic stresses. Though closing the gap between actual and potential maize yields, and the improvement of some nutritional components have been the major focus of breeding programmes in Africa, attributes such as sensory preferences, ease of processing, end-product quality, and storability are important for end-users when adopting new and/or improved maize varieties. ${ }^{[25,27,31]}$ Incorporating end-users' preferences in breeding programmes enables consumers to get their favourite maize foods without having to change their valued traditional ways of food processing, preparation and consumption. It also allows processors to enhance their efficiency and reduce grain losses.[10] Fig. 3.2 shows breeding objectives that are important from the end user and nutritional quality point of view in Africa and how the components of the maize value chain are integrated to achieve food security and nutrition. The identified breeding objectives for processing and nutritional enhancement are discussed in the following paragraphs.

\subsubsection{Breeding to enhance nutrient density}

Vitamin A deficiency remains a major problem in SSA. ${ }^{[32]}$ Development of biofortified crops could contribute to solving the problem. This has been achieved by conventional breeding, and about 40 provitamin A biofortified maize varieties have been released in 8 African countries since 2012, including varieties such as HPH1317 and MH42A that contain the nutritional target of $15 \mathrm{ppm} .{ }^{[1]}$ Due to the chemical nature of carotenoids, any provitamin A enriched maize kernels will be orange. Acceptability studies have shown that consumers do not object to the colour and they like the flavour of provitamin A enriched maize.[5] It is not clear if the flavour difference when compared to white maize is due to preconceived notions or the inherent organoleptic properties of the maize..$^{[5]}$ As mentioned earlier, an extensive blind test of consumer preferences across SSA combined with laboratory analyses of volatile profiles could give a more objective result. Oxidation of lipids in maize, including provitamin A biofortified maize, occurs during storage in tropical conditions and during processing (e.g. cooking, frying and baking), affecting the colour of maize products, causing the formation of offflavours, and reducing the antioxidant status and nutritional value. ${ }^{[15,33]}$ This oxidative tendency can be limited by breeding varieties with an increased level of antioxidants. The variability in kernel tocopherols and carotenoids creates an opportunity to improve both at the same time without affecting the synthesis of the other. Muzhingi et al. [34] observed that an increased level of $\beta$-carotene and $\beta$-cryptoxanthin had no negative effect on the level and the antioxidant capacity of both tocopherols and tocotrienols in maize. Lipoxygenase (LOX)-facilitated deteriorations (e.g. oxidation, rancidity and off- 
flavours) have been a problem in yellow maize. Gayen et al. ${ }^{[33]}$ stabilised the carotenoid content of $\beta$-carotene-enriched golden rice by reducing LOX activity using RNAimediated silencing. As the method has no negative effect on agronomic traits, it can be used to preserve the provitamin A content and flavour of maize during storage.

The prevalence of inadequate intake of zinc in Africa was estimated to be $37-62 \%$ [35], contributing significantly to poor child growth and immune system weakness. ${ }^{[36,37]}$ Introducing maize biofortified zinc (zinc concentration above $37 \mathrm{ppm}$ ) would make a significant contribution. A study of human zinc absorption from biofortified zinc maize in Zambia confirmed that eating biofortified maize can meet zinc requirements.[36] Although kernel zinc content is strongly affected by genetic and environmental effects, the relatively high genetic diversity of zinc in maize (mean $20 \pm 5$, range $15-47 \mu \mathrm{g} / \mathrm{g}$ ) ${ }^{[38]}$, indicates that further improvements of zinc concentration are achievable. ${ }^{[39,40]}$ Similarly, anaemia prevalence rates of $55 \%, 71 \%$ and $46 \%$ were reported in Eastern, Central/Western and Southern Africa, respectively, among children aged under 5 years of age [41], with more than half of the cases due to iron deficiency. Anaemia results in poor mental and physical capacities and decreases the immunological capacity to fight prevailing diseases. Unfortunately, the known genetic diversity of iron content in maize is small (mean 25, range $11-39 \mu \mathrm{g} / \mathrm{g}$ ) and largely due to a location effect. ${ }^{[39,40]} \mathrm{A}$ further hurdle is that the bioavailability of iron in maize is very low, largely offsetting any gains that might be made through breeding for increased iron concentrations. [42] Therefore, breeding to biofortify maize by increasing iron concentration in grain does not seem promising. A more fruitful strategy might be to select varieties with improved iron bioavailability, given that only about $5 \%$ of iron in maize is bioavailable. ${ }^{[42]}$ However, existing screening methodologies for iron bioavailability are not cost-effective to support a breeding program. Transgenic approaches offer a possible solution for improving the iron content of maize as long as they do not result in negative sensory changes and if accepted by the public. Up to $70 \%$ increase in iron content was reported for a transgenic maize bred with a soybean ferritin gene. ${ }^{[43]} \mathrm{New}$ tools like gene editing could open opportunities to develop maize with enhanced iron bioavailability, for example, by modestly reducing the amount of phytate in the grain.

The protein efficiency ratios of quality protein maize (QPM) are more than $50 \%$ higher than for conventional maize and almost comparable to protein in milk. [44] In addition, studies have shown a faster starch digestibility in QPM than in conventional maize, which enhances energy use. ${ }^{[45]}$ About 90 QPM varieties have been released in Africa, which represent $53 \%$ of total worldwide releases. ${ }^{[46]}$ Presently, there are QPM varieties that are as productive as non-QPM varieties, with some having superior yields, e.g. Obatanpa QPM. ${ }^{[46]}$ Considering the limited access of many Africans to assorted protein 
sources, continuous development of QPM to improve its nutritional value, organoleptic quality, yield, disease resistance and tolerance to abiotic stresses is crucial. This development must be accompanied by affordable, fast and high-throughput seed and grain quality control methods to monitor the levels of lysine and tryptophan since outcrossing due to pollination with non-QPM varieties is possible. In addition, prioritizing selection to maintain maize protein content concentrations in maize within the current range of $8-14 \%$ is important because increased grain yield is generally associated with increased starch and reduced total protein concentration in the grain, (Table 3.3). In general, the continuous introduction of nutrient-dense crops with high post-harvest retention and bioavailability in combination with other approaches like diet diversification and nutritional education can contribute to alleviating qualitative malnutrition. Breeding programmes should continuously encourage the release of nutrient-dense maize varieties that are acceptable to maize processors and consumers. 
Table 3.2: Biofortified provitamin A maize varieties released under HarvestPlus by IITA and CIMMYT

\begin{tabular}{|c|c|c|c|}
\hline Country & Varieties & $\begin{array}{l}\text { Provitamin } \\
\text { A } \\
\text { content } \\
\text { (ppm) }\end{array}$ & $\begin{array}{l}\text { Minimal increase } \\
\text { required to meet the } \\
\text { target } 15 \mathrm{ppm}(\%)\end{array}$ \\
\hline $\begin{array}{l}\text { DR } \\
\text { Congo }\end{array}$ & $\begin{array}{l}\text { Sam Vita 4-A, Sam Vita 4-B, Muibaki } \\
\text { 3, Muibaki 2, Muibaki 1, GV662 }\end{array}$ & $5-10$ & 33 \\
\hline Ghana & $\begin{array}{l}\text { Ahoodzin, Dzifoo, Ahoofe, CSIR- } \\
\text { CRI Honampa, CSIR-CRI Odomfo, } \\
\text { CSIR-CRI Owanwa }\end{array}$ & $6-11$ & 27 \\
\hline Malawi & MH39A, MH40A, MH42A, MH43A & $9-15$ & 0 \\
\hline Mali & $\begin{array}{l}\text { Nafama, Abebe, Duba, Kodialan, } \\
\text { Dakan }\end{array}$ & $7-10$ & 53 \\
\hline Nigeria & $\begin{array}{l}\text { Ife Hyb 3, Ife Hyb 4, Sammaz 38, } \\
\text { Sammaz 39, Sammaz 43, Sammaz 44, }\end{array}$ & $7-8$ & 47 \\
\hline Tanzania & HРH1317, HP1005 & $8-15$ & 0 \\
\hline Zambia & $\begin{array}{l}\text { GV671A (HPH1301), GV673A } \\
\text { (HPH1303), GV665A (HP1005), } \\
\text { GV662A (HP1002), GV664A } \\
\text { (HP1004) }\end{array}$ & $5-11$ & 27 \\
\hline Zimbabwe & $\begin{array}{l}\text { ZS242 (HP1005), ZS244 (HPH1301), } \\
\text { ZS246 (HPH1302), ZS248 } \\
\text { (HPH1303) }\end{array}$ & $7-11$ & 27 \\
\hline
\end{tabular}

Adapted from Andersson et al. [1] 
Table 3.3: Genetic, environmental and post-harvest handling effects on main nutrient and nutraceutical compounds in maize kernels

\begin{tabular}{|c|c|c|c|c|}
\hline Compound & $\begin{array}{l}\text { Genetic effect } \\
\text { (Diversity } \\
\text { reported) }\end{array}$ & Environmental effect & $\begin{array}{l}\text { Post-harvest } \\
\text { handling effect }\end{array}$ & References \\
\hline Protein & $8-14 \%$ & $\begin{array}{l}\text { Decrease at lower } \\
\text { nitrogen levels. Higher } \\
\text { plant density leads to } \\
\text { decrease in grain } \\
\text { protein concentration }\end{array}$ & $\begin{array}{l}\text { Digestibility of } \\
\text { protein decrease } \\
\text { during } 6 \text { months } \\
\text { storage at high } \\
\text { temperature }\end{array}$ & [15] \\
\hline Starch & $65-75 \%$ & $\begin{array}{l}\text { Increase at lower } \\
\text { nitrogen levels. }\end{array}$ & $\begin{array}{l}\text { Starch and amylose } \\
\text { content are } \\
\text { negatively } \\
\text { influenced by high } \\
\text { temperatures }\end{array}$ & [15] \\
\hline Fat & $2-4.5 \%$ & $\begin{array}{l}\text { Pollen effect on oil } \\
\text { concentration }\end{array}$ & $\begin{array}{l}\text { Increase acidity and } \\
\text { high peroxide index } \\
\text { by increase of free } \\
\text { fatty acids during } \\
\text { storage at high } \\
\text { temperature }\end{array}$ & [15] \\
\hline Carotenoids & $\begin{array}{l}\text { Total } \\
\text { carotenoids: } \\
0.15-89 \mathrm{ug} / \mathrm{g} \\
\text { DW } \\
\text { ProVA: } \\
0.5 \text { - } 22 \mathrm{ug} / \mathrm{g} \text { DW }\end{array}$ & None reported & $\begin{array}{l}\text { ProVA carotenoid } \\
\text { decay during } \\
\text { storage at high } \\
\text { temperature. } \\
\text { Milling leads to } \\
\text { higher proVA } \\
\text { decay. }\end{array}$ & {$[40,42]$} \\
\hline Tocopherols & $\begin{array}{l}\alpha \text {-tocoferol: } \\
0.4 \text { - } 75 \mu \mathrm{g} / \mathrm{g} \text { DW } \\
\gamma \text {-tocoferol: } \\
\text { 3.3-141 } \mu \mathrm{g} / \mathrm{g} \text { DW }\end{array}$ & $\begin{array}{l}\text { High heritability and } \\
\text { no genotype by } \\
\text { environment effect }\end{array}$ & None reported & [34] \\
\hline Anthocyanins & $\begin{array}{l}2.5 \text { - } 1989 \mathrm{ug} / \mathrm{g} \\
\text { DW Pel }\end{array}$ & $\begin{array}{l}\text { High heritability and } \\
\text { no genotype by } \\
\text { environment effect }\end{array}$ & None reported & [47] \\
\hline
\end{tabular}




\begin{tabular}{|c|c|c|c|c|}
\hline $\begin{array}{l}\text { Phenolic } \\
\text { compounds }\end{array}$ & $\begin{array}{l}\text { Ferulic acid: } \\
0.2-6.9 \mathrm{ug} / \mathrm{g} \\
\text { DW } \\
\text { p-Coumaric acid: } \\
0-6.07 \mathrm{ug} / \mathrm{g} \text { DW }\end{array}$ & None reported & None reported & {$[34,48]$} \\
\hline Resistant starch & $0.1 \quad 9.4 \%$ & None reported & None reported & {$[49,50]$} \\
\hline Iron & $11-39$ ppm & $\begin{array}{l}\text { Large environmental } \\
\text { effect (soil and foliar } \\
\text { fertilization) }\end{array}$ & $\begin{array}{l}\text { Contamination } \\
\text { from soil, threshing } \\
\text { and storing } \\
\text { conditions }\end{array}$ & {$[39,40]$} \\
\hline Zinc & $15-47$ ppm & $\begin{array}{l}\text { Large environmental } \\
\text { effect (soil and foliar } \\
\text { fertilization; high } \\
\text { nitrogen reduces } \mathrm{Zn} \\
\text { content in kernels) }\end{array}$ & $\begin{array}{l}\text { Contamination } \\
\text { from soil, threshing } \\
\text { and storing } \\
\text { conditions }\end{array}$ & {$[39,40]$} \\
\hline
\end{tabular}

\subsubsection{Breeding to enhance the suitability of maize for making bread and snacks}

The use of maize in the production of bread and snacks is limited mainly by the absence of functional gluten, high lipid content that leads to low product storability, and limited use of alternative processing techniques such as nixtamalization. Cooking maize in an alkaline solution, or nixtamalization is used for making more than 300 products in Mexico alone. Wheat is used extensively for making bread and snacks, but because the prevailing agro-ecologies in SSA are unsuitable for wheat production, most wheat is imported. This makes bread unaffordable for many Africans. Breeding of maize varieties useful for making bread and other bakery products is therefore relevant i.e., varieties that give floury, less fibrous, slightly moist and light crumb products. An increase in native lipid complexes with a matrix of starch granules has been shown to slow the staling of bread by decreasing starch retrogradation and gluiness while increasing freeze-thaw stability. ${ }^{[5]}$ Rapid viscosity analysis could help monitor the starch properties, and these anti-staling attributes could be achieved by selecting maize varieties with high polarity lipids in the starch granules. Differential scanning calorimetry (DSC), X-ray diffraction and iodine-binding capacity are important techniques commonly used for monitoring starch-lipid interactions. ${ }^{[5]}$ Development of varieties with wxsu2 (waxy and sugary-2 mutant alleles) may be another useful strategy, given that bread made with flour from maize varieties containing this double mutant 
gene combination has softer, moister crumbs after baking and maintains freshness during storage. ${ }^{[52]}$ A combination of molecular (molecular markers for the alleles) and analytical methods will be required. Varieties with soft endosperm, smaller starch granules and thinner pericarp are more suitable for snacks and bread-like products. ${ }^{[53]}$ However, soft endosperm kernels are more prone to post-harvest losses due to insect damage; thus appropriate storage conditions need to be in place.

Popcorn is an important snack, liked and consumed across Africa with no discrimination between white and yellow coloured kernels.[24] This presents an opportunity in the maize value chain to breed popcorn varieties. Though no separate data on popcorn production in Africa are available, consumption relies on imports, especially from the USA. The cultivation of popcorn varieties has been very limited in Africa due to foliar diseases like rust, blight and streak [24], and the lack of varieties suited for tropical conditions. ${ }^{[54]}$ The most important quality attributes of popcorn are large expansion or popping volume (to obtain a fluffy and tender texture), minimal hull and flavour. ${ }^{[54]}$ Anthony ${ }^{[10]}$ and Iken et al. ${ }^{[24]}$ identified popcorn varieties with a taste profile comparable to that of imported varieties, but susceptible to diseases and with lesser popping volume. Popping volume is affected by non-genetic factors, such as moisture content (optimum: 13.5-14.5\%) and added ingredients, and by genetic factors including kernel pericarp thickness, shape, size and density.[15] Currently, there are highthroughput methodologies based on scanning that could eventually be adapted to support breeding efforts. As a result of the quest to stimulate local production, government policies on food importation in Africa have progressively toughened, thereby strengthening the need for breeding efforts to develop local popcorn varieties. ${ }^{[2,54]}$

\subsubsection{Breeding to improve maize for use as green maize}

In SSA, the first crop to reach the marketplace after the dry season is usually green maize, thus helping to break the hunger gap. Green maize has greater local economic value and increases food security.[5] Green maize is consumed as whole kernels, thus giving more nutritional benefits than most maize-based products, which are prepared using flour from degerminated and decorticated kernels. However, to our knowledge, there are currently no specific research or breeding efforts to improve green maize in Africa. Limited green maize genetic materials are available, but most varieties are intended for grain production and do not meet all the attributes desired by green maize end users. A sweet taste (high sugar content), soft endosperm, large ears/cob, a long shelf life and good roasting qualities (non-popping) are the most desirable attributes for green maize. $[16,24,27,55,56]$ Roasted or boiled green maize is often yellow grained; consumers have no grain colour bias for green maize consumption. Qwabe [5] identified maize hybrids (e.g. GMH129, GMH126, GMH146 and GMH171) with potential for 
green maize in Africa, while a variety like WH301 in Kenya has been acknowledged to be particularly suitable for green maize production. ${ }^{[29]}$ In spite of the increasing demand for green maize foods, their consumption is limited to the rainy season because maize farming in SSA is mainly rain-fed. If suitable green maize varieties are made available, sustainable agricultural intensification via irrigation could make green maize available all year round, thus alleviating the normal long period of hunger during the dry season. Another advantage of green maize research in Africa could be the opportunity to incorporate dual purpose traits i.e., to generate a variety that can produce green maize for food and good quality stover for animal feed.[57] Maize stover quality and quantity are attributes considered important by farmers. ${ }^{[58]}$ Maize stover is very palatable and a good source of nutrients with high digestibility; it is one of the best non-legume fodders. ${ }^{[37]}$ Since 2010, more than 12 maize varieties that maintain green leaves and stems after maturity or after the cobs are harvest have been released in Kenya for use as cattle fodder. ${ }^{[29]}$ Research in Ethiopia has also led to the identification of suitable dual-purpose germplasm. Near-infrared methodologies are used to monitor stover quality parameters and promising genomic regions associated with stover quality have been identified recently.[57] Current research efforts to develop molecular markers for this aspect, if successful, will be very beneficial for a more efficient breeding program. The acceptance of green maize across Africa is good motivation to give attention to developing varieties that meet the desires of both growers and end-users.

\subsubsection{Breeding to improve characteristics that enhance the efficiency of local processing}

Soaking is the first critical step in traditional maize processing in many parts of West Africa [59]; it softens the kernel for easy separation of the hull and milling. Steeping also reduces phytic acid (a significant anti-nutrient in maize) by solubilising it before draining it out. Horny/hard endosperm takes a longer time to steep due to slow water absorption, which means that soft and intermediate kernel texture is most suitable.[60] Grain water absorption is also affected by the thickness of the pericarp, kernel size and protein content and distribution. ${ }^{[61]}$ Soft endosperm has high viscosity and swelling value, and better gelatinization and digestibility, making it suitable for traditional sourdough. ${ }^{[60]}$ Good water absorption correlates with good cooking quality (i.e., cooking takes less time and less energy) and better organoleptic properties.[61] Furthermore, soft maize is preferred for traditional dry milling and wet milling due to ease of processing. [25] Local maize varieties (usually soft endosperm varieties like Gnonli, Gbogboue, Gbaeve, Gougba and Djakpe from Benin) give finer flour and less damage to starch content than improved varieties [62]; this may partly explain the small adoption rates of improved varieties. However, for traditional food processing that requires home-based pounding or refining processes such as de-hulling and de-germination (common in 
southern/eastern Africa), usually hard grain is preferred for easy separation. ${ }^{[27]}$ Many traditional maize-based foods in Africa are made using de-hulling and sieving processes. Despite the extensive nutrient loss during these processes, the aim is to achieve a smoother texture, shorter cooking time, bland taste and white colour. Such processing steps could be minimised by using varieties with a consistent clean colour, thin or soft hulls, less fibre/chaff and soft/ floury endosperm. The aroma, colour, feel, consistency and taste of a finely textured maize meal are usually acceptable in local communities. ${ }^{[8]}$ In the preparation of ogi (porridge), the variety affects the ease of cooking.[63] Appropriate metrics to fulfil the specific quality are needed. However, colorimeter and kernel scanning methodologies are often robust enough to support breeding programmes. 


\subsubsection{Breeding to reduce waste by maximizing useful product yield and minimizing nutrient losses}

Ogi (porridge) has been identified as the most consumed maize food in Western Africa. ${ }^{[64]}$ Breeding programmes in the region must prioritise the suitability of maize for ogi production. Ogi yield is usually between $40 \%$ and $86 \%$ of the starting material (maize) [25, 59, 63], implying high wastage due to maize characteristics (hull, fibre and the nature of starch). The highest yield reported in the literature is $86 \%$ from Gnonli and Gbogboué local maize varieties in Benin. The authors attributed the high yield to a better softening (water absorption) nature of the varieties. ${ }^{[59]}$ Indeed, the floury endosperm is most suitable for wet milling and results in a higher ogi yield. Though kernel weight was found not to influence ogi yield, varietal differences significantly influenced ogi yield.[63] Since ogi preparation is similar to how most maize foods are prepared in Western Africa, the development or selection of varieties with high yield of the fermented and unfermented dough is crucial. In contrast, Eastern/Southern African foods rely mostly on refined maize flour, so in those regions, breeding for varieties with high flour yield during dry milling is important.

\subsubsection{Breeding to reduce anti-nutrient concentrations in grain}

It was estimated that $68 \%$ of total dietary phytate intake in Africa comes from cereals [65], and about 37\% from maize. The high phytate intake in cereal-dependent populations contributes significantly to deficiencies of minerals, i.e., iron and zinc. According to Banerji et al. ${ }^{[66]}$, it is possible to achieve sufficient zinc bioavailability in 46 African countries if phytate intake is reduced at least to half of the current intake. Phytate reduction during traditional maize processing is not sufficient to achieve maximum micronutrient bioavailability. The occurrence of adverse agronomic performance such as poor germination, susceptibility to diseases, reduced grain weight and low abiotic stress tolerance in low phytic acid mutant crops has frustrated breeding programmes aimed at improving nutrient bioavailability. However, maize mutants (Ipa1, Ipa2 and Ipa3) with low phytic acid and high phosphate contents have been reported to have normal seed germination and unaffected dry matter content, which has substantially improved iron and zinc bioavailability in maize-based diets. ${ }^{[67]} \mathrm{A}$ transgenic approach to reduce the expression of the gene encoding for the biosynthesis of inositol-pentakisphosphate 2-kinase ${ }^{[68]}$ and silencing the expression of the multidrug resistance- associated protein ATP-binding cassette (MRP-ABC) transporter [67] are reported to be options for reducing phytate without diminishing agronomic performance. The overexpression of the phytase enzyme in maize is an alternative that is perhaps a more feasible breeding approach since it prevents possible problems associated with reduced seed phytate. Drakakaki et al. ${ }^{[43]}$ and Chen et al. ${ }^{[09]}$ found an increase of up to $50 \%$ in phytase activity in maize through the transgenic expression of 
Aspergillus phyA (encoding phytase), thereby doubling the chance of phytate reduction during processing, preparation and consumption. In the same research, Drakakaki et al. ${ }^{[43]}$ observed a 95\% phytate reduction when transgenic maize flour was mixed with water and fermented, implying that it may be possible to achieve maximum phytate reduction and micronutrient bioavailability through the use of low phytate and/or increased phytase enzyme varieties for making some traditional foods in Africa. However, in most African countries there are severe regulatory constraints and very long delays in getting transgenic varieties into production. Gene editing may offer a viable approach by reducing phytate production sufficiently to meaningfully increase iron and zinc bioavailability but not enough to cause negative agronomic effects. 


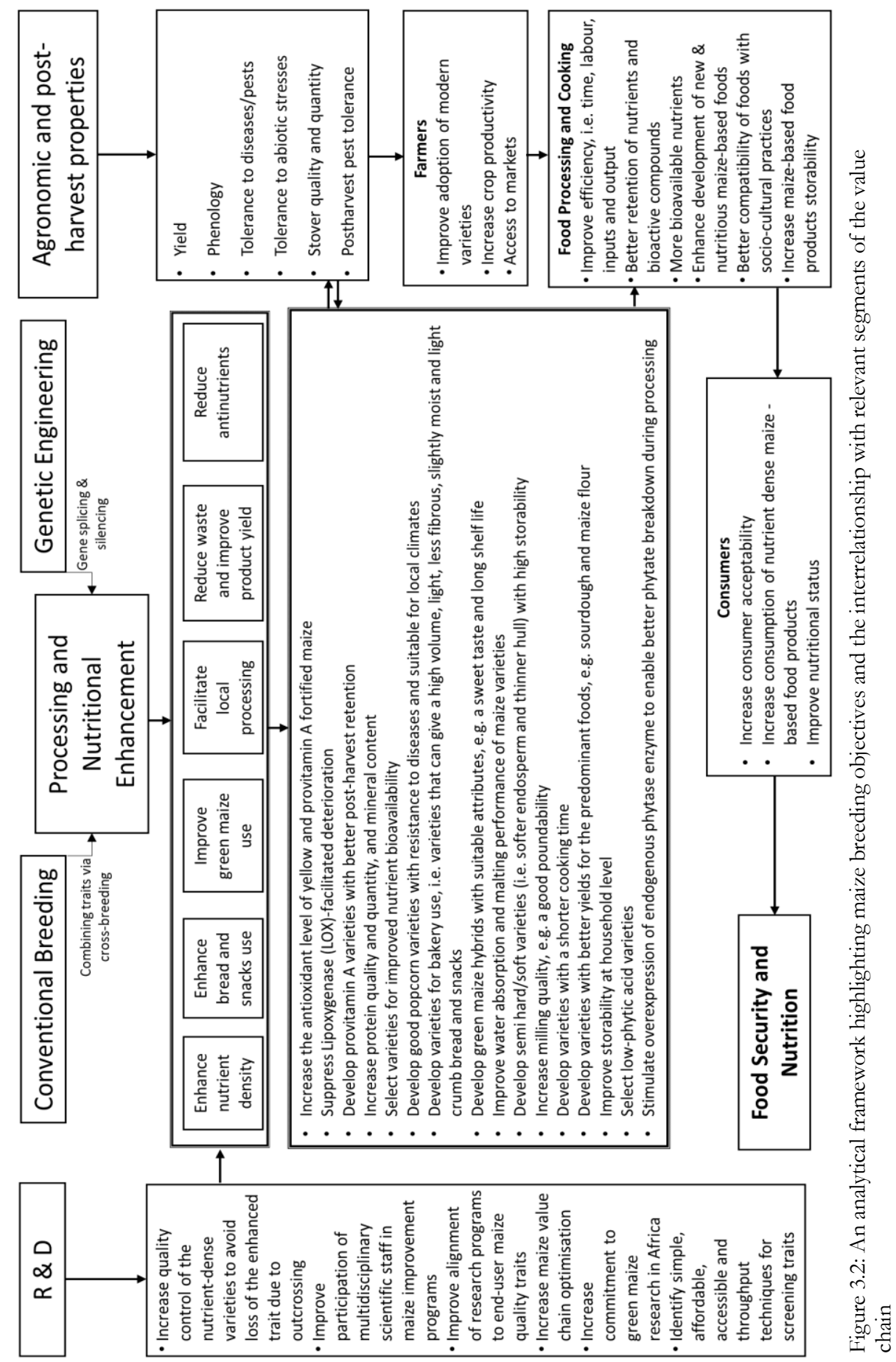




\section{Conclusion}

The current rapid population growth rate in Sub-Saharan Africa, coupled with persistently high malnutrition rates, calls for strategies that stretch across the entire food value chain - a Crop-to-Health Strategy, i.e. from agriculture to nutrition and health. Strategies that enhance nutrition-focused food uses of maize can contribute to providing daily dietary requirements of micronutrients as well as macronutrients. Combining improved grain yield (tolerance to abiotic and biotic challenges) with user preferences and nutritional benefits is essential to meet the growing demand for maize that is suitable for processing into traditional and novel food types. An adequate understanding of needs of the producers, processors and consumers, and incorporating these into breeding programmes will increase the adoption of new varieties, reduce losses, improve nutrition and preserve the socio-cultural and culinary traditions of local communities.

Breeding new varieties takes many years, especially if it concerns traits that are not yet commonly available in elite lines with adequate agroecological adaptation. Timely incorporation of probable future preferences of maize consumers and processors is therefore especially relevant.

Although we have focused on opportunities to enhance breeding strategies to achieve greater grain processing and nutritional qualities, it must be emphasised that these are not isolated or "magic bullet" solutions. Sustainable and profitable diversified crop production strategies, together with post-harvest management strategies that reduce food waste and loss of nutritional goodness, will contribute to improving the nutrition, health and lives of African and global consumers. 


\section{Recommendations}

To achieve higher impact of maize breeding for Africa, we recommend the following:

1. Clearly define maize quality parameters, norms and screening analytical methods from the viewpoints of all actors in the maize value chains, i.e., processors and users as well as to primary producers.

2. High-throughput methods for efficient measurement must be available to support breeding efforts.

3. Ensure that agronomically excellent varieties also fulfil the preferences and needs of processors and consumers.

4. Incorporate the essential quality traits of all value chain actors from the start of any breeding programme. This will require that effective, high-throughput and low cost screening methods are available for each trait.

5. Ensure close interdisciplinary work by including pertinent specialists in the breeding team: socio-economists, food technologists, nutritionists, quality specialists and agronomists. Others may be required depending on the product profile of the varieties that must be developed.

6. Link with processors demanding naturally nutrient-enriched food in order to prioritise the nutritional traits

7. Strengthen efforts to introduce nutrient-dense crops with superior post-harvest performance and enhanced nutrient bioavailability. 


\section{Acknowledgements}

The authors thank Kevin Pixley, maize breeder, for his critical review. This work was supported by the CGIAR research program (CRP) on MAIZE agri-food systems. The CGIAR Research Program MAIZE receives W1 \& W2 support from the governments of Australia, Belgium, Canada, China, France, India, Japan, Korea, Mexico, Netherlands, New Zealand, Norway, Sweden, Switzerland, U.K., and U.S., as well as the World Bank. The contents and opinions expressed herein are those of the authors and do not necessarily reflect the views of the associated and/or supporting institutions. The usual disclaimer applies.

\section{Declarations of interest}

None. 


\section{References}

1. Andersson MS, Saltzman A, Virk P, Pfeiffer W. Progress update: crop development of biofortified staple food crops under HarvestPlus. African Journal of Food, Agriculture, Nutrition and Development. 2017;17(2):11905-35.

2. Ranum P, Peña-Rosas JP, Garcia-Casal MN. Global maize production, utilization, and consumption. Annals of the New York Academy of Sciences. 2014;1312(1):105-12.

3. Smale M, Byerlee D, Jayne T. Maize revolutions in sub-Saharan Africa. an African green revolution: Springer; 2013. p. 165-95.

4. Hebinck P, Mango N, Kimanthi H. 14 Local maize practices and the cultures of seed in Luoland, West Kenya. Cultural sustainability and regional development: Theories and practices of territorialisation. 2015:206.

5. Muzhingi T, Langyintuo AS, Malaba LC, Banziger M. Consumer acceptability of yellow maize products in Zimbabwe. Food Policy. 2008;33(4):352-61.

6. Nkhabutlane P. An investigation of Basotho culinary practices and consumer acceptance of Basotho traditional bread 2014.

7. Ekpa O, Palacios-Rojas N, Kruseman G, Fogliano V, Linnemann AR. Sub-Saharan African Maize-Based Foods - Processing Practices, Challenges and Opportunities. Food Reviews International. 2019:1-31.

8. Khumalo TP, Schönfeldt HC, Vermeulen H. Consumer acceptability and perceptions of maize meal in Giyani, South Africa. Development Southern Africa. 2011;28(2):271-81.

9. McCann J. Maize and grace: Harvard University Press; 2005.

10. Anthony AO. Physical features of some selected Nigerian maize cultivars. American Journal of Plant Sciences. 2014;5(9):1352.

11. Iken J, Amusa N. Consumer acceptability of seventeen popcorn maize (Zea mays L.) varieties in Nigeria. African Journal of Agricultural Research. 2010;5(5):405-7.

12. BFAP. BFAP agricultural outlook 2016 - 2025. putting plans into action: agriculture and economic growth in South Africa. Bureau for Food Agricultural Policy Baseline; 2016.

13. Rosegrant MW, Paisner MS, Meijer S, Witcover J. 2020 global food outlook: trends, alternatives, and choices: Intl Food Policy Res Inst; 2001.

14. Pillay K, Derera J, Siwela M, Veldman FJ. Consumer acceptance of yellow, provitamin Abiofortified maize in KwaZulu-Natal: original research. South African Journal of Clinical Nutrition. 2011;24(4):186-91.

15. White PJ, Johnson LA. Corn: chemistry and technology: American Association of Cereal Chemists; 2003.

16. De Groote H, Kimenju SC. Consumer preferences for maize products in urban Kenya. Food and nutrition bulletin. 2012;33(2):99-110.

17. Stevens R, Winter-Nelson A. Consumer acceptance of provitamin A-biofortified maize in Maputo, Mozambique. Food Policy. 2008;33(4):341-51.

18. Meenakshi J, Banerji A, Manyong V, Tomlins K, Mittal N, Hamukwala P. Using a discrete choice experiment to elicit the demand for a nutritious food: Willingness-to-pay for orange maize in rural Zambia. Journal of Health Economics. 2012;31(1):62-71.

19. Sibiya J, Tongoona P, Derera J, Makanda I. Farmers' desired traits and selection criteria for maize varieties and their implications for maize breeding: A case study from KwaZulu-Natal Province, South Africa. Journal of Agriculture and Rural Development in the Tropics and Subtropics (JARTS). 2013;114(1):39-49. 
20. Lunduka R, Fisher M, Snapp S. Could farmer interest in a diversity of seed attributes explain adoption plateaus for modern maize varieties in Malawi? Food Policy. 2012;37(5):504-10.

21. Yener S, Sánchez-López JA, Granitto PM, Cappellin L, Märk TD, Zimmermann R, et al. Rapid and direct volatile compound profiling of black and green teas (Camellia sinensis) from different countries with PTR-ToF-MS. Talanta. 2016;152:45-53.

22. Guild G, Parkes E, Nutti M, Palacios-Rojas N, Stangoulis J. High-throughput measurement methodologies for developing nutrient-dense crops. African Journal of Food, Agriculture, Nutrition and Development. 2017;17(2):11941-54.

23. Serna-Saldivar SO. Cereal Grains: Properties, Processing, and Nutritional Attributes: CRC Press; 2016.

24. Iken J, Amusa N. Review: Maize research and production in Nigeria. African Journal of Biotechnology. 2004;3(6):302-7.

25. Omueti O, Iken JE, Kling JG, Okoruwa AE. Comparison of component yields and sensory properties of traditional Nigerian foods (Ogi and Eko) derived from eleven maize varieties. Journal Of Food Agriculture And Environment. 2006;4(1):115.

26. Hassan RM, Mekuria M, Mwangi W. Maize Breeding Research in Eastern and Southern Africa: Current Status and Impact of Past Investments Made by the Public and Private Sectors, 196697: CIMMYT; 2001.

27. Badu-Apraku B, Fakorede M, Menkir A, Sanogo D. Conduct and management of maize field trials. IITA, Ibadan, Nigeria. 2012;59.

28. Pircher T, Almekinders CJ, Kamanga BC. Participatory trials and farmers' social realities: understanding the adoption of legume technologies in a Malawian farmer community. International Journal of Agricultural Sustainability. 2013;11(3):252-63.

29. Walker T, Alene A, Ndjeunga J, Labarta R, Yigezu Y, Diagne A, et al. Measuring the effectiveness of crop improvement research in Sub-Saharan Africa from the perspectives of varietal output, adoption, and change: 20 crops, 30 countries, and 1150 cultivars in farmers' fields. Synthesis Report for Objectives. 2014;1.

30. Tadesse D, Medhin ZG, Ayalew A. Participatory on farm evaluation of improved maize varieties in Chilga district of North Western Ethiopia. International Journal of Agriculture and Forestry. 2014;4(5):402-7.

31. Pircher T. maize as a mirror of life: A case study from Malawi about the diversity of farming and smallholders' performance in growing maize. [Msc Thesis]: Wageningen University 2010.

32. Simpungwe E, Dhliwayo T, Palenberg M, Taleon V, Birol E, Oparinde A, et al. Orange maize in Zambia: crop development and delivery experience. African Journal of Food, Agriculture, Nutrition and Development. 2017;17(2):11973-99.

33. Gayen D, Ali N, Sarkar SN, Datta SK, Datta K. Down-regulation of lipoxygenase gene reduces degradation of carotenoids of golden rice during storage. Planta. 2015;242(1):353-63.

34. Muzhingi T, Palacios-Rojas N, Miranda A, Cabrera ML, Yeum KJ, Tang G. Genetic variation of carotenoids, vitamin $\mathrm{E}$ and phenolic compounds in Provitamin A biofortified maize. Journal of the Science of Food and Agriculture. 2017;97(3):793-801.

35. Caulfield LE, Black RE. Zinc deficiency. Comparative quantification of health risks: global and regional burden of disease attributable to selected major risk factors. 2004;1:257-80.

36. Chomba E, Westcott CM, Westcott JE, Mpabalwani EM, Krebs NF, Patinkin ZW, et al. Zinc absorption from biofortified maize meets the requirements of young rural Zambian children. The Journal of nutrition. 2015;145(3):514-9. 
37. Chaudhary DP, Kumar D, Verma R, Langyan S, Sangwan S. Nutritional Quality of Maize. Maize: Nutrition Dynamics and Novel Uses: Springer; 2014. p. 135-40.

38. Hindu V, Palacios-Rojas N, Babu R, Suwarno WB, Rashid Z, Usha R, et al. Identification and validation of genomic regions influencing kernel zinc and iron in maize. Theoretical and Applied Genetics. 2018;131(7):1443-57.

39. Bänziger M, Long J. The potential for increasing the iron and zinc density of maize through plant-breeding. Food and Nutrition Bulletin. 2000;21(4):397-400.

40. Ortiz-Monasterio J, Palacios-Rojas N, Meng E, Pixley K, Trethowan R, Pena R. Enhancing the mineral and vitamin content of wheat and maize through plant breeding. Journal of Cereal Science. 2007;46(3):293-307.

41. Stevens GA, Finucane MM, De-Regil LM, Paciorek CJ, Flaxman SR, Branca F, et al. Global, regional, and national trends in haemoglobin concentration and prevalence of total and severe anaemia in children and pregnant and non-pregnant women for 1995-2011: a systematic analysis of population-representative data. The Lancet Global Health. 2013;1(1):e16-e25.

42. Pixley KV, Palacios-Rojas N, Glahn RP. The usefulness of iron bioavailability as a target trait for breeding maize (Zea mays L.) with enhanced nutritional value. Field Crops Research. 2011;123(2):153-60.

43. Drakakaki G, Marcel S, Glahn RP, Lund EK, Pariagh S, Fischer R, et al. Endosperm-specific co-expression of recombinant soybean ferritin and Aspergillus phytase in maize results in significant increases in the levels of bioavailable iron. Plant molecular biology. 2005;59(6):86980.

44. Prasanna B, Vasal S, Kassahun B, Singh N. Quality protein maize. 2001.

45. Hasjim J, Srichuwong S, Scott MP, Jane J-1. Kernel composition, starch structure, and enzyme digestibility of opaque- 2 maize and quality protein maize. Journal of agricultural and food chemistry. 2009;57(5):2049-55.

46. Twumasi-Afriye S, Palacios Rojas N, Friesen D, Teklewold A, Gissa DW, De Groote H, et al. Guidelines for the quality control of Quality Protein Maize (QPM) seed and grain: Technical bulletin. 2016.

47. Hernández-Quintero JdD, Rosales-Nolasco A, Molina-Macedo A, Miranda-Piliado A, Willcox M, Hernández-Casillas JM, et al. Cuantificación de antocianinas mediante espectroscopía de infrarrojo cercano y cromatografía líquida en maíces pigmentados. Revista Fitotecnia Mexicana. 2017;40(2).

48. Cuevas Montilla E, Hillebrand S, Antezana A, Winterhalter P. Soluble and bound phenolic compounds in different Bolivian purple corn (Zea mays L.) cultivars. Journal of agricultural and food chemistry. 2011;59(13):7068-74.

49. Vázquez-Carrillo G, García-Lara S, Salinas-Moreno Y, Bergvinson DJ, Palacios-Rojas N. Grain and tortilla quality in landraces and improved maize grown in the highlands of Mexico. Plant Foods for Human Nutrition. 2011;66(2):203-8.

50. Pollak LM, Scott MP, Duvick SA. Resistant starch and starch thermal characteristics in exotic corn lines grown in temperate and tropical environments. Cereal chemistry. 2011;88(5):435-40.

51. Thakur R, Pristijono P, Golding JB, Stathopoulos CE, Scarlett CJ, Bowyer M, et al. Amyloselipid complex as a measure of variations in physical, mechanical and barrier attributes of rice starch- $\iota$-carrageenan biodegradable edible film. Food Packaging and Shelf Life. 2017;14:108-15.

52. Zallie J, Trimble R, Bell H. Bread containing wxsu2 genotype starch as an anti-stalent. Google Patents; 1986. 
53. Narváez-González ED, de Dios Figueroa-Cárdenas J, Taba S, Tostado EC, Peniche RÁM, Sánchez FR. Relationships between the microstructure, physical features, and chemical composition of different maize accessions from Latin America. Cereal chemistry. 2006;83(6):595-604.

54. Jele P, Derera J, Siwela M. Assessment of popping ability of new tropical popcorn hybrids. Australian Journal of Crop Science. 2014;8(6):831.

55. Qwabe FNP. Breeding Investigations for Development of Specialty Green Maize Hybrids: Citeseer; 2011.

56. Alamu O, Maziya-Dixon B, Olaofe O, Menkir A. Varietal and harvesting time effects on physical characteristics and sensory properties of roasted fresh yellow maize hybrids. IOSR Journal of Applied Chemistry (IOSR-JAC). 2015;8(2):55-63.

57. Erenstein O, Blummel M, Grings E. Potential for dual-purpose maize varieties to meet changing maize demands: overview. 2013.

58. De Groote H, Dema G, Sonda GB, Gitonga ZM. Maize for food and feed in East Africa-The farmers' perspective. Field Crops Research. 2013;153:22-36.

59. Nago MC, Hounhouigan JD, Akissoe N, Zanou E, Mestres C. Characterization of the Beninese traditional ogi, a fermented maize slurry: physicochemical and microbiological aspects. International journal of food science \& technology. 1998;33(3):307-15.

60. Kikuchi K, Takatsuji I, Tokuda M, Miyake K. Properties and uses of horny and floury endosperms of corn. Journal of Food Science. 1982;47(5):1687-92.

61. Oladeji BS, Oladeji BS, Irinkoyenikan OA, Irinkoyenikan OA, Gbadamosi OS, Gbadamosi OS, et al. Comparative analysis of physico-chemical properties and amino acids profile of three tropical maize hybrid cultivars in Nigeria. Nutrition \& Food Science. 2016;46(5):695-705.

62. Nago M, Akissoë N, Matencio F, Mestres C. End Use Quality of Some African Corn Kernels. 1. Physicochemical Characteristics of Kernels and Their Relationship with the Quality of "Lifin", a Traditional Whole Dry-Milled Maize Flour from Benin. Journal of Agricultural and Food Chemistry. 1997;45(3):555-64.

63. Adeyemi I, Osunsami A, Fakorede M. Effect of corn varieties on ogi quality. Journal of Food Science. 1987;52(2):322-4.

64. Olayiwola I, Oganah B, Onabanjo O, Oguntona C, Popoola A, Sanni S, et al. Consumption Pattern Of Maize Based Dishes In Four Agro-Ecological Zones Of Nigeria. Journal of Agricultural Science and Environment. 2016;12(2):45-61.

65. Joy EJ, Ander EL, Young SD, Black CR, Watts MJ, Chilimba AD, et al. Dietary mineral supplies in Africa. Physiologia plantarum. 2014;151(3):208-29.

66. Banerji A, Chowdhury S, De Groote H, Meenakshi JV, Haleegoah J, Ewool M. Using elicitation mechanisms to estimate the demand for nutritious maize: Evidence from experiments in rural Ghana. International Food Policy Research Institute (IFPRI), Washington, DC. 2013.

67. Shi J, Wang H, Schellin K, Li B, Faller M, Stoop JM, et al. Embryo-specific silencing of a transporter reduces phytic acid content of maize and soybean seeds. Nature biotechnology. 2007;25(8):930-7.

68. Shi J, Wang H, Wu Y, Hazebroek J, Meeley RB, Ertl DS. The maize low-phytic acid mutant lpa2 is caused by mutation in an inositol phosphate kinase gene. Plant Physiology. 2003;131(2):50715.

69. Chen R, Xue G, Chen P, Yao B, Yang W, Ma Q, et al. Transgenic maize plants expressing a fungal phytase gene. Transgenic research. 2008;17(4):633-43. 


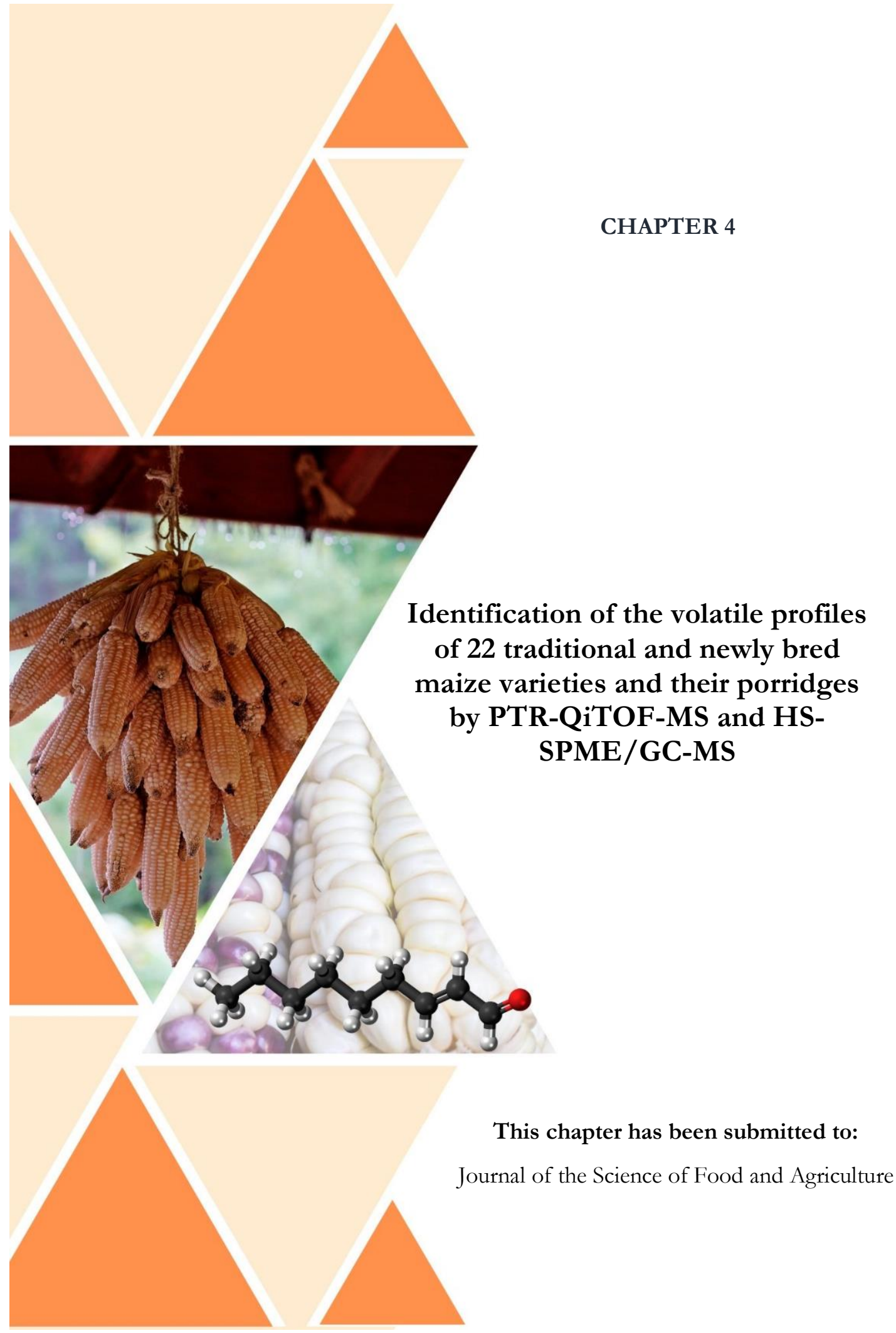




\begin{abstract}
Background: Low adoption of maize varieties bred to address the nutritional needs of the growing African population limits their impact. Aroma is essential in consumer preference but has hitherto hardly been studied. We analysed the volatile organic compounds of flours and porridges of 22 maize varieties belonging to four nutritionally distinct groups, namely provitamin A maize, quality protein maize, yellow and white maize.

Results: PTR-QiTOF-MS analysis generated 524 mass peaks ranging from 16.007 to $448.089 \mathrm{~m} / \mathrm{z}$. Principal component analysis clearly separated the varieties belonging to the four groups. With HS-SPME/GC-MS, 48 volatile compounds were identified in maize flour and 21 in maize porridge, including hexane, nonane, pentanoic acid, 1octen-3-ol, 1-hexanol, hexanal, nonanal, 2-pentylfuran and 2-heptanone. Volatile compounds such as 1,2,4-trimethylbenzene, associated with thermal degradation of carotenoids, increased in the porridge of yellow and provitamin A maize.

Conclusion: The results indicate that PTR-QiTOF-MS and HS-SPME/GC-MS combined with multivariate analysis are instrumental to study the volatile aroma compounds of different maize varieties.
\end{abstract}

Keywords: volatile aroma compounds; maize; porridge; PTR-MS; GC-MS; Africa 


\subsubsection{Introduction}

Several maize varieties have been bred to cater for the rising food demand (i.e. high yield, drought and pest-resistant varieties) and nutritional deficiencies (i.e. quality protein, provitamin A, zinc and iron biofortified varieties) in Africa.[1] However, low acceptance and adoption of these improved varieties persist, resulting in a limited impact on the target population. Various reasons have been proposed to explain low adoption.[2] Of particular interest is the sensory quality: Africans have shown a high preference for the flavour of white maize and their traditional varieties. ${ }^{[1]}$ Considering that flavour properties can significantly affect consumer preferences, one would expect the aroma profile of maize to have been thoroughly studied and reported. Surprisingly, this is not the case: very few and old publications are available. ${ }^{[3-6]}$

Volatile compounds of other cereals such as rice, wheat and recently millet have been widely studied. [7] Extensive VOC studies on rice have facilitated a significant improvement of its taste and acceptability. ${ }^{[8]}$ A particular point of concern regarding maize is that some biofortified maize varieties, such as the yellow and orange, are rich in oils and carotenoids. Therefore they are prone to lipid spoilage, especially under tropical conditions, which could result in off-flavour formation during processing and storage. ${ }^{[9]}$ In this paper, the volatile compounds determining the aroma of maize were assessed by headspace analysis with a proton-transfer-reaction quadrupole ion time-offlight mass spectrometry (PTR-QiTOF-MS). This innovative instrument enables direct injection of headspace volatiles without any need for pre-treatment or chemical extraction and has a high resolution and sensitivity, thereby allowing high-speed data collection and detection of trace compounds that are essential for aroma profiling. ${ }^{[10]}$ Such sophisticated and high-resolution equipment is crucial because maize is characterized by low levels of aroma compounds. ${ }^{[11]}$ However, the PTR-QiTOF-MS technique is not sufficient to give a confirmatory identification of VOC, hence headspace solid-phase microextraction gas chromatography-mass spectrometry (HSSPME/GC-MS) was also used.

In the present study, PTR-QiTOF-MS was used for the first time on maize to identify the volatile profile or fingerprint of different varieties and their porridges. We opted for porridges as these are the most common foods prepared from maize flour throughout Africa. ${ }^{[2]}$ Knowledge about maize aroma could help breeders to fine-tune improved varieties to meet users' preferences, and thus develop maize varieties with appreciated flavours, which will improve consumer acceptability. Hence the main objective of this research was to determine the volatile profiles of flour from 22 commonly used maize varieties, i.e. quality protein maize, pro-vitamin A biofortified maize, white and yellow maize, as well as their porridges. 


\subsubsection{Materials and methods}

\subsubsection{Maize flour, porridge preparation and reagents}

Twenty-two maize varieties were obtained from the International Institute of Tropical Agriculture (IITA), Nigeria, and the Centre de Recherches Agricoles, Benin (INRAB), S1 Table. The moisture content was determined according to AACC method 44-15-02. Maize porridge was prepared by slowly adding boiling water to $30 \%$ maize flour under continuous stirring for 10 minutes. Next, the porridge was covered with aluminium foil and allowed to stand for 5 min. ${ }^{[13]}$

The following standards were used for identification of VOCs by GCMS: C7-C40 saturated alkanes (multi-component solution with 34 analytes), heptanoic acid, 2propanol, 2-octanol, 1-heptanol, acetaldehyde, limonene, 2-mercaptoethanol, benzaldehyde, hexanal, 2-butanol, ethanol, benzene, dimethyl sulfoxide, 1-octanol, acetonitrile, 2-propanol, n-hexanes and pentane. All standards had purity higher than 99\% and were purchased from Merck, Fluka and Actu-All Chemicals.

\subsubsection{PTR-QiTOF-MS analysis}

Three gram of maize sample in $250 \mathrm{ml}$ glass bottle was agitated at $60 \mathrm{rpm}$ for $30 \mathrm{~min}$ at $40^{\circ} \mathrm{C}$. The headspace of the sample was analysed by connecting the bottle to the inlet flow of the PTR-QiTOF-MS-MS 8000 instrument (Ionicon Analytic GmbH, Innsbruck, Austria). The mass scale was calibrated using the peaks of recognized components, namely the $\mathrm{NO}^{+}$peak, $\mathrm{m} / \mathrm{z}=29.9974$ and acetone, $\mathrm{C}_{3} \mathrm{H}_{7} \mathrm{O}^{+}, \mathrm{m} / \mathrm{z}$ $=59.0497$, to guarantee high mass accuracy throughout the analysis. The instrumental conditions for the proton transfer were: a drift voltage of $650 \mathrm{~V}$, drift temperature of $60^{\circ} \mathrm{C}$, drift pressure of $3.80 \mathrm{mbar}$, and an E/N (Electric field strength/particle density number) value of $120 \mathrm{Td}\left(1 \mathrm{Td}=10^{-17} \mathrm{~cm}^{2} \mathrm{~V}^{-1} \mathrm{~s}^{-1}\right)$. Sampling was at a flow rate of 50 $\mathrm{mL}$ per min. Every sample measurement started with flushing the PTR machine with ambient air of the bottle for 10 secs. as the blank. Then, the sample was measured for 40 secs, followed by flushing for 10 secs.

\subsubsection{Headspace SPME GC-MS analysis}

Samples were analysed using stabilwax DA capillary column (30 m x $0.25 \mathrm{~mm}$ ID x 0.25 $\mu \mathrm{m}$ ) and SPME fibre assembly DVB/CAR/PDMS (Supelco, Bellefonte, PA, USA). Calibration of HS-SPME/GC-MS mass scale was regularly performed using perfluorotributylamine (PFTBA). Two gram of the maize flour was put in a $10 \mathrm{~mL}$ glass vial, crimped, and incubated at $40^{\circ} \mathrm{C}$ for $15 \mathrm{~min}$. This was followed by $10 \mathrm{~min}$ of headspace absorption and another $10 \mathrm{~min}$ desorption in the $\mathrm{GC}$. The oven temperature for SPME injection was $40^{\circ} \mathrm{C}$ for $2 \mathrm{~min}$, increased at $10^{\circ} \mathrm{C} / \mathrm{min}$ to $200^{\circ} \mathrm{C}$ and then held at $200^{\circ} \mathrm{C}$ for $5 \mathrm{~min}$. The carrier gas was helium at a flow rate of $1 \mathrm{ml} / \mathrm{min}$. 


\subsubsection{Data processing and statistical analysis}

The raw PTR-QiTOF-MS data were processed using PTRwid. ${ }^{[14]}$ The data was blank corrected using RStudio 1.1.383 (the R Foundation for Statistical Computing, Vienna, Austria) and all ions interfering (especially water clusters) were manually removed. Integrated peaks signals from PTR-QiTOF-MS in units of cps (corresponding to the mass spectral intensity) were used for further analysis.

Chromeleon 7.2 (Thermo Fisher Scientific Inc., USA) was used to analyse the GC-MS data. The VOCs detected were identified by matching their mass peaks with the NIST spectral library database, the retention indexes according to literature and C7 - C40 saturated alkanes retention index marker probe. When available, the MS identifications were confirmed by matching the GC retention times of the analytes with pure standards.

Nonparametric tests (Kruskall Wallis test and Dunn's post - hoc test) were performed using IBM SPSS ${ }^{\circledR}$ software version 23 since the experimental groups had different sample sizes, unequal variances and the data were not normally distributed (ShapiroWilk test $<0.05) \cdot{ }^{[15]}$ For both porridge and flour data, principal component analysis (PCA) was performed using XLSTAT ${ }^{\circledR}$ data analysis software (version 2018.5.52280, Addinsoft, New York) for Microsoft Excel ${ }^{\circledR}$. The significance level was fixed at $\mathrm{p}<0.05$.

\subsubsection{Results and discussion}

\subsubsection{Detection of volatile compounds in maize flour and porridge by PTR- QiTOF-MS}

The analysis of maize samples (flour and porridge) generated 524 mass peaks in the range of $\mathrm{m} / \mathrm{z} 16.007$ - 448.089. The average blank corrected masses in count per seconds (cps) served as a means of comparison between each sample and group. An example of the predominant mean mass peaks in the four groups is shown in Figure 4.1. White maize group recorded the lowest peaks in maize flour but showed higher peak of VOCs in the porridge. Compounds having masses such as $\mathrm{m} / \mathrm{z} 33.030,38.034$, $51.044,127.112$ and 143.143 increased in all porridges. On the other hand, a compound having a mass of $\mathrm{m} / \mathrm{z} 61.029$ was lost in the porridge of all varieties, possibly due to high volatility, fast thermal degradation or hydrolysis in contact with hot water, Figure 4.1. For instance, $\mathrm{m} / \mathrm{z} 41.039$, 43.017, 43.054, 57.069, 58.072, 73.064, 74.067, 85.101, $89.059,93.069$ and 137.133 were reduced up to $90 \%$ in all the samples (4.S2 Table). The mass peaks of the porridges show degradation of many masses that were abundant in the maize flour. Buttery et al. ${ }^{[3]}$ observed that volatiles found in uncooked maize were below detection in cooked maize due to steam vaporization during cooking. Some lower stable masses in porridge possibly existed as a thermal degradation fragment of higher masses. Correlation matrix (Spearman) showed that lower molecular weight ions are 
negatively correlated to the higher molecular weight ions in porridge, whereas in flour the ions are positively correlated, 4.S3 Table.

Multiple pairwise comparisons using Dunn's procedure / two-tailed test showed that masses such as $\mathrm{m} / \mathrm{z} 53.002,58.04,59.05,75.079,76.075,77.059,82.040,83.049,84.052$, 85.064, 85.101, 87.080, 101.095, 102.098 and twenty other masses significantly differentiated white maize and provitamin A maize flour, 4.S2 Table. White maize and quality protein maize are significantly differentiated by $\mathrm{m} / \mathrm{z} 54.034,97.064,98.068$, 99.080, 100.044, 100.081, 112.047, 129.127 and 429.089. The yellow maize and provitamin A maize, which are closely related, are only significantly different in $\mathrm{m} / \mathrm{z}$ 84.185 and 256.780. A similar trend was observed in maize porridges wherein 43 masses significantly differentiated white maize and provitamin A maize flour, 4.S2 Table. In contrast to the result of maize flour, $\mathrm{m} / \mathrm{z}$ 80.047, 95.047, 123.044, 152.148 and 193.16 significantly distinguished white maize from yellow maize porridge. In general, there is an abundance of masses that differentiate white maize from provitamin A maize compared to other pairwise comparisons. Differences in volatile composition and abundance were observed among the maize varieties within the same group, Figure 4.1 (box plot). In PVA porridge, for instance, variety A4 recorded the lowest peak intensity (1791.53 cps) while variety A5 in the same group had a peak intensity of $4352.82 \mathrm{cps}$ for $\mathrm{m} / \mathrm{z} 83.049$ - methyl-furan. Such diversity within the same group creates an opportunity for future improvement of maize varieties. 

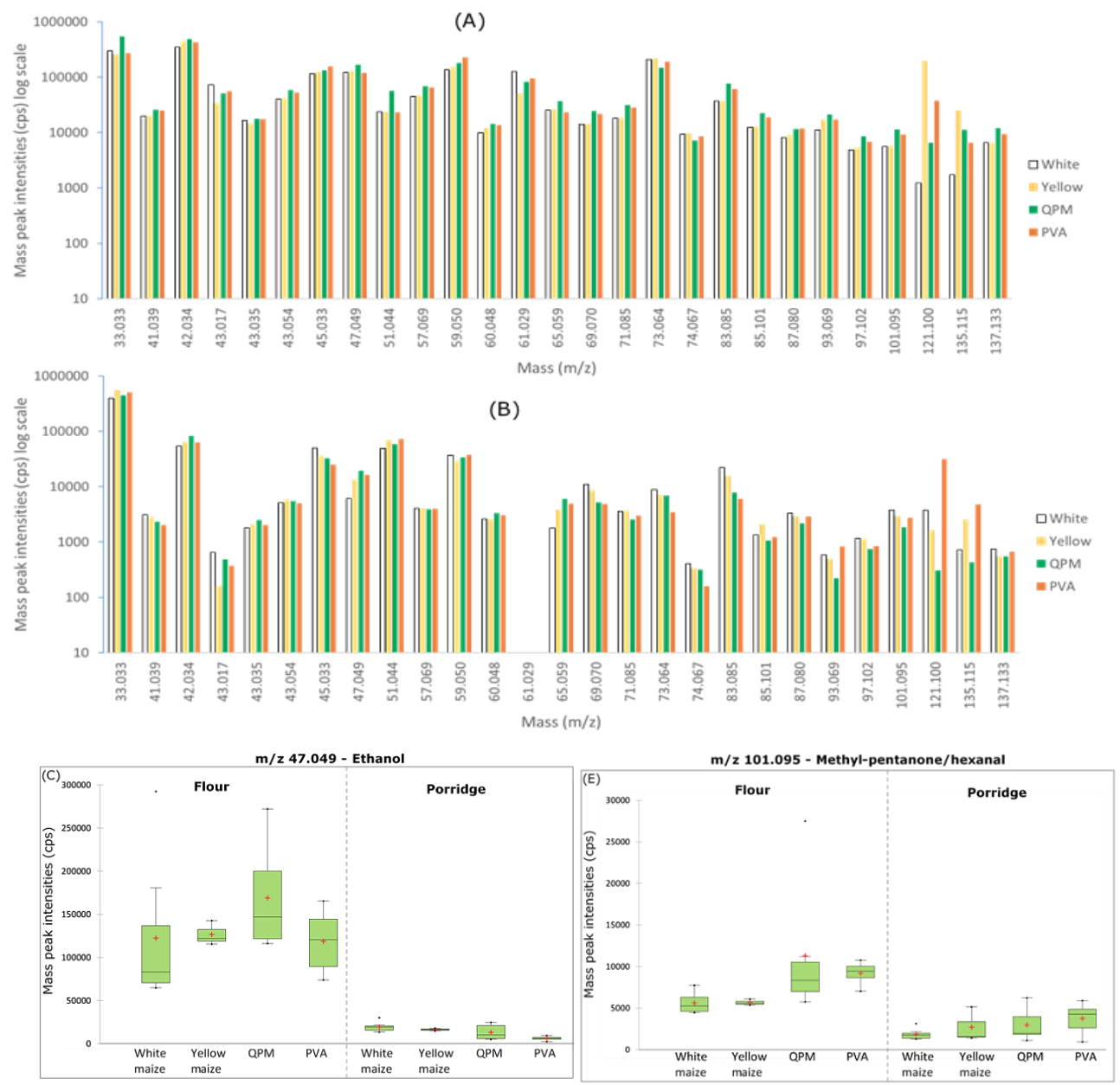

Figure 4.1: Mean mass peak intensities of the dominant ions (A) maize flour and (B) maize porridge in the headspace generated by PTR-QiTOF-MS. Box plot of some selected mass peaks generated by PTRQiTOF-MS significantly different in the maize samples (the mass peaks tentatively identified as shown on the charts). "+" indicates mean point and "." indicates minimum/maximum point. 


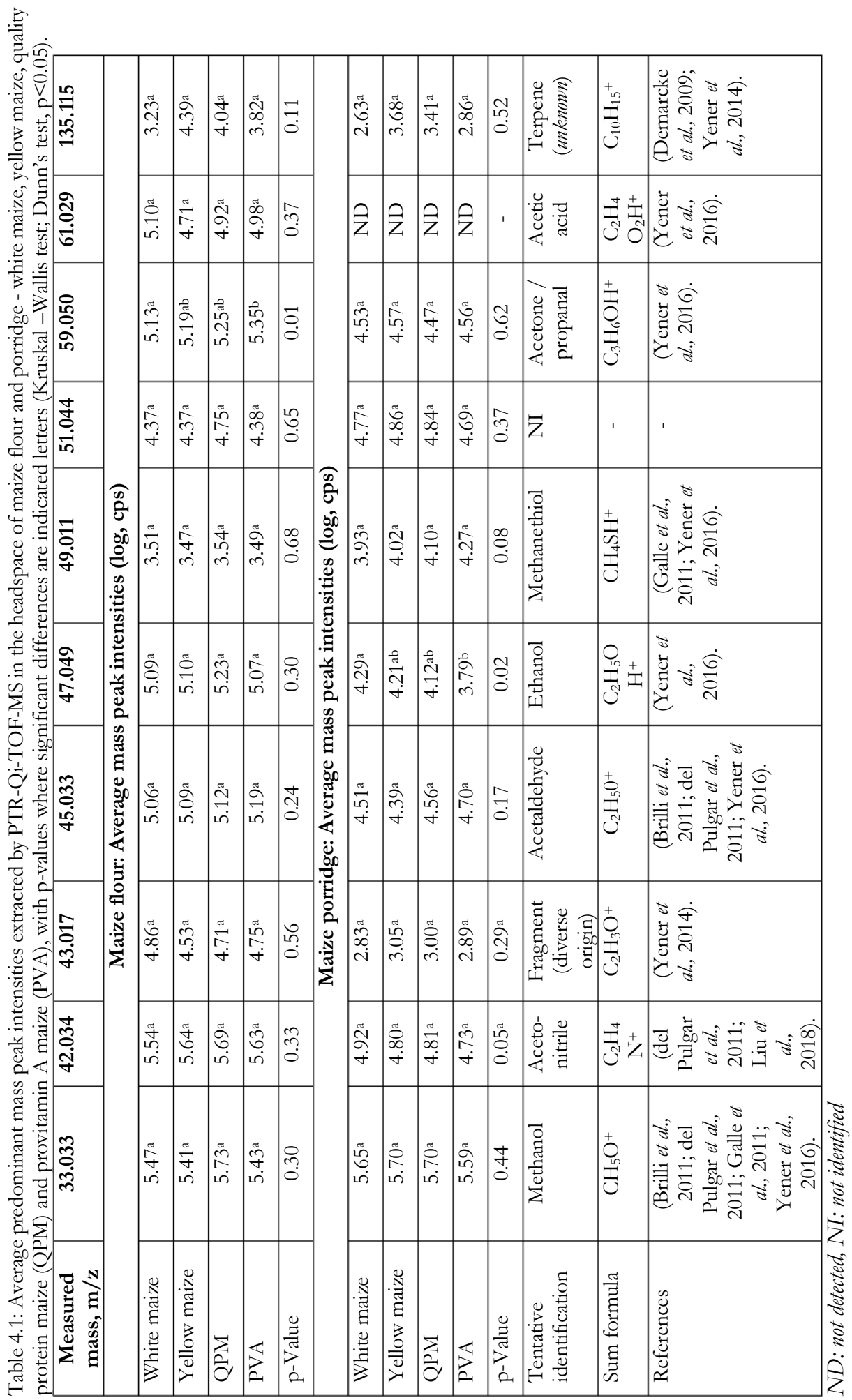


As shown in Table 4.1, the most abundant mass peaks of maize flour and porridge detected by PTR-QiTOF-MS were m/z 33.033, 42.034, 43.017, 45.033, 47.049, 49.011, 51.044, 59.050, 61.029 and 135.115. These masses, tentatively identified as methanol, acetonitrile, acetaldehyde, ethanol, methanethiol, acetone/propanal, acetic acid and terpene, respectively, have been associated with maize through conventional GC-MS analysis.[3-5, 16, 17] In fact, Flora et al. [16] identified methanethiol, acetaldehyde, ethanol and acetone as the predominant peaks responsible for the fruity and sulphurous aroma of sweet corn. Likewise, Gonçalves et al. [11] found $\beta$-myrcene (MW - 136.23; monoterpene) to be abundant in maize flour. Terpene compounds of similar masses such as limonene and $\beta$-ocimene have been found in maize by other researchers.[5,11]

Generally, the amount of the ten predominant masses decreased in the porridge, except for $\mathrm{m} / \mathrm{z} 33.033$ and 51.044, which showed stability and a significant increase in all varieties except the QPM. M/z 61.029 was abundant in maize flour but not present in the porridge. This compound could have been lost by thermal degradation and vaporization. Volatiles present in raw maize and below detection in cooked maize, are likely lost due to vaporization. ${ }^{[3]}$ A new compound such as $\mathrm{m} / \mathrm{z}-49.011$, methanethiol (otherwise known as methyl mercaptan, which has a rotten cabbage smell), was generated during porridge preparation, possibly due to heat treatment and/or hydration processes. In combination with other VOCs, methanethiol is an important aroma contributor to cooked cereals, e.g. cooked rice. ${ }^{[8]}$ Overall, only $\mathrm{m} / \mathrm{z} 59.050$ showed a significant difference $(\mathrm{p}$-value $=0.01)$ in the ten predominant masses in the four groups, while $\mathrm{m} / \mathrm{z} 42.034$ and 47.049 were significantly different in porridges at $\mathrm{p}$-values $=0.05$ and 0.02 , respectively, Table 4.1. Other masses with significant differences $(p<0.05)$ but not dominant are shown in (4.S2 Table).

\subsubsection{Clustering of the volatiles of the four groups of maize varieties}

Kruskal-Wallis test and Dunn's test as post hoc analysis of the 524 mass peaks generated by PTR-QiTOF-MS indicated 66 significantly different mass peaks for maize flour and 69 for maize porridge ( $\mathrm{p}<0.05)$, (4.S2 Table). All significantly different mass peaks were subjected to principal component analysis (PCA) to identify differences between the 22 maize varieties. A PCA score plot is shown in Figure 4.2, which indicates the grouping of the maize samples for the four groups.

The first two PCs for maize flour explain 77.75\% variance. All maize flour samples (except the PVA maize) are more spread out as compared to the maize porridge. The QPM varieties are located in between the other the three groups, although the distribution is dispersed. Overlap is between the region of QPM and others, suggesting that the groups are more diverse in their volatile profiles. This is not strange because 
QPM varieties are usually developed from either the white or yellow maize. In fact, QPM maize (P2) and (P4) located close to the yellow maize were identified as the yellowish 2000 EVDT Y STR QPM and 2009 TZE OR2 DT STR QPM, respectively, Figure 4.2. Similarly, QPM variety (P6) located near the white maize group was identified as white DMR ESR/QPM, (4.S1 Table). The loading plots corresponding to the PC1 versus PC2 are shown in Figure 4.2 (right), indicating masses that are important to each cluster.

The first two PCs for maize porridge explain 59.08\% variance - much lower than for maize flour, see Figure 4.2. Although all varieties are well separated in the PCA, the lower explained variance shows the complexity of the differences between the varieties after porridge preparation. QPM varieties are well separated in the PCA, the samples were spread out and formed a borderline between all varietal groups, as seen in maize flour PCA. Interestingly, all QPM varieties that are white (P5, P6 \& P7) tilted towards white maize group while those that are yellow (P1, P2 \& P4) drifted towards yellow/orange groups. As shown in the PCA plot, a large difference exists in the volatile profiles of white maize and the provitamin A maize. Concerning the PCA plot, our preliminary run using Pirouette ${ }^{\circledR}$ Infometrix software based on mean centred and normalized scale pre-processing method resulted in good separation and explained more than 90\% (PC1 and PC2) of the total variability in the samples. However, the current research adopted a method with minimal preprocessing of data, XLSTAT, to maintain data as close as possible to their raw and reproducible form. Considering the pattern of the PCA, it can be resolved that the distinguishing VOCs of the maize varieties were found with the help of PTR-QiTOF-MS. Hence this rapid and direct technique can be used for characterisation of different maize varieties. 

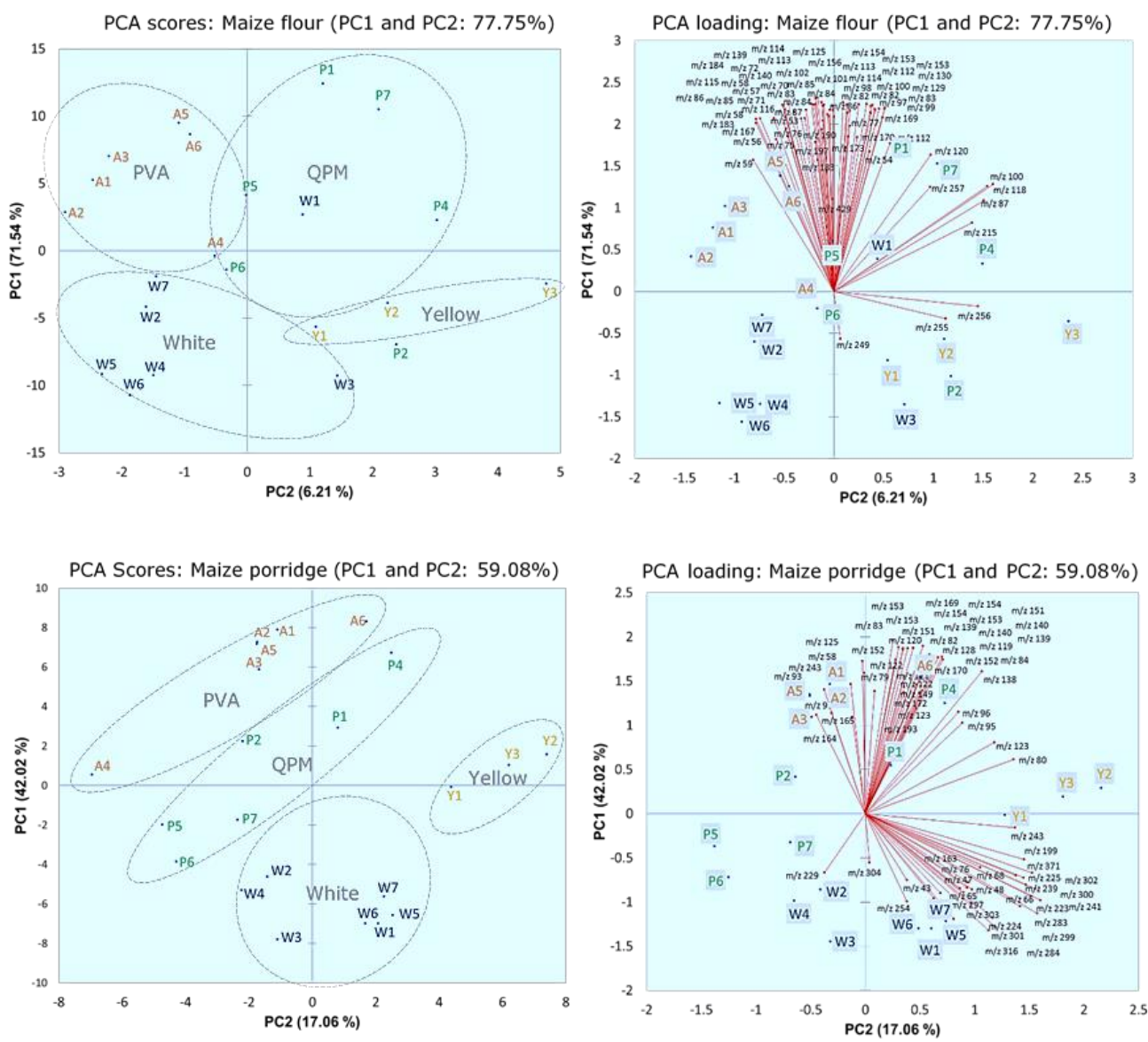

Figure 4.2: Plots of two dimensions of PCA on the mass spectral data of VOCs in maize flour and porridge of the PTR-QiTOF-MS data. The plots were derived from 66 and 69 mass peaks extracted from maize flour and porridge, respectively. These masses showed significant difference $(p<0.05$, KruskalWallis test and Dunn's test) in all varieties, thus being useful for PCA cluster formation. White maize (blue), provitamin A maize (orange), yellow maize (yellow) and quality protein maize (green) are separated in the PCA plot.

\subsubsection{Composition of volatiles in maize flour and porridge assessed by GC-MS}

GC-MS is the conventional method for volatile analysis in food matrices due to its reliable compound identification and quantification. On the other hand, PTR-MS equipment is rapid and sensitive but difficult for compound identification even with the advent of the new versions with time-of-flight (TOF).[18] Therefore, identification of compounds with PTR techniques remain tentative and depend on in-depth understanding of volatiles in the specific food matrix. However, PTR-MS techniques have shown to be effective in fingerprinting or "quick scan" and classification of samples, thus the current work focused on this important ability of the instrument, while 
GC-MS was used for compound identification. A one-on-one link between the two instruments has not been established. ${ }^{[18,19]}$ Furthermore, an alternative method to static headspace volatile detection used in the current work is simultaneous distillation extraction (SDE) for sample preparation before gas chromatography, but extraction method may not signify actual volatile production in the flour or porridge under tropical or cooking conditions. [7]

Figure 4.3 shows the abundance of VOCs in maize flour and porridge expressed as the average of total peak area of maize flour and porridge. The abundance of VOCs in the flour is in order of yellow maize $>$ white maize $>$ quality protein maize $>$ provitamin A maize. In the porridges, a significant reduction was observed. This is in agreement with the PTR-QiTOF-MS results but in contrast to Zhang et al. [7], who observed a higher VOC concentration for millet after porridge preparation. However, in the aforementioned research, porridge was prepared in sealed vials thus measuring concentrated volatiles in the headspace. In this study, porridge preparation was based on the traditional African method, in which the escape of volatiles occurs. In other research, Liu et al. ${ }^{[20]}$ observed that the content of volatile compounds in millet porridge decreased with an increase in water content. Apart from volatile loss by vaporization, a lower volatile composition of the porridge can be explained by the possibility of interaction of volatiles with the gelatinized maize matrix, i.e. volatiles trapped in the gel, thus resulting in less release to the headspace. Aromas form strong supramolecular interactions with gelatinised starches, thus increasing their retention in the matrix. ${ }^{21]}$

Comparing the four groups of maize, the release of volatiles was more prominent in variety P1 and A5, mainly caused by hexanal and 1,2,4-trimethylbenzene (psi-cumene), respectively. High concentrations of trimethylbenzene have been reported in barley, oat, rye and wheat. ${ }^{[22]}$ Both hexanal and trimethylbenzene have also been linked to fungal volatiles and wheat off odour.[23] The oversaturated peaks (bar chart in Figure 4.3, not instrumental) shown for variety $\mathrm{Y} 3$ in maize flour and porridge emanate mainly from compounds such as 1-ethyl-3-methylbenzene, 1,3,4-trimethylbenzene and 1,2,4trimethylbenzene. These compounds have been reported to be present in cereal grains. ${ }^{[5}$, 22] Trimethylbenzene derivatives were found to increase during heating of carotenoidrich sweet corn juice.[24] Aroma compounds having a benzene ring have been proposed to be degradation products of carotenoids. [24] Yellow and provitamin maize rich in carotenoid showed a significant increase in these compounds during thermal treatment of porridge. Zepka et al. [25] found similar volatile compounds during thermal degradation of the carotenoids in cashew apple products. 


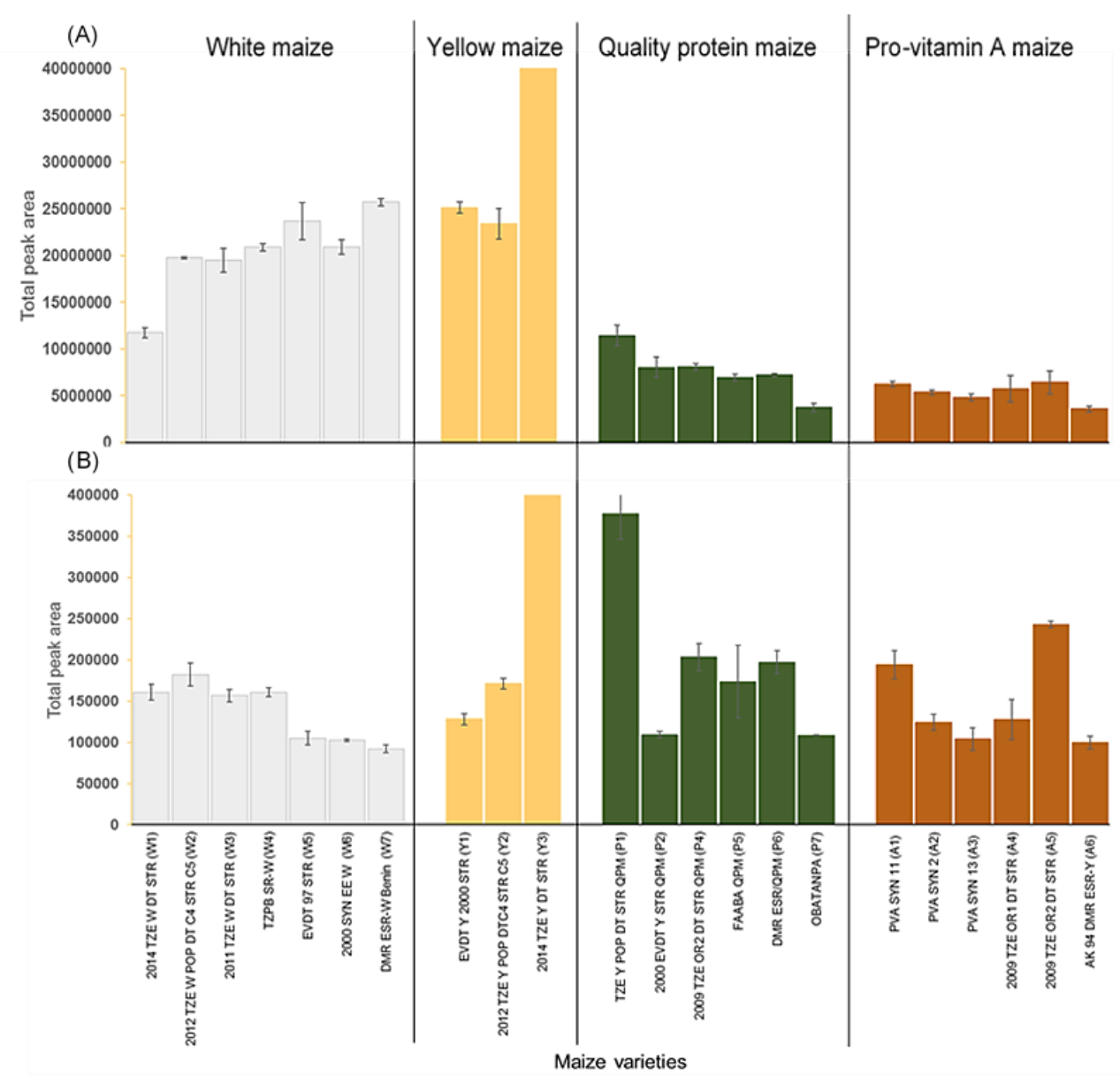

Figure 4.3: Abundance of volatile organic compound detected in maize flour (A) and their porridges (B) expressed as peak area, obtained as average of triplicate for flour and duplicate for porridge. Variety 2014 TZE Y DT STR (Y3) oversaturates the chart with total peak area + standard error of $8.6+0.4$ $(\mathrm{x} 108$, counts*min) in flour and $5.3+0.08(\mathrm{x} 105$, counts*min) in porridge.

The identified VOCs in the four maize groups (averages of all varieties in the same group) are shown in Table 4.2 and 4.3. For maize flours, 48 VOCs were identified, namely saturated hydrocarbons (2); unsaturated hydrocarbons (1); acids (8); alcohols (14); aldehydes (7); sulfur-containing compounds, esters \& ethers (5); arenes \& furans (11). The maize porridges generated a total of 21 VOCs, namely saturated hydrocarbons (4); acids (7); alcohols (2); aldehydes (2); arenes \& furans (4) and nitrogen-containing compounds, ester \& ether (2). Figure 4.4 shows the volatile fractions in the flours and porridges according to chemical families. The charts also highlight the compositional changes that occur due to the transformation of flour into porridge. The two 
hydrocarbons - hexane and nonane identified in maize flour had relative total peak areas $(\%)$ of $7.08 \pm 1.64,4.16 \pm 1.85,8.62 \pm 1.91$ and $8.4 \pm 2.15$ for white, yellow, QPM and PVA, respectively, Table 4.2. Preparation of porridge generated decane, 2,6dimethylheptadecane, 6-methyloctadecane and dodecane. No significant difference was found in hydrocarbons in maize flour and porridge ( $\mathrm{p}>0.05)$. Macku et al. ${ }^{26]}$ reported similar GC-MS peak areas (\%) in heated corn oil; octane and heptane were found to be the second and third most abundant peak area. Although hydrocarbons had high peak areas, their contribution to overall flavour may be low due to high human sensing thresholds. ${ }^{[8]}$ Limonene that has a very low flavour threshold value of $0.21 \mathrm{ppm}$ (in water) was found to have between $0.19-0.33 \%$ peak area but its sensory contribution may be more significant ${ }^{[8]}$, Table 4.2 .

Table 4.2: Volatile organic compounds identified in maize flour of four variety groups: white, yellow, QPM and PVA by HS-SPME/GC-MS (extraction temperature $40^{\circ} \mathrm{C}$ for $10 \mathrm{~min}$ )

\begin{tabular}{|c|c|c|c|c|c|}
\hline \multirow[t]{2}{*}{ Compounds } & \multicolumn{4}{|c|}{ Maize porridge (peak area $\% \pm \mathrm{SE}$ ) } & \multirow{2}{*}{$\begin{array}{c}\text { P- } \\
\text { value }\end{array}$} \\
\hline & $\begin{array}{l}\text { White } \\
\text { Maize }\end{array}$ & $\begin{array}{l}\text { Yellow } \\
\text { Maize }\end{array}$ & $\begin{array}{c}\text { QPM } \\
\text { Maize }\end{array}$ & $\begin{array}{c}\text { PVA } \\
\text { Maize }\end{array}$ & \\
\hline \multicolumn{6}{|l|}{ Hydrocarbon } \\
\hline Hexane & $2.42 \pm 0.9$ & $1.8 \pm 0.42$ & $5.13 \pm 1.24$ & $4.18 \pm 1.05$ & 0.22 \\
\hline Nonane & $4.66 \pm 0.74$ & $2.36 \pm 1.43$ & $3.49 \pm 0.67$ & $4.22 \pm 1.1$ & 0.44 \\
\hline Subtotal & $7.08 \pm 1.64$ & $4.16 \pm 1.85$ & $8.62 \pm 1.91$ & $8.4 \pm 2.15$ & \\
\hline \multicolumn{6}{|l|}{ Terpenes } \\
\hline Limonene & $0.33 \pm 0.04$ & $0.25 \pm 0.13$ & $0.2 \pm 0.03$ & $0.19 \pm 0.06$ & 0.33 \\
\hline Subtotal & $0.33 \pm 0.04$ & $0.25 \pm 0.13$ & $0.2 \pm 0.03$ & $0.19 \pm 0.06$ & \\
\hline \multicolumn{6}{|c|}{ Aldehydes } \\
\hline Hexanal & $4.99 \pm 0.28$ & $2.77 \pm 1.32$ & $8.76 \pm 1.3$ & $7.77 \pm 1.13$ & 0.01 \\
\hline Nonanal & $0.7 \pm 0.07$ & $0.47 \pm 0.2$ & $0.65 \pm 0.08$ & $0.73 \pm 0.14$ & 0.72 \\
\hline 2-Undecenal & $0.21 \pm 0.01$ & $0.13 \pm 0.05$ & $0.04 \pm 0$ & $0.02 \pm 0$ & 0.01 \\
\hline 2,4-Decadienal & $0.46 \pm 0.02$ & $0.51 \pm 0.23$ & $0.39 \pm 0.05$ & $0.52 \pm 0.05$ & 0.38 \\
\hline 2-Butyl-2-octenal & $0.15 \pm 0.01$ & $0.09 \pm 0.01$ & $0.12 \pm 0.05$ & $0.08 \pm 0.02$ & 0.64 \\
\hline $\begin{array}{l}\text { 3,4- } \\
\text { Dimethylbenzaldehyde }\end{array}$ & $0.2 \pm 0.02$ & $0.13 \pm 0.06$ & $0.1 \pm 0.02$ & $0.05 \pm 0.01$ & 0.01 \\
\hline Benzaldehyde & $0.6 \pm 0.1$ & $0.28 \pm 0.13$ & $0.57 \pm 0.07$ & $0.38 \pm 0.05$ & 0.08 \\
\hline Subtotal & $7.31 \pm 0.51$ & $4.38 \pm 2.00$ & $10.63 \pm 1.57$ & $9.55 \pm 1.4$ & \\
\hline \multicolumn{6}{|c|}{ Alcohols } \\
\hline 2-Butyloctanol & $2.13 \pm 0.18$ & $1.54 \pm 0.67$ & $2.54 \pm 0.45$ & $2.35 \pm 0.42$ & 0.55 \\
\hline 2-Methyl-1-undecanol & $2.12 \pm 0.2$ & $1.54 \pm 0.68$ & $2.15 \pm 0.33$ & $1.91 \pm 0.2$ & 0.67 \\
\hline 1-Methoxy-2-propanol & $4.19 \pm 0.74$ & $1.9 \pm 0.7$ & $2.89 \pm 0.89$ & $2.49 \pm 0.31$ & 0.28 \\
\hline 1-Pentanol & $1.79 \pm 0.37$ & $1.6 \pm 0.83$ & $2.44 \pm 0.5$ & $3.26 \pm 0.48$ & 0.18 \\
\hline 1-Octen-3-ol & $1.08 \pm 0.23$ & $0.85 \pm 0.4$ & $0.91 \pm 0.16$ & $1.3 \pm 0.17$ & 0.48 \\
\hline 2-Ethylhexanol & $0.4 \pm 0.03$ & $0.24 \pm 0.11$ & $0.22 \pm 0.04$ & $0.2 \pm 0.02$ & 0.02 \\
\hline 1-Nonanol & $0.22 \pm 0.02$ & $0.16 \pm 0.08$ & $0.11 \pm 0.02$ & $0.15 \pm 0.02$ & 0.03 \\
\hline
\end{tabular}




\begin{tabular}{|c|c|c|c|c|c|}
\hline 3-Methoxybutanol & $2.95 \pm 0.84$ & $1.52 \pm 0.72$ & $1.16 \pm 0.19$ & $1.06 \pm 0.11$ & 0.27 \\
\hline 1-Hexanol & $4.22 \pm 0.66$ & $4.23 \pm 2.02$ & $5.84 \pm 1.67$ & $5.67 \pm 0.7$ & 0.56 \\
\hline Ethanol & $6.36 \pm 1.27$ & $4.08 \pm 1.89$ & $14.11 \pm 3.77$ & $13.97 \pm 2.07$ & \\
\hline 2-Heptanol & $0.58 \pm 0.14$ & $0.35 \pm 0.17$ & $0.59 \pm 0.11$ & $0.63 \pm 0.09$ & 0.70 \\
\hline Benzenemethanol & $0.06 \pm 0$ & $0.05 \pm 0.01$ & $0.02 \pm 0$ & $0.03 \pm 0.01$ & 0.01 \\
\hline Mercaptoethanol & $1.13 \pm 0.05$ & $0.94 \pm 0.41$ & $1.58 \pm 0.14$ & $1.95 \pm 0.17$ & 0.00 \\
\hline 2,3-Butanediol & $3.26 \pm 1.38$ & $0.73 \pm 0.64$ & $0.15 \pm 0.02$ & $0.13 \pm 0.02$ & 0.04 \\
\hline Subtotal & $30.49 \pm 6.11$ & $19.73 \pm 9.33$ & $34.71 \pm 8.29$ & $35.1 \pm 4.79$ & \\
\hline \multicolumn{6}{|l|}{ Arenes \& furans } \\
\hline Propylbenzene & $0.13 \pm 0.02$ & $1.56 \pm 1.13$ & $0.55 \pm 0.24$ & $0.87 \pm 0.29$ & 0.07 \\
\hline 2-Pentylfuran & $2.24 \pm 0.54$ & $1.54 \pm 0.73$ & $2.91 \pm 0.59$ & $3.72 \pm 0.6$ & 0.20 \\
\hline $\begin{array}{l}1,3,4- \\
\text { Trimethylbenzene }\end{array}$ & $0.19 \pm 0.05$ & $6.21 \pm 5.03$ & $2 \pm 0.97$ & $2.78 \pm 1.21$ & 0.07 \\
\hline $\begin{array}{l}\text { 1-Ethyl-3- } \\
\text { methylbenzene }\end{array}$ & $1.56 \pm 0.15$ & $\begin{array}{c}22.83 \pm \\
17.84\end{array}$ & $8.02 \pm 3.62$ & $12.32 \pm 5.71$ & 0.08 \\
\hline $\begin{array}{l}\text { 1,4-Dimethyl-2- } \\
\text { ethylbenzene }\end{array}$ & $0.48 \pm 0.08$ & $0.3 \pm 0.16$ & $0.2 \pm 0.03$ & $0.17 \pm 0.03$ & 0.03 \\
\hline $\begin{array}{l}\text { 1,2,3-Trimethyl } \\
\text { benzene }\end{array}$ & $0.21 \pm 0.05$ & $4.32 \pm 3.45$ & $2.08 \pm 0.89$ & $2.29 \pm 1.06$ & 0.02 \\
\hline Indane & $0.06 \pm 0.01$ & $0.98 \pm 0.78$ & $0.63 \pm 0.26$ & $0.34 \pm 0.13$ & 0.01 \\
\hline $\begin{array}{l}\text { 1,3-Di-tert- } \\
\text { butylbenzene }\end{array}$ & $23.81 \pm 2.66$ & $16.18 \pm 7.13$ & $13.86 \pm 1.7$ & $8.12 \pm 0.7$ & 0.01 \\
\hline Durene & $0.14 \pm 0.02$ & $0.13 \pm 0.03$ & $0.22 \pm 0.07$ & $0.18 \pm 0.03$ & 0.66 \\
\hline Benzocyclohexane & $6.31 \pm 1.07$ & $5.93 \pm 1.22$ & $0.04 \pm 0.01$ & $0.04 \pm 0.02$ & 0.02 \\
\hline Phenol & $0.24 \pm 0.02$ & $0.16 \pm 0.06$ & $0.18 \pm 0.02$ & $0.2 \pm 0.02$ & 0.20 \\
\hline Subtotal & $35.37 \pm 4.67$ & $\begin{array}{c}60.14 \pm \\
37.56\end{array}$ & $30.69 \pm 8.4$ & $31.03 \pm 9.8$ & \\
\hline \multicolumn{6}{|l|}{ Acids } \\
\hline Heptanoic acid & $0.32 \pm 0.01$ & $0.22 \pm 0.1$ & $0.13 \pm 0$ & $0.13 \pm 0.01$ & 0.02 \\
\hline Octanoic Acid & $0.28 \pm 0.01$ & $0.19 \pm 0.09$ & $0.14 \pm 0.01$ & $0.11 \pm 0.01$ & 0.01 \\
\hline Hexanoic acid & $1.36 \pm 0.11$ & $1.18 \pm 0.54$ & $1.02 \pm 0.12$ & $1.37 \pm 0.14$ & 0.23 \\
\hline Pentanoic acid & $0.51 \pm 0.03$ & $0.39 \pm 0.17$ & $0.31 \pm 0.03$ & $0.36 \pm 0.04$ & 0.04 \\
\hline Butanoic acid & $0.14 \pm 0.02$ & $0.21 \pm 0.1$ & $0.22 \pm 0.07$ & $0.54 \pm 0.09$ & 0.04 \\
\hline Acetic acid & $7.79 \pm 1.3$ & $5.59 \pm 2.56$ & $5.04 \pm 0.85$ & $6.73 \pm 0.96$ & 0.60 \\
\hline $\begin{array}{l}\text { Dimethyl ester } \\
\text { Butanedioic acid }\end{array}$ & $0.23 \pm 0.05$ & $0.1 \pm 0.05$ & $0.08 \pm 0.02$ & $0.08 \pm 0.01$ & 0.03 \\
\hline $\begin{array}{l}\text { 4-Hydroxybutanoic } \\
\text { acid }\end{array}$ & $0.26 \pm 0.05$ & $0.15 \pm 0.07$ & $0.14 \pm 0.03$ & $0.24 \pm 0.03$ & 0.18 \\
\hline Subtotal & $10.89 \pm 1.58$ & $8.03 \pm 3.68$ & $7.08 \pm 1.13$ & $9.56 \pm 1.29$ & \\
\hline \multicolumn{6}{|c|}{ Sulfur-containing compounds, ester $\&$ ether } \\
\hline 1-Propenethiol & $6.42 \pm 0.64$ & $3.56 \pm 1.51$ & $8.44 \pm 0.41$ & $5.47 \pm 0.16$ & \\
\hline $\begin{array}{l}\text { Sulfurous acid, } \\
\text { cyclohexylmethyl hexyl } \\
\text { ester }\end{array}$ & $0.72 \pm 0.02$ & $0.44 \pm 0.19$ & $0.15 \pm 0.01$ & $0.13 \pm 0.01$ & 0.005 \\
\hline
\end{tabular}




\begin{tabular}{|l|c|c|c|c|c|}
\hline Dimethyl sulfone & $0.16 \pm 0.02$ & $0.12 \pm 0.05$ & $0.13 \pm 0.02$ & $0.17 \pm 0.02$ & 0.551 \\
\hline $\begin{array}{l}\text { Sulfurous acid, } \\
\text { cyclohexylmethyl } \\
\text { dodecyl ester }\end{array}$ & $1.85 \pm 0.08$ & $1.16 \pm 0.5$ & $0.67 \pm 0.15$ & $0.36 \pm 0.04$ & $\mathbf{0 . 0 0 6}$ \\
\hline $\begin{array}{l}\text { Vanillin, tert- } \\
\text { butyldimethylsilyl ether }\end{array}$ & $0.31 \pm 0.02$ & $0.2 \pm 0.09$ & $0.48 \pm 0.04$ & $0.54 \pm 0.05$ & $\mathbf{0 . 0 0 2}$ \\
\hline Subtotal & $\mathbf{9 . 4 6} \pm \mathbf{0 . 7 8}$ & $\mathbf{5 . 4 8} \pm \mathbf{2 . 3 4}$ & $\mathbf{9 . 8 7} \pm \mathbf{0 . 6 3}$ & $\mathbf{6 . 6 7} \pm \mathbf{0 . 2 8}$ & \\
\hline
\end{tabular}

${ }^{\text {aThe }}$ p-values (Kruskal-Wallis). P-values marked in bold fonts are significantly different $(\mathrm{p}<$ $0.05)$.

VOCs in the acid group are mainly responsible for cheesy, fatty, sour, vinegar, rancid, fruity and sweaty aroma. ${ }^{[8]}$ As shown in Table 4.2, the relative total peak area of the acids in maize flour of white, yellow, QPM and PVA were $10.89 \pm 1.58,8.03 \pm 3.68$, $7.08 \pm 1.13$ and $9.56 \pm 1.29$, respectively. Higher relative total peak areas were observed in maize porridge, i.e. white - $18.87 \pm 2.04$, yellow - 8.63 \pm 2.34 , QPM - $16.33 \pm 4.56$ and PVA - $13.15 \pm 1.91$ see Figure 4.4. The relative increase in acids from flour to porridge could be due to changes in other volatiles. Some compounds were lost during porridge preparation, thereby allowing the relative amount of acids to rise since they showed better stability. Although Goicoechea et al. ${ }^{[17]}$ reported that the number and proportion of acids (especially formic, acetic and hexanoic acid) increased in maize oil after long storage ( $1-10$ years) due to oxidation, this cannot be the case in this research since the analysis was after storing at $4^{\circ} \mathrm{C}$. However, it is known that in the mechanism of hexose fragmentation through 1-deoxy-2,4-hexodiulose, hydrolytic beta-dicarbonyl cleavage can lead to the production of acetic acid.[27] Therefore, hexose reaction (in the presence of water, independent of oxygen) can explain acetic acid formed during porridge preparation. Acetic acid was found to have the highest relative peak area within the acid group. In maize flour, the white maize had the highest peak area for acetic acid, i.e. 7.79 \pm 1.3 , while QPM had highest peak area (12.16 \pm 3.64$)$ in porridge, respectively, see Table 4.3. Acetic acid has a strong, pungent, sour and vinegar odour but the flavour threshold value is high. Hence it likely contributes little to the flavour of maize. Other acids, e.g. butanoic acid, pentanoic acid, hexanoic acid, heptanoic acid and octanoic acid, have been reported to have extremely low flavour threshold values and hence their flavour impact is not negligible regardless of their infinitesimal amounts. ${ }^{[8]}$ 
Table 4.3: Volatile organic compounds identified in maize porridge of four variety groups: white, yellow, QPM and PVA by HS-SPME/GC-MS (extraction temperature $40^{\circ} \mathrm{C}$ for $10 \mathrm{~min}$ )

\begin{tabular}{|c|c|c|c|c|c|}
\hline \multirow[t]{2}{*}{ Compounds } & \multicolumn{4}{|c|}{ Maize porridge (peak area $\% \pm \mathrm{SE}$ ) } & \multirow{2}{*}{$\begin{array}{c}\mathbf{P} \text { - } \\
\text { value }^{\mathrm{a}}\end{array}$} \\
\hline & $\begin{array}{l}\text { White } \\
\text { Maize }\end{array}$ & $\begin{array}{l}\text { Yellow } \\
\text { Maize }\end{array}$ & $\begin{array}{c}\text { QPM } \\
\text { Maize }\end{array}$ & $\begin{array}{l}\text { PVA } \\
\text { Maize }\end{array}$ & \\
\hline \multicolumn{6}{|c|}{ Saturated hydrocarbons } \\
\hline Decane & $5.25 \pm 1.58$ & $4.62 \pm 3.19$ & $6.66 \pm 1.79$ & $4.37 \pm 0.73$ & 0.77 \\
\hline 2,6-Dimethylheptadecane & $1.31 \pm 0.47$ & $1 \pm 0.74$ & $1.97 \pm 0.75$ & $2.05 \pm 0.39$ & 0.48 \\
\hline 6-Methyloctadecane & $3.96 \pm 0.85$ & $2.59 \pm 1.58$ & $3.51 \pm 1.24$ & $2.93 \pm 0.46$ & 0.75 \\
\hline Dodecane & $2.78 \pm 0.66$ & $1.61 \pm 0.5$ & $3.38 \pm 0.61$ & $3.05 \pm 0.51$ & 0.21 \\
\hline Subtotal & $12.73 \pm 3.56$ & $9.82 \pm 6.01$ & $15.52 \pm 4.39$ & $12.4 \pm 2.09$ & \\
\hline \multicolumn{6}{|l|}{ Acids } \\
\hline Acetic acid & $10.5 \pm 1.26$ & $4.06 \pm 1.17$ & $12.16 \pm 3.64$ & $9.21 \pm 1.33$ & 0.12 \\
\hline 2-Methylpropanoic acid & $4.24 \pm 0.31$ & $2.48 \pm 0.7$ & $2.5 \pm 0.4$ & $2.42 \pm 0.29$ & 0.02 \\
\hline 3-Hydroxydodecanoic acid & $0.32 \pm 0.03$ & $0.22 \pm 0.04$ & $0.17 \pm 0.1$ & $0.13 \pm 0.05$ & 0.12 \\
\hline Hexanoic acid & $2.09 \pm 0.31$ & $0.87 \pm 0.21$ & $0.95 \pm 0.25$ & $0.77 \pm 0.13$ & 0.02 \\
\hline Heptanoic acid & $0.83 \pm 0.06$ & $0.49 \pm 0.1$ & $0.31 \pm 0.09$ & $0.32 \pm 0.04$ & 0.01 \\
\hline Octanoic Acid & $0.89 \pm 0.07$ & $0.51 \pm 0.12$ & $0.32 \pm 0.09$ & $0.3 \pm 0.07$ & 0.01 \\
\hline Subtotal & $18.87 \pm 2.04$ & $8.63 \pm 2.34$ & $16.41 \pm 4.57$ & $13.15 \pm 1.91$ & \\
\hline \multicolumn{6}{|c|}{ Alcohol } \\
\hline 1-Pentanol & $5.32 \pm 0.64$ & $4.2 \pm 1.45$ & $5.12 \pm 0.51$ & $6.79 \pm 0.84$ & 0.27 \\
\hline $\begin{array}{l}\text { 2-(2-ethoxyethoxy) - } \\
\text { Ethanol }\end{array}$ & $3.16 \pm 0.28$ & $2.01 \pm 0.51$ & $2.17 \pm 0.32$ & $2.4 \pm 0.25$ & 0.10 \\
\hline Subtotal & $8.48 \pm 0.92$ & $6.21 \pm 1.96$ & $7.29 \pm 0.83$ & $9.19 \pm 1.09$ & \\
\hline \multicolumn{6}{|l|}{ Aldehydes \& Ketones } \\
\hline 2-Heptanone & $10 \pm 1.52$ & $3.64 \pm 1.4$ & $7.18 \pm 1.19$ & $12.65 \pm 1.89$ & 0.02 \\
\hline Hexanal & $5.73 \pm 2.59$ & $14.75 \pm 6.03$ & $19.98 \pm 8.74$ & $7.42 \pm 1.54$ & 0.10 \\
\hline Subtotal & $15.73 \pm 4.11$ & $18.39 \pm 7.43$ & $27.16 \pm 9.93$ & $20.07 \pm 3.43$ & \\
\hline \multicolumn{6}{|l|}{ Arene \& Furan } \\
\hline 2-Methylfuran & $4.35 \pm 0.65$ & $4.84 \pm 2.12$ & $2.65 \pm 0.54$ & $7.29 \pm 1.58$ & 0.04 \\
\hline 2-Pentylfuran & $5.93 \pm 0.76$ & $3.76 \pm 1.11$ & $5.36 \pm 0.8$ & $6.29 \pm 0.76$ & 0.31 \\
\hline 1,2,4-Trimethylbenzene & $0.42 \pm 0.16$ & $\begin{array}{c}24.68 \pm \\
23.28\end{array}$ & $1.9 \pm 1.42$ & $8.77 \pm 5.25$ & 0.10 \\
\hline 1,3-Ditertiarybutylbenzene & $5.28 \pm 2.14$ & $4.55 \pm 3.33$ & $6.95 \pm 2.2$ & $4.64 \pm 1.13$ & 0.73 \\
\hline Subtotal & $15.98 \pm 3.71$ & $\begin{array}{c}37.83 \pm \\
29.84\end{array}$ & $16.86 \pm 4.96$ & $26.99 \pm 8.72$ & \\
\hline \multicolumn{6}{|c|}{ Nitrogen/Sulfur-containing compounds, Ester \& Ether } \\
\hline Acetonitrile & $6.07 \pm 0.55$ & $4.09 \pm 1$ & $3.33 \pm 1.29$ & $1.8 \pm 0.34$ & 0.01 \\
\hline $\begin{array}{l}\text { Mercaptoacetic acid, 2TMS } \\
\text { derivative }\end{array}$ & $21.98 \pm 1.87$ & $14.09 \pm 4.15$ & $13.39 \pm 2.25$ & $14.73 \pm 1.53$ & 0.05 \\
\hline Octyl ether & $1.49 \pm 0.17$ & $0.95 \pm 0.21$ & $0.72 \pm 0.21$ & $2.56 \pm 1.89$ & 0.10 \\
\hline Subtotal & $29.54 \pm 2.59$ & $19.13 \pm 5.36$ & $17.44 \pm 3.75$ & $19.09 \pm 3.76$ & \\
\hline
\end{tabular}

${ }^{a}$ The $\mathrm{p}$-values (Kruskal-Wallis). P-values marked in bold fonts are significantly different $(\mathrm{p}<$ $0.05)$.

Alcohols are important contributors to the overall green, floral, fruity, grassy, and earthy aroma profile of maize. ${ }^{[3]}$ Some members of this group possess extremely low threshold 
values (in water). For instance, 3-hexan-1-ol has a flavour threshold value of 0.0038 ppm (in water); ethanol, which has the highest peak area in this research, has $53 \mathrm{ppm}$ (in water). ${ }^{[8]}$ In total 14 alcohol compounds were detected in flour samples and 2 in porridge. From the highest to lowest, the alcohol contents in maize samples were: yellow - 19.73 \pm 9.33, white - 30.49 \pm 6.11, QPM - $34.71 \pm 8.29$ and PVA - $35.1 \pm 4.79$, see Figure 4.4. One-hexanol had the second-highest percentage in flour while 1pentanol was the highest in porridge. Similar alcohol compositions were recently reported in gluten-free flour and maize starch. ${ }^{[28]}$ Some of the alcohols detected, e.g. 1octen-3-ol, 1-pentanol, 1-nonanol, 2-heptanol and 1-hexanol, have been identified as the volatile compounds in cereals contributing to the green, grass-like, mushroom, fruity, herbaceous, plastic, and citrus aroma characteristics.[11, 16] In porridge these compounds were lost, leaving only 1-pentanol. Alcohols in food can be abundant but their impact on flavour is likely to be lower than that of aldehydes. ${ }^{[8]}$

Aldehydes are very prominent in VOC composition of food and their flavour threshold level for human sensing is low, implying crucial contributions to aroma perception. Aldehydes mainly contribute green, grassy, soapy, citric and malty notes. ${ }^{[8]}$ In maize flour, aldehyde peak areas (\%) were for white - 7.31 \pm 0.51 , yellow - 4.38 \pm 2.00 , QPM - $10.63 \pm 1.57$ and PVA - 9.55 \pm 1.40 , see Figure 4.4. The number of different aldehydes was reduced from 7 in maize flour to only hexanal in porridge. Hexanal is very common in food aroma, and when considered in a single state, has a green bean and grassy character. Pyysalo et al. ${ }^{29]}$, observed a low odour threshold value for hexanal, i.e. 0.02 ( $\mathrm{mg} /$ litre in water), signifying its important contribution to the overall aroma of maize. The proportion of hexanal was most prominent in provitamin PVA and QPM maize. Hexanal is commonly formed during cooking processes, thus the higher proportion in the porridge was to be expected. Hexanal can be generated by lipid breakdown (commonly oxidative degradation of linoleic acid) initiated by lipoxygenase. ${ }^{[5,17]}$ In fact, hexanal is often used as an indicator for human perception of rancidity. Other researchers have found hexanal to be most abundant in maize starch.[5] The high proportion of hexanal and 2-heptanone in carotenoid-rich maize could be attributed to enzymatic degradation of the oil. Besides, autoxidation of free fatty acids has been described as a major source of ketones [8] but only 2-heptanone was found in this research. Two-heptanone (having a fruity, green, nutty, soapy smell) has been identified as an odour-active compound in maize, thus its contribution to maize aroma is relevant.[3,5]

Aromatic hydrocarbons (arene) and furans are interesting groups of VOCs in maize. In maize flour, the peak areas (\%) were: white - 35.37 \pm 4.67 , yellow $-60.14 \pm 37.56$, QPM - 30.69 \pm 8.4 and PVA - 31.03 \pm 9.8 , see Figure 4.4 and Table 4.3. Most VOCs of the 
yellow maize variety belonged to this group; this may be an important classification characteristic of the variety. Furans can potently contribute to aroma, even in minute amounts. Two main furans were found in our samples: 2-methylfuran and 2pentylfuran. The latter is known for its crucial contribution to the aroma and flavour of popcorn.[6] Furans are usually formed during thermal processing of food, thus explaining the increase in porridge. Benzene derivatives such as propylbenzene, 1 -ethyl3-methylbenzene and 1,3,4-trimethylbenzene were found to be a major contributor of VOCs in maize, especially for the yellow maize cultivar. Aromatic hydrocarbons and furans have relatively low threshold values. Hence their presence as found in all the samples especially the carotenoid-rich varieties is noteworthy for their role in maize aroma. 

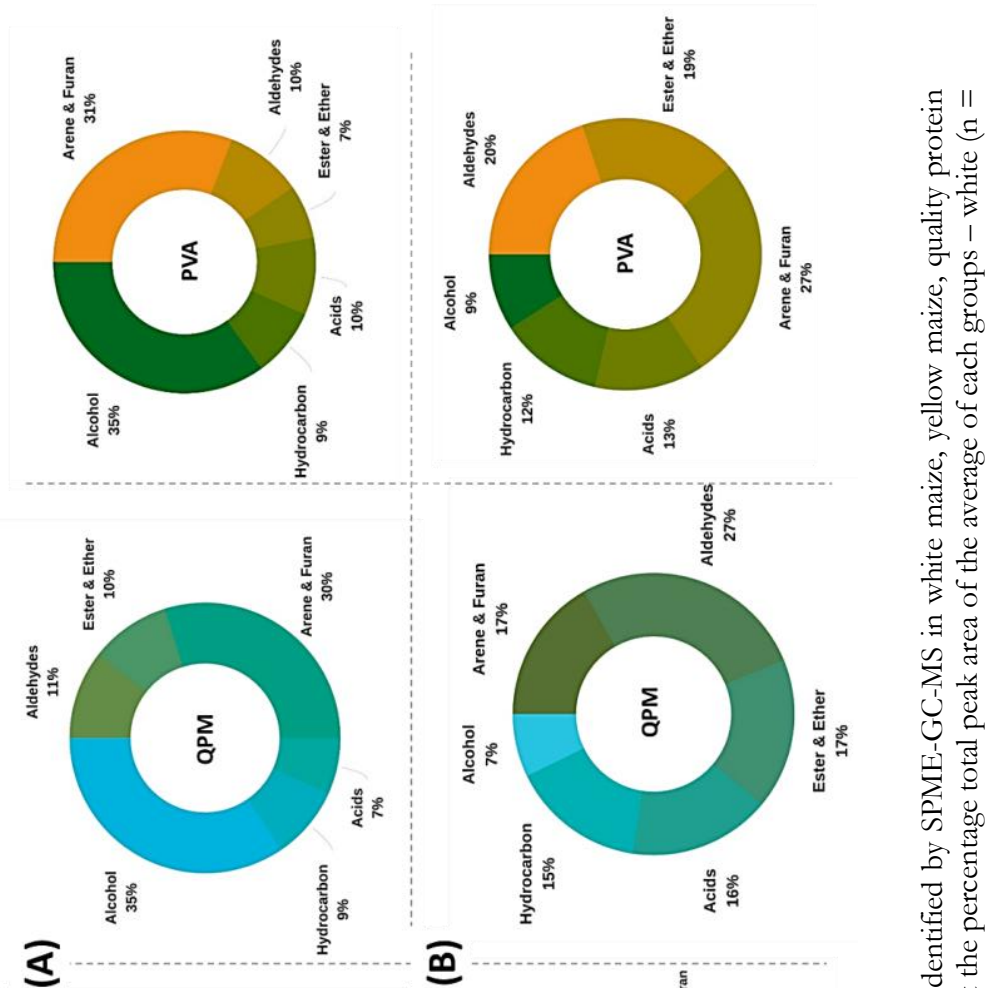

घ

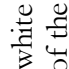

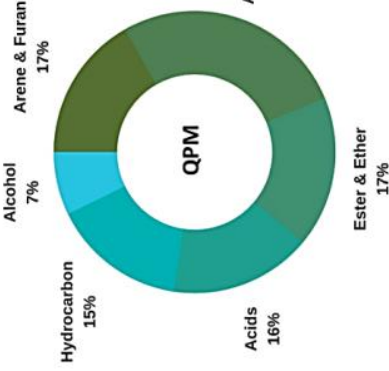

$\overline{\underline{m}}$
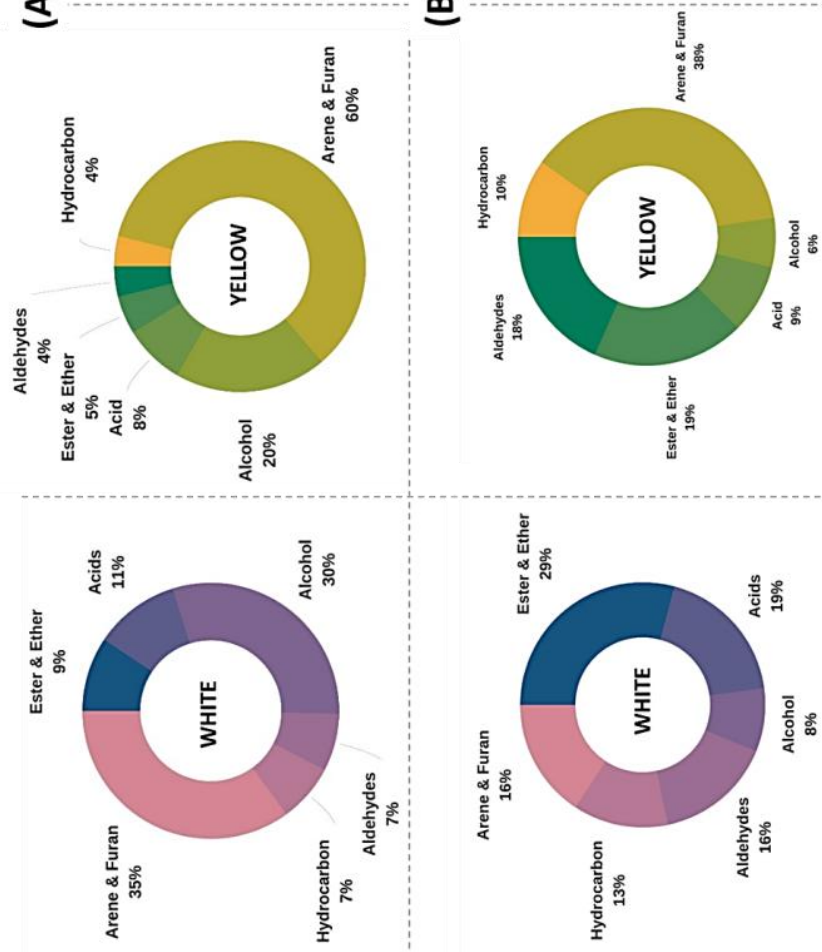

ヨ

象

ن

兵焉

依

令苞

艺

몸

๑ิ

800

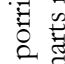

믈

दे है

ษड

苛家

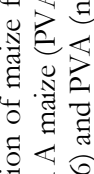

荀. 青 II

हृ. है

营

융

活方

ํํㄹ

总 泉 


\section{Conclusions}

This is the first study on volatile compounds in maize using PTR-QiTOF-MS. Maize varieties from different groups were successfully grouped by PCA. With such sophisticated, highly sensitive and fast equipment, coupled with a statistical tool for multivariate analysis, the diversity in maize odour-active compounds can be assessed as input to improve sensory qualities of new varieties. HS-SPME/GC-MS was used to identify VOCs and this was also the first time the method was used on improved maize cultivars developed for the nutritional needs of the growing African population. The study identified differences in volatile composition of maize cultivars and their corresponding porridges. Results of this study can be the basis for further research of flavour threshold values and identification of the association between consumer perception and the inherent volatiles compounds. This will contribute to the understanding of consumer preferences for maize varieties in Africa and help breeders to build a data bank for volatiles that will enable the incorporation of aroma traits during variety selection and development. Breeding for aroma is a difficult task for maize breeders because aroma is yet to be properly understood and classified genetically, but our current research paves ways to generate information useful for further classification.

Our results show that maize has a vast volatile variability that is still untapped: considering that aroma is a major contributor to taste and food crop acceptance, this research aspect requires further efforts. An investigation into methods to monitor offflavour during post-harvest handling of the nutrient-rich maize varieties is recommended. For instance, hexanal production is a good indicator of lipid oxidation and could be used to evaluate storage stability, especially in provitamin A biofortified maize. 


\section{Acknowledgements}

The authors thank Franco Biasioli (Fondazione Edmund Mach), PTR-MS expert, for his review. We acknowledge Baffour Badu-Apraku - International Institute of Tropical Agriculture (IITA), for providing the maize samples. We also appreciate the enthusiastic contribution of Aniek de Vos and Marijn van den Dikkenberg in GC-MS and PTR-MS analysis. Many thanks to Sara Erasmus and Sine Yener of Wageningen University \& Research for their technical support on PTR-MS analyses.

\section{Supplementary material and data:}

https://www.dropbox.com/sh/3wz62j0xjhnz4fo/AAA7YNilkMNGLJPzg OFdpWy a?dl $=0$ 


\section{References}

1. Ekpa O, Palacios-Rojas N, Kruseman G, Fogliano V, Linnemann AR. Sub-Saharan African maize-based foods: Technological perspectives to increase the food and nutrition security impacts of maize breeding programmes. Global Food Security. 2018;17:48-56.

2. Pillay K, Derera J, Siwela M, Veldman FJ. Consumer acceptance of yellow, provitamin Abiofortified maize in KwaZulu-Natal: original research. South African Journal of Clinical Nutrition. 2011;24(4):186-91.

3. Buttery RG, Stern DJ, Ling LC. Studies on flavor volatiles of some sweet corn products. Journal of Agricultural and Food Chemistry. 1994;42(3):791-5.

4. Legendre MG, Dupuy HP, Ory RL, McIlrath WO. Instrumental analysis of volatiles from rice and corn products. Journal of Agricultural and Food Chemistry. 1978;26(5):1035-8.

5. Sayaslan A, Chung OK, Seib PA, Seitz LM. Volatile compounds in five starches. Cereal chemistry. 2000;77(2):248-53.

6. Walradt JP, Lindsay RC, Libbey LM. Popcorn flavor: identification of volatile compounds. Journal of Agricultural and Food Chemistry. 1970;18(5):926-8.

7. Zhang Y, Yang N, Fray RG, Fisk I, Liu C, Li H, et al. Characterization of volatile aroma compounds after in-vial cooking of foxtail millet porridge with gas chromatography-mass spectrometry. Journal of Cereal Science. 2018;82:8-15.

8. Mottram D, Maarse H. Volatile compounds in foods and beverages. New York: Marcel Dekker. 1991:107-77.

9. Muzhingi T, Langyintuo AS, Malaba LC, Banziger M. Consumer acceptability of yellow maize products in Zimbabwe. Food Policy. 2008;33(4):352-61.

10. Yener S, Sánchez-López JA, Granitto PM, Cappellin L, Märk TD, Zimmermann R, et al. Rapid and direct volatile compound profiling of black and green teas (Camellia sinensis) from different countries with PTR-ToF-MS. Talanta. 2016;152:45-53.

11. Gonçalves JL, Figueira JA, Rodrigues FP, Ornelas LP, Branco RN, Silva CL, et al. A powerful methodological approach combining headspace solid phase microextraction, mass spectrometry and multivariate analysis for profiling the volatile metabolomic pattern of beer starting raw materials. Food chemistry. 2014;160:266-80.

12. De Groote H, Kimenju SC. Consumer preferences for maize products in urban Kenya. Food and nutrition bulletin. 2012;33(2):99-110.

13. Onyango C. Physical properties of dry-milled maize meals and their relationship with the texture of stiff and thin porridge. African Journal of Food Science. 2014;8(8):435-43. 
14. Holzinger R. PTRwid: A new widget tool for processing PTR-TOF-MS data. Atmospheric Measurement Techniques. 2015;8(9):3903-22.

15. Shapiro SS, Wilk MB. An analysis of variance test for normality (complete samples). Biometrika. 1965;52(3/4):591-611.

16. Flora L, Wiley R. Sweet corn aroma, chemical components and relative importance in the overall flavor response. Journal of Food Science. 1974;39(4):770-3.

17. Goicoechea E, Guillén MD. Volatile compounds generated in corn oil stored at room temperature. Presence of toxic compounds. European journal of lipid science and technology. 2014;116(4):395-406.

18. Cappellin L, Aprea E, Granitto P, Wehrens R, Soukoulis C, Viola R, et al. Linking GCMS and PTR-TOF-MS fingerprints of food samples. Chemometrics and Intelligent Laboratory Systems. 2012;118:301-7.

19. Majchrzak T, Wojnowski W, Lubinska-Szczygeł M, Różańska A, Namieśnik J, Dymerski T. PTR-MS and GC-MS as complementary techniques for analysis of volatiles: A tutorial review. ANALYTICA CHIMICA ACTA. 2018;1035:1-13.

20. Liu J-k, Liu S-y, Zhao W, Li Y, Zhang Y-z. Influence of Different Water Addition on Volatile Flavour Compounds of Millet Porridge. Food Research and Development. 2011;9:004.

21. Misharina T, Samusenko A, Kalinchenko M. Binding by cornstarch of components of a mixture of volatile organic substances from aqueous solutions. Applied Biochemistry and Microbiology. 2004;40(6):609-12.

22. Buśko M, Jeleń H, Góral T, Chmielewski J, Stuper K, Szwajkowska-Michałek L, et al. Volatile metabolites in various cereal grains. Food Additives and contaminants. 2010;27(11):1574-81.

23. Olsson J, Börjesson T, Lundstedt T, Schnürer J. Volatiles for mycological quality grading of barley grains: determinations using gas chromatography-mass spectrometry and electronic nose. International journal of food microbiology. 2000;59(3):167-78.

24. Song J, Chen J, Li D, Xiao Y, Liu C. Thermal Isomerization and Degradation Behaviours of Carotenoids in Simulated Sweet Corn Juice. Food and Bioprocess Technology. 2018;11(4):836-44.

25. Zepka LQ, Garruti DS, Sampaio KL, Mercadante AZ, Da Silva MAA. Aroma compounds derived from the thermal degradation of carotenoids in a cashew apple juice model. Food research international. 2014;56:108-14. 
26. Macku C, Shibamoto T. Volatile antioxidants produced from heated corn oil/glycine model system. Journal of agricultural and food chemistry. 1991;39(11):1990-3.

27. Davıdek T, Fabien R, Devaud S, Arce Vera F, Blank I. Sugar fragmentation in the Maillard reaction cascade: Formation of short-chain carboxylic acids by a new oxidative R-dicarbonyl cleavage pathway. J Agric Food Chem. 2006;54:6677-84.

28. Pico J, Tapia J, Bernal J, Gómez M. Comparison of different extraction methodologies for the analysis of volatile compounds in gluten-free flours and corn starch by GC/QTOF. Food chemistry. 2018;267:303-12.

29. Pyysalo T, Suihko M, Honkanen E. Odour thresholds of the major volatiles identified in cloudberry (Rubus chamaemorus L.) and arctic bramble (Rubus arcticus L.). LWT Lebensmitt Wissensch Technol. 1977;10:36-9. 


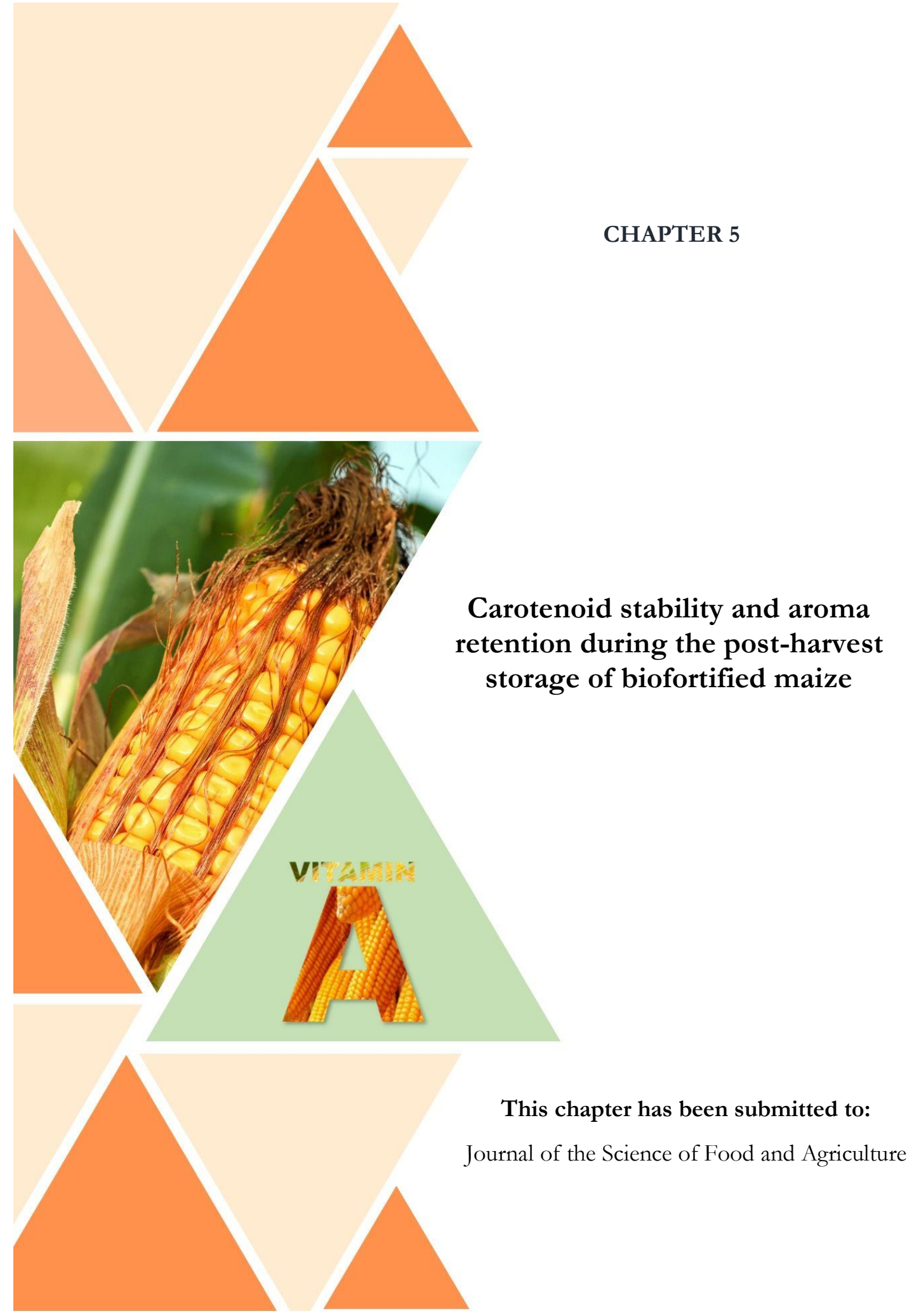




\begin{abstract}
Maize varieties that are rich in carotenoids have been developed to combat vitamin A deficiency in Sub-Saharan Africa. Unfortunately, after harvest carotenoids degrade and off-flavour volatiles develop, which affect nutrient intake and consumer acceptance, respectively. This study evaluated carotenoid retention and aroma compound stability in provitamin A biofortified maize, variety Pool 8A, as influenced by dry milling and storage in different packaging and temperature conditions. Results show that improving the storage conditions (i.e. at a lower temperature and with better packaging material) inhibits carotenoid degradation and off-odour formation. The lowest amount of total carotenoids was found in flour stored in laminated paper bags at $37^{\circ} \mathrm{C}$ (only $16 \%$ retention after 180 days), attributable to the high storage temperature and oxygen permeability of the packaging material. No significant effect on carotenoid degradation was found for dry milling, either by rotor mill or freezer mill, but the formation of volatile compounds was significantly $(\mathrm{P}<0.05)$ affected. Volatile compounds such as hexanal, 2-pentylfuran, 1-propanol, 2-heptanone, butyrolactone, limonene and hexanoic acid were found in different proportions after milling. The highest concentration of hexanal was in flour milled by rotor mill or freezer mill, and stored in laminated paper bags at $37^{\circ} \mathrm{C}$ after 180 days, while the lowest concentrations were for flour in aluminium bags and double-layered polyethylene bags stored at $4^{\circ} \mathrm{C}$. Maize flour stored in double-layered polyethylene bags had the highest carotenoid retention and aroma stability. Importantly, the use of these bags is economically feasible for use in low-income countries. Overall, our results show that effective control of storage conditions is crucial to prevent carotenoid loss and decrease off-odour formation.
\end{abstract}

Key Words: Carotenoids; biofortified maize; provitamin A; volatile aroma compounds; Africa 


\subsubsection{Introduction}

Vitamin A deficiency (VAD) is a nutritional disorder caused by lack of Vitamin A intake. Globally, one-third of children under 5 years are affected by VAD with $48 \%$ living in Sub-Saharan Africa (SSA).[1] VAD results in preventable vision loss, poor growth, and a vulnerable immune system, potentially leading to an increased risk of infections and premature death. Dependence on starch-dense crops as major food source, such as white maize, which contain no retinol activity is the major cause of VAD in SSA. Due to the severity of VAD, biofortification of key staple crops such as maize, cassava and sweet potatoes is applied to alleviate the problem. ${ }^{[2]}$ More than 30 biofortified maize varieties have been developed through conventional breeding and released in SSA.[3] Biofortified maize is rich in provitamin $A$ carotenoids such as $\alpha$-carotene, $\beta$-carotene and $\beta$-cryptoxanthin in addition to elevated contents of the non-provitamin $A$ carotenoids such as zeaxanthin and lutein. ${ }^{[4]}$

The consumption of biofortified maize enhances the vitamin A status of children in SSA. However, carotenoids are partially degraded during post-harvest handling, i.e. storage, processing and cooking. [5] The rate of carotenoid reduction has been associated with the presence of oxygen, heat, light, enzymatic and non-enzymatic factors, which can be controlled through the improvement of post-harvest conditions. ${ }^{[4]}$ The degradation rate of carotenoids is influenced by the packaging material, the storage conditions and processing methods. For instance, Burt et al. [6], Sowa et al. [7] and Simpungwe et al. ${ }^{[8]}$ found 50 to $65 \%$ carotenoid loss after 4 to 6 months under traditional storage conditions, showing a significant reduction in the nutritional quality of biofortified maize.

Besides the nutritional concern related to carotenoid loss, the sensory quality of biofortified maize can be affected during post-harvest storage by changes in the profile of the volatile organic compounds (VOCs). VOCs play an important role in the sensory perception of food, having a major impact on food appreciation and acceptance by consumers. The germ of maize is rich in unsaturated fats, which is predisposed to rancidity under storage and processing conditions, resulting in an unpleasant taste and aroma. ${ }^{[9]}$ The oxidation products are mostly VOCs, which are associated with offodour. ${ }^{[9]}$ Changes in VOCs of maize flour during milling, storage and processing could contribute to the poor consumer acceptance of biofortified maize as some consumers perceived the smell to be disagreeable.[10] To date, no information on VOC stability or changes during storage and processing of provitamin A biofortified maize is available. Post-harvest handling must be optimized to increase acceptance, thus improving the impact on the target population. 
The study assessed carotenoid retention and changes in VOCs during six months storage under different conditions using different milling methods, packaging materials and temperature conditions.

\subsubsection{Materials and methods}

\subsubsection{Chemicals and standards}

Extraction and HPLC solvents, i.e. absolute ethanol, butylhydroxytoluene, potassium hydroxide, hexane, ammonium acetate, methanol, 2-dichloroethane and methyl-t-butylether, were obtained from Sigma-Aldrich Chemie BV, Zwijndrecht, The Netherlands. The standards $\beta$-carotene, $\beta$-cryptoxanthin, lutein, zeaxanthin and $\beta$-apo- 8 -carotenal were obtained from Sigma-Aldrich Chemie BV, Zwijndrecht, The Netherlands and CaroteNature, Switzerland and used for carotenoid identification, calibration curves and determination of extraction efficiency. For VOC identification, C7-C40 saturated alkanes and hexanal were obtained from Merck KGaA, Darmstadt, Germany.

\subsubsection{Biofortified provitamin A maize, milling and storage}

Orange maize variety Pool 8A (at $<11 \%$ grain moisture) was obtained from the Rwanda Agriculture Board. Maize kernels were milled using two different machines, namely a freezer mill (FM) at low heat $\left(<150^{\circ} \mathrm{C}\right.$ ) (SPEX samplePrep 6875 freezer/Mill, Metuchen, USA), and a rotor mill $(\mathrm{RM})$ at $20,000 \mathrm{rpm}$ with frictional heat $\left(>60^{\circ} \mathrm{C}\right)$ (Pulverisette 14, Fritsch International; Idar-Obenstein, Germany). Three different packaging materials (i.e. aluminium pouches, laminated paper bags and double-layered polyethylene bags), commonly used to store food products, were tested. The doublelayered polyethylene bag contained two liners folded and sealed separately. Equal samples $(10 \mathrm{~g})$ of maize flour were packed in the three types of bags, sealed airtight and stored at $4{ }^{\circ} \mathrm{C}$ in a laboratory refrigerator and at $37^{\circ} \mathrm{C}$ in laboratory incubators, figure 5.1. Samples were analysed for carotenoid content at intervals of $0,10,20,30,60,90$, 120, 150 and 180 days to cover a six-month storage period. Moisture content was determined by the American Association of Cereal Chemistry (AACC) method 44-15A. Samples were stored at $-20^{\circ} \mathrm{C}$ until analysis. 


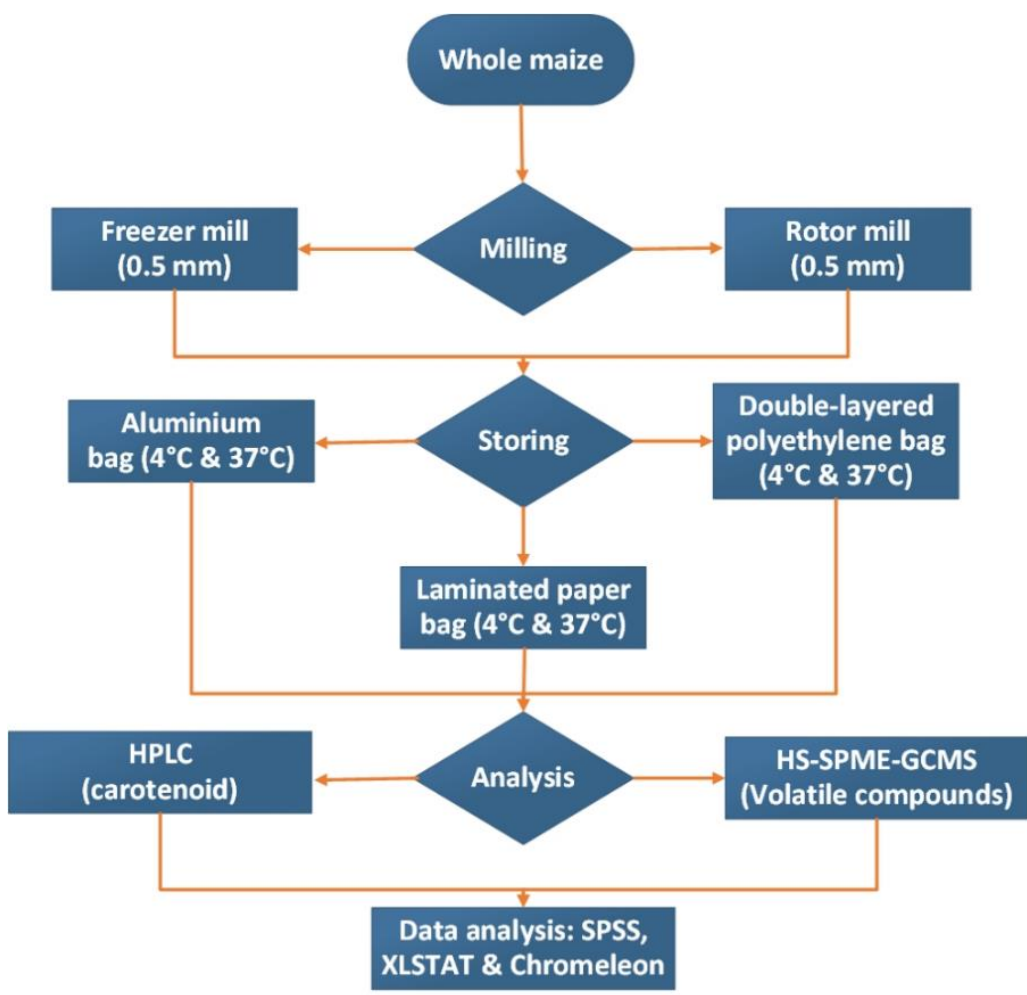

Figure 5.1: Sampling and experimental scheme of the maize flour storage study. Samples were taken for analysis at an intervals of $0,10,20,30,60,90,120,150$ and 180 days.

\subsubsection{Carotenoid extraction and quantification by HPLC}

Carotenoid extraction was according to Rosales et al. [11]. Briefly, $600 \mathrm{mg}$ sample was precipitated for 5 min using $6 \mathrm{~mL}$ ethanol (containing $0.1 \%$ butylated hydroxytoluene) at $85^{\circ} \mathrm{C}$ in a water bath before saponification with $500 \mu \mathrm{L} 80 \%$ (w/v) $\mathrm{KOH}$ solution during $10 \mathrm{~min}$. After saponification, samples were immediately placed in ice followed by addition of $3 \mathrm{~mL}$ of cold deionized water. Carotenoids were extracted 3 times with $3 \mathrm{~mL}$ of hexane by centrifugation at 3,000 rpm for approximately $10 \mathrm{~min}$. The combined hexane layers were dried by vacuum evaporator at $60^{\circ} \mathrm{C}$ and $335 \mathrm{mmHg}$. The extract was resuspended in $2 \mathrm{~mL}$ 50:50 methanol:dichloroethane (v/v). Carotenoid extractions and analyses were all performed under red light to prevent degradation. The resuspension was filtered using $0.25 \mu \mathrm{m}$. Next, $20 \mu \mathrm{L}$ of the sample was injected into the Thermo Scientific Dionex UltiMate 3000 HPLC system equipped with a photodiode array detector (Thermo Fisher Scientific, Amsterdam, The Netherlands). The separation 
was performed using a YMC30 $4.6 \mathrm{~mm} \times 250 \mathrm{~mm}$ with $5 \mu \mathrm{m}$ particle size (YMC Europe GmbH, Dinslaken, Germany).

\subsubsection{Aroma compounds analysis by GC-MS}

Maize flour was analysed using a Stabilwax DA capillary column (30 m x 0.25 mm ID x $0.25 \mu \mathrm{m}$ ) and SPME fibre assembly DVB/CAR/PDMS (Supelco, Bellefonte, USA). An internal standard, viz. perfluorotributylamine (PFTBA, FC43; Thermo Fisher Scientific Inc., Waltham, USA), was used to calibrate the HS-SPME GC-MS every two weeks. Maize flour (1 g) was placed in a $10 \mathrm{~mL}$ glass bottle with crimp caps and incubated for $10 \mathrm{~min}$ at $40^{\circ} \mathrm{C}$. The fibre was automatically injected into the injector port of the GC-MS and desorbed for $10 \mathrm{~min}$. The oven temperature was set at $40^{\circ} \mathrm{C}$ for 2 min, increased at $10^{\circ} \mathrm{C} \mathrm{min}^{-1}$ to $200^{\circ} \mathrm{C}$ and then fixed at $200^{\circ} \mathrm{C}$ for $5 \mathrm{~min}$. Split injection was used as the injection method at $225^{\circ} \mathrm{C}$, split ratio 19:1. Helium carrier gas with a flow rate of $1 \mathrm{~mL} \mathrm{~min}^{-1}$ was used. Each analysis was performed in triplicate.

\subsubsection{Data analysis}

The raw data from the HPLC and GC-MS were reprocessed by Thermo Scientific Dionex Chromeleon ${ }^{\circledR} 7.2$ chromatography data system (CDS) software before further analysis in XLSTAT version 2020.1.1.54525 and IBM SPSS $®$ software version 23, using the Tukey test for pairwise comparison. The aroma compounds were identified by comparing their mass spectra with the National Institute of Standards and Technology (NIST) database, retention indexes from literature as well as the retention time of the standards. For volatile compound quantification, maize flour spiked with a stock solution (hexanal) was used to obtain a calibration curve. Carotenoid peaks were identified by comparing the UV spectra of compounds with literature Muzhingi et al. [12] and the retention times of pure carotenoid standards. Provitamin A was calculated as all-trans $\beta C+(1 / 2)$ ( $\beta$-cryptoxanthin). The total carotenoid content was calculated as the sum of all carotenoids (zeaxanthin + lutein $+\beta$-cryptoxanthin $+\beta$-carotene). The extraction efficiency was calculated based on $\beta$-apo- $8{ }^{-}$-carotenal and moisture content to express concentration on weight basis.

\subsubsection{Results and discussion}

\subsubsection{Carotenoid content of biofortified maize}

The carotenoid content of biofortified maize flour processed using two different milling methods is reported in table 5.1. The main carotenoids were lutein, zeaxanthin, $\beta$ cryptoxanthin and $\beta$-carotene. The total carotenoid content of biofortified maize was $23.8 \pm 3.7 \mu \mathrm{g} / \mathrm{g}$ with $\beta$-cryptoxanthin and zeaxanthin as the major carotenoids, i.e. 8.2 and $9.2 \mu \mathrm{g} / \mathrm{g}$, respectively. Carotenoid loss was between 11 to $12 \%$ for milling in the rotor mill. 
Table 5.1: Carotenoid content $(\mu \mathrm{g} / \mathrm{g} \text { dry weight })^{*}$ of freezer-milled and rotor-milled maize flour of biofortified variety Pool 8A grown in Rwanda.

\begin{tabular}{ccccccc}
\hline & $\boldsymbol{\beta C}$ & $\boldsymbol{\beta C X}$ & ZEA & LUT & PVAC & TCC \\
\hline Freezer mill & $1.09 \pm 0.28^{\mathrm{a}}$ & $8.27 \pm 0.11^{\mathrm{a}}$ & $9.21 \pm 2.17^{\mathrm{a}}$ & $5.19 \pm 1.3^{\mathrm{a}}$ & $5.23 \pm 0.25^{\mathrm{a}}$ & $23.76 \pm 3.65^{\mathrm{a}}$ \\
Rotor mill & $0.96 \pm 0.22^{\mathrm{a}}$ & $7.27 \pm 0.52^{\mathrm{a}}$ & $8.20 \pm 0.78^{\mathrm{a}}$ & $4.55 \pm 0.05^{\mathrm{a}}$ & $4.60 \pm 0.04^{\mathrm{b}}$ & $20.99 \pm 0.93^{\mathrm{a}}$ \\
$\%$ loss** & 11.93 & 12.09 & 10.97 & 12.33 & 12.05 & 11.66 \\
\hline
\end{tabular}

$* \overline{\text { Different superscript letters indicate significant differences within columns (Tukey; } \mathrm{p}<0.05) \text {. Values }}$ are mean \pm standard deviation of triplicates. $\beta \mathrm{C}=\beta$-carotene, $\beta \mathrm{CX}=\beta$-cryptoxanthin, $\mathrm{ZEA}=$ zeaxanthin, LUT $=$ lutein; PVAC $=$ provitamin $A$ carotenoids and TCC $=$ Total carotenoid content.

**The percentage of carotenoid loss due to frictional heat in the rotor mill.

Zeaxanthin and $\beta$-cryptoxanthin accounted for $73.6 \%$ of the total carotenoids. Total carotenoid contents in this study are comparable to the results of Mugode et al. ${ }^{[13]}$ and Taleon et al. ${ }^{[4]}$, who reported a range of 12.8 to $30.8 \mu \mathrm{g} / \mathrm{g}$ dry weight. Similarly, Ortiz et al. ${ }^{[14]}$ reported zeaxanthin as the predominant carotenoid (37.9 to 61.3\%) in nine maize genotypes. Provitamin A carotenoids accounted for $22.0 \%$ of the carotenoids present in biofortified maize. The amount of provitamin A carotenoid is within the range of 0.6 to $12.7 \mu \mathrm{g} / \mathrm{g}(17.4 \%$ to $26.9 \%)$ reported by Rosales et al. ${ }^{[11]}$. Note that the values of the $\beta$-carotene isomers - 15-cis-, 13-cis- and 9-cis - were not included in the provitamin A carotenoid data presented. The isomers - 15-cis-, 13-cis- and 9-cis- $\beta$-carotene in biofortified maize were found in the range 0.4 to $1.4 \mu \mathrm{g} / \mathrm{g}, 0.1$ to $1.2 \mu \mathrm{g} / \mathrm{g}$ and 0.3 to $2.2 \mu \mathrm{g} / \mathrm{g}$, respectively, which corroborate the low values of provitamin A carotenoids obtained in the current study. [4, 14] Mugode et al. [13] and Pixley et al. [3] reported $\beta$ cryptoxanthin to be twofold higher than $\beta$-carotene, but a much higher $\beta$-cryptoxanthin amount of about sevenfold was found in the present study. Varietal differences in carotenoid content of biofortified maize have been widely reported in literature. $[3,4,11$ 13,15] Besides, differences in the carotenoid content due to postharvest handling, milling method, extraction and chromatographic separation techniques could also have contributed to the differences in data. Regarding the current experiment, sun-drying was applied in Rwanda before sampling. This could have reduced the carotenoid content before our experimental treatments. For instance, sundried carotenoid-rich sweet potato was reported to have a carotenoid retention of 66 to $67 \%$ [16], and an even more severe loss occurred at a lower relative humidity. ${ }^{[14]}$ Furthermore, other maize genotypes have been used in previous studies, which might also explain the differences in carotenoid profiles. Varieties with high $\beta$-carotene and $\beta$-cryptoxanthin are desirable for VAD affected regions due to the retinol and antioxidant activity. Although $\beta$ cryptoxanthin is usually present in higher amounts in biofortified maize, it has a $50 \%$ lower retinol activity equivalent (RAE) than $\beta$-carotene, i.e. the Institute of Medicine (IOM) ${ }^{[17]}$ set a default value of $12 \mu \mathrm{g} / \mathrm{g} \beta$-carotene and $24 \mu \mathrm{g} / \mathrm{g} \beta$-cryptoxanthin for 1 RAE. Better bioequivalence factors have been found for biofortified maize by Li et al. ${ }^{[18]}$ and Muzhingi et al. ${ }^{[19]}$. In general, the provitamin A carotenoid content of the tested 
variety was low compared to the global biofortified breeding target of $15 \mu \mathrm{g} / \mathrm{g}$, which was established to provide $50 \%$ of the Estimated Average Requirement (EAR) of vitamin A, particularly for vulnerable groups such as preschool children.[20]

No significant difference $(\mathrm{p}<0.05)$ for the two milling methods was found in lutein, zeaxanthin, $\beta$-cryptoxanthin, $\beta$-carotene and the total carotenoid content, even though they differed in heat production (absence of heat for the freezer mill and presence of heat for the rotor mill). The $\beta$-cryptoxanthin value in RM flour was slightly lower than in FM flour but not significantly. This agrees with the report of Mugode et al. [13], which indicated that $\beta$-cryptoxanthin is stable during milling. However, the provitamin A carotenoid content showed a significant difference $(p<0.05)$, signifying that the milling method affected the provitamin A retention in maize. Milling has been reported to have different effects on the carotenoid profile. Mugode et al. ${ }^{[13]}$ found $60 \%$ retention for $\beta$ cryptoxanthin, while Pillay et al. [21] reported a retention of 118.9 to $137.2 \%$ of $\beta$ cryptoxanthin in milled maize. In general, the carotenoid loss in the current study could be attributed to the effect of frictional heat, light and oxygen exposure during milling in the rotor mill. However, since no significant difference $(p<0.05)$ was found for the milling method, other factors during postharvest handling, especially the storage conditions, appear to be more important as reported in the next paragraph.

\subsubsection{Carotenoid retention during storage}

The total carotenoid content and provitamin A carotenoid content are presented in figure 5.2, table 5.S1 and table 5.S2. Carotenoid retention after 180 days of storage in aluminium, laminated paper and double-layered polyethylene bags at $4^{\circ} \mathrm{C}$ and $37^{\circ} \mathrm{C}$ was determined to assess the stability. The total carotenoid content of FM maize flour stored at $4^{\circ} \mathrm{C}$ was 13.5 to $17.1 \mu \mathrm{g} / \mathrm{g} \mathrm{DW}$ after 180 days, which is equivalent to a retention index of 53 to $73 \%$. At $37^{\circ} \mathrm{C}$ a range of 4.1 to $10.8 \mu \mathrm{g} / \mathrm{g}$ DW, which is equal to a retention index of 16 to $42 \%$, was found. The lowest total carotenoid content was in laminated paper bags at $37^{\circ} \mathrm{C}(16 \%$ retention). The laminated paper bags had the highest oxygen permeability of the three tested materials, thus autoxidation coupled with temperature triggered a significant loss in total carotenoid content over time. Considerable degradation of carotenoids in maize during grain and flour storage has been reported. $[4$, 13] Bechoff et al. [16] suggested that oxygen is the main cause of $\beta$-carotene degradation in the high carotenoid crop. Ortiz et al. ${ }^{[14]}$ reported 55 to $76 \%$ retention of total carotenoid content in three maize varieties after 90 days of storage, suggesting the likelihood of even more degradation after 180 days and proving that varietal differences affect the stability of carotenoids. Other authors reported similar trends. ${ }^{4,13]}$ Generally, the double-layered polyethylene bags showed better retention, followed by the aluminium bags. Taleon et al. ${ }^{[4]}$ observed that aluminium pouches with oxygen absorber 
had better retention than double-layered polyethylene bags during the storage of biofortified maize grain. However, in the present study, no oxygen scavenger or vacuum condition was used. The high retention of double-layered polyethylene bags was due to better barrier properties resulting from the double liners, which decreased oxygen and light penetration through the package. Although aluminium and double-layered polyethylene bags preserved the carotenoids better, the air trapped in the bags during sealing might have contributed to the reported degradation. However, vacuum packaging is not a guarantee for preserving carotenoids: a study found that provitamin A rich cassava flour stored under vacuum had a higher loss of carotenoids than without vacuum. ${ }^{[22]}$ Besides, packaging materials that can hold vacuum are very expensive for the targeted smallholder farmers and resource-poor households. Double-layered polyethylene bags have been proposed as a cheaper alternative to reduce maize grain loss during storage in Africa.[23]

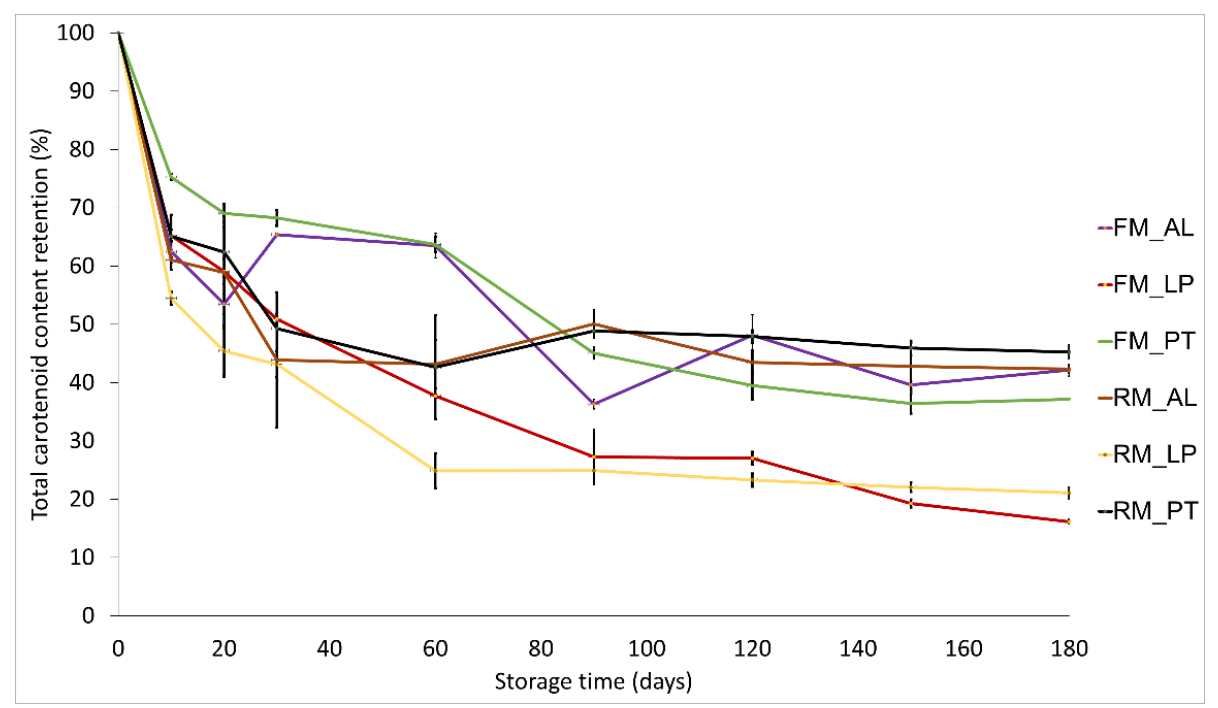

Figure 5.2: Effect of storage method on total carotenoid content (TCC) retention in maize milled with freezer mill (FM) and rotor mill (RM) using different packaging materials for 180 days at $37^{\circ} \mathrm{C}$. AL Aluminium, LP - laminated pap, PT - Double layered polyethylene. 
For both FM and RM flour, samples stored in aluminium, laminated paper and doublelayered polyethylene bags differed significantly $(<0.01)$ in total carotenoid content between $4^{\circ} \mathrm{C}$ and $37^{\circ} \mathrm{C}$. However, no significant differences were found within either storage temperature, except for flour in the laminated paper bag at $37^{\circ} \mathrm{C}$ that showed a higher loss in carotenoids. Regarding storage temperature, our results show that storage at $4^{\circ} \mathrm{C}$ improves provitamin $\mathrm{A}$ and total carotenoid retention. The same was observed for biofortified maize samples stored at $4^{\circ} \mathrm{C}$ and $55^{\circ} \mathrm{C}$ in the study of Ortiz et al. [14]. Similarly, Sowa et al. ${ }^{17]}$ showed that storage at $-22^{\circ} \mathrm{C}$ stopped degradation almost completely. Temperature is known to speed up deterioration reactions such as oxidation, which is why it was anticipated that a lower storage temperature would retain carotenoids better. FM flour (from a cryogenic mill) was expected to be more stable during storage because of a lower exposure to heat during milling but this effect was not found. A possible explanation is that the endogenous enzymes in the kernel were not inactivated during freezer milling, resulting in enzymatically induced oxidation of the carotenoids during storage. Destruction of cell membranes during milling inactivates antioxidants and improves the availability of oxidation reactants ${ }^{24]}$, which might explain the instability of FM flour immediately after milling.

Table 5.S1 and 5.S2 show the retention of $\beta$-carotene and $\beta$-cryptoxanthin during storage for 180 days at different temperatures in different materials. Significant differences in degradation during storage were observed across packaging materials, temperature and flour type, especially in samples stored at $37^{\circ} \mathrm{C}$. High $\beta$-carotene variability was detected in all packaging materials at $37^{\circ} \mathrm{C}$, indicating poor stability during storage, while at $4^{\circ} \mathrm{C}$ a better stability was observed.

For FM flour, the lowest retention of $\beta$-carotene was $13 \%$ in laminated paper bags at $37^{\circ} \mathrm{C}$ (table 5.S2) and the highest retention was $79 \%$ in double-layered polyethylene bags at $4^{\circ} \mathrm{C}$, table 5.S1. A similar trend was observed in RM flour. Sowa et al. [7] reported a high loss of $\beta$-carotene (up to $95 \%$ ) in maize flour stored at $37^{\circ} \mathrm{C}$ for 12 months. The extent of the loss was reported to depend on genotype. Therefore, aside from processing and storage conditions, genotypes with better carotenoid stability should be targeted during crop breeding. Besides, as tropical temperatures are detrimental to carotenoid retention, prolonged storage should be avoided as much as possible.

Table 5.S1 and 5.S2 show the retention of non-provitamin A carotenoids such as lutein and zeaxanthin during storage for 180 days at different temperatures in different materials. Generally, a high retention of both carotenoids was found at $4^{\circ} \mathrm{C}$, but at $37^{\circ} \mathrm{C}$, all samples showed a significant decrease in retention. Laminated paper bags retained only $21 \%$ of zeaxanthin and $17 \%$ of lutein. Sowa et al. ${ }^{[7]}$ reported a similar trend with 
about $10 \%$ retention after 12 months of storage. Overall, these results confirm that the storage of maize flour could have both linear and quadratic degradation kinetics depending on the storage conditions and duration. Other workers have established that carotenoids are better preserved when maize is stored as kernels than when it is stored as flour. ${ }^{[4,14]}$ Consequently, milling just before consumption may result in a higher carotenoid content.

\subsubsection{Volatiles and off-odour production}

Table 5.2 shows the concentrations of VOCs found in the maize flour after milling with the freezer mill (FM) and the rotor mill (RM). Of the 26 volatiles detected, there were six aldehydes (hexanal, heptanal, octanal, nonanal, 2-octenal and 2-heptenal), two aromatics (benzaldehyde and 2-pentylfuran), five alcohols (ethanol, 1-propanol, 1pentanol, 1-hexanol and 1-Methoxy-2-propanol), five ketones (2-heptanone, 2octanone, 6-methyl-5-heptene-2-one, butyrolactone, 3-octen-2-one), one monoterpene (limonene) and three acids (acetic acid, pentanoic acid and hexanoic acid). Similar lists of compounds have been found for sweet maize, millet, rice and barley.[25-27] Compounds in the alcohol group had the highest total concentration (1491 to 2157 $\mu \mathrm{g} / \mathrm{kg}$ ). The aldehydes ranged from 81 to $94 \mu \mathrm{g} / \mathrm{kg}$. Annan et al. ${ }^{[28]}$ reported higher concentrations of aldehydes in raw maize, i.e. $400 \mu \mathrm{g} / \mathrm{kg}$ and $7400 \mu \mathrm{g} / \mathrm{kg}$ of 2 -nonenal and heptanal, respectively. The authors found four times lower concentrations of alcohols such as 1-pentanol and 1-hexanol compared to the current study. A range of 10 to $90 \mu \mathrm{g} / \mathrm{kg}$ of benzaldehyde was found in maize extruded at different temperatures and with different moisture contents. ${ }^{[29]}$ Generally, studies on maize VOCs are scanty, and the ones available ${ }^{[30-32]}$ used peak area for quantification, which makes those results uncomparable to our current findings.

From all the compounds found, hexanal was selected for further investigation because it has been used extensively to determine the level of rancidity or off-odours in cereals. ${ }^{[3-35]}$ Besides, focusing on one compound gives an in-depth understanding as monitoring trends of formation and degradation of VOCs is complex. Aldehydes and ketones are derived from lipid oxidation, and therefore useful to assess the deterioration of maize flour aroma. 
Table 5.2: Concentrations of volatiles in maize milled with a freezer mill and a rotor mill $(\mu \mathrm{g} / \mathrm{kg})$

\begin{tabular}{|c|c|c|c|}
\hline \multirow{2}{*}{$\begin{array}{l}\text { Volatile organic } \\
\text { compounds }\end{array}$} & $\begin{array}{c}\text { Freezer milled } \\
\text { flour }\end{array}$ & $\begin{array}{c}\text { Rotor milled } \\
\text { flour }\end{array}$ & \multirow[t]{2}{*}{ Odour description* } \\
\hline & \multicolumn{2}{|c|}{$(\mu \mathrm{g} / \mathrm{kg}$, mean $\pm \mathrm{SD})$} & \\
\hline Octane & $92.13 \pm 1.97$ & $81.62 \pm 0.49$ & alkane, fat, oil, sweet \\
\hline Decane & $340.22 \pm 10.32$ & $104.04 \pm 3.48$ & fusel-like, fruit, sweet \\
\hline Tridecane & $194.11 \pm 20.81$ & $86.19 \pm 1.73$ & alkane \\
\hline Tetrahydrofuran & $347.51 \pm 16.27$ & $414.28 \pm 14.70$ & floral, fruit \\
\hline Hexanal & $84.74 \pm 0.28$ & $92.1 \pm 1.80$ & grass, fat, herbal \\
\hline Heptanal & $93.29 \pm 1.08$ & $81.19 \pm 0.14$ & citrus, dry fish, fat, green \\
\hline Octanal & $83.56 \pm 0.23$ & $81.47 \pm 0.37$ & fat, soap, lemon, green \\
\hline Nonanal & $89.5 \pm 3.07$ & $83.48 \pm 0.52$ & fat, citrus, green, wax, \\
\hline 2-Octenal & $81.14 \pm 0.13$ & $80.96 \pm 0.02$ & green, nut, fat \\
\hline 2-Heptenal & $81.82 \pm 0.16$ & $80.94 \pm 0.01$ & fat, citrus, rancid \\
\hline Benzaldehyde & $87.7 \pm 2.88$ & $82.14 \pm 0.35$ & almond, burnt sugar \\
\hline 2-pentyl-Furan & $86.28 \pm 0.59$ & $82.22 \pm 0.61$ & green bean, butter \\
\hline Ethanol & $770.08 \pm 10.25$ & $1149.1 \pm 88.57$ & alcohol, floral, apple, sweet \\
\hline 1-Propanol & $81.11 \pm 0.08$ & $85.23 \pm 0.25$ & candy, must, pungent, fruit \\
\hline 1-Pentanol & $87.05 \pm 2.32$ & $88.01 \pm 0.45$ & balsamic, fruit, green, yeast \\
\hline 1-Hexanol & $115.71 \pm 2.47$ & $109.27 \pm 3.96$ & resin, flower, green \\
\hline 1-Methoxy-2-propanol & $437.93 \pm 3.02$ & $726.38 \pm 85.38$ & fruit \\
\hline 2-Heptanone & $150.44 \pm 5.83$ & $89.92 \pm 3.13$ & blue cheese, cinnamon, nut \\
\hline Limonene & $84.35 \pm 0.88$ & $85.78 \pm 0.81$ & balsamic, citrus, fruit, herb \\
\hline 2-Octanone & $89.74 \pm 0.42$ & $82.73 \pm 0.48$ & herb, butter, resin \\
\hline 6-Methyl-5-heptene-2-one & $86.35 \pm 0.67$ & $85.98 \pm 0.36$ & metal \\
\hline Butyrolactone & $192.31 \pm 62.9$ & $86.18 \pm 0.25$ & caramel, sweet \\
\hline 3-Octen-2-one & $81.76 \pm 0.49$ & $80.98 \pm 0.00$ & herb, butter, resin \\
\hline Acetic acid & $112.64 \pm 8.09$ & $99.83 \pm 0.58$ & fruit, pungent, sour, vinegar \\
\hline Pentanoic acid & $94.86 \pm 3.77$ & $82.53 \pm 0.32$ & sweat \\
\hline Hexanoic acid & $83.94 \pm 1.02$ & $81.91 \pm 0.70$ & sweat, cheese \\
\hline
\end{tabular}

*www.flavornet.org and www.vcf-online.nl

Figure 5.3 shows that RM flour had a significantly different $(p<0.05)$ hexanal content of $92 \mu \mathrm{g} / \mathrm{kg}$ compared to $85 \mu \mathrm{g} / \mathrm{kg}$ in FM flour. The latter was produced at a temperature below $-150^{\circ} \mathrm{C}$. The amount of hexanal in FM might have been present in the kernel before milling. The heat $\left(>60^{\circ} \mathrm{C}\right)$ produced by the rotor mill during milling of the kernel is the key reason for the $8 \%$ increase in hexanal production. However, heat production during milling could be of advantage during storage as it may inactivate the endogenous lipase enzyme, whereas in the cryogenic mill the preserved endogenous enzyme could be activated during storage leading to a product more susceptible to degradation. On the other hand, heat can also expose the maize flour to non-enzymatic oxidation. [36] Lampi et al. [36] reported that an extrusion temperature of $70^{\circ} \mathrm{C}$ was 
sufficient to deactivate lipase enzymes in oats to give a stable product while a higher temperature could result in non-enzymatic lipid oxidation.

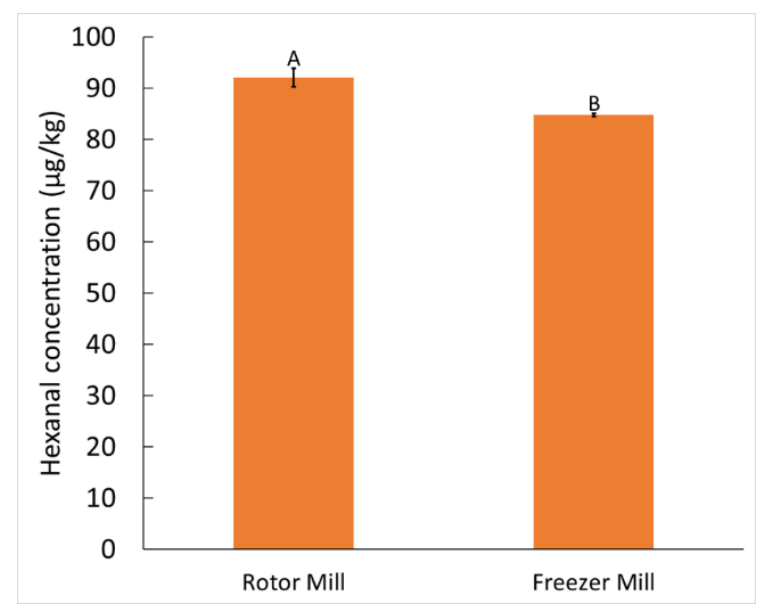

Figure 5.3:Hexanal production during milling of maize using rotor mill $(\mathrm{RM})$ and freezer mill $(\mathrm{FM})$. Bar with different letter are significantly different $(\mathrm{n}=3, \mathrm{P}<0.05)$.

Figure 5.4 shows the hexanal content of maize flour stored with different packaging materials at $37^{\circ} \mathrm{C}$ for 180 days. The highest amount of hexanal found in this study was in RM and FM maize flour stored in laminated paper bags at $37^{\circ} \mathrm{C}$, namely $2429 \mu \mathrm{g} / \mathrm{kg}$ on day 150 and $2493 \mu \mathrm{g} / \mathrm{kg}$ on day 180, respectively. In both cases, significant hexanal production started after 60 days and continued to increase until 180 days of storage. Hexanal in all maize flours stored at $4^{\circ} \mathrm{C}$ (excluded in the chart) was below $100 \mu \mathrm{g} / \mathrm{kg}$ and showed no significant differences throughout the 180 days storage period. In all bags, suppression of hexanal production in both FM and RM flours at low temperature $\left(4^{\circ} \mathrm{C}\right)$ was detected, thus differences at $4^{\circ} \mathrm{C}$ between the packaging materials was insignificant. The suppression of hexanal formation during storage at $4^{\circ} \mathrm{C}$ is due to the inhibition of the lipid oxidation process. The temperature and nature of packaging material significantly reduced the hexanal formation. This effect is seen for both milling methods but is more obvious in samples stored in laminated paper bags. Considering the packaging materials, the most evident difference was observed at $37^{\circ} \mathrm{C}$ between laminated paper bag samples compared to aluminium and double-layered polyethylene bag samples. Understanding the volatile degradation at $37^{\circ} \mathrm{C}$ was relevant because cold storage is not applicable in the daily practice of the relevant populations. 


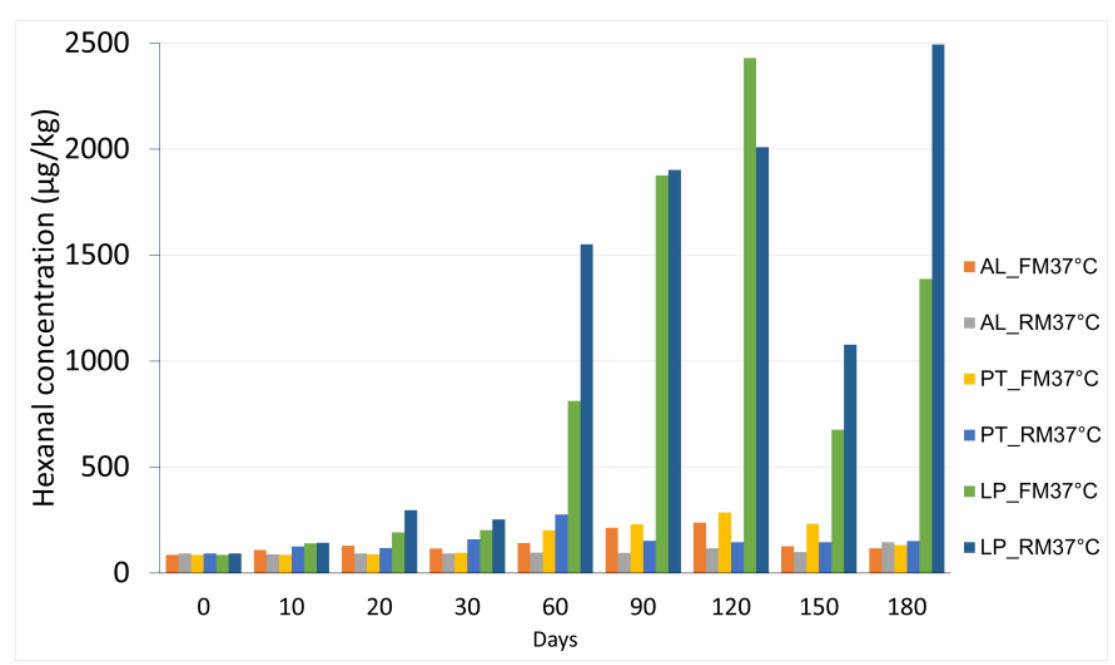

Figure 5.4: Hexanal production in maize milled with a freezer mill (FM) and rotor mill (RM) stored using different packaging materials for 180 days at $37^{\circ} \mathrm{C}$. AL - Aluminium, LP laminated paper, PT - Double layered polyethylene.

Annan et al. [28] found $5000 \mu \mathrm{g} / \mathrm{kg}$ hexanal in whole maize kernel obtained from a retail outlet in Ghana. While the authors do not mention the duration of storage at room temperature $\left(30^{\circ} \mathrm{C}\right)$ before analysis, the reported hexanal value is twice as high as in our maize flour samples stored at $37^{\circ} \mathrm{C}$ for 180 days. Bredie et al. ${ }^{[29]}$ reported a range of 9 to $170 \mu \mathrm{g} / \mathrm{kg}$ of hexanal in extruded maize, which corresponds to the values for maize flour stored for 180 days in aluminium bags and double-layered polyethylene bags in the current research.

Compared to RM flour, the hexanal production was generally high in FM flour, except when stored in laminated paper bags. Increases in hexanal and heptanal were reported in rice during storage at $35^{\circ} \mathrm{C}$, causing the development of a stale flavour. ${ }^{[37]}$ The author suggested that lipoxygenase-3 enzyme contributed to aldehyde production after detecting an increased activity of the enzyme. Hexanal, heptanal, octanal, nonanal, and 2-heptanone have been evaluated in other studies regarding flavour deterioration in oats, wheat and whey powder. ${ }^{[34,38,39]}$ Aldehydes have a low flavour threshold value in water, making them very important flavour compounds. Their aromas have been reported to be grassy, fatty, fishy, citrus, rancid and musty.[34] Heiniö et al. [33] reported that hexanal was perceived as a rancid flavour in oats. Rancidity is caused by lipid oxidation, which can be accelerated by light, heat, presence of moisture, but most importantly the presence of oxygen. ${ }^{34,40]}$ This implies that the low hexanal formation in the samples stored in the aluminium bags and double-layered polyethylene bags was due to the low oxygen permeability of the packaging materials. Samples stored in 
laminated paper bags at $37^{\circ} \mathrm{C}$ showed a steady increase in hexanal due to the higher oxygen permeability of these bags. FM samples had higher hexanal after storage compared to RM. Milling at freezing temperature leaves the endogenous enzymes intact, thereby catalysing deterioration upon activation at a higher storage temperature. Therefore, thermal deactivation of the oxidative enzymes during milling in RM was beneficial to aroma stability during storage.

Furthermore, VOCs in maize can be derived from non-volatile precursors such as polyphenols, carotenoids, unsaturated fatty acids, sugars and amino acids through autoxidation, thermal breakdown and enzymatic reactions. Volatile degradation products from carotenoids, such as damascenone, geranylactone, 6-methyl-5-hepten-2one and -ionones, were not found in this study. ${ }^{[41,42]}$ However, oxidative degradation of carotenoids together with lipoxidase can result in the development of off-odour compounds. ${ }^{[41]}$ Carotenoid-based volatiles can contribute to aroma changes if present above the threshold values. Future studies should try to track the presence of these products to ascertain the by-products of carotenoid degradation in biofortified maize. This is important since studies up till now have focused mainly on enzyme-dependent degradation of unsaturated fatty acids, even with evidence showing that carotenoidbased changes may affect aroma profile. ${ }^{[41,42]}$

Rotor and hammer mills seem suitable and feasible for maize milling in SSA; the type of storage material and the storage temperature play a more important role in the preservation of maize aroma. Double layered polyethylene is a feasible material for storing maize due to a proper stability of carotenoids (table 5.S1 and 5.S2) and VOCs (Figure 5.4). However, the polyethylene bags pose environmental challenges. Many African countries have banned or reduced the use of plastics bags for this reason. ${ }^{[43]}$ Biodegradable plastic could be a solution only if cost-effective for smallholder farmers and resource-poor households. 


\section{Conclusion}

This study assessed the stability of carotenoids during milling and storage of provitamin A biofortified maize variety Pool $8 \mathrm{~A}$. We found $\beta$-carotene, $\beta$-cryptoxanthin, zeaxanthin, and lutein within the range reported by previous studies. No difference in carotenoid retention was detected after milling with rotor mill and freezer mill but substantial differences were observed in both flours during storage. Temperature plays an important role in carotenoid retention during postharvest storage since a rapid loss was observed at $37^{\circ} \mathrm{C}$. Our findings stress the need to pay more attention to postharvest handling to retain carotenoids in end products. Storage of maize flour in laminated paper bags showed the worst carotenoid retention while double-layered polyethylene and aluminium bags showed improved retention. Milling method influenced the formation of off-odour. Hexanal production was significantly high in laminated paper bags at $37^{\circ} \mathrm{C}$ while lower temperature suppressed the formation. Hexanal was least formed in aluminium bags, followed by polyethylene bags and laminated paper bags. The rate of carotenoid degradation and formation of sensory defects can be mitigated through the improvement of postharvest handling practices, thereby enhancing food security and consumer acceptance of provitamin A biofortified maize. 


\section{Reference}

1. Stevens GA, Bennett JE, Hennocq Q, Lu Y, De-Regil LM, Rogers L, et al. Trends and mortality effects of vitamin A deficiency in children in 138 low-income and middle-income countries between 1991 and 2013: a pooled analysis of population-based surveys. The Lancet Global Health. 2015;3(9):e528-e36.

2. De Moura FF, Miloff A, Boy E. Retention of provitamin A carotenoids in staple crops targeted for biofortification in Africa: cassava, maize and sweet potato. Critical reviews in food science and nutrition. 2015;55(9):1246-69.

3. Pixley K, Rojas NP, Babu R, Mutale R, Surles R, Simpungwe E. Biofortification of maize with provitamin A carotenoids. Carotenoids and Human Health: Springer; 2013. p. 271-92.

4. Taleon V, Mugode L, Cabrera-Soto L, Palacios-Rojas N. Carotenoid retention in biofortified maize using different post-harvest storage and packaging methods. Food chemistry. 2017;232:60-6.

5. Gannon B, Kaliwile C, Arscott SA, Schmaelzle S, Chileshe J, Kalungwana N, et al. Biofortified orange maize is as efficacious as a vitamin A supplement in Zambian children even in the presence of high liver reserves of vitamin A: a community-based, randomized placebo-controlled trial. The American journal of clinical nutrition. 2014;100(6):1541-50.

6. Burt AJ, Grainger CM, Young JC, Shelp BJ, Lee EA. Impact of postharvest handling on carotenoid concentration and composition in high-carotenoid maize (Zea mays L.) kernels. Journal of agricultural and food chemistry. 2010;58(14):8286-92.

7. Sowa M, Yu J, Palacios-Rojas N, Goltz SR, Howe JA, Davis CR, et al. Retention of carotenoids in biofortified maize flour and $\beta$-cryptoxanthin-enhanced eggs after household cooking. ACS Omega. 2017;2(10):7320-8.

8. Simpungwe E, Dhliwayo T, Palenberg M, Taleon V, Birol E, Oparinde A, et al. Orange maize in Zambia: crop development and delivery experience. African Journal of Food, Agriculture, Nutrition and Development. 2017;17(2):11973-99.

9. Gwirtz JA, Garcia-Casal MN. Processing maize flour and corn meal food products. Annals of the New York Academy of Sciences. 2014;1312(1):66-75.

10. Pillay K, Derera J, Siwela M, Veldman FJ. Consumer acceptance of yellow, provitamin Abiofortified maize in KwaZulu-Natal: original research. South African Journal of Clinical Nutrition. 2011;24(4):186-91.

11. Rosales A, Agama-Acevedo E, Arturo Bello-Pérez L, Gutiérrez-Dorado R, Palacios-Rojas N. Effect of Traditional and Extrusion Nixtamalization on Carotenoid Retention in Tortillas Made from Provitamin A Biofortified Maize (Zea mays L.). Journal of agricultural and food chemistry. 2016;64(44):8289-95.

12. Muzhingi T, Palacios-Rojas N, Miranda A, Cabrera ML, Yeum KJ, Tang G. Genetic variation of carotenoids, vitamin $\mathrm{E}$ and phenolic compounds in Provitamin A biofortified maize. Journal of the Science of Food and Agriculture. 2017;97(3):793-801.

13. Mugode L, Ha B, Kaunda A, Sikombe T, Phiri S, Mutale R, et al. Carotenoid retention of biofortified provitamin a maize (Zea mays L.) after Zambian traditional methods of milling, cooking and storage. Journal of agricultural and food chemistry. 2014;62(27):6317-25. 
14. Ortiz D, Rocheford T, Ferruzzi MG. Influence of temperature and humidity on the stability of carotenoids in biofortified maize (Zea mays L.) genotypes during controlled postharvest storage. Journal of Agricultural and Food Chemistry. 2016;64(13):2727-36.

15. Cabrera-Soto L, Pixley KV, Rosales-Nolasco A, Galicia-Flores LA, Palacios-Rojas N. Carotenoid and tocochromanol profiles during kernel development make consumption of biofortified "fresh" maize an option to improve micronutrient nutrition. Journal of agricultural and food chemistry. 2018;66(36):9391-8.

16. Bechoff A, Dhuique-Mayer C, Dornier M, Tomlins KI, Boulanger R, Dufour D, et al. Relationship between the kinetics of $\beta$-carotene degradation and formation of norisoprenoids in the storage of dried sweet potato chips. Food Chemistry. 2010;121(2):348-57.

17. Otten JJ, Hellwig JP, Meyers LD. Dietary reference intakes: the essential guide to nutrient requirements: National Academies Press; 2006.

18. Li S, Nugroho A, Rocheford T, White WS. Vitamin A equivalence of the $\beta$-carotene in $\beta$ carotene-biofortified maize porridge consumed by women. The American journal of clinical nutrition. 2010;92(5):1105-12.

19. Muzhingi T, Gadaga TH, Siwela AH, Grusak MA, Russell RM, Tang G. Yellow maize with high $\beta$-carotene is an effective source of vitamin $A$ in healthy Zimbabwean men. The American journal of clinical nutrition. 2011;94(2):510-9.

20. Saltzman A, Birol E, Bouis HE, Boy E, De Moura FF, Islam Y, et al. Biofortification: progress toward a more nourishing future. Global Food Security. 2013;2(1):9-17.

21. Pillay K, Siwela M, Derera J, Veldman FJ. Provitamin A carotenoids in biofortified maize and their retention during processing and preparation of South African maize foods. Journal of food science and technology. 2014;51(4):634-44.

22. Chavez A, Sanchez T, Ceballos H, Rodriguez-Amaya D, Nestel P, Tohme J, et al. Retention of carotenoids in cassava roots submitted to different processing methods. Journal of the Science of Food and Agriculture. 2007;87(3):388-93.

23. Tefera T, Kanampiu F, De Groote H, Hellin J, Mugo S, Kimenju S, et al. The metal silo: An effective grain storage technology for reducing post-harvest insect and pathogen losses in maize while improving smallholder farmers' food security in developing countries. Crop protection. 2011;30(3):240-5.

24. Doblado-Maldonado AF, Pike OA, Sweley JC, Rose DJ. Key issues and challenges in whole wheat flour milling and storage. Journal of cereal science. 2012;56(2):119-26.

25. Buttery RG, Stern DJ, Ling LC. Studies on flavor volatiles of some sweet corn products. Journal of Agricultural and Food Chemistry. 1994;42(3):791-5.

26. Gonçalves JL, Figueira JA, Rodrigues FP, Ornelas LP, Branco RN, Silva CL, et al. A powerful methodological approach combining headspace solid phase microextraction, mass spectrometry and multivariate analysis for profiling the volatile metabolomic pattern of beer starting raw materials. Food chemistry. 2014;160:266-80.

27. Cho S, Nuijten E, Shewfelt RL, Kays SJ. Aroma chemistry of African Oryza glaberrima and Oryza sativa rice and their interspecific hybrids. Journal of the Science of Food and Agriculture. 2014;94(4):727-35. 
28. Annan NT, Poll L, Plahar WA, Jakobsen M. Aroma characteristics of spontaneously fermented Ghanaian maize dough for kenkey. European Food Research and Technology. 2003;217(1):53-60.

29. Bredie WL, Mottram DS, Guy RC. Aroma volatiles generated during extrusion cooking of maize flour. Journal of Agricultural and Food Chemistry. 1998;46(4):1479-87.

30. Sayaslan A, Chung OK, Seib PA, Seitz LM. Volatile compounds in five starches. Cereal chemistry. 2000;77(2):248-53.

31. Goicoechea E, Guillén MD. Volatile compounds generated in corn oil stored at room temperature. Presence of toxic compounds. European journal of lipid science and technology. 2014;116(4):395-406.

32. Pico J, Martínez MM, Bernal J, Gómez M. Evolution of volatile compounds in gluten-free bread: From dough to crumb. Food Chemistry. 2017;227:179-86.

33. Heiniö RL, Lehtinen P, Oksman-Caldentey KM, Poutanen K. Differences between sensory profiles and development of rancidity during long-term storage of native and processed oat. Cereal chemistry. 2002;79(3):367-75.

34. Sjövall O, Virtalaine T, Lapveteläinen A, Kallio H. Development of rancidity in wheat germ analyzed by headspace gas chromatography and sensory analysis. Journal of agricultural and food chemistry. 2000;48(8):3522-7.

35. Shahidi F, Wanasundara UN. Methods for measuring oxidative rancidity in fats and oils. Food lipids: Chemistry, nutrition and biotechnology. 2002;17:387-403.

36. Lampi A-M, Damerau A, Li J, Moisio T, Partanen R, Forssell P, et al. Changes in lipids and volatile compounds of oat flours and extrudates during processing and storage. Journal of Cereal Science. 2015;62:102-9.

37. Suzuki Y, Ise K, Li C, Honda I, Iwai Y, Matsukura U. Volatile components in stored rice [Oryza sativa (L.)] of varieties with and without lipoxygenase-3 in seeds. Journal of agricultural and food chemistry. 1999;47(3):1119-24.

38. Mahajan S, Goddik L, Qian M. Aroma compounds in sweet whey powder. Journal of Dairy Science. 2004;87(12):4057-63.

39. Janeš D, Kantar D, Kreft S, Prosen H. Identification of buckwheat (Fagopyrum esculentum Moench) aroma compounds with GC-MS. Food chemistry. 2009;112(1):120-4.

40. Champagne ET. Rice aroma and flavor: a literature review. Cereal Chemistry. 2008;85(4):445-54.

41. Mottram D, Maarse H. Volatile compounds in foods and beverages. New York: Marcel Dekker. 1991:107-77.

42. Stevens MA. Relationship between polyene-carotene content and volatile compound composition of tomatoes. Journal of the American Society of Horticultural Science. 1970;95:461-4.

43. Mbau SN. Zero plastic waste for a healthier ecosystem: an assessment of sustainable waste management in Runda estate, Nairobi: University of Nairobi; 2015. 
Appendix: Supplementary Material

Table 5.S1: Effect of storage method on carotenoid retention in maize flour after 180 days at $4^{\circ} \mathrm{C}$

\begin{tabular}{|c|c|c|c|c|c|}
\hline \multirow[b]{2}{*}{ Carotenoid } & \multirow[b]{2}{*}{ Bag_temp. } & \multicolumn{4}{|c|}{ Days (\% retention) } \\
\hline & & 10 & 20 & 30 & 60 \\
\hline \multirow[t]{6}{*}{ Lutein } & FM_AL & $70.05 \pm 1.91$ & $63.79 \pm 1.80$ & $61.53 \pm 6.97$ & $78.78 \pm 7.98$ \\
\hline & FM_LP & $67.28 \pm 6.50$ & $56.81 \pm 2.39$ & $58.81 \pm 6.70$ & $70.29 \pm 1.24$ \\
\hline & FM_PT & $78.91 \pm 0.10$ & $61.09 \pm 2.47$ & $79.34 \pm 1.84$ & $87.10 \pm 3.11$ \\
\hline & RM_AL & $99.53 \pm 0.14$ & $98.78 \pm 3.73$ & $93.10 \pm 3.57$ & $97.74 \pm 2.02$ \\
\hline & RM_LP & $93.13 \pm 0.90$ & $88.27 \pm 2.04$ & $86.77 \pm 1.18$ & $79.72 \pm 17.37$ \\
\hline & RM_PT & $76.18 \pm 3.38$ & $73.93 \pm 4.18$ & $74.42 \pm 4.53$ & $73.91 \pm 2.56$ \\
\hline \multirow[t]{6}{*}{ Zeaxanthin } & FM_AL & $70.93 \pm 1.76$ & $65.10 \pm 0.53$ & $59.38 \pm 6.84$ & $84.14 \pm 10.23$ \\
\hline & FM_LP & $71.50 \pm 7.89$ & $58.31 \pm 2.40$ & $55.31 \pm 0.96$ & $68.89 \pm 0.38$ \\
\hline & FM_PT & $76.49 \pm 0.75$ & $61.72 \pm 0.85$ & $62.17 \pm 4.35$ & $69.82 \pm 2.46$ \\
\hline & RM_AL & $90.6 \pm 0.33$ & $90.87 \pm 0.09$ & $83.83 \pm 6.76$ & $88.79 \pm 1.64$ \\
\hline & RM_LP & $90.55 \pm 1.21$ & $85.20 \pm 2.15$ & $85.89 \pm 0.87$ & $76.96 \pm 16.33$ \\
\hline & RM_PT & $82.92 \pm 4.17$ & $78.46 \pm 4.00$ & $85.58 \pm 6.94$ & $87.55 \pm 12.85$ \\
\hline \multirow{6}{*}{$\begin{array}{l}\beta- \\
\text { Cryptoxanthin }\end{array}$} & FM_AL & $62.69 \pm 1.10$ & $65.03 \pm 0.90$ & $60.91 \pm 1.47$ & $76.27 \pm 8.98$ \\
\hline & FM_LP & $59.94 \pm 2.72$ & $53.92 \pm 6.11$ & $58.6 \pm 3.02$ & $84.34 \pm 0.94$ \\
\hline & FM_PT & $64.76 \pm 1.84$ & $74.69 \pm 1.11$ & $74.58 \pm 0.06$ & $78.45 \pm 3.66$ \\
\hline & RM_AL & $100.11 \pm 0.56$ & $101.17 \pm 5.83$ & $104.7 \pm 5.06$ & $89.02 \pm 11.63$ \\
\hline & RM_LP & $91.57 \pm 2.74$ & $84.7 \pm 1.03$ & $82.81 \pm 0.17$ & $61.72 \pm 11.92$ \\
\hline & RM_PT & $81.63 \pm 0.23$ & $74.78 \pm 8.25$ & $93.33 \pm 1.71$ & $80.45 \pm 9.08$ \\
\hline \multirow[t]{6}{*}{$\beta$-Carotene } & FM_AL & $66.20 \pm 3.03$ & $65.09 \pm 0.64$ & $60.36 \pm 2.88$ & $92.19 \pm 7.78$ \\
\hline & FM_LP & $65.73 \pm 3.02$ & $59.13 \pm 9.41$ & $59.03 \pm 12.47$ & $75.41 \pm 0.66$ \\
\hline & FM_PT & $80.36 \pm 7.56$ & $74.11 \pm 9.27$ & $79.2 \pm 4.02$ & $84.68 \pm 3.32$ \\
\hline & RM_AL & $109.9 \pm 39.66$ & $81.34 \pm 10.06$ & $79.94 \pm 0.86$ & $88.15 \pm 8.52$ \\
\hline & RM_LP & $83.47 \pm 3.00$ & $63.32 \pm 4.37$ & $68.63 \pm 15.16$ & $67.15 \pm 13.08$ \\
\hline & RM_PT & $79.58 \pm 10.77$ & $92.83 \pm 1.89$ & $92.22 \pm 0.21$ & $87.75 \pm 9.07$ \\
\hline \multirow{6}{*}{$\begin{array}{l}\text { Provitamin A } \\
\text { carotenoid }\end{array}$} & FM_AL & $61.55 \pm 1.46$ & $63.11 \pm 0.56$ & $59.00 \pm 1.71$ & $77.24 \pm 8.47$ \\
\hline & FM_LP & $59.34 \pm 2.70$ & $53.38 \pm 6.6$ & $56.96 \pm 4.85$ & $80.03 \pm 0.59$ \\
\hline & FM_PT & $66.01 \pm 0.12$ & $72.36 \pm 2.73$ & $73.31 \pm 0.87$ & $77.39 \pm 3.48$ \\
\hline & RM_AL & $89.61 \pm 8.31$ & $84.61 \pm 1.92$ & $86.71 \pm 3.25$ & $77.77 \pm 9.56$ \\
\hline & RM_LP & $78.55 \pm 1.25$ & $69.88 \pm 1.57$ & $67.44 \pm 3.15$ & $55.13 \pm 10.67$ \\
\hline & RM_PT & $71.06 \pm 2.00$ & $69.09 \pm 5.95$ & $81.49 \pm 1.19$ & $71.90 \pm 7.95$ \\
\hline \multirow{6}{*}{$\begin{array}{l}\text { Total } \\
\text { carotenoid } \\
\text { content }\end{array}$} & FM_AL & $64.06 \pm 0.57$ & $61.3 \pm 0.32$ & $57.2 \pm 4.59$ & $76.25 \pm 8.68$ \\
\hline & FM_LP & $62.76 \pm 3.26$ & $53.47 \pm 3.77$ & $54.34 \pm 0.30$ & $70.79 \pm 0.68$ \\
\hline & FM_PT & $69.29 \pm 0.56$ & $63.01 \pm 0.09$ & $67.34 \pm 0.97$ & $73.29 \pm 2.90$ \\
\hline & RM_AL & $80.05 \pm 1.70$ & $79.1 \pm 0.54$ & $76.77 \pm 1.40$ & $75.07 \pm 4.56$ \\
\hline & RM_LP & $75.35 \pm 0.11$ & $69.95 \pm 1.53$ & $69.45 \pm 0.20$ & $59.39 \pm 12.29$ \\
\hline & RM_PT & $68.99 \pm 1.51$ & $65.7 \pm 4.33$ & $73.92 \pm 3.93$ & $70.97 \pm 9.60$ \\
\hline
\end{tabular}

*Freezer mill (FM) and rotor mill (RM); AL - Aluminium, LP - laminated paper, PT - Double layered polyethylene 
Cont.:

Table 5.S1: Effect of storage method on carotenoid retention in maize flour after 180 days at $4^{\circ} \mathrm{C}$

\begin{tabular}{|c|c|c|c|c|c|}
\hline \multirow[b]{2}{*}{ Carotenoid } & \multirow[b]{2}{*}{ Bag_temp. } & \multicolumn{4}{|c|}{ Days (\% retention) } \\
\hline & & 90 & 120 & 150 & 180 \\
\hline \multirow[t]{6}{*}{ Lutein } & FM AL & $58.89 \pm 2.96$ & $63.17 \pm 6.11$ & $62.27 \pm 1.32$ & $57.49 \pm 3.58$ \\
\hline & FM_LP & $60.05 \pm 0.95$ & $56.59 \pm 4.45$ & $61.3 \pm 0.18$ & $59.51 \pm 0.66$ \\
\hline & FM_PT & $73.95 \pm 3.47$ & $69.97 \pm 4.99$ & $70.19 \pm 0.90$ & $69.77 \pm 0.81$ \\
\hline & RM_AL & $91.16 \pm 0.93$ & $93.07 \pm 5.92$ & $91.8 \pm 1.67$ & $96.79 \pm 6.68$ \\
\hline & RM_LP & $81.11 \pm 4.03$ & $84.19 \pm 4.72$ & $83.67 \pm 5.42$ & $73.23 \pm 7.04$ \\
\hline & RM_PT & $72.76 \pm 2.08$ & $69.3 \pm 3.44$ & $65.38 \pm 4.35$ & $64.12 \pm 0.29$ \\
\hline \multirow[t]{6}{*}{ Zeaxanthin } & FM_AL & $58.35 \pm 3.70$ & $65.85 \pm 2.47$ & $60.75 \pm 1.22$ & $57.48 \pm 2.99$ \\
\hline & FM_LP & $60.85 \pm 0.48$ & $52.97 \pm 4.38$ & $60.54 \pm 0.08$ & $60.13 \pm 1.25$ \\
\hline & FM_PT & $72.28 \pm 4.26$ & $68.5 \pm 5.16$ & $69.85 \pm 1.65$ & $70.30 \pm 1.57$ \\
\hline & RM_AL & $80.52 \pm 2.01$ & $82.4 \pm 5.44$ & $82.96 \pm 0.08$ & $85.43 \pm 5.33$ \\
\hline & RM_LP & $79.69 \pm 3.51$ & $79.72 \pm 4.76$ & $76.12 \pm 4.10$ & $71.04 \pm 2.65$ \\
\hline & RM_PT & $79.73 \pm 1.52$ & $82.64 \pm 5.21$ & $79.31 \pm 4.3$ & $73.00 \pm 1.18$ \\
\hline \multirow{6}{*}{$\begin{array}{l}\beta- \\
\text { Cryptoxanthin }\end{array}$} & FM_AL & $56.64 \pm 0.77$ & $71.23 \pm 3.83$ & $60.23 \pm 1.41$ & $59.30 \pm 4.16$ \\
\hline & FM_LP & $51.39 \pm 2.69$ & $44.21 \pm 2.90$ & $49.2 \pm 0.20$ & $49.57 \pm 0.38$ \\
\hline & FM_PT & $73.32 \pm 1.43$ & $69.25 \pm 2.46$ & $69.16 \pm 1.23$ & $71.45 \pm 1.21$ \\
\hline & RM_AL & $87.21 \pm 0.00$ & $89.71 \pm 5.91$ & $83.79 \pm 0.37$ & $89.52 \pm 3.22$ \\
\hline & RM_LP & $72.95 \pm 7.74$ & $67.60 \pm 2.14$ & $70.87 \pm 9.26$ & $66.04 \pm 8.91$ \\
\hline & RM_PT & $84.71 \pm 0.57$ & $92.46 \pm 5.46$ & $84.38 \pm 3.96$ & $83.7 \pm 7.79$ \\
\hline \multirow[t]{6}{*}{$\beta$-Carotene } & FM_AL & $63.06 \pm 0.13$ & $69.73 \pm 20.12$ & $62.79 \pm 0.47$ & $62.31 \pm 3.95$ \\
\hline & FM_LP & $57.81 \pm 2.03$ & $54.36 \pm 1.40$ & $48.72 \pm 2.52$ & $52.43 \pm 0.53$ \\
\hline & FM_PT & $87.82 \pm 0.06$ & $83.02 \pm 4.11$ & $75.27 \pm 0.62$ & $79.19 \pm 0.49$ \\
\hline & RM_AL & $82.03 \pm 4.07$ & $78.94 \pm 0.13$ & $78.17 \pm 0.93$ & $86.68 \pm 12.47$ \\
\hline & RM_LP & $66.04 \pm 1.93$ & $59.46 \pm 5.73$ & $60.53 \pm 1.04$ & $56.64 \pm 5.20$ \\
\hline & RM_PT & $84.91 \pm 7.29$ & $83.23 \pm 0.93$ & $75.71 \pm 0.61$ & $22.23 \pm 5.02$ \\
\hline \multirow{6}{*}{$\begin{array}{l}\text { Provitamin A } \\
\text { carotenoid }\end{array}$} & FM_AL & $56.27 \pm 0.62$ & $68.82 \pm 1.15$ & $58.97 \pm 1.18$ & $58.16 \pm 3.99$ \\
\hline & FM_LP & $51.17 \pm 2.47$ & $44.96 \pm 2.51$ & $47.64 \pm 0.36$ & $48.69 \pm 0.40$ \\
\hline & FM_PT & $74.09 \pm 1.11$ & $69.99 \pm 2.72$ & $68.35 \pm 0.82$ & $70.9 \pm 1.03$ \\
\hline & RM_AL & $75.32 \pm 0.81$ & $76.39 \pm 3.96$ & $72.23 \pm 0.06$ & $77.81 \pm 0.33$ \\
\hline & RM_LP & $62.49 \pm 5.61$ & $57.56 \pm 0.30$ & $59.98 \pm 6.46$ & $55.94 \pm 7.06$ \\
\hline & RM_PT & $74.21 \pm 1.08$ & $79.11 \pm 3.50$ & $72.14 \pm 2.80$ & $60.97 \pm 6.27$ \\
\hline \multirow{6}{*}{$\begin{array}{l}\text { Total } \\
\text { carotenoid } \\
\text { content }\end{array}$} & FM_AL & $54.99 \pm 2.24$ & $63.64 \pm 1.85$ & $57.75 \pm 1.21$ & $55.2 \pm 3.38$ \\
\hline & FM_LP & $54.22 \pm 1.34$ & $48.14 \pm 3.55$ & $53.28 \pm 0.06$ & $53.02 \pm 0.45$ \\
\hline & FM_PT & $69.78 \pm 2.76$ & $66.01 \pm 3.92$ & $66.19 \pm 1.17$ & $67.17 \pm 0.33$ \\
\hline & RM_AL & $70.47 \pm 0.98$ & $72.00 \pm 1.13$ & $70.23 \pm 0.39$ & $73.9 \pm 2.52$ \\
\hline & RM_LP & $63.67 \pm 4.13$ & $62.42 \pm 2.74$ & $62.15 \pm 4.97$ & $57.11 \pm 4.87$ \\
\hline & RM_PT & $68.68 \pm 0.44$ & $72.08 \pm 4.31$ & $68.19 \pm 3.16$ & $53.2 \pm 3.15$ \\
\hline
\end{tabular}

*Freezer mill (FM) and rotor mill (RM); AL - Aluminium, LP - laminated paper, PT - Double layered polyethylene 
Table 5.S2: Effect of storage method on carotenoid retention in maize flour after 180 days at $37^{\circ} \mathrm{C}$

\begin{tabular}{|c|c|c|c|c|c|}
\hline \multirow[b]{2}{*}{ Carotenoid } & \multirow[b]{2}{*}{ Bag_temp. } & \multicolumn{4}{|c|}{ Days (\% retention) } \\
\hline & & 10 & 20 & 30 & 60 \\
\hline \multirow[t]{6}{*}{ Lutein } & FM_AL & $62.14 \pm 0.58$ & $54.72 \pm 3.12$ & $69.97 \pm 2.43$ & $65.91 \pm 2.28$ \\
\hline & FM_LP & $68.27 \pm 1.94$ & $64.55 \pm 0.58$ & $51.78 \pm 2.17$ & $46 \pm 0.24$ \\
\hline & FM_PT & $76.18 \pm 3.38$ & $73.93 \pm 4.18$ & $74.42 \pm 4.53$ & $73.91 \pm 2.56$ \\
\hline & RM_AL & $84.31 \pm 3.28$ & $82.4 \pm 13.12$ & $61.84 \pm 13.55$ & $62.29 \pm 3.48$ \\
\hline & RM_LP & $86.54 \pm 3.85$ & $70.13 \pm 9.25$ & $67.39 \pm 3.64$ & $40.68 \pm 3.5$ \\
\hline & RM_PT & $98.84 \pm 6.43$ & $89.84 \pm 6.78$ & $75.39 \pm 8.65$ & $59.53 \pm 8.44$ \\
\hline \multirow[t]{6}{*}{ Zeaxanthin } & FM_AL & $63.5 \pm 0.89$ & $54.85 \pm 3.91$ & $68.99 \pm 1.88$ & $70.58 \pm 1.73$ \\
\hline & FM_LP & $67.37 \pm 2.55$ & $62.2 \pm 1.13$ & $52.42 \pm 1.25$ & $39.25 \pm 0.16$ \\
\hline & FM_PT & $76.08 \pm 0.52$ & $74.88 \pm 1.53$ & $72.86 \pm 2.95$ & $72.27 \pm 2.53$ \\
\hline & RM_AL & $76.97 \pm 2.65$ & $74.55 \pm 11.31$ & $54.55 \pm 14.41$ & $55.06 \pm 2.81$ \\
\hline & RM_LP & $56.53 \pm 2.8$ & $47.62 \pm 4.04$ & $45.22 \pm 2.31$ & $25.67 \pm 3.45$ \\
\hline & RM_PT & $68.53 \pm 3.54$ & $67.27 \pm 4.33$ & $52.02 \pm 6.74$ & $46.08 \pm 10.44$ \\
\hline \multirow{6}{*}{$\begin{array}{l}\beta- \\
\text { Cryptoxanthin }\end{array}$} & FM_AL & $69.84 \pm 6.14$ & $56.88 \pm 0.16$ & $67.98 \pm 0.77$ & $62.22 \pm 2.58$ \\
\hline & FM_LP & $69.69 \pm 1.42$ & $61.71 \pm 4.49$ & $55.95 \pm 1.94$ & $36.19 \pm 0.42$ \\
\hline & FM_PT & $85.6 \pm 4.51$ & $69.8 \pm 0.22$ & $68.84 \pm 1.35$ & $57.11 \pm 0.38$ \\
\hline & RM_AL & $64.91 \pm 0.75$ & $61.94 \pm 11.12$ & $46.9 \pm 13.84$ & $43.59 \pm 8.23$ \\
\hline & RM_LP & $63.71 \pm 3.16$ & $53.67 \pm 4.55$ & $50.97 \pm 2.6$ & $28.93 \pm 3.88$ \\
\hline & RM_PT & $77.24 \pm 3.99$ & $75.82 \pm 4.88$ & $58.63 \pm 7.59$ & $51.94 \pm 11.76$ \\
\hline \multirow[t]{6}{*}{$\beta$-Carotene } & FM_AL & $78.52 \pm 10.08$ & $76.34 \pm 7.27$ & $73.93 \pm 8.26$ & $81.34 \pm 2.93$ \\
\hline & FM_LP & $79.15 \pm 4.92$ & $58.03 \pm 3.61$ & $59.72 \pm 4.48$ & $41.31 \pm 2.56$ \\
\hline & FM_PT & $80.3 \pm 0.37$ & $76.28 \pm 0.3$ & $79.66 \pm 6.1$ & $69.98 \pm 0.09$ \\
\hline & RM_AL & $65.49 \pm 0.65$ & $61.8 \pm 10.47$ & $46.42 \pm 14.24$ & $46.42 \pm 6.59$ \\
\hline & RM_LP & $63.84 \pm 0.31$ & $54.4 \pm 2.94$ & $49.11 \pm 1.87$ & $26.81 \pm 3.88$ \\
\hline & RM_PT & $81.37 \pm 5.7$ & $74.8 \pm 6.15$ & $57.18 \pm 6.63$ & $57.48 \pm 16.67$ \\
\hline \multirow{6}{*}{$\begin{array}{l}\text { Provitamin A } \\
\text { carotenoid }\end{array}$} & FM_AL & $69.54 \pm 6.76$ & $59.14 \pm 1.6$ & $67.17 \pm 1.08$ & $64.26 \pm 2.57$ \\
\hline & FM_LP & $69.55 \pm 0.09$ & $59.14 \pm 4.18$ & $55.06 \pm 2.4$ & $36.15 \pm 0.85$ \\
\hline & FM_PT & $81.99 \pm 3.38$ & $69.05 \pm 0.11$ & $69 \pm 2.27$ & $58.03 \pm 0.28$ \\
\hline & RM_AL & $56.95 \pm 0.64$ & $54.2 \pm 9.61$ & $40.97 \pm 12.19$ & $38.73 \pm 6.88$ \\
\hline & RM_LP & $55.81 \pm 2.07$ & $47.13 \pm 3.66$ & $44.25 \pm 2.13$ & $24.91 \pm 3.4$ \\
\hline & RM_PT & $68.45 \pm 3.84$ & $66.18 \pm 4.53$ & $51.04 \pm 6.46$ & $46.58 \pm 11.28$ \\
\hline \multirow{6}{*}{$\begin{array}{l}\text { Total } \\
\text { carotenoid } \\
\text { content }\end{array}$} & FM_AL & $62.5 \pm 1.97$ & $53.46 \pm 1.73$ & $65.39 \pm 0.25$ & $63.53 \pm 2.09$ \\
\hline & FM_LP & $65.21 \pm 1.09$ & $59.04 \pm 2.15$ & $50.93 \pm 0.85$ & $37.72 \pm 0.24$ \\
\hline & FM_PT & $75.29 \pm 0.52$ & $69.07 \pm 1.53$ & $68.29 \pm 1.36$ & $63.74 \pm 1.35$ \\
\hline & RM_AL & $61.05 \pm 1.68$ & $58.92 \pm 9.59$ & $43.89 \pm 11.59$ & $43.2 \pm 4.15$ \\
\hline & RM_LP & $54.47 \pm 1.1$ & $45.41 \pm 4.37$ & $43.16 \pm 2.21$ & $24.89 \pm 3$ \\
\hline & RM_PT & $65.11 \pm 3.66$ & $62.42 \pm 4.25$ & $49.3 \pm 6.15$ & $42.67 \pm 8.92$ \\
\hline
\end{tabular}

*Freezer mill (FM) and rotor mill (RM); AL - Aluminium, LP - laminated paper, PT - Double layered polyethylene 
Cont::

Table 5.S2: Effect of storage method on carotenoid retention in maize flour after 180 days at $37^{\circ} \mathrm{C}$

\begin{tabular}{|c|c|c|c|c|c|}
\hline \multirow[b]{2}{*}{ Carotenoid } & \multirow[b]{2}{*}{ Bag_temp. } & \multicolumn{4}{|c|}{ Days ( $\%$ retention) } \\
\hline & & 90 & 120 & 150 & 180 \\
\hline \multirow[t]{6}{*}{ Lutein } & FM_AL & $41.02 \pm 0.76$ & $35.13 \pm 1.6$ & $39.46 \pm 1.69$ & $38.63 \pm 0.01$ \\
\hline & FM_LP & $30.36 \pm 5.9$ & $33.12 \pm 2.23$ & $23.5 \pm 1.62$ & $21.42 \pm 1.19$ \\
\hline & FM_PT & $72.76 \pm 2.08$ & $69.3 \pm 3.44$ & $65.38 \pm 4.35$ & $64.12 \pm 0.29$ \\
\hline & RM_AL & $66.81 \pm 4.67$ & $59.31 \pm 3.12$ & $59.87 \pm 0.39$ & $54.98 \pm 2.6$ \\
\hline & RM_LP & $37.84 \pm 0.94$ & $33.4 \pm 1.06$ & $31.02 \pm 0.95$ & $29 \pm 0.03$ \\
\hline & RM_PT & $67.16 \pm 0.45$ & $67.28 \pm 0.1$ & $65.14 \pm 2.94$ & $64.36 \pm 0.68$ \\
\hline \multirow[t]{6}{*}{ Zeaxanthin } & FM_AL & $40.2 \pm 1.3$ & $37.07 \pm 1.3$ & $40.03 \pm 0.92$ & $42.89 \pm 0.31$ \\
\hline & FM_LP & $26.31 \pm 4.38$ & $26.99 \pm 0.83$ & $19.79 \pm 0.79$ & $16.56 \pm 0.01$ \\
\hline & FM_PT & $41.48 \pm 0.88$ & $33.1 \pm 1.87$ & $29.25 \pm 2.1$ & $30.23 \pm 0.33$ \\
\hline & RM_AL & $59.8 \pm 4.07$ & $53.73 \pm 2.89$ & $54.24 \pm 12.1$ & $56.05 \pm 1.77$ \\
\hline & RM_LP & $26.83 \pm 0.67$ & $26.6 \pm 1.07$ & $25.27 \pm 0.97$ & $23.88 \pm 0.98$ \\
\hline & RM_PT & $53.68 \pm 1.54$ & $52.47 \pm 1.75$ & $50.99 \pm 0.5$ & $51.13 \pm 1.21$ \\
\hline \multirow{6}{*}{$\begin{array}{l}\beta- \\
\text { Cryptoxanthin }\end{array}$} & FM_AL & $33.78 \pm 0.52$ & $35.59 \pm 0.58$ & $43.63 \pm 0.28$ & $46.72 \pm 2.18$ \\
\hline & FM_LP & $30.22 \pm 5.04$ & $27.23 \pm 0.72$ & $19.38 \pm 0.09$ & $15.22 \pm 0.04$ \\
\hline & FM_PT & $37.98 \pm 0.53$ & $33.13 \pm 2.47$ & $31.41 \pm 0.07$ & $32.89 \pm 0.42$ \\
\hline & RM_AL & $58.47 \pm 0.44$ & $48.47 \pm 1.6$ & $45.08 \pm 0.52$ & $44.61 \pm 1.28$ \\
\hline & RM_LP & $30.24 \pm 0.76$ & $28.2 \pm 2.06$ & $26.92 \pm 2.34$ & $26.38 \pm 2.06$ \\
\hline & RM_PT & $60.51 \pm 1.73$ & $59.3 \pm 1.63$ & $56.08 \pm 2.04$ & $54.66 \pm 2.36$ \\
\hline \multirow[t]{6}{*}{$\beta$-Carotene } & FM_AL & $44.2 \pm 0.7$ & $42.35 \pm 0.6$ & $55.99 \pm 1.99$ & $72.18 \pm 4.37$ \\
\hline & FM_LP & $31.51 \pm 3.94$ & $28.24 \pm 1.9$ & $16.95 \pm 0.12$ & $13.17 \pm 0.56$ \\
\hline & FM_PT & $44.1 \pm 0.75$ & $39.06 \pm 2.59$ & $32.87 \pm 0.66$ & $36.92 \pm 0.04$ \\
\hline & RM_AL & $54.25 \pm 0.01$ & $43.55 \pm 1.31$ & $43.6 \pm 1.05$ & $42.04 \pm 2.31$ \\
\hline & RM_LP & $21.5 \pm 0.62$ & $17.83 \pm 0.11$ & $17.29 \pm 0.22$ & $16.91 \pm 0.34$ \\
\hline & RM_PT & $56.06 \pm 1.93$ & $48.86 \pm 0.67$ & $46.36 \pm 0.12$ & $42.23 \pm 0.42$ \\
\hline \multirow{6}{*}{$\begin{array}{l}\text { Provitamin A } \\
\text { carotenoid }\end{array}$} & FM_AL & $34.9 \pm 0.54$ & $44.96 \pm 2.51$ & $44.85 \pm 0.62$ & $50.51 \pm 2.56$ \\
\hline & FM_LP & $29.59 \pm 4.67$ & $26.63 \pm 0.94$ & $18.31 \pm 0.05$ & $14.36 \pm 0.14$ \\
\hline & FM_PT & $38.1 \pm 0.55$ & $33.35 \pm 2.42$ & $30.78 \pm 0.19$ & $32.73 \pm 0.33$ \\
\hline & RM_AL & $50.35 \pm 0.3$ & $41.45 \pm 1.34$ & $39.17 \pm 0.14$ & $38.54 \pm 1.33$ \\
\hline & RM_LP & $24.73 \pm 0.64$ & $22.61 \pm 1.41$ & $21.64 \pm 1.63$ & $21.2 \pm 1.46$ \\
\hline & RM_PT & $52.08 \pm 1.56$ & $49.83 \pm 1.23$ & $47.15 \pm 1.4$ & $45.37 \pm 1.51$ \\
\hline \multirow{6}{*}{$\begin{array}{l}\text { Total } \\
\text { carotenoid } \\
\text { content }\end{array}$} & FM_AL & $36.32 \pm 0.84$ & $48.14 \pm 3.55$ & $39.61 \pm 0.53$ & $42.16 \pm 1$ \\
\hline & FM_LP & $27.28 \pm 4.67$ & $27.02 \pm 1.1$ & $19.29 \pm 0.67$ & $16.16 \pm 0.3$ \\
\hline & FM_PT & $45.08 \pm 0.97$ & $39.51 \pm 2.34$ & $36.44 \pm 1.76$ & $37.17 \pm 0.08$ \\
\hline & RM_AL & $50.1 \pm 2.27$ & $43.51 \pm 2$ & $42.81 \pm 4.06$ & $42.31 \pm 0.57$ \\
\hline & RM_LP & $24.9 \pm 0.29$ & $23.3 \pm 1.12$ & $22.06 \pm 0.82$ & $21.08 \pm 0.92$ \\
\hline & RM_PT & $48.85 \pm 1.15$ & $47.91 \pm 1.07$ & $45.95 \pm 1.27$ & $45.28 \pm 1.17$ \\
\hline
\end{tabular}

*Freezer mill (FM) and rotor mill (RM); AL - Aluminium, LP - laminated paper, PT - Double layered polyethylene 



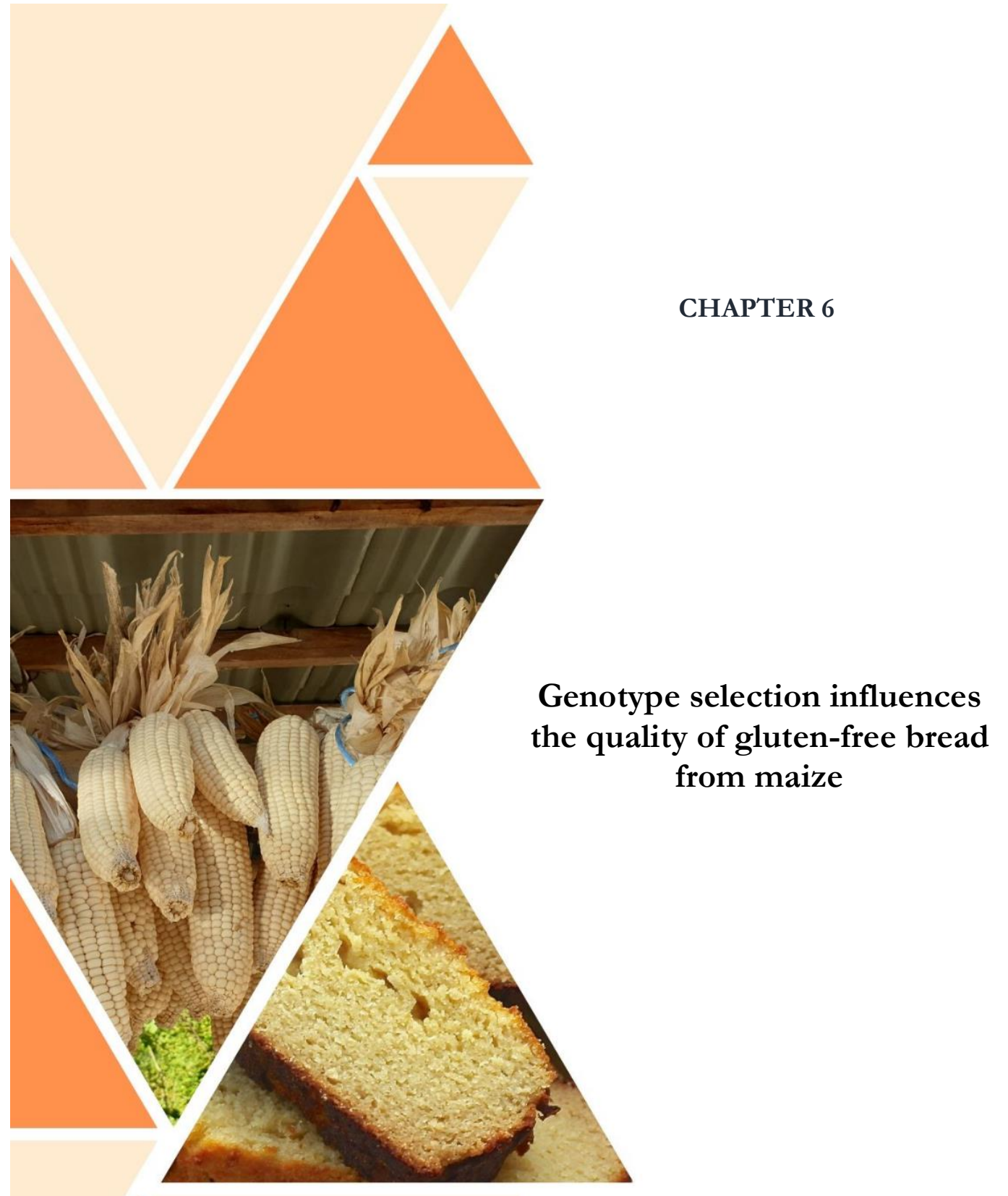

This chapter has been published as:

Ekpa O, Palacios-Rojas N, Rosales A, Renzetti S, Fogliano V, Linnemann AR. Genotype selection influences the quality of gluten-free bread from maize. LWT'. 2020:109214. 


\begin{abstract}
Making bread from maize is a technological challenge due to the poor viscoelastic properties of the dough. Maize germplasm as well as the thermoalkaline processing technique commonly used in Mexico can be harnessed for bread-making purposes. We assessed the bread-making performance of two maize hybrids, two landraces, and their thermoalkaline processed flour in addition to their blend with high zinc wheat. Significant differences $(\mathrm{P} \leq 0.05)$ were found in physical kernel characteristics such as flotation index, hardness, size and weight. Doughs had a higher consistency, springiness and gumminess than the untreated reference. Landrace L1 (Jala) had a larger specific volume $(1.99 \mathrm{~mL} / \mathrm{g})$, softer texture $(13.10 \mathrm{~N})$ and faster springiness $(0.90)$ but a relatively high staling (1.60), while landrace L2 (Cacahuacintle) and hybrid H1 (CSTH19001) had a lower staling $(<0.50)$. The specific volume and softness of bread reduced in all thermoalkaline processed flours. Genotypes demonstrated significantly different performances during bread-making, indicating that the choice of maize genotype significantly affected the final product. Thermoalkaline processed flour did not seem to improve bread quality, hence its application in bread making requires further study.
\end{abstract}

Keywords: Maize flour; gluten-free bread; landraces; hybrids; Africa 


\subsubsection{Introduction}

Bread is commonly made with wheat flour. The flours of other cereals, including rye, barley, maize, oats, sorghum, millet and rice, are used to a lesser extent. With the exception of rye, these cereals are usually combined with wheat to derive suitable rheological and textural properties. Maize is a staple crop in many countries in Africa and Latin America. Its uses are multiple in Latin America with more than 600 food products being made with maize, mainly derived from thermoalkaline processed flour. ${ }^{[1]}$ However, maize proteins do not develop into a continuous network upon hydration and shear, resulting in doughs lacking extensibility and gas holding properties.

Maize germplasm has a vast genetic and functional variability, which could be exploited for bread-making purposes. Identification of maize germplasm with proper breadmaking properties could open opportunities for the growing gluten-free markets.[2] Garzón et al. [2] observed differences in maize genotypes for dough rheology and glutenfree bread making performance. Mexico, the centre of diversity of maize, has around 60 landraces with most of them still cultivated throughout the country. ${ }^{[3]}$ Cacahuacintle and Jala are two popular maize landraces characterized by large-sized grains with more than $80 \%$ floury endosperm, preferred for the preparation a soup called pozole, cookies and thermoalkaline processed tortillas. ${ }^{[4]}$

Solutions to improve the bread-making performance of maize include the use of functional ingredients such as hydrocolloids, dough conditioners, protein sources, modified starches, and processing technologies such as high hydrostatic pressure.[5] However, these advanced technological solutions appear inappropriate for low and middle-income countries. Solutions such as using pre-gelatinized starch, thermoalkaline processing (so-called nixtamalization), sprouting and composite flours offer better possibilities for adoption.[6] Thermoalkaline processing improves dough viscoelasticity and network stability, which could ameliorate the bread-making performance of maize flour.[7]

In this study, we compared the dough rheology and bread-making performance of two maize hybrids and two Mexican landraces, namely Jala and Cacahuacintle. Moreover, the physicochemical and functional properties during bread-making from thermoalkaline processed flour of these genotypes were evaluated. Finally, bread from a maize/high zinc wheat blend was analysed to test whether the observed differences in maize genotypes were sustained in a blend with wheat. 


\subsubsection{Materials and methods}

\subsubsection{Plant materials}

Grains of the Cacahuacintle landrace were purchased from Ixtenco market and of Jala landrace from a farmer in Jala, Jalisco, Mexico (Figure 6.1). Both landraces were produced in the spring-summer cycle of 2018 and harvested in December 2018. The hybrids, one commercial and one advanced hybrid from CIMMY'T's tropical maize breeding program were grown in the autumn-winter cycle 2019 in the experimental station of CIMMYT in Agua Fria, Mexico. Genotypes with contrasting quality parameters commonly used to prepare maize snacks were selected. High $\mathrm{Zn}$ wheat was produced at CIMMY'T experimental station in Ciudad Obregon, Mexico, and was harvested in April 2019. Composite flour consisted of $75 \%$ high-Zn wheat and raw maize or thermoalkaline processed maize flour based on prior trials (Table 6.S1).

\subsubsection{Thermoalkaline processing, drying and milling}

Thermoalkaline processing was performed as described by Roque-Maciel et al. [8]. Briefly, a pan with $3 \mathrm{~L}$ water containing $1 \mathrm{~kg}$ maize kernels and $10 \mathrm{~g}$ food-grade calcium hydroxide (Oxical ${ }^{\circledR}$, Mexico) was placed on stove at a regularly monitored minimum steam level. Cooking time was based on grain hardness as described by Vázquez-Carrillo et al. [9]. The cooked maize was steeped in the closed pan for $16 \mathrm{~h}$. Next, the cooking water was discarded, followed by washing the grains three times in clean water. Then the grains were milled using a wet milling machine (Fumasa, M100, Mexico) to produce a paste, so-called masa, which was subsequently lyophilized with the Labconco equipment (model 7755041). The dried dough was re-milled using a hammer miller (Christy Turner 43220 Series 3000 mill - Suffolk, UK) equipped with a $0.5 \mathrm{~mm}$ mesh.

\subsubsection{Physical and chemical properties of grains}

The flotation index (FI) was used to determine kernel hardness by the method of Wichser ${ }^{[10]}$. One hundred grains were placed in a sodium nitrate solution with a specific density of $1.250 \mathrm{~g} / \mathrm{mL}$ after which the number of floating grains after six strokes of mild stirring was recorded. Grain and flour colour were measured using the MiniEscan HunterLab colorimeter (Reston, VA, USA). The colour differences $\left(\Delta \mathrm{E}^{*} \mathrm{ab}\right)$ after processing into thermoalkaline processed flour were calculated and interpreted according to Cserhalmi et al. [11]. Colour changes become more perceptible to human eyes with increasing values.

Grain size distribution was determined by passing $1 \mathrm{~kg}$ kernels through a set of meshes standard no. $24(9.53 \mathrm{~mm}), 22(8.73 \mathrm{~mm}), 20(7.94 \mathrm{~mm})$ and $18(7.14 \mathrm{~mm})$ with constant agitation for $1 \mathrm{~min}$ and determination of the percentage. Grain moisture, starch, protein and oil content were determined by Near-Infrared Spectroscopy (NIS) with the 
Infratec $^{\text {TM }} 1241$ Grain Analyser (FOSS, Denmark) and calibrations provided by the manufacturer. Hundred kernel weight was determined by weighing 100 grains. ${ }^{[12]}$ Mineral contents were analysed by Inductively Coupled Plasma-Optical Emission Spectrometry (ICP-OES).[13]

\subsubsection{Bread making}

Maize bread making was adapted from Falade [14], namely on flour weight, as follows: $5 \%$ sugar, $3 \%$ dry yeast, $2 \%$ margarine, $2 \%$ salt and $130 \%$ hydration (based on the dry matter). For wheat bread, the same formulation was used with adjusted hydration based on the solvent retention index and Mixolab $\AA$, i.e. a hydration level of $70 \%$ for whole wheat and 64\% for refined wheat. Solvent retention capacity (SRC) and Mixolab® data were inadequate to determine the proper hydration level for baking maize bread. Hence empirical trials were conducted first to optimize the crumb structure. All samples were aligned based on the moisture content of the flour to establish equal treatment. For maize bread, the batter was placed in a loaf tin and kept for $1 \mathrm{~h}$ at room temperature for proofing, then baked for $25 \mathrm{~min}$ at $200^{\circ} \mathrm{C}$ and relative humidity $(\mathrm{RH})$ of $85 \%$. Bread samples were prepared in duplicate.

\subsubsection{Starch characterization}

Total starch, amylose, amylopectin and resistant starch contents were determined in maize flour using the Megazyme assay kit (Megazyme, Bray, Ireland) based on AACC methods 76-13.01 and 32-40.01.[15] In addition, the resistant starch content of thermoalkaline processed flour and all bread samples were determined. Bread samples were lyophilized prior to analysis.

\subsubsection{Solvent retention capacity}

SRC of all samples (including the flours of the maize/wheat blend) was determined by the AACC 56 - 11 method with slight modifications. Four solvents were individually used to determine the SRC values: $0.5 \mathrm{~g} / \mathrm{mL}$ sucrose (SuRC); $0.05 \mathrm{~g} / \mathrm{mL}$ sodium carbonate (SCRC), $0.05 \mathrm{~g} / \mathrm{mL}$ lactic acid (LARC) and water (WRC). For each sample, $300 \mathrm{mg}$ were weighed in duplicate in a $2 \mathrm{~mL}$ graduated round-bottom centrifuge tube after which $1.5 \mathrm{~mL}$ of solvent was added, followed by vigorous shaking for $10 \mathrm{~s}$ and immediate transfer to a thermomixer at $1400 \mathrm{rpm}$ for $5 \mathrm{~min}$ at $25^{\circ} \mathrm{C}$. Next samples were centrifuged for $2 \mathrm{~min}$ at $4000 \times \mathrm{g}$ at $25^{\circ} \mathrm{C}$. The SRC was calculated as the weight of solvent retained by samples after centrifugation and gel drainage for $10 \mathrm{~min}$, and expressed as a percentage of sample weight on respective moisture content, as follows: Haynes et al. [16]. 


$$
\operatorname{SRC}(\%)=\left(\frac{\text { gel }(\mathrm{g})}{\text { flour }(g)}-1\right) *\left(\frac{86}{100-\text { flour moisture }(\%)}\right) * 100
$$

\subsubsection{Thermal characterization of flour}

Thermal properties were determined using a Differential Scanning Calorimeter (DSC) equipped with a thermal analysis data station (PerkinElmer Corp Norwalk, USA). For gelatinization analysis, a dry flour sample of approximately $5 \mathrm{mg}$ was dispersed in distilled water at $1: 3 \mathrm{w} / \mathrm{v}$ in stainless steel capsule, which was then hermetically sealed and incubated for $2 \mathrm{~h}$ to equilibrate the moisture. Sample and reference pans (balanced to within $\pm 0.5 \mathrm{mg}$ ) were loaded at ambient temperature, cooled to $10^{\circ} \mathrm{C}$, and held for 2 min before scanning to $120^{\circ} \mathrm{C}$. The temperatures of the characteristic transitions, onset $\left(T_{0}\right)$, peak $\left(T_{p}\right)$ and endpoint $\left(T_{f}\right)$ were recorded and the enthalpy $(\Delta H)$ of the transition was expressed as $\mathrm{J} / \mathrm{g}$. The degree of gelatinization (DG) was calculated as [1 $-\Delta \mathrm{Hs}) / \Delta \mathrm{Hn}] \times 100$, where $\Delta \mathrm{Hs}$ is thermoalkaline processed flour and $\Delta \mathrm{Hn}$ is untreated maize flour.

\subsubsection{Rheological behaviour (Mixolab ${ }^{\circledR}$ )}

Rheological behaviour of flour was determined using the Chopin ${ }^{+}$protocol with a dough weight of $100 \mathrm{~g}$ but without a target consistency.[17] The Mixolab ${ }^{\circledR}$ was originally developed to analyse wheat flour but can also be used for non-wheat flours after adjustment of the protocol, e.g. dough weight. ${ }^{[18,19]}$ Rheological behaviour of maize dough was determined using a mixing speed of $80 \mathrm{rpm}$ at a temperature regime of 6 min at $30^{\circ} \mathrm{C}$, heating of $4 \mathrm{~K} / \mathrm{min}$ until $90^{\circ} \mathrm{C}, 7$ min at $90^{\circ} \mathrm{C}$, cooling for $4 \mathrm{~K} / \mathrm{min}$ until $50^{\circ} \mathrm{C}$, and $5 \mathrm{~min}$ at $55^{\circ} \mathrm{C}$. Dough consistency and temperature during the entire process were measured to determine protein power, starch gelatinization, amylase activity and starch retrogradation. The tests were carried out for each sample at constant hydration of $110 \%$ (based on the dry matter; corrected for moisture content of each sample). 


\subsubsection{Loaf characteristics}

Loaf specific volume was measured upon cooling by the rapeseed displacement method according to AACC method 10-05.01, while bake loss was determined by the weight difference before and after baking. Texture profile analysis (TPA) was performed using a TA-XT texture analyser (Stable Micro Systems, Surrey, UK) equipped with a $50 \mathrm{~kg}$ load cell and a $20 \mathrm{~mm}$ aluminium cylindrical probe. Pre-test speed, test speed and posttest speed were $2 \mathrm{~mm} / \mathrm{s}$. The sliced samples (20 mm thickness) were tested using double compression (20\%) with a trigger force of $20 \mathrm{~g}$ at $5 \mathrm{~s}$ wait time between the first and second cycle. TPA measurements were performed $2 \mathrm{~h}$ after baking and on the fifth day. Bread staling was calculated using the following equation by Hager et al. ${ }^{20]}$ :

$$
\text { Bread staling }=\frac{\text { crumb hardness on day } 5-\text { crumb hardness on day } 0}{\text { crumb hardness on day } 0}
$$

\subsubsection{Statistical analysis}

Data analysis was by IBM SPSS $\AA$ software (version 23) and XLSTAT $®$ software (version 2018.5.52280, Addinsoft, New York). The significance level was fixed at $\mathrm{p}<$ 0.05. Data are presented as the mean of two or three determinations depending on the parameter. 


\subsubsection{Results and discussion}

\subsubsection{Physical and proximate characteristics of kernels from maize genotypes}

Table 6.1 shows significant differences $(\mathrm{p}<0.05)$ in all physical parameters measured, except colour (lightness). The highest FI (79-83\%) was observed for the landraces, i.e. soft, while the hybrids showed the lowest FI (3.5-8\%), indicating very hard kernels. This reflects the large proportion of floury endosperm of the popular landraces and the relatively high proportion of vitreous endosperm in the hybrids. Grain hardness is a crucial quality parameter in determining the type of food product to be made and setting optimal processing conditions at industrial and household level. The average grain size (US mesh 24) varied from 95.8 to $98.4 \%$ in the landraces to $12-19.8 \%$ in the hybrids (Table 6.1 \& Figure. 6.1). To date, no relation between the physical properties of maize grains and their bread-making performance has been reported, but the association between tortilla (flatbread) quality and maize physical characteristics has been studied.[8, 21] Industries producing thermoalkaline processed flour prefer grains with hard endosperm ( $\mathrm{FI} \leq 20 \%$ ), kernel weight between 32 and $40 \mathrm{~g}$, grain colour lightness of $\geq 50$ and medium-sized grains. ${ }^{[9]}$ However, the masa-tortilla industry prefers softer kernels with a FI of about 40\%. Garzón et al. [2] found that soft maize improved glutenfree breadmaking performance compared to hard maize. The protein content of all samples did not differ significantly except for hybrid (H2), which had a higher protein content (Table 6.1). Hybrid (H1) with the highest starch content, had the lowest amount of other components. 


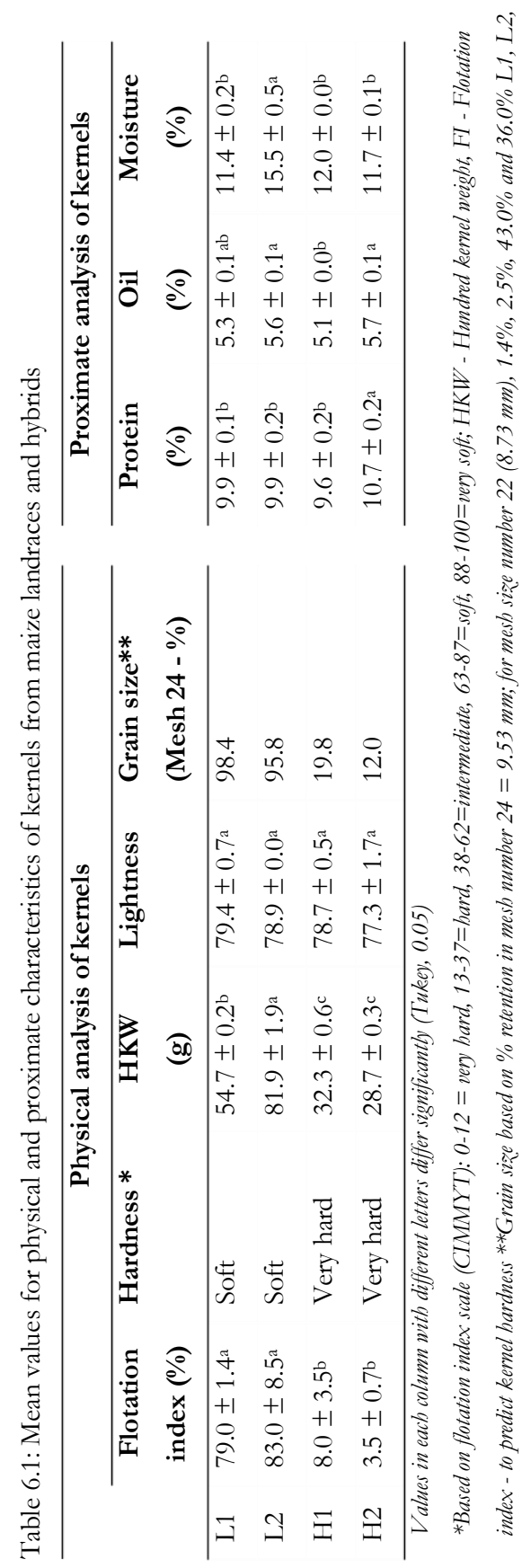




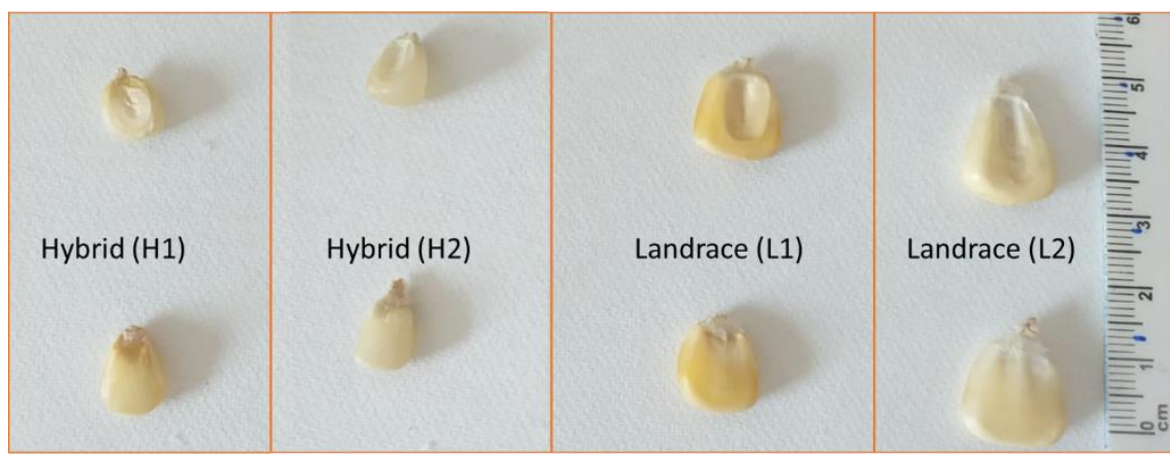

Figure 6.1: Maize hybrids and landraces. H1 (CSTH19001), H2 (Commercial hybrid), L1 (Jala) and L2 (Cacahuacintle). Pictures showing the side views of maize kernels.

\subsubsection{Colour of maize flour}

The colour values for untreated and thermoalkaline processed maize flour are shown in Table 6.2. The lightness $\left(\mathrm{L}^{*}\right)$ of the flour from both landraces decreased significantly (P $<0.05)$ after thermoalkaline cooking, signifying a darker colour. On the contrary, hybrid maize $(\mathrm{H} 1)$ showed an increase in $\mathrm{L}^{*}$. The $\Delta \mathrm{E}^{*}$ ab values indicate that the flours from the landraces after thermoalkaline treatment differ visually in colour, while the colour changes in the hybrids are much smaller. Vázquez-Carrillo et al. ${ }^{[9]}$ reported that large differences $\left(\Delta \mathrm{E}^{*} \mathrm{ab}\right)$ in the colour of landrace flours could be due to the relatively high proportion of phenolic polymers, which easily oxidize under alkaline conditions.

Table 6.2: Colour values for untreated and thermoalkaline processed maize flour

\begin{tabular}{|c|c|c|c|c|c|c|c|}
\hline & \multicolumn{3}{|c|}{ Maize flour } & \multicolumn{4}{|c|}{ Nixtamalized maize flour } \\
\hline & $\mathbf{L}^{*}$ & $a^{*}$ & $\mathrm{~b}^{*}$ & L* & $a^{*}$ & $\mathrm{~b}^{*}$ & $\Delta \mathrm{E}^{*} \mathrm{ab}$ \\
\hline L1 & $96.8^{\mathrm{b}}$ & $-0.4^{a}$ & $15.1^{\mathrm{b}}$ & $93.8^{\mathrm{b}}$ & $-1.7^{b}$ & $18.5^{\mathrm{c}}$ & 4.8 \\
\hline L2 & $100.5^{\mathrm{a}}$ & $-0.3^{a}$ & $11.2^{\mathrm{f}}$ & $95.2^{\mathrm{b}}$ & $-1.6^{a}$ & $18.3^{\mathrm{f}}$ & 8.9 \\
\hline H1 & $96.5^{\mathrm{b}}$ & $-0.5^{\mathrm{a}}$ & $11.7^{\mathrm{e}}$ & $97.7^{\mathrm{c}}$ & $-1.5^{b}$ & $12.7^{\mathrm{a}}$ & 1.8 \\
\hline $\mathrm{H} 2$ & $97.7^{b}$ & $-0.4^{a}$ & $12.2^{\mathrm{d}}$ & $97.4^{\mathrm{bc}}$ & $-0.7^{b}$ & $11.0^{\mathrm{a}}$ & 1.3 \\
\hline
\end{tabular}

$* \Delta \mathrm{E} *$ ab colour interpretation: $0-0.5$ (not noticeable), $0.5-1.5$ (slightly noticeable), $1.5-3.0$ (noticeable), $3.0-6.0$ (well visible) and $6.0-12.0$ (greatly visible). Values are mean of triplicate.

\subsubsection{Total starch, amylose, amylopectin and resistant starch}

Maize samples were characterized by their chemical properties (Table 6.3). The hardest maize sample $(\mathrm{H} 2)$ and the softest $(\mathrm{L} 2)$ significantly differed $(\mathrm{P}<0.05)$ in starch content with $74.5 \pm 0.04$ and $72.4 \pm 0.22$, respectively. RS and its transformation during processing depend on variety. ${ }^{[22]}$ After the thermoalkaline process, more than doubled the resistance starch content was quantified. L1, L2, H1 and H2 had RS contents of $0.83 \%, 0.81 \%, 1.19 \%$ and $1.18 \%$, respectively. This agrees with data from Villada et al. 
[23] for masa (0.917\%) and tortilla (1.477\%) (Table 6.3). Three types of resistant starch have been reported in the processing of maize into masa: (1) physically inaccessible starch in the cellular matrix, (2) amylose-lipid complexes or amylose-calcium complexes, and (3) retrograded starch formed on cooling to low temperatures. [21] RS has several health-supporting properties, such as lowering the risk of colorectal cancer, reduction of insulin sensitivity and lowering the glycaemic index.[23] On the other hand, an increased RS content can negatively affect crumb hardness.

Table 6.3: Total starch, amylose, amylopectin and resistant starch

\begin{tabular}{|c|c|c|c|c|c|c|c|}
\hline & \multirow{2}{*}{$\begin{array}{l}\text { Total } \\
\text { starch }\end{array}$} & \multirow[b]{2}{*}{ Amylose* } & \multirow[b]{2}{*}{ Amylopectin* } & \multicolumn{4}{|c|}{ Resistant starch, dw \% } \\
\hline & & & & $\mid \begin{array}{ll}\text { Raw maize } \\
\text { flour }\end{array}$ & $\begin{array}{l}\text { Nixtamalized } \\
\text { maize flour }\end{array}$ & $\begin{array}{l}\text { Raw maize } \\
\text { bread }\end{array}$ & $\begin{array}{l}\text { Nixtamalized } \\
\text { maize bread }\end{array}$ \\
\hline L1 & $73.8 \pm 0.5^{\mathrm{ab}}$ & $32.6 \pm 1.7^{\mathrm{a}(\mathrm{a})}$ & $67.4^{\mathrm{a}(\mathrm{b})}$ & $0.43 \pm 0.00^{a}$ & $0.83 \pm 0.01^{\mathrm{a}}$ & $1.9 \pm 0.04^{\mathrm{a}}$ & $1.88 \pm 0.04^{\mathrm{a}}$ \\
\hline L2 & $72.4 \pm 0.2^{\mathrm{b}}$ & $32.9 \pm 0.1^{\mathrm{a}(\mathrm{ab})}$ & $67.1^{\mathrm{a}(\mathrm{ab})}$ & $0.33 \pm 0.03^{\mathrm{a}}$ & $0.81 \pm 0.00^{\mathrm{a}}$ & $1.93 \pm 0.03^{\mathrm{b}}$ & $1.48 \pm 0.05^{\mathrm{a}}$ \\
\hline H1 & $72.7 \pm 0.5^{\mathrm{b}}$ & $35.6 \pm 1.1^{\mathrm{a}(\mathrm{b})}$ & $64.4^{\mathrm{a}(\mathrm{a})}$ & $0.38 \pm 0.00^{\mathrm{ab}}$ & $1.19 \pm 0.02^{\mathrm{b}}$ & $2.02 \pm 0.05^{\mathrm{bc}}$ & ${ }^{c} 1.87 \pm 0.03^{a}$ \\
\hline $\mathrm{H} 2$ & $74.5 \pm 0.0^{\mathrm{a}}$ & $35.0 \pm 0.5^{\mathrm{a}(\mathrm{ab})}$ & $65.0^{\mathrm{a}(\mathrm{ab})}$ & $0.42 \pm 0.01^{\mathrm{b}}$ & $1.18 \pm 0.01^{b}$ & $2.18 \pm 0.01^{\mathrm{c}}$ & $1.85 \pm 0.12^{\mathrm{b}}$ \\
\hline
\end{tabular}

$*$ Percentage in the starch of maize flour. Amylopectin determined by amylose difference. Values in each column with different letters are significantly different (Tukey, 0.05). Letters in bracket are based on (Fisher (LSD); 0.05). Values are mean \pm standard deviation of duplicates.

\subsubsection{Solvent retention capacity}

Both the untreated and thermoalkaline processed flours differed significantly in their ability to retain the tested solvents $(\mathrm{P}<0.05)$, as shown in Figure 6.2. Soft maize flour (L1) had the lowest SRC profile for all solvents tested, possibly due to differences in chemical composition, especially the damaged starch content. Flour from hard or vitreous endosperm has been reported to contain significantly more $(p<0.05)$ damaged starch than flour from the floury (soft) endosperm because hard grains have a higher resistance to milling. [24] The physicochemical and thermal properties of starch are significantly influenced by the damaged starch content. Generally, the untreated maize flours and their corresponding thermoalkaline treated samples had different SRC values. Sucrose retention capacity, which corresponds to pentosan characteristics, increased in all thermoalkaline cooked samples. Hydrolysis and solubilization of maize pericarp during thermoalkaline processing generates pentosans, which in part act as hydrocolloids and confer good viscoelastic properties to dough. ${ }^{[21]}$ On the contrary, the lactic acid retention capacity (LARC) (associated with protein characteristics) significantly decreased in all samples up to $22 \%$ in L2 and H1. LARC was the most sensitive property, perhaps because of denaturation of the protein due to the thermoalkaline treatment. High positive correlations were observed among the SRCs: SCRC and LARC; WRC and SCRC; WRC and LARC ( $\mathrm{r}=0.98, \mathrm{P}<0.05)$. However, a negative correlation was found between RS and all SRC profiles, e.g. RS and SuCR ( $\mathrm{r}=$ 
$-0.85, \mathrm{P}<0.05)$ (Table 6.S2). SRC data show a significant difference $(\mathrm{P}=0.004)$ between hybrid and landrace maize while no significant difference $(P=0.937)$ was found between raw and nixtamalized flour (Table 6.S3). Principal Component Analysis (PCA) based on SRC values of untreated and thermoalkaline processed flour (Figure 6.3) distinctively separated (PCA $=87.53 \%$ ) landrace L1 (Jala) from the other maize genotypes. Furthermore, Figure 6.S1 shows that solvent retention parameters of all maize flours are well distant from those of both whole and refined wheat, with L1 (Jala) being the least distant $(\mathrm{PCA}=96.79 \%$ ).

\subsubsection{Thermo-mechanical behaviour of batter}

The Mixolab ${ }^{\circledR}$ measures in real-time the torque generated by a dough between two paddles, thus allowing the study of baking quality and thermo-mechanical performance of hydrated flour. The profiles derived from the maize landraces, hybrids and their respective thermoalkaline cooked flour are summarized in Figure 6.4. The profiles show the parameters of maize batter behaviour during mixing (C1 \& C2), cooking (C3 \& C4) and cooling (C5).[18] Substantial differences were found between the samples for all measured parameters. L1 (Jala) gave the lowest peak value for C1 and C2, namely 0.21 $\mathrm{Nm}$ and $0.04 \mathrm{Nm}$, respectively, which indicates a relatively poor protein quality during mixing at a fixed temperature $\left(30^{\circ} \mathrm{C}\right)$. However, this landrace also had the highest peak torque at C3 (starch gelatinization) as well as at C5 (starch retrogradation at cooling phase). Generally, the viscosity of untreated landrace dough at starch gelatinization was higher than for the hybrids. This confirms previous findings where flint maize showed a lower maximum viscosity and lower retrogradation than dent varieties. ${ }^{[6]}$ The high starch retrogradation value corresponds to shorter shelf life, thus methods to lower starch recrystallization are necessary to improve stability of flour for bread making.[18] L2 (Cacahuacintle) had the slowest retrogradation value. Matos et al. ${ }^{[18]}$ found a significant correlation $(\mathrm{r}=0.7533 \mathrm{P}<0.001)$ between $\mathrm{C} 5$ and hardness. The present study showed a positive correlation between $\mathrm{C} 5$ and cohesiveness $(\mathrm{r}=0.737, \mathrm{P}<0.05)$ and resilience $(\mathrm{r}=0.818, \mathrm{P}<0.05)$, suggesting that genotypes with a low C5 like L2 (Cacahuacintle) could have better bread-making performance, particularly a slow staling.

Thermoalkaline processed flour resulted in dough with at least a two-fold increase in the torque for all parameters, attributable to denaturation of proteins and partial gelatinization of starch (Figure 6.4). Through calcium incorporation, thermoalkaline processing confers malleability and functionality to maize flour suggesting improved viscoelasticity that can compensate for the lack of gluten in maize dough. [7] From a techno-functional perspective, the enhanced dough consistency confers stability to maintain the shape of final product. [7] 


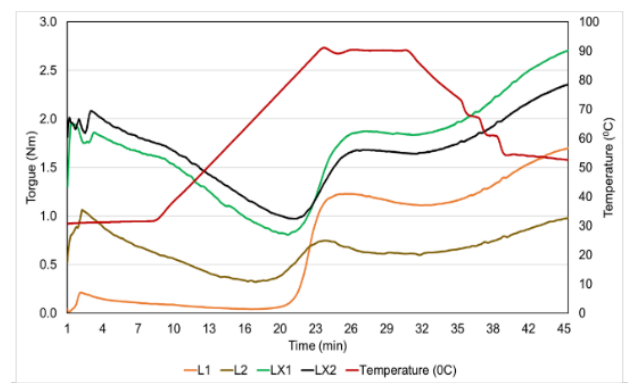

\begin{tabular}{|c|c|c|c|c|c|c|c|}
\hline & \multicolumn{5}{|c|}{ Torque $(\mathrm{Nm})$} & \multirow{2}{*}{$\begin{array}{l}\text { Amplitude } \\
-\quad(\mathrm{Nm})\end{array}$} & \multirow{2}{*}{$\begin{array}{c}\text { Stability } \\
\text { (min) }\end{array}$} \\
\hline & $\mathrm{C} 1$ & $\mathrm{C} 2$ & $\mathrm{C} 3$ & $\mathrm{C} 4$ & $\mathrm{C} 5$ & & \\
\hline L1 & 0.21 & 0.04 & 1.23 & 1.11 & 1.72 & 0.03 & 0.37 \\
\hline L2 & 1.06 & 0.32 & 0.75 & 0.60 & 0.98 & 0.04 & 1.87 \\
\hline LX1 & 1.95 & 0.81 & 1.87 & 1.83 & 2.71 & 2.88 & 0.42 \\
\hline$\underline{\mathrm{LX} 2}$ & 2.08 & 0.97 & 1.68 & 1.64 & 2.36 & 3.28 & 0.40 \\
\hline
\end{tabular}

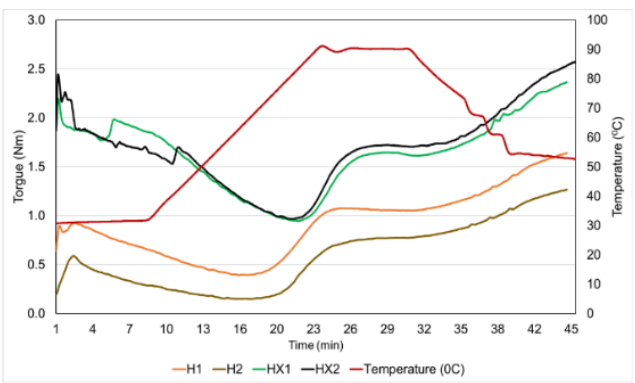

$-\mathrm{H} 1-\mathrm{H} 2-\mathrm{HX} 1-\mathrm{HX} 2-$ Temperature $(0 \mathrm{C})$

\begin{tabular}{cccccccc} 
& \multicolumn{3}{c}{ Torque (Nm) } & \multicolumn{3}{c}{$\begin{array}{c}\text { Amplitude } \\
(\mathrm{Nm})\end{array}$} & $\begin{array}{c}\text { Stability } \\
(\mathrm{min})\end{array}$ \\
\cline { 1 - 4 } $\mathrm{C} 1$ & $\mathrm{C} 2$ & $\mathrm{C} 3$ & $\mathrm{C} 4$ & $\mathrm{C} 5$ & & \\
\hline 0.90 & 0.41 & 1.07 & 0.05 & 1.64 & 0.09 & 4.27 \\
0.57 & 0.15 & 0.77 & 0.72 & 1.26 & 0.03 & 1.17 \\
2.19 & 0.97 & 1.64 & 1.61 & 2.40 & 0.21 & 1.23 \\
2.42 & 0.97 & 1.72 & 1.71 & 2.58 & 2.21 & 1.55 \\
\hline
\end{tabular}

\subsubsection{Thermal properties of untreated and thermoalkaline processed maize flour}

The thermal characteristics of untreated and thermoalkaline processed maize flour measured by DSC are presented in Table 6.4. Untreated flour from L1 (Jala) had a significantly higher enthalpy $(\mathrm{J} / \mathrm{g})$ and gelatinization temperature than the other untreated flours. This indicates that the amylopectin content of the genotype is more stable during heating, making it harder for gelatinization to take place. However, hybrid maize $\mathrm{H} 1$ and $\mathrm{H} 2$ with hard endosperm had a significantly higher gelatinization temperature range. The decrease in the transition temperature range is influenced by a decrease in the onset temperatures (To) rather than a change in the end temperatures (Tc), possibly due to a lower expansion of the starch granule caused by a higher amylose content. The thermal behaviour of starch is influenced by granule size, damaged starch content, amylose/amylopectin ratio and granule crystallinity. ${ }^{[25,26]}$ Thermoalkaline processing raised the gelatinization temperature and decreased the enthalpy of all samples. Maize starch becomes difficult to gelatinize after heat treatment. [26] GonzálezAmaro et al. ${ }^{[25]}$ reported similar thermal properties of maize landraces Cacahuacintle and Bolita, namely a $\mathrm{Tp}\left({ }^{\circ} \mathrm{C}\right)$ of 66.4 and 67.0 respectively. Hybrid maize (H1 and $\left.\mathrm{H} 2\right)$ had a higher degree of gelatinization because hydration saturation is quicker in smaller grains. 
Table 6.4: Thermal parameters of untreated and thermoalkaline processed maize flour a

\begin{tabular}{|c|c|c|c|c|c|c|}
\hline & $\mathbf{T}_{\mathrm{o}}\left({ }^{\circ} \mathrm{C}\right)^{\mathrm{b}}$ & $\mathbf{T}_{\mathrm{p}}\left({ }^{\circ} \mathbf{C}\right)^{\mathrm{b}}$ & $\mathrm{T}_{\mathrm{f}}\left({ }^{\circ} \mathrm{C}\right)^{\mathrm{b}}$ & $\mathrm{T}_{\mathrm{f}}-\mathrm{T}_{\mathrm{o}}\left({ }^{\circ} \mathrm{C}\right)^{\mathrm{b}}$ & $\Delta H(J / g)^{b}$ & DG $(\%)^{b}$ \\
\hline \multicolumn{7}{|c|}{ Raw maize flour } \\
\hline $\mathbf{L} 1$ & $64.5 \pm 0.3^{\mathrm{d}}$ & $70.3 \pm 0.6^{\mathrm{d}}$ & $76.4 \pm 0.1^{\mathrm{e}}$ & $5.8 \pm 0.3^{b}$ & $10.4 \pm 0.5^{a}$ & na \\
\hline $\mathbf{L} 2$ & $59.0 \pm 0.0^{\mathrm{f}}$ & $67.5 \pm 0.0^{\mathrm{g}}$ & $73.0 \pm 0.1^{f}$ & $5.4 \pm 0.1^{\mathrm{c}}$ & $7.4 \pm 0.1^{\mathrm{bc}}$ & na \\
\hline H1 & $57.5 \pm 0.1^{\mathrm{f}}$ & $69.5 \pm 0.0^{\mathrm{e}}$ & $76.8 \pm 0.0^{\mathrm{e}}$ & $7.3 \pm 0.0^{\mathrm{a}}$ & $9.4 \pm 0.1^{\mathrm{ab}}$ & na \\
\hline H2 & $61.0 \pm 0.2^{\mathrm{e}}$ & $69.1 \pm 0.0^{\mathrm{f}}$ & $76.6 \pm 0.1^{\mathrm{e}}$ & $7.6 \pm 0.1^{\mathrm{a}}$ & $9.6 \pm 0.7^{\mathrm{ab}}$ & na \\
\hline \multicolumn{7}{|c|}{ Nixtamalized maize flour } \\
\hline LX1 & $67.8 \pm 0.1^{\mathrm{c}}$ & $73.3 \pm 0.2^{b}$ & $79.9 \pm 0.2^{c}$ & $6.6 \pm 0.1^{b c}$ & $7.8 \pm 0.9^{\mathrm{b}}$ & $24.6 \pm 5.0^{\mathrm{a}}$ \\
\hline LX2 & $66.2 \pm 0.8^{\mathrm{cd}}$ & $71.4 \pm 0.0^{\mathrm{c}}$ & $78.8 \pm 0.0^{\mathrm{d}}$ & $7.4 \pm 0.0^{\mathrm{a}}$ & $4.7 \pm 0.6^{\mathrm{d}}$ & $36.7 \pm 8.2^{\mathrm{a}}$ \\
\hline HX1 & $76.4 \pm 0.4^{a}$ & $76.7 \pm 0.1^{\mathrm{a}}$ & $82.3 \pm 0.3^{\mathrm{a}}$ & $5.5 \pm 0.4^{c}$ & $5.5 \pm 0.7^{\mathrm{c}}$ & $41.8 \pm 7.4^{\mathrm{a}}$ \\
\hline HX2 & $70.4 \pm 0.7^{\mathrm{b}}$ & $76.7 \pm 0.1^{\mathrm{a}}$ & $81.3 \pm 0.1^{\mathrm{b}}$ & $4.6 \pm 0.0^{\mathrm{d}}$ & $4.4 \pm 0.5^{\mathrm{d}}$ & $54.3 \pm 8.0^{\mathrm{a}}$ \\
\hline
\end{tabular}

a Data are means \pm standard deviations. Values in the same column with different letters are significantly different $(\mathrm{p}<0.05)$. ${ }^{\mathrm{b}} \mathrm{T}_{\mathrm{o}}=$ onset temperature; $\mathrm{T}_{\mathrm{p}}=$ peak temperature; $\mathrm{T}_{\mathrm{f}}=$ final temperature; $\Delta \mathrm{H}=$ gelatinization enthalpy; and DG $=$ degree of gelatinization. na $=$ not applicable. Values are mean \pm standard deviation of duplicates.

\subsubsection{Loaf characteristics}

The produced bread differed in specific volume, springiness, resilience and staling. Notably, landrace L1 had a significant $(\mathrm{P}<0.05)$ increase in specific volume. As expected, bread L1 and $\mathrm{H} 1$ with the highest specific volumes, $1.99 \mathrm{~mL} / \mathrm{g}$ and 1.30 $\mathrm{mL} / \mathrm{g}$, respectively, also had the lowest hardness. However, this was not significantly different $(\mathrm{P}<0.05)$ from other bread (Table 6.5). Lower hardness could theoretically be due to less amylose but this does not apply to the current research since the genotypes did not significantly differ in their amylose contents. Bread specific volume and firmness are strong indicators of consumer preference; consumers from subSaharan Africa consider hard bread to be old and no longer fresh. ${ }^{[1]}$ High volume per weight is most preferred, thus giving landrace L1 an edge over other genotypes regarding consumer acceptance. Statistically significant differences existed for bread springiness; H2 hybrid (hard endosperm) showed the lowest value (0.82), while L1 landrace (soft endosperm) showed the highest value (0.90). Soft maize varieties have higher springiness than hard maize, according to Garzón et al. [2]. Bread with a higher specific volume corresponds to higher springiness (Table 6.5). Bread with low springiness crumbles during cutting due to brittleness. Attributes such as hardness, springiness, cohesiveness, chewiness and resilience increased in all bread made from thermoalkaline processed maize flour of all genotypes. Guadarrama-Lezama et al. [7] also observed increased hardness of bread from thermoalkaline processed flour but other textural characteristics decreased. Pregelatinization generally increases dough 
consistency, gumminess and springiness. ${ }^{[6]}$ However, the rheological changes in the dough did not translate to improvement in specific volume and softness of the final product. Using morphological analysis (SEM), Guadarrama-Lezama et al. ${ }^{[7]}$ showed that dough from thermoalkaline processed flour can form a compact microstructure causing increasing hardness in bread.

Table 6.S4 shows the loaf characteristics of composite bread from wheat and maize. As expected, refined wheat composite bread showed a higher specific volume than whole wheat composite bread. In both categories, composite bread made with L1 and H2 genotypes had the highest specific volume, $3.27-3.93 \mathrm{~mL} / \mathrm{g}$ and $3.34-3.86 \mathrm{~mL} / \mathrm{g}$, respectively. In composite bread from thermoalkaline processed flour, volume was reduced by at least 30\%. Wheat bran strongly binds to added water, making it inaccessible for gluten; reactive components in bran (such as glutathione and phytate) and bran-related enzymes (such as endopeptidases) can contribute to weakening of gluten. ${ }^{[27]}$ The volume of all maize bread was at least $40 \%$ lower volume than for their respective wheat composite bread. Concerning the overall texture, the L1R (landrace 1 with refined wheat) composite was the most favourable with a high specific volume (3.93 $\mathrm{mL} / \mathrm{g})$, springiness (1.58), cohesiveness (0.87), chewiness $(1.21 \mathrm{~N})$ and low hardness $(0.92 \mathrm{~N})$.

Lastly, L2 with the lowest amylose content (32.91\%) had the slowest staling. The retrogradation rate of amylose is faster than of amylopectin. Furthermore, the values of C1 showed a negative correlation with the specific volume of bread $(r=-0.721)$ and positive correlation $(r=0.714)$ with hardness (Table 6.S5 - supplementary material). 


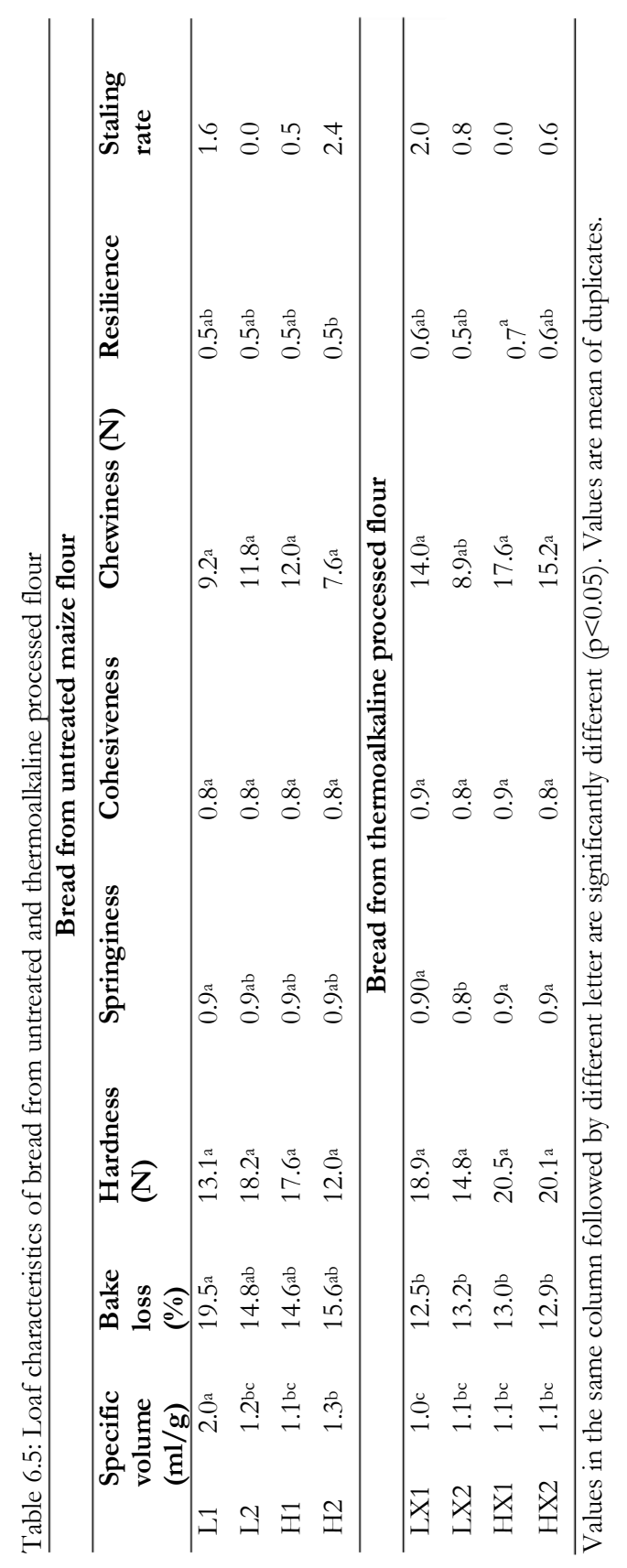




\section{Conclusion}

Bread making performance is not yet considered during maize breeding in spite of the potential for gluten-free bread applications and the available variability in maize germplasm. Furthermore, landrace germplasm traditionally used for bread making is losing its genetic diversity due to the very limited kernel characteristics and strong focus on productivity during the breeding process. In the current research, significant differences $(\mathrm{P}<0.05)$ between maize landraces and hybrids were found in terms of physical kernel characteristics such as flotation index, hardness, size and weight. Maize landraces and hybrids had significantly different $(\mathrm{P}<0.05)$ resistant starch content, solvent retention capacity and the produced bread had differences in specific volume, hardness, springiness and other quality parameters. Hybrid and landrace maize demonstrated significantly different performances during bread-making, hence exploring different landraces with different kernel characteristics will be important to improve the quality of the final product.

\section{CRediT authorship contribution statement}

Onu Ekpa: Conceptualization, Formal analysis, Funding acquisition, Investigation, Visualization, Methodology, Writing - original draft, Writing - review \& editing. Natalia Palacios-Rojas: Conceptualization, Funding acquisition, Methodology, Project administration, Resources, Supervision, Writing - review \& editing. Aldo Rosales: Formal analysis, Methodology, Resources. Stefano Renzetti: Supervision, Writing review \& editing. Vincenzo Fogliano: Funding acquisition, Project administration, Resources, Supervision, Writing - review \& editing. Anita R. Linnemann: Conceptualization, Funding acquisition, Methodology, Project administration, Supervision, Writing - review \& editing.

\section{Acknowledgements}

We thank Hongeun Choi for support in laboratory work and data respectively, for providing the grain used for analysis. We also thank Cristian Zapata of the CIMMYT GenBank for providing Jala landrace maize. We appreciate the staff of the CIMMYT maize and wheat quality

laboratories for technical assistance and the European Cereal Atlas Fund (ECAF) for financial support of the internship of OE at CIMMYT. Financial support from MAIZE-CRP is also appreciated.

\section{Appendix A. Supplementary data}

Supplementary data to this article can be found online at:

https://doi.org/10.1016/j.lwt.2020.109214 


\section{References}

1. Ekpa O, Palacios-Rojas N, Kruseman G, Fogliano V, Linnemann AR. Sub-Saharan African Maize-Based Foods - Processing Practices, Challenges and Opportunities. Food Reviews International. 2019:1-31.

2. Garzón R, Rosell CM, Malvar RA, Revilla P. Diversity among maize populations from Spain and the United States for dough rheology and gluten-free breadmaking performance. International journal of food science \& technology. 2017;52(4):1000-8.

3. Arteaga MC, Moreno-Letelier A, Mastretta-Yanes A, Vázquez-Lobo A, Breña-Ochoa A, Moreno-Estrada A, et al. Genomic variation in recently collected maize landraces from Mexico. Genomics Data. 2016;7:38-45.

4. Figueroa Cárdenas JdD, Narváez González DE, Mauricio Sánchez A, Taba S, Gaytán Martínez M, Medina V, et al. Propiedades físicas del grano y calidad de los grupos raciales de maíces nativos (criollos) de México. Revista fitotecnia mexicana. 2013;36:305-14.

5. Zannini E, Jones JM, Renzetti S, Arendt EK. Functional replacements for gluten. Annual review of food science and technology. 2012;3:227-45.

6. Brites C, Trigo MJ, Santos C, Collar C, Rosell CM. Maize-based gluten-free bread: influence of processing parameters on sensory and instrumental quality. Food and Bioprocess Technology. 2010;3(5):707-15.

7. Guadarrama-Lezama AY, Carrillo-Navas H, Vernon-Carter E, Alvarez-Ramirez J. Rheological and thermal properties of dough and textural and microstructural features of bread obtained from nixtamalized corn/wheat flour blends. Journal of cereal science. 2016;69:158-65.

8. Roque-Maciel L, Arambula-Villa G, Lopez-Espindola M, Ortiz-Laurel H, CarballoCarballo A, Herrera-Corredor J. Nixtamalization of five corn varieties with different kernel hardness: impact in fuel consumption and physicochemical properties. Agrociencia (Montecillo). 2016;50(6):727-45.

9. Vázquez-Carrillo G, García-Lara S, Salinas-Moreno Y, Bergvinson DJ, Palacios-Rojas N. Grain and tortilla quality in landraces and improved maize grown in the highlands of Mexico. Plant Foods for Human Nutrition. 2011;66(2):203-8.

10. Wichser W. The world of corn processing. Am Miller Process. 1961;89(4):29-31.

11. Cserhalmi Z, Sass-Kiss A, Tóth-Markus M, Lechner N. Study of pulsed electric field treated citrus juices. Innovative Food Science \& Emerging Technologies. 2006; 7 (12):49-54.

12. Palacios Rojas N. Calidad nutricional e industrial de maiz: laboratorio de calidad nutricional de maíz "Evangelina Villegas": protocolos. CIMMYT; 2018.

13. Zarcinas B, Cartwright B, Spouncer L. Nitric acid digestion and multi-element analysis of plant material by inductively coupled plasma spectrometry. Communications in Soil Science and Plant Analysis. 1987;18(1):131-46.

14. Falade AT. Improving the quality of non-wheat bread made from maize using sourdough fermentation: University of Pretoria; 2014.

15. McCleary BV, Monaghan DA. Measurement of resistant starch. Journal of AOAC International. 2002;85(3):665-75. 
16. Haynes LC, Bettge AD, Slade L. Soft wheat and flour products methods review: solvent retention capacity equation correction. Cereal Foods World. 2009;54(4):174-5.

17. Dubat A. Whole-Kernel Mixolab Testing for Different Cereals. Mixolab: Elsevier; 2013. p. 85-8.

18. Matos ME, Rosell CM. Understanding gluten-free dough for reaching breads with physical quality and nutritional balance. Journal of the Science of Food and Agriculture. 2015;95(4):653-61.

19. Xie L, Chen N, Tang S, Luo J, Jiao G, Hu P. Use of Mixolab in predicting rice quality. Cereal chemistry. 2011;88(4):333-7.

20. Hager A-S, Wolter A, Czerny M, Bez J, Zannini E, Arendt EK, et al. Investigation of product quality, sensory profile and ultrastructure of breads made from a range of commercial gluten-free flours compared to their wheat counterparts. European Food Research and Technology. 2012;235(2):333-44.

21. Santiago-Ramos D, de Dios Figueroa-Cárdenas J, Mariscal-Moreno RM, EscalanteAburto A, Ponce-García N, Véles-Medina JJ. Physical and chemical changes undergone by pericarp and endosperm during corn nixtamalization-A review. Journal of Cereal Science. 2018;81:108-17.

22. García-Rosas M, Bello-Pérez A, Yee-Madeira H, Ramos G, Flores-Morales A, MoraEscobedo R. Resistant starch content and structural changes in maize (Zea mays) tortillas during storage. Starch-Stärke. 2009;61(7):414-21.

23. Villada J, Sánchez-Sinencio F, Zelaya-Ángel O, Gutiérrez-Cortez E, RodríguezGarcía M. Study of the morphological, structural, thermal, and pasting corn transformation during the traditional nixtamalization process: From corn to tortilla. Journal of Food Engineering. 2017;212:242-51.

24. Xu A, Lin L, Guo K, Liu T, Yin Z, Wei C. Physicochemical properties of starches from vitreous and floury endosperms from the same maize kernels. Food chemistry. 2019;291:149-56.

25. González-Amaro RM, de Dios Figueroa-Cárdenas J, Perales H, Santiago-Ramos D. Maize races on functional and nutritional quality of tejate: A maize-cacao beverage. LWT-Food Science and Technology. 2015;63(2):1008-15.

26. Miyazaki M, Morita N. Effect of heat-moisture treated maize starch on the properties of dough and bread. Food Research International. 2005;38(4):369-76.

27. Hemdane S, Jacobs PJ, Dornez E, Verspreet J, Delcour JA, Courtin CM. Wheat (Triticum aestivum L.) bran in bread making: a critical review. Comprehensive reviews in food science and food safety. 2016;15(1):28-42. 



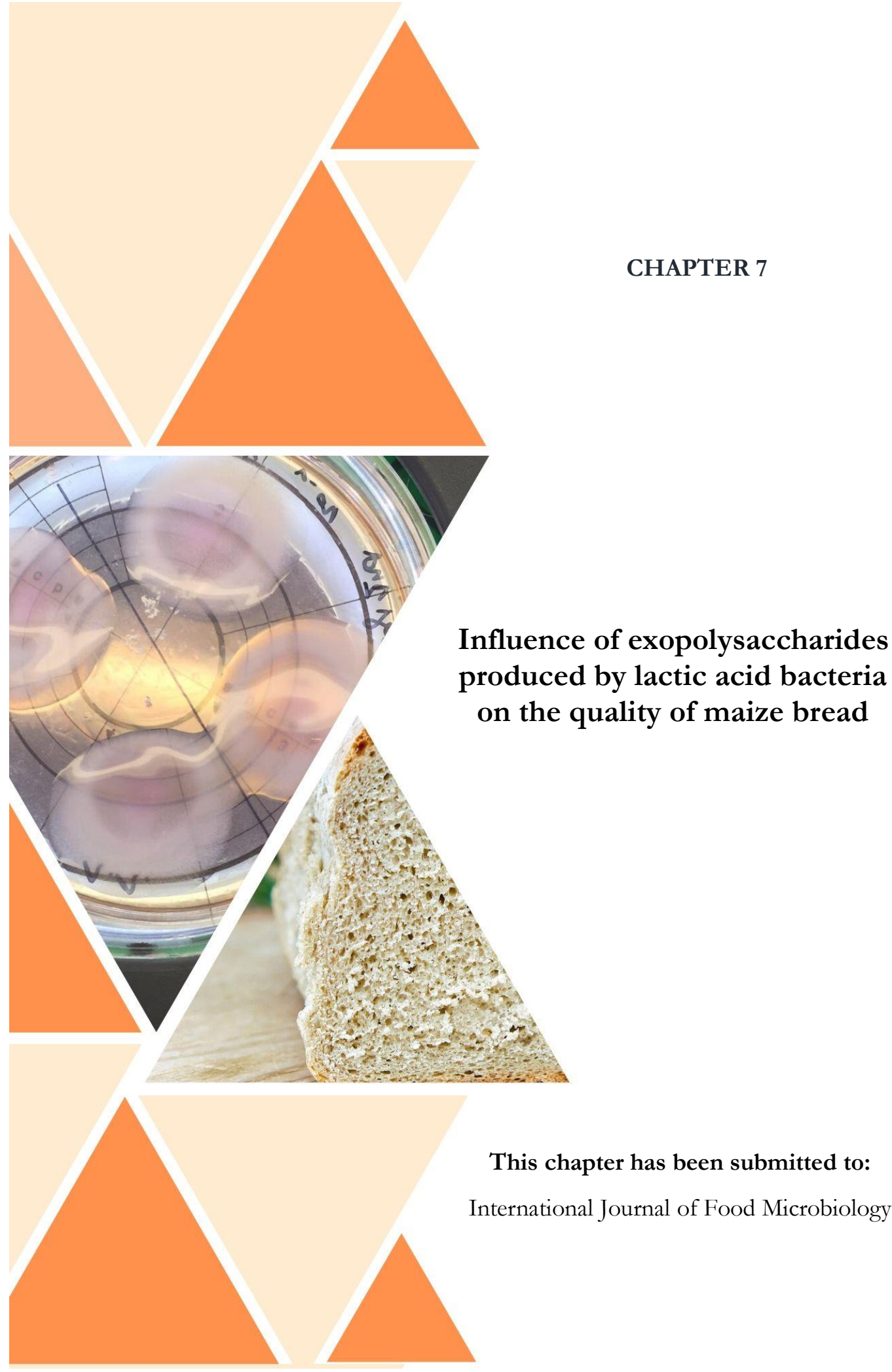




\begin{abstract}
Sourdough has been used to improve the texture of gluten-free bread for its in situ acidification and production of exopolysaccharides (EPS). Since wheat is not sufficiently cultivated in Sub-Saharan Africa where the demand for bread is on the rise, the application of sourdough can serve as a viable option for making gluten-free bread from maize. In our research, sourdoughs were fermented using isolated bacteria with or without $10 \%$ addition of sucrose or sprouted maize flour as source of carbon. Lactic acid bacteria were isolated from two traditional African foods, namely munkoyo and ogi, of which $22 \%$ and $10 \%$, respectively, were EPS producers having slimy, viscous and mucoidal colonies. The total yield of EPS in modified MRS broth ranged from 5.0 to $9.6 \mathrm{~g} / \mathrm{L}$, with the highest amount for Weissella confusa strain Mk02. Significant differences $(\mathrm{p}<0.05)$ were observed in $\mathrm{pH}$, TTA and organic acids among the sourdoughs, showing diverse buffering capacities of the formulations. Peak viscosity of the control increased from $627 \mathrm{~Pa} \cdot \mathrm{s}$ to $901 \mathrm{~Pa} \cdot \mathrm{s}$ and $1326 \mathrm{~Pa} \cdot \mathrm{s}$ after fermentation at $30^{\circ} \mathrm{C}$ with $\mathrm{W}$. confusa and Lactobacillus plantarum, respectively. After fermentation at $37^{\circ} \mathrm{C}$, peak viscosities of $897 \mathrm{~Pa} \cdot \mathrm{s}$ and $684 \mathrm{~Pa} \cdot \mathrm{s}$ were found for $W$. confusa and L. plantarum, respectively. Sourdough with the highest viscosity did not correspond with the highest amount of EPS. Gelatinization parameters such as onset temperature, peak temperature, final temperature and temperature range were not significantly $(p<0.05)$ different among sourdoughs but a significant difference $(p<0.05)$ in enthalpy was observed. Bread derived from the formulation containing sprouted maize flour, which held the highest EPS content, had the highest specific volume $(2.04 \mathrm{~mL} / \mathrm{g})$ and the lowest bread hardness $(12.62 \mathrm{~N})$. The role of EPS in modulating rheological properties of dough and textural properties of maize bread could not be conclusively established in this study because of confounding factors caused by acidification during fermentation.
\end{abstract}

Keywords: Sourdough fermentation; Lactic acid bacteria; exopolysaccharides; glutenfree bread quality; Weissella confusa 


\subsubsection{Introduction}

The growing urbanization in Sub-Saharan Africa (SSA) has increasingly led to shifts towards consumption of bread, mainly produced from wheat, which is not sufficiently cultivated on the continent.[1] This trend is expected to continue at the expense of socioeconomic development of people if no alternative solution is presented. Thus there is a sense of urgency to investigate appropriate technologies to improve indigenous crops that are naturally resilient and climate-smart such as maize, sorghum and millet for nonwheat bread production. ${ }^{[2]}$ However, these crops, which are entrenched in the traditional food system of the people in SSA, lack technological requirements such as the development of a viscoelastic dough upon hydration. [3]

Maize accounts for $45 \%$ of the cereal production in SSA [4], making it a suitable alternative crop for making gluten-free bread in this region. However, maize flour does not have network-forming proteins, thus resulting in bread characterized by a low specific volume, hard crumb and poor mouthfeel. ${ }^{5,6}$ 6] Generally, ingredients to substitute gluten, such as hydrocolloids, are added to maize flour. Moreover, enzyme and sourdough technology is applied to improve bread crumb structure. ${ }^{[7]}$ Sourdough technology improves flavour, nutritional quality, shelf life and textural properties of bakery products when properly applied. [8] One of the aspects of sourdough technology that is gaining traction in research is the ability of bacteria to produce organic acids and exopolysaccharides (EPS) in situ during food fermentation. Acidification during fermentation drops the $\mathrm{pH}$ below the isoelectric point of protein, thereby conferring a net positive charge on the protein and activating proteinases. This increases protein solubility and consequently enhances bread texture.[9-11] EPS are biopolymers commonly produced in situ by bacteria that can act as a natural stabilizer, hydrocolloid and emulsifier. The application of sourdough technology to gluten-free flour confers suitable rheological properties to baked products. ${ }^{[11]}$ The nature of the EPS - molecular weight, composition of the chain (homo/hetero-saccharide), chain length and degree of branching - determine the physical properties as regards dough viscoelasticity and bread crumb structure.[11,12] The quantity of EPS and their chemical structure depend on the microorganism and substrate present. Flour made from sprouted grains contains mono- and disaccharides (i.e. maltose, sucrose and glucose), which can serve as substrates for EPS production. ${ }^{[13]}$ Aside from their rheological contribution, EPS have beneficial health functions through their prebiotic effects such as anticholesteremic, antitumor and immunomodulating effects. ${ }^{[14]}$ Suitable EPS producing bacteria can be obtained from studies on natural diversity of lactic acid bacteria (LAB) in locally fermented maize-based foods and beverages in SSA such as ogi (in Nigeria) ${ }^{[2]}$ and munkoyo (in Zambia) ${ }^{[2]}$. Isolated bacteria can serve as pure starter cultures for making sourdough, which can be sustained at household level through backslopping. $[8,15]$ 
Hüttner et al. ${ }^{[15]}$ and Schwab et al. ${ }^{[16]}$ found that LAB such Lactobacillus reuteri, Weissella cibaria, Lactobacillus plantarum, Leuconostoc argentinum, Leuconostoc mesenteroides, Lactobacillus coryniformis and Pedicoccus pentosaceus have vast potential to increase the loaf-specific volume as well as other quality parameters of gluten-free bread due to their EPS producing abilities. LAB are generally recognized as safe (GRAS). Hence they can serve as a source of food-grade polysaccharides to enhance texture and sensory properties of maize sourdough bread.

The present study aimed to isolate, screen and identify EPS-producing LAB in ogi (a traditional fermented maize-based dough consumed as porridge in West Africa) and munkoyo (a cereal-based traditional fermented beverage in Zambia) as well as assess their potential for the production of sourdough maize bread.

\subsubsection{Materials and methods}

\subsubsection{Materials}

White maize, variety MM603, was provided by a farmer in Zambia. L. plantarum (Lb0073) was obtained on MRS agar from the laboratory of Food Microbiology, Wageningen University, the Netherlands. Ogi was bought on a local market in Nigeria and munkoyo was collected from Zambia. All chemicals and microbial media were purchased from Sigma-Aldrich Chemie NV, Zwijndrecht, the Netherlands.

\subsubsection{Sprouted maize flour and native maize flour}

Sprouted maize was prepared as described by Adegbehingbe [17]. The kernels were placed in a container with $500 \mathrm{~mL}$ of water and soaked for $24 \mathrm{~h}$. The soaked maize was rinsed and drained 3 times per day until the third day when all kernels germinated (free of the green coleoptile). Samples were then dried in a hot air dryer (Retsch Quick Drying Machine type TG2200, Germany) at $50^{\circ} \mathrm{C}$ with an airflow of $40 \mathrm{~m}^{3} / \mathrm{h}$ until the moisture content was below $12 \%$. The sprouted maize and native maize were separately milled in a rotor mill using a $500 \mu \mathrm{m}$ mesh.

\subsubsection{Isolation, purification and characterization of EPS producing bacteria}

To derive bacteria isolates, $10 \mathrm{~g}$ of ogi and $10 \mathrm{~mL}$ of munkoyo were separately suspended in $90 \mathrm{~mL}$ of sterile phosphate-buffered saline (PBS) solution and stomached in triplicates, followed by serial dilution $\left(10^{-1}\right.$ to $\left.10^{-5}\right) \cdot[18]$ One millilitre of each diluted sample was pour-plated on MRS agar and incubated anaerobically for $48 \mathrm{~h}$ at $37^{\circ} \mathrm{C}$. Three consecutive streak plating steps were used to purify the bacteria.

All isolated bacteria were tested for EPS production. The MRS agar cultivation medium was supplemented with $60 \mathrm{~g} / \mathrm{L}$ sucrose. After incubation for $48 \mathrm{~h}$ at $37^{\circ} \mathrm{C}$, EPS 
producing bacteria were isolated using a visual approach, i.e. mucoidal colonies (creamy and slimy) were classified as EPS producers. Isolated colonies were re-streaked on MRS broth, grown and stored in $25 \% \mathrm{v} / \mathrm{v}$ glycerol at $-80^{\circ} \mathrm{C}$ as a stock culture.

The EPS producers were phenotypically and biochemically characterized before the experiment. Isolated colonies were identified using microscopic observation, gram staining, catalase activity and oxidase test. To identify the bacteria to species level, API $50 \mathrm{CHL}$ medium was used, with known L. plantarum as control. The tubes were filled with cell suspension and covered with mineral oil before incubating for $48 \mathrm{~h}$ at $30^{\circ} \mathrm{C}$. The biochemical profiles obtained for the strains were identified using the Apiweb ${ }^{\mathrm{TM}}$ identification software with database (V5.2).

\subsubsection{Extraction of EPS}

EPS extraction, purification and quantification were done as previously described by Adesulu-Dahunsi et al. ${ }^{[18]}$ with modifications. Before extraction, the growth curve of the bacteria was determined at $30^{\circ} \mathrm{C}$ for $72 \mathrm{~h}$, see Figure $7 . \mathrm{S} 1$ in the appendix. Five bacterial isolates were tested for EPS production. The cell pellet was resuspended with ultrapure water to attain turbidity of McFarland standard one, Figure 7.S2 in the appendix. One millilitre of isolated bacteria (McFarland standard 1, i.e. 3 × $10^{8}$ $\mathrm{CFU} / \mathrm{mL}$ ) were grown in MRS (plus $100 \mathrm{~g} / \mathrm{L}$ sucrose) broth at $30^{\circ} \mathrm{C}$ and $37^{\circ} \mathrm{C}$ for 48 $\mathrm{h}$ with intermittent shaking.

After incubation, the culture broth was heated at $80{ }^{\circ} \mathrm{C}$ for $10 \mathrm{~min}$, then cooled in ice before adding $15 \%(\mathrm{v} / \mathrm{v})$ of $80 \%$ trichloroacetic acid (TCA) to precipitate DNA and protein. The mixture was incubated at $37^{\circ} \mathrm{C}$ for $30 \mathrm{~min}$ at $100 \mathrm{rpm}$ then centrifuged in $250 \mathrm{ml}$ bottles at $10,000 \mathrm{xg}$ for $10 \mathrm{~min}$ at $4^{\circ} \mathrm{C}$ to remove cell pellets (biomass). The supernatant was precipitated using double volume ice-cold ethanol $(95 \%, \mathrm{v} / \mathrm{v})$ overnight $(24 \mathrm{~h})$ at $4^{\circ} \mathrm{C}$. The precipitate was collected in a $50 \mathrm{ml}$ tube and centrifuged at $4,500 \times \mathrm{g}$ for $20 \mathrm{~min}$ at $4^{\circ} \mathrm{C}$, followed by three rounds of precipitation. Extracted EPS was resuspended in $5 \mathrm{~mL}$ ultrapure water, vortexed and dialyzed against distilled water using $10 \mathrm{kDa}$ dialysis membranes for $48 \mathrm{~h}$. Pure EPS was collected in a $50 \mathrm{~mL}$ tube, covered with parafilm, freezed at $-80^{\circ} \mathrm{C}$ and lyophilized at $-50^{\circ} \mathrm{C}$ for $48 \mathrm{~h}$. The total quantity of EPS was measured by the weight of solids after lyophilization. The same process was applied for extraction of EPS from maize dough. 


\subsubsection{Sourdough preparation}

All flour samples were pre-treated at $60^{\circ} \mathrm{C}$ for $30 \mathrm{~min}$ to reduce the initial microbial load, see table 7.S1 in the appendix for sample description. The addition of $10 \%$ sprouted maize flour and sucrose were to support EPS production by the bacteria, i.e. $W$. confusa (EPS producer) and L. plantarum (non-EPS producer). Sourdough was prepared using a flour-water ratio of 1:2, followed by inoculation of $1 \mathrm{~mL}$ cell suspension $\left(10^{8}(\mathrm{CFU}) / \mathrm{mL}\right)$ that was determined using $1 \mathrm{McFarland}$ solution standard as proposed by Galle et al. [11]. Samples were incubated for $48 \mathrm{~h}$ at $30^{\circ} \mathrm{C}$ and $37^{\circ} \mathrm{C}$, then freeze-dried and stored at $-21^{\circ} \mathrm{C}$.

\subsection{6 $\mathrm{pH}$, total titratable acidity (TTA) and organic acid}

The $\mathrm{pH}$ and TTA were determined before sourdough fermentation and after $48 \mathrm{~h}$ of fermentation. Ten grams of freeze-dried sourdough was prepared in $90 \mathrm{~mL}$ of sterile water. The $\mathrm{pH}$ results were determined by a $\mathrm{pH}$ meter and the samples were then titrated with $0.1 \mathrm{M} \mathrm{NaOH}$ to $\mathrm{pH} 8.5$ to analyse TTA as described by Wolter et al. [8]. The protein in the flour for organic acid determination was first precipitated with $7 \%$ perchloric acid overnight at $4^{\circ} \mathrm{C}$ for $15 \mathrm{~h}$. The supernatant was pipetted after centrifugation $(2000 \mathrm{x} \mathrm{g}, 20 \mathrm{~min})$ and filtered through a $0.45 \mu \mathrm{m}$ filter before measurement by an Agilent 1200 HPLC system coupled to a refractive index detector and a REZEX $8 \mu$ Organic Acid Column (Phenomenex, USA).

\subsubsection{Water absorption capacity (WAC)}

Two grams of freeze-dried sourdough was weighed into a $15 \mathrm{~mL}$ centrifuge tube and $10 \mathrm{~mL}$ of distilled water was added, then vigorously shaken by a vortex for $1 \mathrm{~min}$ and left for $30 \mathrm{~min}$. The mixture was centrifuged at $2200 \mathrm{x}$ g for $20 \mathrm{~min}$. The supernatant was decanted and the weight of the tube with the sediment was measured. Water absorption capacity was calculated following equation:

$$
\text { Water absorption capacity }=\frac{(\text { Sediment }- \text { Sample weight })}{\text { sample weight }(\text { dry basis })} * 100
$$

\subsubsection{Thermal characterization of native maize flour and freeze-dried sourdough}

Differential Scanning Calorimeter (DSC) (Perkin-Elmer Corp Norwalk. USA) was used to analyse the thermal properties (including gelatinization temperatures). ${ }^{[19]}$ In short, 5 $\mathrm{mg}$ dry flour sample was dissolved in distilled water in a ratio of $1: 3 \mathrm{w} / \mathrm{v}$ in airtight stainless steel capsules and left to equilibrate for $2 \mathrm{~h}$. Sample and reference in duplicate pans were cooled to $10^{\circ} \mathrm{C}$, and held for 2 min before scanning to $120^{\circ} \mathrm{C}$. The onset $\left(\mathrm{T}_{0}\right)$, 
peak $\left(T_{p}\right)$, endpoint $\left(T_{f}\right)$ of gelatinization temperature and the enthalpy $(\Delta H)$ were recorded.

\subsubsection{Rheological properties}

A rheometer (Anton Paar MCR-102 with geometries CC17/Ti-38491 and C-CC17/Ti21932) was used to measure pasting properties of the samples.[20] Three grams of sourdough were prepared with $18 \mathrm{~mL}$ of demi water. For the thermal profile, the initial temperature of the system was $50^{\circ} \mathrm{C}$ and held there for $1 \mathrm{~min}$. The sample was then heated from 50 to $90^{\circ} \mathrm{C}$ for $5.3 \mathrm{~min}$, held constant at $90^{\circ} \mathrm{C}$ for $5.3 \mathrm{~min}$, cooled to $50^{\circ} \mathrm{C}$ for $5.3 \mathrm{~min}$ and held at $50^{\circ} \mathrm{C}$ for $2 \mathrm{~min}$. All samples were performed in duplicate. Pasting temperature, peak viscosity, final viscosity, breakdown viscosity and setback viscosity were recorded.

\subsubsection{Bread production}

Sourdough bread was prepared by using the native maize, sourdough and a composite containing 20\% sourdough and native maize. The recipe for maize bread making was adapted from Falade [10]. The formula used was based on flour weight, as follows: $5 \%$ sugar, $3 \%$ dry yeast, $2 \%$ margarine, $2 \%$ salt and $110 \%$ hydration. The batters were proofed in small loaf tins (width: $4.3 \mathrm{~cm}$, height: $3.1 \mathrm{~cm}$, length: $9.1 \mathrm{~cm}$ ) at $30^{\circ} \mathrm{C}$ and $85 \%$ relative humidity $(\mathrm{RH})$ for $1 \mathrm{~h}$. The oven was preheated to $210^{\circ} \mathrm{C}$ top and bottom and the batters were baked for $25 \mathrm{~min}$. The loaves were left to cool at room temperature for $2 \mathrm{~h}$ and subsequently analysed or stored in plastic bags at ambient temperature. All bread was prepared with sourdough that had been fermented at $37^{\circ} \mathrm{C}$ since this condition showed optimal EPS production.

\subsubsection{Bread characteristics}

Loaf specific volume was measured after cooling using the rapeseed displacement method according to AACC method 10-05.01, and bake loss was calculated by the percentage of weight difference before and after baking. Texture Profile Analysis (TPA) of breadcrumb was determined on three slices taken from the centre of each loaf using a TA-XT2 texture analyser (Stable Micro Systems, Godalming, UK) following the procedure of Falade et al. [3]. The texture analyser was equipped with a $50 \mathrm{~kg}$ load cell and a $35 \mathrm{~mm}$ aluminium cylindrical probe. Pre-test speed, test speed and post-test speed were $2 \mathrm{~mm} / \mathrm{s}$, trigger force was $0.05 \mathrm{~N}$, the distance was $10 \mathrm{~mm}$ (40\% compression) and wait time between the first and second compression cycle was $5 \mathrm{~s}$. Results using TA-XT2 software were calculated in terms of hardness, cohesiveness, springiness and chewiness of the bread at day 0 after $2 \mathrm{~h}$ baking. 


\subsubsection{Image analysis}

An IRIS V400 electronic visual analyser (Alpha MOS, France) was used to determine breadcrumb structure with a $25 \mathrm{~mm}$ lens. After applying a colour filter to isolate different parts of the bread, slice area, cell volume, porosity and crumb brightness were obtained for calculation of breadcrumb parameters. Porosity was calculated using the 'colour descriptor' option available in the software by changing the hue, saturation, value (HSV) of the image. Porosity was calculated as the difference in total crumb area minus the non-pore area. All analyses were performed in triplicate for each baking batch cut transversely into $10 \mathrm{~mm}$ slices.

\subsubsection{Data analysis}

ANOVA and Tukey's pairwise posthoc test were used to identify the significant differences between the functional characteristics of the flour mixtures and bread quality attributes through IBM SPSS ${ }^{\circledR}$ software (version 23) and XLSTAT ${ }^{\circledR}$ software (version 2018.5.52280, Addinsoft, New York).

\subsubsection{Results and discussion}

\subsubsection{Isolation and identification of EPS producers}

Ninety-six bacterial colonies were isolated from munkoyo and 105 colonies from ogi. None of the colonies showed signs of slime or mucoid when grown on normal MRS agar (no sucrose supplement). When colonies were grown on EPS agar supplemented with sucrose using a four-spot plating technique, non-EPS producers showed rough and irregular colonies, while EPS producers showed slimy, viscous and mucoidal colonies, figure 7.1. In total, $10 \%$ (9 bacteria) of colonies isolated from ogi were EPS producers while $22 \%$ (23 bacteria) of those separated from munkoyo were EPS producers, figure 7.2. It is important to point out that some colonies counted as nonproducers showed no growth, i.e. the cells were not viable after plating on MRS sucrose plates. 


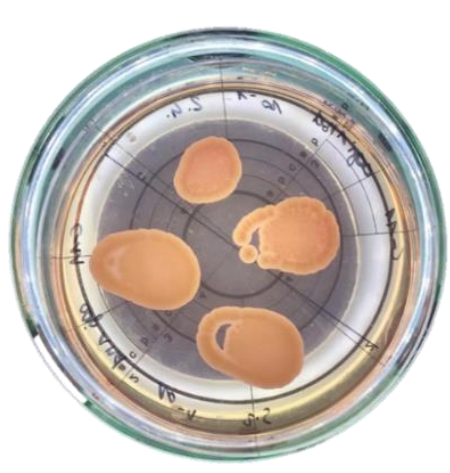

(A) (MRS/Suc ${ }^{+}$) No EPS

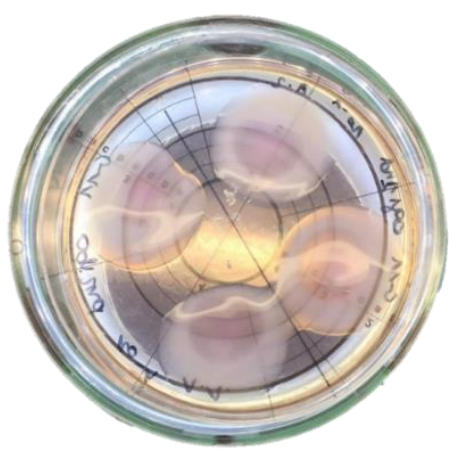

(B) (MRS/Suc $)$ EPS

Figure 7.1: Irregular colonies due to the absence of EPS (A) and slimy colonies due to EPS production by LAB (B)

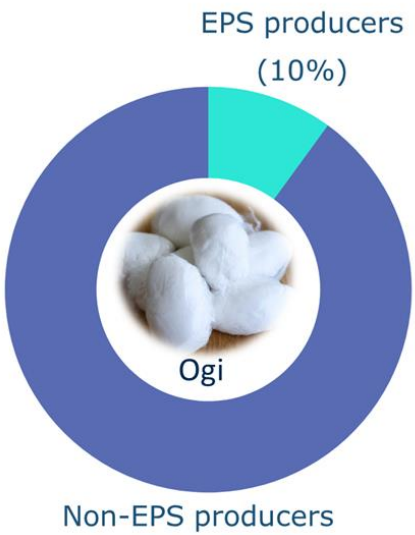

$(90 \%)$

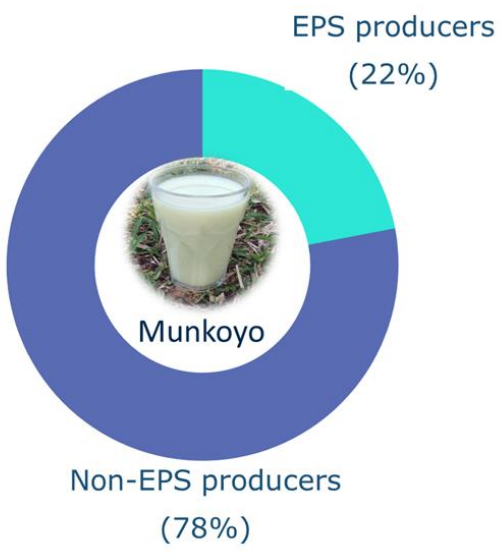

Figure 7.2: Percentage of EPS and non-EPS producers in ogi (left) and munkoyo (right)

It is not known why munkoyo beverage had a higher number of EPS producers. However, organisms may produce EPS to protect themselves against stress conditions, e.g. absence of nutrients and oxygen, suboptimal temperatures, desiccation, osmotic pressure, lethal compounds and phage attacks. ${ }^{[1]}$ Munkoyo is made by cooking maize meal in water before adding an inoculant (Rhynchosia heterophylla root).[22] Furthermore, munkoyo is fermented in containers such as buckets or calabashes, which usually have biofilms on their surfaces. ${ }^{[22]}$ The organisms resident in the biofilms, which act as a starter culture, could be responsible for the higher numbers of EPS producers in 
munkoyo compared to ogi, where no biofilm nor obvious stress conditions were present.

From all the EPS producers, five bacterial colonies were selected for identification based on their relatively high mucoidal colony formation on MRS sucrose agar. All five organisms were characterized as rods, gram-positive, catalase-negative and growing on MRS agar (table 7.1), thus implying that these organisms were LAB. Based on a biochemical test (API $50 \mathrm{CHL})$, the bacterial strains were identified as $W$. confusa (Mk01), $W$. confusa (Mk02), L. brevis (Og01), W. confusa $(\mathrm{Og} 02)$ and $W$. confusa $(\mathrm{Og} 03)$, table 7.1. Unexpectedly, the selected organisms belonged to the same species except for Og01. Different EPS producing LAB have been identified in literature. ${ }^{[8,11,16,21,23,24]} W$. confusa is a LAB species that is often found in fermented foods. The genera $W$ eissella and Lactobacillus have been widely studied for their ability to produce significant amounts of EPS.[16, 18, 25, 26] $W$. confusa has been found in traditional African foods such as ogi [18], fura ${ }^{[27]}$, lafun ${ }^{28]}$, borde ${ }^{[29]}$ and togwa. ${ }^{[30]}$ Other bacteria associated with EPS production are Lactobacillus reuteri and Leuconostoc mesenteroides. ${ }^{[16,31]}$

Table 7.1: Biochemical and morphological characteristics of LAB from ogi and munkoyo

\begin{tabular}{l|c|c|c|c|l}
\hline Code & Gram & Catalase & Oxidase & Slime EPS & Bacterium * \\
\hline $\mathrm{Mk} 01$ & + & - & - & ++ & Weissella confusa \\
$\mathrm{Mk} 02$ & + & - & - & +++ & Weissella confusa \\
$\mathrm{Og} 01$ & + & - & - & + & Lactobacillus brevis \\
$\mathrm{Og} 02$ & + & - & - & ++ & Weissella confusa \\
$\mathrm{Og} 03$ & + & - & - & ++ & Weissella confusa \\
\hline
\end{tabular}

*\% Identification: $>99 \%$ - based on carbohydrate fermentation profiles analysed using API-WEBTM API 50 CHL V5.2 software. Bacteria with "Mk" were isolated from munkoyo while "Og" from ogi. + represents the degree of mucoidal colonies on modified MRS plate.

\subsubsection{EPS production}

First, the EPS production of the five selected bacteria in MRS broth was quantified (including non-EPS producing $L$. plantarum as control). The $W$. confusa Mk02 isolated from munkoyo showed the highest EPS production $(9.6 \mathrm{~g} / \mathrm{L})$, figure 7.3 . Based on the results obtained in MRS broth, $\mathrm{Mk} 02$ was used as inoculum for the maize flour based sourdoughs. EPS production in sucrose supplemented dough (SuMF) was significantly lower than in MRS broth, figure 7.4. The low yield could not have been due to a low amount of fermentable sugars because the control sample (NaMF) that contained no sucrose or sprouted flour had a higher EPS production. The highest EPS production was found in SpMF (maize flour supplemented with sprouted maize flour) fermented at $30^{\circ} \mathrm{C}$ and $37^{\circ} \mathrm{C}$. The supplementation of sprouted maize provided metabolites necessary for building the polysaccharides.[13] EPS production is affected by the fermentation conditions, the nature of the organism and the available nutrients. 

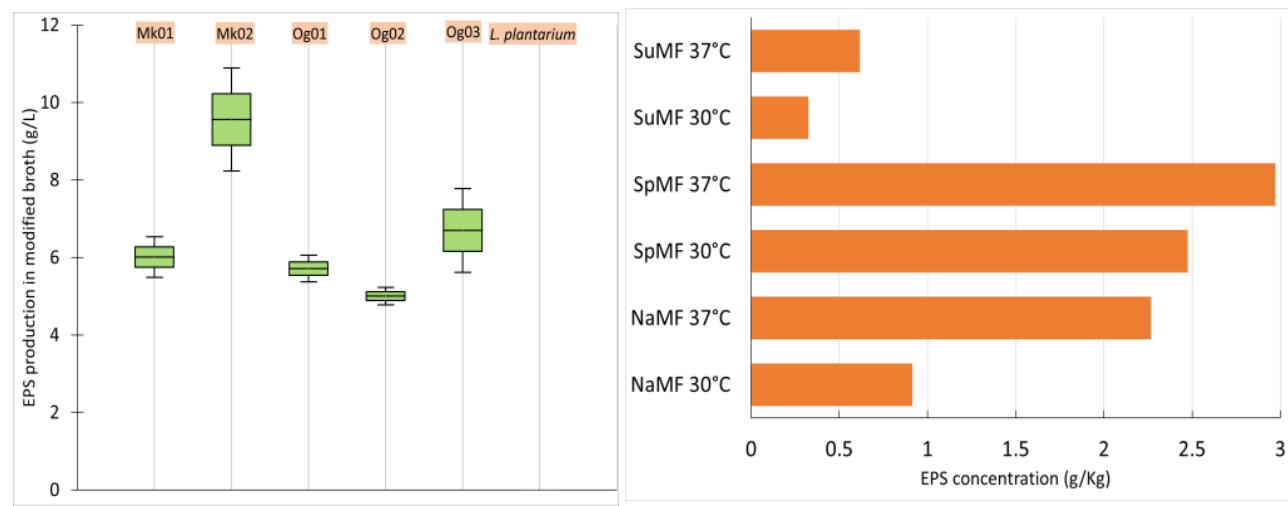

Figure 7.3: EPS concentrations in modified

Figure 7.4: EPS in modified maize sourdough (sucrose or sprouted flour) by bacterial strain $\mathrm{Mk} 02$ after $72 \mathrm{~h}$ of fermentation at $30^{\circ} \mathrm{C}$ and $37^{\circ} \mathrm{C}$ on SuMF (with sucrose), SpMF (with sprouted flour) and NaMF (maize flour).

EPS production was higher at $37^{\circ} \mathrm{C}$ for all samples, irrespective of the substrate used. Wolter et al. ${ }^{[8]}$ found higher amounts of EPS $(4.0 \mathrm{~g} / \mathrm{kg})$ than in the current research during in situ fermentation of buckwheat. Besides the different fermentation conditions and the nature of the substrate used by the authors, there was a difference in the mixing ratio of water to flour. Moreover, literature points at capsular EPS (i.e., bacterial pellet with EPS attached to cell wall material) and extracellular EPS (i.e., slime secreted) since EPS can be cell-bound and/or secreted.[21,32] In the current study, only the extracellular EPS was determined; the bacterial cells were centrifuged into a pellet and discarded to enable better control as well as the easy harvest of the soluble EPS. In addition, EPS degradation is common during lengthy incubation, which could also be responsible for lower figures. Furthermore, Degeest et al. [23] and Kaditzky et al. [33] studied the kinetics of EPS production and reported a decline in EPS production after $24 \mathrm{~h}$ of fermentation. Finally, EPS synthesis depends on the nature of the substrate or growth medium, which mostly differed in published research, providing an additional reason for the variation in reported data. $[11,14,18,24,32,34]$

\subsection{3 $\mathrm{pH}$, titratable acidity, organic acid and water absorption of sourdough}

Figure 7.5 presents the values of the $\mathrm{pH}$, total titrable acidity (TTA), organic acid and water absorption profiles of the different sourdoughs. $\mathrm{pH}$ and TTA of flours before fermentation were 6.2 and $6.0 \mathrm{~mL}$, respectively. Fermentation resulted in a significant drop in $\mathrm{pH}$ and a concomitant increase in TTA $(\mathrm{P}<0.0001)$. The highest amount of TTA was SuMF: LP37 (maize flour with sucrose), which correlates with the organic acid value. A high amount of organic acid in NaMF: WC37 and the relatively high pH suggest that it had the best buffering capacity. Lactic acid was the dominant organic acid 
in all sourdoughs tested. The values of formic acid and acetic acid were below 0.006 $\mathrm{mg} / \mathrm{mL}$ even in sourdough with a heterofermenter such as $W$. confusa known to produce a cocktail of organic acids. The presence of acetic acid can give an unacceptable vinegar flavour in sourdough and decrease the specific volume of bread. ${ }^{[35]}$ Therefore, its absence is considered an advantage.
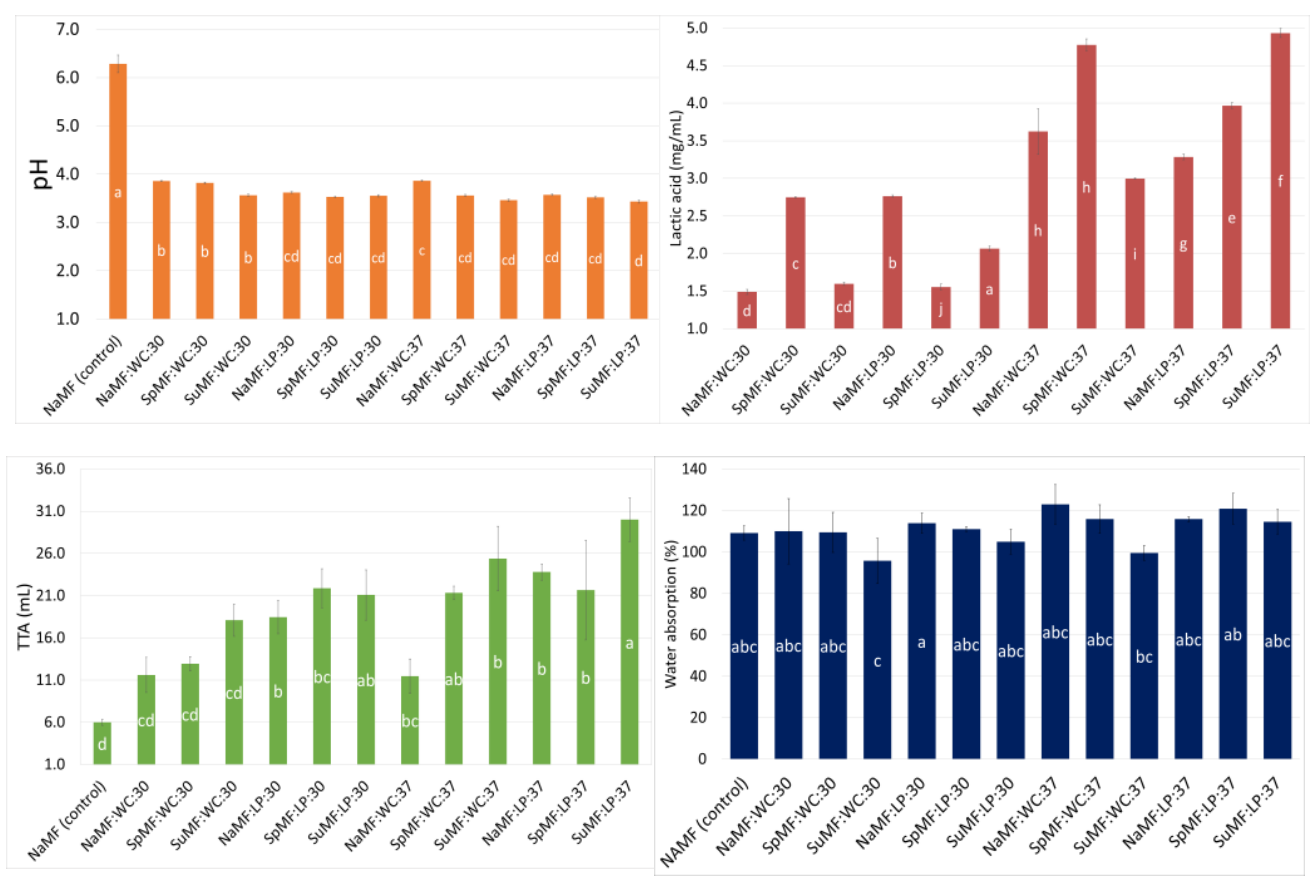

Figure 7.5: $\mathrm{pH}$, TTA, organic acid and water absorption profiles of twelve sourdoughs fermented with $W$. confusa (WC) and L. plantarum (LP) at $30^{\circ} \mathrm{C}$ and $37^{\circ} \mathrm{C}$. SuMF (maize flour with sucrose), SpMF (maize flour with sprouted maize flour) and $\mathrm{NaMF}$ (maize flour). ( $\mathrm{n}=3, \alpha=0.05)$.

Significant differences $(\mathrm{p}<0.05)$ in $\mathrm{pH}$, TTA and organic acids among the sourdoughs were observed. This indicates that flours possess different buffering abilities. However, in most of the flours, the increase in organic acid production resulted in lower $\mathrm{pH}$ values, showing that the flour samples overall had weak buffering capacities. A higher buffering capacity helps fermentation to continue longer without substantially changing the $\mathrm{pH}$ and excessively souring the flavour. The $\mathrm{pH}$ of sourdoughs containing $W$. confusa was not significantly different from L. plantarum but at $37^{\circ} \mathrm{C}$, a lower $\mathrm{pH}$ and higher TTA were recorded. Generally, the highest TTA concentration corresponded to the highest organic acid concentration.

\subsubsection{Pasting properties of sourdough}

The pasting properties (i.e., pasting temperature, peak viscosity, final viscosity, breakdown, holding power and setback) of the lyophilized sourdough was measured 
and compared to the non-fermented flour, figure 7.6. The peak viscosity of the control $(\mathrm{NaMF}$ ) was $627 \mathrm{~Pa} \cdot \mathrm{s}$ before fermentation but increased to $901 \mathrm{~Pa} \cdot \mathrm{s}$ and $1326 \mathrm{~Pa} \cdot \mathrm{s}$ after fermentation at $30^{\circ} \mathrm{C}$ with $W$. confusa (NaMF:WC30) and L. plantarum - NaMF:LP30, respectively. After fermentation at $37^{\circ} \mathrm{C}$, peak viscosities of $897 \mathrm{~Pa} \cdot \mathrm{s}$ and $684 \mathrm{~Pa} \cdot \mathrm{s}$ were found in $W$. confusa (NaMF:WC37) and L. plantarum (NaMF:LP37), respectively. Fermentation had considerable effects on the pasting properties of the maize flour. In general, the highest peak viscosity among the sourdoughs fermented at $30^{\circ} \mathrm{C}$ was 1326 $\mathrm{Pa} \cdot \mathrm{s}$ (NaMF:LP30), while for the sourdough fermented at $37^{\circ} \mathrm{C}$, the highest viscosity was $995 \mathrm{~Pa} \cdot \mathrm{s}$ (SuMF:LP37). Contrary to expectation, sourdough samples with the highest viscosity were not corresponding to the sourdough with the highest amounts of EPS, i.e. doughs fermented with $W$. confusa (EPS producer) showed lower peak viscosities than those fermented with L. plantarum (non-EPS producer). Pasting properties of sourdough are influenced by the protein hydrolysis, starch hydrolysis, hydrolysis of non-starch polysaccharides (hemicelluloses), acidification and amount of EPS. The current pasting properties were similar to the results of $\mathrm{Xu}$ et al. ${ }^{24]}$ who found that dough fermented by $W$. confusa had the lowest viscosity after fermentation even though their dextran contents were not the lowest. The authors attributed this phenomenon to differences in the structural and molecular weight of dextrans produced by organisms. [24] Similarly, Zhang et al. [36] reported a significant decrease in peak viscosity $(p<0.05)$ after addition of dextran to wheat, suggesting that dextran could prevent swelling and gelatinization by depriving starch of water or covering the starch surface. More evidence is required to ascertain the role of EPS as viscosity enhancer in in situ fermentation. However, it has been acknowledged that EPS produced by bacteria in situ plays a viscosity-enhancing role, which influences the rheological properties of the end product.[11, 14, 24, 34, 37] However, the level of the viscosity depends on the molecular properties of the polymer, e.g. molar mass and monomeric composition (heteropolymer or homopolymer).[11,32] Therefore, the nature of EPS secreted in the current work apparently could not induce sufficient viscosity to overrule other confounding factors such as the acidification in both sourdough made from non-EPS and EPS producing bacteria. Houben et al. ${ }^{38]}$ reported that viscosity and elasticity increase in amaranth dough mainly due to the changes in protein, fat and carbohydrates induced by the presence of organic acid and the activated acid-sensitive latent enzymes during fermentation. Fermentation degrades proteins into smaller polypeptides, which in turn leads to weakening of protein-protein and protein-starch interactions. ${ }^{[8,11]}$ This explanation is relevant to the current study since SuMF:LP37 (fermented by a non-EPS producer) with the highest organic acid showed the highest peak viscosity $(1326 \mathrm{~Pa} \cdot \mathrm{s})$. The lower viscosity of the fermented sourdough at $37^{\circ} \mathrm{C}$ compared to $30^{\circ} \mathrm{C}$ could be attributed to the presence of bacteria-secreted amylolytic enzymes capable of breaking 
the starch and rendering it more porous to absorb more water and consequently reduce viscosity.[24, 39-41]

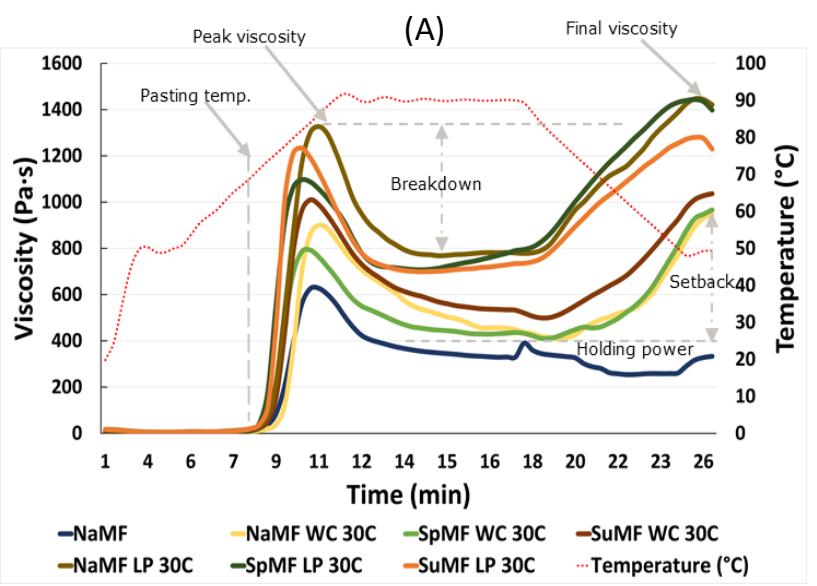

(B)

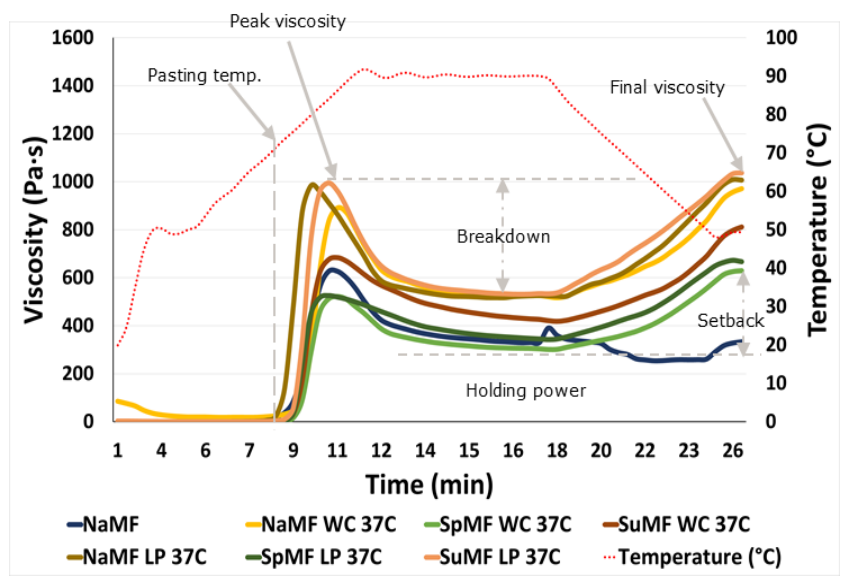

Figure 7.6: Viscosity profile of control and sucrose/sprout-enriched maize sourdough fermented with $W$. confusa (WC) and L. plantarum (LP) at $30^{\circ} \mathrm{C}$ and $37^{\circ} \mathrm{C}$. SuMF (maize flour with sucrose), SpMF (maize flour with sprouted maize flour) and NaMF (maize flour). 
The results of the thermal analysis obtained by DSC are presented in table 7.2. Analysis of variance showed that fermentation at $30^{\circ} \mathrm{C}$ and $37^{\circ} \mathrm{C}$ with $\mathrm{W}$. confusa and L. plantarum did not significantly $(\mathrm{p}<0.05)$ change gelatinization parameters such as onset temperature $\left(\mathrm{T}_{0}\right)$, peak temperature $\left(\mathrm{T}_{\mathrm{p}}\right)$, final temperature $\left(\mathrm{T}_{\mathrm{f}}\right)$ and temperature range $\left(T_{\mathrm{f}}-\mathrm{T}_{\mathrm{o}}\right)$. A similar result was obtained for pasting properties using a rheometer, Figure 7.6. In addition, the supplementation with sucrose or sprouted maize did not affect gelatinization temperatures. A significant difference $(p<0.05)$ in enthalpy was observed after fermentation at both temperatures. All samples had at least a $30 \%$ increase in enthalpy due to fermentation, which indicates a more crystalline formation of the amylopectin component of the starch granules. In general, the higher levels observed for enthalpy after fermentation indicate a higher internal granule stability. No clear pattern was deduced from the current work in terms of EPS production since samples such as NaMF:LP37 with no EPS had a high enthalpy $(12.88 \mathrm{~J} / \mathrm{g})$ while NaMF:WC30 with EPS had the lowest enthalpy $(9.23 \mathrm{~J} / \mathrm{g})$. Zhang et al. ${ }^{[36]}$ showed that the presence of dextran can reduce enthalpy but a drop in $\mathrm{pH}$ may lead to an increase in enthalpy. [9] Therefore, the role of acidification in the sourdough seems to have overruled the influence of EPS on enthalpy in our research.

Table 7.2: Thermal properties of native maize flour and sourdough: enthalpy $(\Delta H)$, onset temperature $\left(T_{0}\right)$, peak temperature $\left(T_{p}\right)$, final temperature $\left(T_{f}\right)$ and temperature range $T_{f}-T_{0}$ of gelatinization

\begin{tabular}{l|c|c|c|c|c}
\hline Sample & $\begin{array}{c}\mathbf{T}_{\mathbf{0}} \\
\left.\mathbf{(}^{\circ} \mathbf{C}\right)\end{array}$ & $\begin{array}{c}\mathbf{T}_{\mathbf{p}} \\
\left.\mathbf{(}^{\circ} \mathbf{C}\right)\end{array}$ & $\begin{array}{c}\mathbf{T}_{\mathbf{f}} \\
\left({ }^{\circ} \mathbf{C}\right)\end{array}$ & $\begin{array}{c}\text { Range, } \\
\mathbf{T}_{\mathbf{f}}-\mathbf{T}_{\mathbf{0}}\left({ }^{\circ} \mathbf{C}\right)\end{array}$ & $\begin{array}{c}\mathbf{\Delta H} \\
\mathbf{( J / g})\end{array}$ \\
\hline SpMF & $70.99^{\mathrm{a}}$ & $75.14^{\mathrm{a}}$ & $79.88^{\mathrm{a}}$ & $8.89^{\mathrm{a}}$ & $7.57 \mathrm{de}$ \\
NaMF & $69.63^{\mathrm{a}}$ & $73.98^{\mathrm{ab}}$ & $79.47^{\mathrm{a}}$ & $9.85^{\mathrm{a}}$ & $6.59^{\mathrm{a}}$ \\
SpMF:LP37 & $69.45^{\mathrm{a}}$ & $74.57^{\mathrm{ab}}$ & $79.09^{\mathrm{a}}$ & $9.64^{\mathrm{a}}$ & $10.56^{\mathrm{abcd}}$ \\
SpMF:LP30 & $69.42^{\mathrm{a}}$ & $74.51^{\mathrm{ab}}$ & $79.33^{\mathrm{a}}$ & $9.91^{\mathrm{a}}$ & $10.8^{\mathrm{abcd}}$ \\
SuMF:WC37 & $68.99^{\mathrm{a}}$ & $74.64^{\mathrm{a}}$ & $80.28^{\mathrm{a}}$ & $11.29^{\mathrm{a}}$ & $13.75^{\mathrm{a}}$ \\
SpMF:WC30 & $68.86^{\mathrm{a}}$ & $74.71^{\mathrm{a}}$ & $80.70^{\mathrm{a}}$ & $11.84^{\mathrm{a}}$ & $12.24^{\mathrm{abc}}$ \\
NaMF:WC37 & $68.85^{\mathrm{a}}$ & $74.17^{\mathrm{ab}}$ & $79.22^{\mathrm{a}}$ & $10.37^{\mathrm{a}}$ & $11.66^{\mathrm{abc}}$ \\
NaMF:LP37 & $68.64^{\mathrm{a}}$ & $74.32^{\mathrm{ab}}$ & $78.95^{\mathrm{a}}$ & $10.31^{\mathrm{a}}$ & $12.88^{\mathrm{ab}}$ \\
SuMF:WC30 & $68.58^{\mathrm{a}}$ & $74.18^{\mathrm{ab}}$ & $79.57^{\mathrm{a}}$ & $10.99^{\mathrm{a}}$ & $9.93^{\mathrm{bcde}}$ \\
NaMF:LP30 & $68.52^{\mathrm{a}}$ & $73.74^{\mathrm{ab}}$ & $79.02^{\mathrm{a}}$ & $10.5^{\mathrm{a}}$ & $9.96^{\mathrm{bcde}}$ \\
SuMF:LP37 & $68.40^{\mathrm{a}}$ & $73.82^{\mathrm{ab}}$ & $78.9^{\mathrm{a}}$ & $10.51^{\mathrm{a}}$ & $11.75^{\mathrm{abc}}$ \\
NaMF:WC30 & $68.35^{\mathrm{a}}$ & $74.24^{\mathrm{ab}}$ & $80.38^{\mathrm{a}}$ & $12.04^{\mathrm{a}}$ & $9.23 \mathrm{cde}$ \\
SuMF:LP30 & $68.08^{\mathrm{a}}$ & $73.07^{\mathrm{b}}$ & $78.35^{\mathrm{a}}$ & $10.27^{\mathrm{a}}$ & $10.63^{\mathrm{abcd}}$ \\
SpMF:WC37 & $67.18^{\mathrm{a}}$ & $74.58^{\mathrm{ab}}$ & $79.39^{\mathrm{a}}$ & $12.21^{\mathrm{a}}$ & $11.43^{\mathrm{abc}}$
\end{tabular}

*Values in the same column followed by different letter are significantly different $(\mathrm{n}=2, \alpha=0.05)$. Samples are based on $W$. confusa (WC) and L. plantarum (LP) fermentation at $30^{\circ} \mathrm{C}$ and $37^{\circ} \mathrm{C}$. NaMF (native maize flour) SpMF (Sprouted maize flour), SuMF (maize flour with sucrose), SpMF ( maize flour with sprouted maize flour) and $\mathrm{NaMF}$ (maize flour). 


\subsubsection{Bread characteristics}

Figure 7.7 presents the porosity of bread measured by the IRIS electronic visual analyser based on the ratio of bread pore area and slice area. The highest porosity (34\%) was found in SpMFWC. Bread made from maize flour supplemented with sprouted flour had a $12.5 \%$ increase in porosity compared to the native maize bread, while the addition of $20 \%$ of the same flour to native maize flour led to a $10.3 \%$ increase in porosity. Similarly, the application of $20 \%$ sourdough led to a significant increase in porosity of bread crumb structure in all cases.

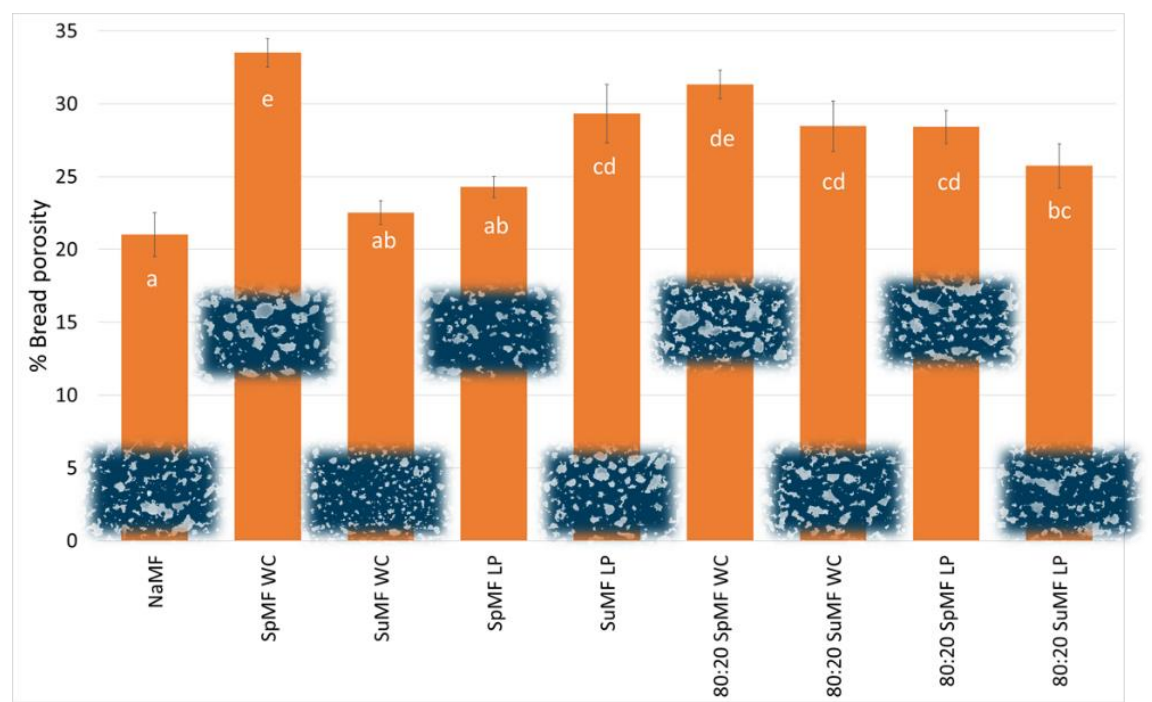

Figure 7.7: Crumb porosity based on the ratio of pore areas and total crumb area. Images on the bars show the porosity, i.e. the blue part represents the non-pore region while the white spots are the pores (gas bubbles). Bars with the same letter are not significantly different ( $\mathrm{n}=3, \alpha=0.05)$.

The presence of organic acids can lead to softening of the protein structure of sourdough, thus resulting in a higher bread volume and porosity. Similarly, an increase in porosity could be attributed to the better absorption of simple sugars and consequently, more gas production by yeast during proofing. RŘhmkorf et al. [12] reported that the addition of EPS did not increase bread porosity. Hence the increase in porosity observed in the current work may be largely ascribed to the presence of organic acids or other changes during maize fermentation. Bread acidification has been shown to increase porosity. ${ }^{[12]}$ The porosity of all bread samples was below the range of values previously reported, $47.8 \%$ to $58.4 \%$ for buckwheat, oat, quinoa, sorghum, teff, wheat and maize bread. $\left.{ }^{6,8}, 8\right]$ The differences are attributed to the analytical method since the authors used a C-Cell colour imaging system, which works differently from the IRIS imaging used in the current work. Besides, differences in dough hydration contributed to the variation in porosity. In samples with larger pores such as SpMFWC and 80:20 SpMFWC, the crumb structure was not strong enough to support the bread weight, 
resulting in a dent at the top. This might lead to a specific volume reduction due to the breakage of gas cells, thus optimizing the recipe to achieve better porosity is critical. Variation in the flour formulations (inclusion of sugar or sprouted maize), as well as the sourdough $\mathrm{pH}$, has a major effect on yeast activity and therefore affects $\mathrm{CO}_{2}$ production and porosity.

Table 7.3: Baking properties of native maize flour, sourdough and 20\% sourdough substituted bread

\begin{tabular}{l|c|c|c|c|c}
\hline \multicolumn{1}{c|}{ Samples } & $\begin{array}{c}\text { Specific volume } \\
(\mathbf{m L / g})\end{array}$ & $\begin{array}{c}\text { Hardness } \\
(\mathbf{N})\end{array}$ & Cohesiveness & Springiness & $\begin{array}{c}\text { Chewiness } \\
(\mathbf{N})\end{array}$ \\
\hline NaMF & $1.64 \pm 0.03^{\mathrm{ab}}$ & $16.02 \pm 1.14^{\mathrm{d}}$ & $0.47 \pm 0.03^{\mathrm{b}}$ & $0.83 \pm 0.03^{\mathrm{b}}$ & $6.22 \pm 0.99^{\mathrm{bc}}$ \\
SpMF WC & $1.63 \pm 0.10^{\mathrm{ab}}$ & $25.55 \pm 2.49^{\mathrm{b}}$ & $0.66 \pm 0.02^{\mathrm{a}}$ & $0.92 \pm 0.02^{\mathrm{a}}$ & $15.37 \pm 1.69^{\mathrm{a}}$ \\
SuMF WC & $1.49 \pm 0.02^{\mathrm{a}}$ & $29.96 \pm 0.29^{\mathrm{a}}$ & $0.63 \pm 0.01^{\mathrm{a}}$ & $0.90 \pm 0.01^{\mathrm{ab}}$ & $16.85 \pm 0.29^{\mathrm{a}}$ \\
SpMF LP & $1.62 \pm 0.06^{\mathrm{ab}}$ & $27.76 \pm 0.95^{\mathrm{ab}}$ & $0.66 \pm 0.03^{\mathrm{a}}$ & $0.89 \pm 0.04^{\mathrm{ab}}$ & $16.12 \pm 0.44^{\mathrm{a}}$ \\
SuMF LP & $1.70 \pm 0.05^{\mathrm{b}}$ & $26.01 \pm 0.73^{\mathrm{b}}$ & $0.66 \pm 0.05^{\mathrm{a}}$ & $0.90 \pm 0.03^{\mathrm{ab}}$ & $15.23 \pm 0.86^{\mathrm{a}}$ \\
8020 SpMF WC & $2.04 \pm 0.03^{\mathrm{c}}$ & $12.62 \pm 1.30^{\mathrm{e}}$ & $0.49 \pm 0.04^{\mathrm{b}}$ & $0.90 \pm 0.04^{\mathrm{ab}}$ & $5.48 \pm 0.25^{\mathrm{c}}$ \\
8020 SuMF WC & $1.92 \pm 0.05^{\mathrm{c}}$ & $20.88 \pm 0.60^{\mathrm{c}}$ & $0.47 \pm 0.05^{\mathrm{b}}$ & $0.87 \pm 0.05^{\mathrm{ab}}$ & $8.43 \pm 0.76^{\mathrm{b}}$ \\
8020 SpMF LP & $1.98 \pm 0.02^{\mathrm{c}}$ & $17.72 \pm 0.57^{\mathrm{cd}}$ & $0.50 \pm 0.05^{\mathrm{b}}$ & $0.87 \pm 0.02^{\mathrm{ab}}$ & $7.50 \pm 0.64^{\mathrm{bc}}$ \\
8020 SuMF LP & $1.71 \pm 0.01^{\mathrm{b}}$ & $16.77 \pm 0.39^{\mathrm{d}}$ & $0.48 \pm 0.03^{\mathrm{b}}$ & $0.90 \pm 0.02^{\mathrm{a}}$ & $7.23 \pm 0.41^{\mathrm{bc}}$ \\
\hline
\end{tabular}

Values given as mean \pm standard deviation $(\mathrm{n}=3, \alpha=0.05)$. Different letters of superscripts in the same column indicate statistically significant differences $(\mathrm{p}<0.05)$. Samples are based on $W$. confusa (WC) and $L$. plantarum (LP) fermentation at $37^{\circ} \mathrm{C}$. NaMF (native maize flour), SuMF (maize flour with sucrose), SpMF ( maize flour with sprouted maize flour) and NaMF (maize flour). The " 8020 " recipes represent a 20\% substitution of the respective sourdough with $80 \%$ native maize flour.

The baking characteristics of bread made from dough fermented with $W$. confusa and $L$. plantarum as well as their substitutes with $80 \%$ native maize flour are presented in table 7.3. Bread derive from composite flour made from sprouted maize had the highest specific volume $(2.04 \mathrm{~mL} / \mathrm{g})$. The same formulation had the lowest bread hardness $(12.62 \mathrm{~N}), \mathrm{p}<0.05$. Supplementation of the $20 \%$ sourdough with $80 \%$ native maize increased both specific volume and softness of bread. The sole use of the sourdough for bread making led to a significant increase in bread hardness. The effects of acidification and the presence of EPS differ depending on the flour formulation, although EPS produced during dough fermentation have been reported to improve bread softness. ${ }^{[42]}$ The presence of organic acids has been mostly associated with softness in sourdough bread due to unfolding and solubilization of the protein network. $[8,11,36,40]$ The role of organic acids in reducing hardness and increasing specific volume could be observed in the current study since formulation SpMF with the highest amount of organic acids (figure 7.4) had the highest volume and softness. Factors such as the presence of organic acids and other fermentation metabolites may play more important roles than EPS in the quality improvement reported in sourdough bread. This assertion was corroborated by Galle et al. ${ }^{[1]}$ who reported that in situ dextran synthesis did not enhance the specific volume of bread. Yet RŘhmkorf et al. ${ }^{[12]}$ observed that ex situ addition of purified higher molecular size $(8 \times 107$ - 24x107Da) EPS isolated from 
LAB increased specific volume and softness of gluten-free bread, possibly due to the absence of acidification. This suggests that the presence of organic acids in the sourdough may work against the positive impact of EPS in in situ fermentation. EPS can interfere with protein-starch and starch-starch interactions, thus increasing bread hardness and reducing specific volume, which in turn affect other quality parameters such as loaf cohesiveness, gumminess, springiness and chewiness. ${ }^{[8,11]}$

\section{Conclusion}

The production of bread in SSA currently depends on wheat importation. Hence, to make bread more accessible, acceptable, affordable and available for the local population, the use of maize is considered necessary. Using a starter culture derived from traditionally fermented foods in Africa would be an appropriate choice. Sourdough technology is a simple and inexpensive way of producing bread in SSA, given that local fermentation of food is a common practice in the region. Besides, sourdough can be obtained from hydrocolloid producing bacteria readily available in the microflora of local foods and environment.

This study showed that EPS producing LAB can be obtained from local African foods such as munkoyo and ogi, which had $22 \%$ and $10 \%$ EPS producers, respectively. These organisms, which were able to grow in a maize food system, can be further characterized and optimized for use as a starter culture in sourdough production for gluten-free bread. Weissella confusa was found to be the dominant EPS producer in both food matrices tested. EPS production in a maize medium depends on the substrate used. The highest production in our research was found in maize flour supplemented with sprouted maize flour. The added sprouted maize provided an assortment of metabolites needed for building the polysaccharides. The role of EPS in improving rheological properties of dough and textural properties of bread could not be ascertained in this study. This is attributed to the strong acidification during fermentation, which plays overlapping roles with EPS. Thus, separating these factors in subsequent research is recommended to clarify conflicting data found on dough and bread properties. 


\section{References}

1. Reardon T, Echeverria R, Berdegué J, Minten B, Liverpool-Tasie S, Tschirley D, et al. Rapid transformation of food systems in developing regions: Highlighting the role of agricultural research \& innovations. Agricultural systems. 2019;172:47-59.

2. Ekpa O, Palacios-Rojas N, Kruseman G, Fogliano V, Linnemann AR. Sub-Saharan African Maize-Based Foods - Processing Practices, Challenges and Opportunities. Food Reviews International. 2019:1-31.

3. Falade AT, Buys EM, Taylor JR. Effect of Different Non-Wheat Bread Making Methods on the Quality of Maize Bread. Journal of Food Technology. 2017;15(1):1-6.

4. OECD-FAO. World cereal projections", in OECD-FAO Agricultural Outlook 2018-2027. OECD Publishing, Paris; 2018.

5. Nkhabutlane P, du Rand GE, de Kock HL. Quality characterization of wheat, maize and sorghum steamed breads from Lesotho. Journal of the Science of Food and Agriculture. 2014;94(10):2104-17.

6. Hager A-S, Wolter A, Czerny M, Bez J, Zannini E, Arendt EK, et al. Investigation of product quality, sensory profile and ultrastructure of breads made from a range of commercial gluten-free flours compared to their wheat counterparts. European Food Research and Technology. 2012;235(2):333-44.

7. Zannini E, Jones JM, Renzetti S, Arendt EK. Functional replacements for gluten. Annual review of food science and technology. 2012;3:227-45.

8. Wolter A, Hager A-S, Zannini E, Czerny M, Arendt EK. Impact of sourdough fermented with Lactobacillus plantarum FST 1.7 on baking and sensory properties of gluten-free breads. European food research and technology. 2014;239(1):1-12.

9. Zhang Y, Guo L, Li D, Jin Z, Xu X. Roles of dextran, weak acidification and their combination in the quality of wheat bread. Food chemistry. 2019;286:197-203.

10. Falade AT. Improving the quality of non-wheat bread made from maize using sourdough fermentation: University of Pretoria; 2014.

11. Galle S, Schwab C, Dal Bello F, Coffey A, Gänzle MG, Arendt EK. Influence of in-situ synthesized exopolysaccharides on the quality of gluten-free sorghum sourdough bread. International journal of food microbiology. 2012;155(3):105-12.

12. Ř̌hmkorf C, Jungkunz S, Wagner M, Vogel RF. Optimization of homoexopolysaccharide formation by lactobacilli in gluten-free sourdoughs. Food microbiology. 2012;32(2):286-94. 
13. Marti A, Cardone G, Nicolodi A, Quaglia L, Pagani MA. Sprouted wheat as an alternative to conventional flour improvers in bread-making. LWT. 2017;80:230-6.

14. Welman AD. Exploitation of exopolysaccharides from lactic acid bacteria: nutritional and functional benefits. Bacterial polysaccharides: Current innovations and future trends. 2009:331e44.

15. Hüttner EK, Dal Bello F, Arendt EK. Identification of lactic acid bacteria isolated from oat sourdoughs and investigation into their potential for the improvement of oat bread quality. European Food Research and Technology. 2010;230(6):849-57.

16. Schwab C, Mastrangelo M, Corsetti A, Gänzle M. Formation of oligosaccharides and polysaccharides by Lactobacillus reuteri LTH5448 and Weissella cibaria 10M in sorghum sourdoughs. Cereal Chemistry. 2008;85(5):679-84.

17. Adegbehingbe K. Fermented sprouted and unsprouted maize for Ogi production. Int J Adv Res. 2013;1(10):428-34.

18. Adesulu-Dahunsi AT, Sanni AI, Jeyaram K, Ojediran JO, Ogunsakin AO, Banwo K. Extracellular polysaccharide from Weissella confusa OF126: Production, optimization, and characterization. International Journal of Biological Macromolecules. 2018;111:514-25.

19. Evageliou V, Richardson R, Morris E. Effect of sucrose, glucose and fructose on gelation of oxidised starch. Carbohydrate Polymers. 2000;42(3):261-72.

20. Hernández-Becerra E, Gutierrez-Oñate MP, Martinez-Soto G, Vega-Rojas LJ, AcostaOsorio AA, Contreras-Padilla M, et al. Physicochemical characterization of corn-sorghum nixtamalized flours as a function of the steeping time. Journal of Food Measurement and Characterization. 2016;10(3):434-43.

21. Subramanian SB, Yan S, Tyagi RD, Surampalli R. Extracellular polymeric substances (EPS) producing bacterial strains of municipal wastewater sludge: isolation, molecular identification, EPS characterization and performance for sludge settling and dewatering. Water research. 2010;44(7):2253-66.

22. Phiri S, Schoustra SE, van den Heuvel J, Smid EJ, Shindano J, Linnemann A. Fermented cereal-based Munkoyo beverage: Processing practices, microbial diversity and aroma compounds. PloS one. 2019;14(10).

23. Degeest B, Janssens B, De Vuyst L. Exopolysaccharide (EPS) biosynthesis by Lactobacillus sakei 0-1: production kinetics, enzyme activities and EPS yields. Journal of Applied Microbiology. 2001;91(3):470-7. 
24. Xu Y, Wang Y, Coda R, Säde E, Tuomainen P, Tenkanen M, et al. In situ synthesis of exopolysaccharides by Leuconostoc spp. and Weissella spp. and their rheological impacts in fava bean flour. International journal of food microbiology. 2017;248:63-71.

25. Katina K, Maina NH, Juvonen R, Flander L, Johansson L, Virkki L, et al. In situ production and analysis of Weissella confusa dextran in wheat sourdough. Food microbiology. 2009;26(7):734-43.

26. Dertli E, Colquhoun IJ, Côté GL, Le Gall G, Narbad A. Structural analysis of the $\alpha$-Dglucan produced by the sourdough isolate Lactobacillus brevis E25. Food chemistry. 2018;242:45-52.

27. Owusu-Kwarteng J, Akabanda F, Nielsen DS, Tano-Debrah K, Glover RL, Jespersen L. Identification of lactic acid bacteria isolated during traditional fura processing in Ghana. Food microbiology. 2012;32(1):72-8.

28. Padonou SW, Nielsen DS, Hounhouigan JD, Thorsen L, Nago MC, Jakobsen M. The microbiota of Lafun, an African traditional cassava food product. International journal of food microbiology. 2009;133(1-2):22-30.

29. Abegaz K, Beyene F, Langsrud T, Narvhus JA. Parameters of processing and microbial changes during fermentation of borde, a traditional Ethiopian beverage. 2002.

30. Mugula JK, Nnko SAM, Narvhus JA, Sørhaug T. Microbiological and fermentation characteristics of togwa, a Tanzanian fermented food. International Journal of Food Microbiology. 2003;80(3):187-99.

31. Kajala I, Mäkelä J, Coda R, Shukla S, Shi Q, Maina NH, et al. Rye bran as fermentation matrix boosts in situ dextran production by Weissella confusa compared to wheat bran. Applied microbiology and biotechnology. 2016;100(8):3499-510.

32. Ruas-Madiedo P. Methods for the screening, isolation, and characterization of exopolysaccharides produced by lactic acid bacteria. J Dairy Sci. 2005;88:853-66.

33. Kaditzky S, Vogel RF. Optimization of exopolysaccharide yields in sourdoughs fermented by lactobacilli. European Food Research and Technology. 2008;228(2):291.

34. Juszczak L, Witczak T, Ziobro R, Korus J, Cieślik E, Witczak M. Effect of inulin on rheological and thermal properties of gluten-free dough. Carbohydrate polymers. 2012;90(1):353-60.

35. Katongole JN. The microbial succession in indigenous fermented maize products: University of the Free State; 2008. 
36. Zhang Y, Guo L, Xu D, Li D, Yang N, Chen F, et al. Effects of dextran with different molecular weights on the quality of wheat sourdough breads. Food chemistry. 2018;256:373-9.

37. Di Cagno R, De Angelis M, Limitone A, Minervini F, Carnevali P, Corsetti A, et al. Glucan and fructan production by sourdough Weissella cibaria and Lactobacillus plantarum. Journal of Agricultural and Food Chemistry. 2006;54(26):9873-81.

38. Houben A, Götz H, Mitzscherling M, Becker T. Modification of the rheological behavior of amaranth (Amaranthus hypochondriacus) dough. Journal of Cereal Science. 2010;51(3):350-6.

39. Wolter A, Hager A-S, Zannini E, Arendt EK. In vitro starch digestibility and predicted glycaemic indexes of buckwheat, oat, quinoa, sorghum, teff and commercial gluten-free bread. Journal of Cereal Science. 2013;58(3):431-6.

40. Moore MM, Dal Bello F, Arendt EK. Sourdough fermented by Lactobacillus plantarum FSTá1. 7 improves the quality and shelf life of gluten-free bread. European Food Research and Technology. 2008;226(6):1309-16.

41. Schober TJ, Bean SR, Boyle DL, Park S-H. Improved viscoelastic zein-starch doughs for leavened gluten-free breads: Their rheology and microstructure. Journal of Cereal Science. 2008;48(3):755-67.

42. Arendt EK, Moroni A, Zannini E, editors. Medical nutrition therapy: use of sourdough lactic acid bacteria as a cell factory for delivering functional biomolecules and food ingredients in gluten free bread. Microbial Cell Factories; 2011: Springer. 


\section{Appendix: Supplementary Material}

Table 7.S1: Sample description

\begin{tabular}{|c|c|c|c|c|c|}
\hline \multirow[t]{2}{*}{ Samples } & \multirow[t]{2}{*}{ Description } & \multicolumn{2}{|c|}{ Microorganism } & \multicolumn{2}{|c|}{$\begin{array}{c}\text { Fermentation } \\
\text { temperature }\end{array}$} \\
\hline & & W.confusa & L.plantarum & $30^{\circ} \mathrm{C}$ & $37^{\circ} \mathrm{C}$ \\
\hline $\mathrm{NaMF}$ & Native maize flour & $x$ & $x$ & $x$ & $x$ \\
\hline NaMF WC 30C & Native maize flour & $\checkmark$ & $x$ & $\checkmark$ & $x$ \\
\hline SpMF WC 30C & $\begin{array}{l}\text { Native maize flour with } \\
10 \% \text { sprouted maize }\end{array}$ & $\checkmark$ & $x$ & $\checkmark$ & $x$ \\
\hline SuMF WC 30C & $\begin{array}{l}\text { Native maize flour with } \\
10 \% \text { sucrose }\end{array}$ & $\checkmark$ & $x$ & $\checkmark$ & $x$ \\
\hline NaMF LP 30C & Native maize flour & $x$ & $\checkmark$ & $\checkmark$ & $x$ \\
\hline SpMF LP 30C & $\begin{array}{l}\text { Native maize flour with } \\
10 \% \text { sprouted maize }\end{array}$ & $x$ & $\checkmark$ & $\checkmark$ & $x$ \\
\hline SuMF LP 30C & $\begin{array}{l}\text { Native maize flour with } \\
10 \% \text { sucrose }\end{array}$ & $x$ & $\checkmark$ & $\checkmark$ & $x$ \\
\hline NaMF WC 37C & Native maize flour & $\checkmark$ & $x$ & $x$ & $\checkmark$ \\
\hline SpMF WC 37C & $\begin{array}{l}\text { Native maize flour with } \\
10 \% \text { sprouted maize }\end{array}$ & $\checkmark$ & $x$ & $x$ & $\checkmark$ \\
\hline SuMF WC 37C & $\begin{array}{l}\text { Native maize flour with } \\
10 \% \text { sucrose }\end{array}$ & $\checkmark$ & $x$ & $x$ & $\checkmark$ \\
\hline NaMF LP 37C & Native maize flour & $x$ & $\checkmark$ & $x$ & $\checkmark$ \\
\hline SpMF LP 37C & $\begin{array}{l}\text { Native maize flour with } \\
10 \% \text { sprouted maize }\end{array}$ & $x$ & $\checkmark$ & $x$ & $\checkmark$ \\
\hline SuMF LP 37C & $\begin{array}{l}\text { Native maize flour with } \\
10 \% \text { sucrose }\end{array}$ & $x$ & $\checkmark$ & $x$ & $\sqrt{ }$ \\
\hline
\end{tabular}

$\checkmark$ Applicable; $\boldsymbol{X}$ not applicable 


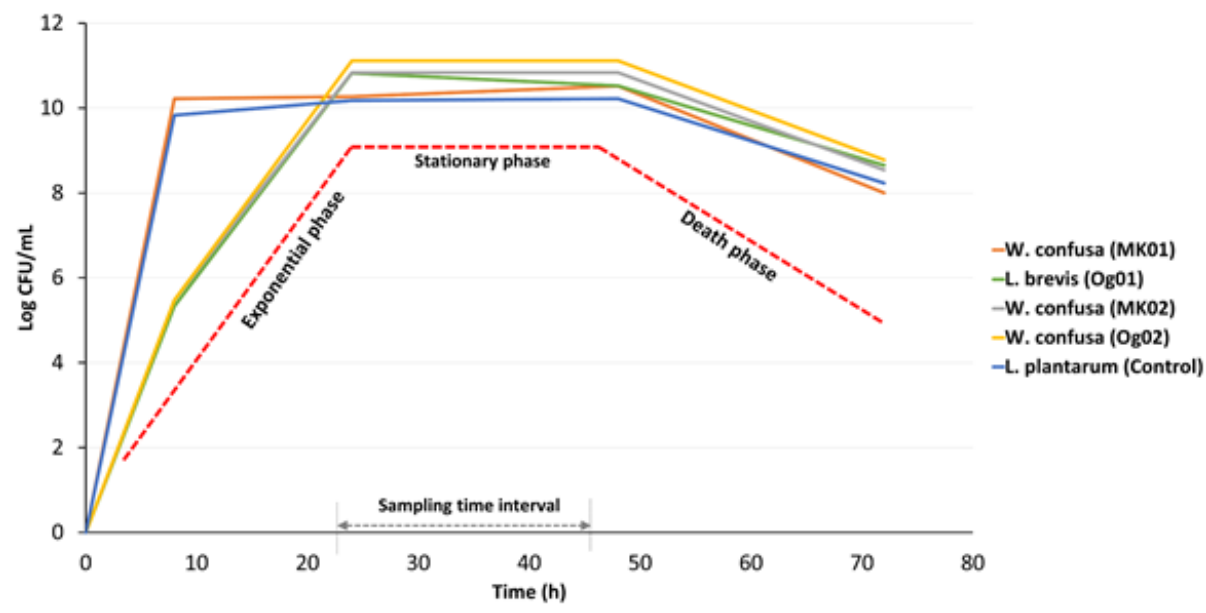

Figure 7.S1: The growth curve of bacteria strains. Organisms for fermentation were taken at mid-stationary phase to avoid the negative effects of pre-formed EPS degrading enzymes during the late stationary phase or death phase. 


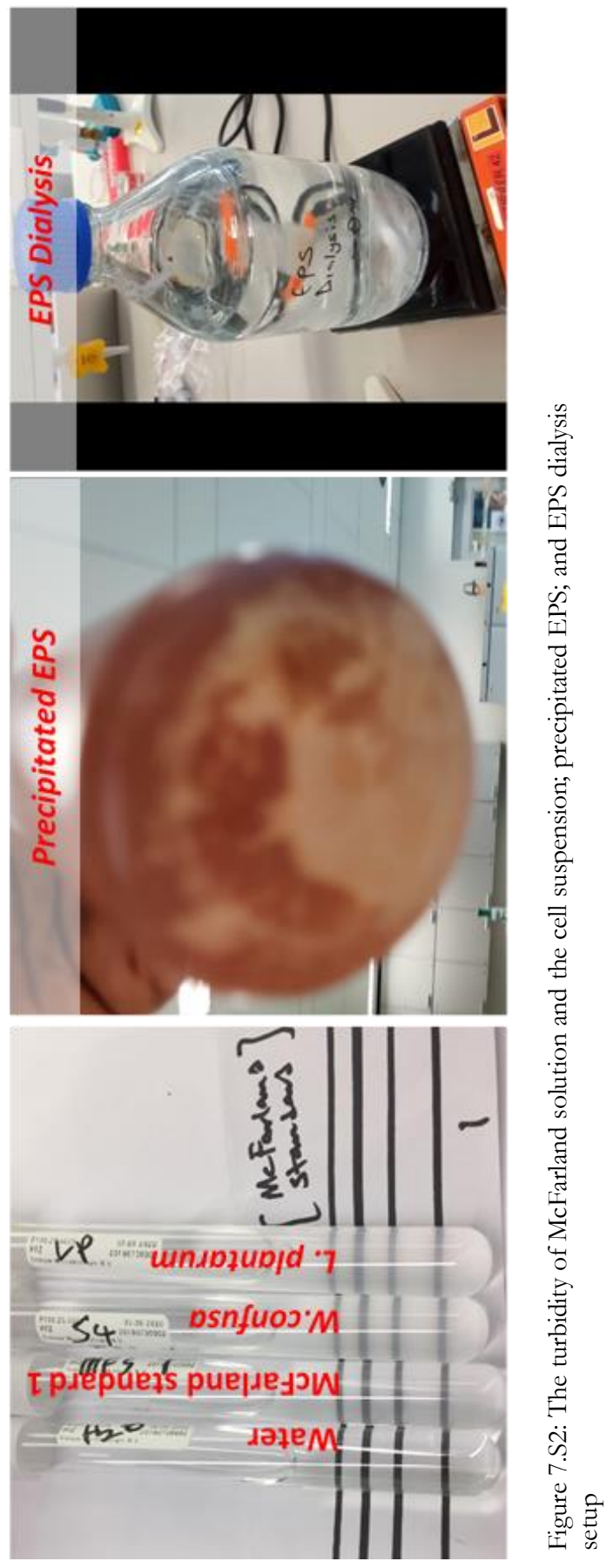




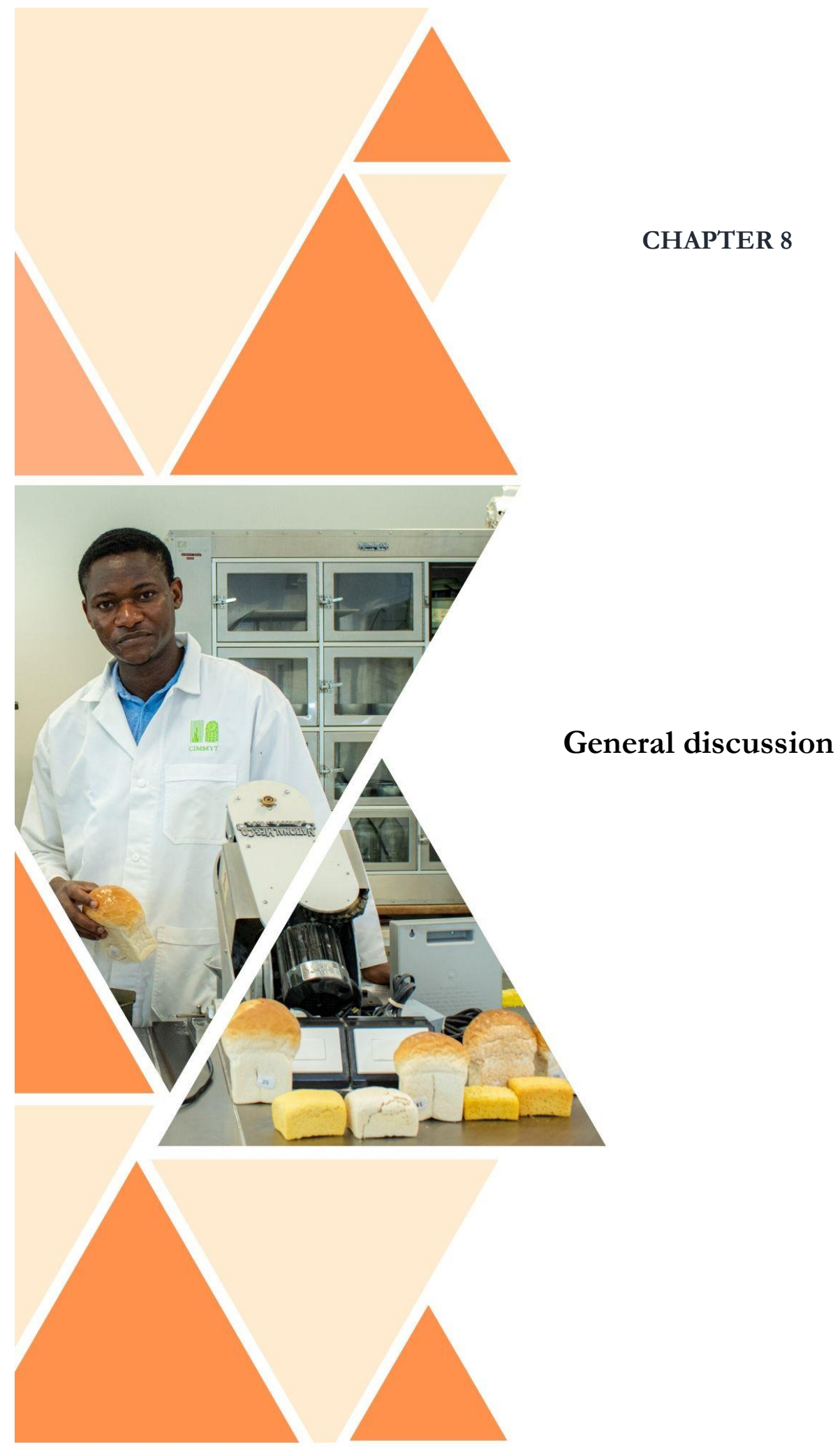




\subsection{Introduction}

This thesis project aimed to improve the nutritional value and diversification of maize-based foods in Sub-Saharan Africa (SSA) through the use of appropriate technology. To this effect, the following specific research aims were identified:

- Assess maize-based food processing and consumption patterns and establish the objectives to meet processors' and consumers' needs and preferences.

- Determine the volatile profiles of the most commonly used maize varieties and their respective porridges as a basis for alignment with consumer preferences.

- Evaluate carotenoid stability and changes in volatile organic compounds during grain and maize flour storage in different packaging materials.

- Screen maize genotypes suitable for making gluten-free bread.

- Enhance the functional properties of maize flour using readily available local techniques such as fermentation.

\subsection{The maize value chain in Africa}

The maize value chain in Africa needs improvement and better coordination to meet the increasing demand for high quality products for domestic, regional and international markets.[1] Chapter 2 centred on the main maize-based foods in SSA and their processing methods, followed by analyses of the limitations of traditional processing and opportunities to enhance the nutritional value and product diversification. Detailed analyses of physical and chemical characteristics of maize-based foods (especially the magnitude of changes in nutritional components) would have enriched this chapter but wide discrepancies in the available data led to the exclusion of such information. However, traditional maize processing has shown significant losses in nutrients, e.g. a range of $13-42 \%$ of protein is lost during the production of ogi.[2-6] Moreover, the overall nutritional contribution of provitamin A maize is significantly reduced by the loss of carotenoids along the value chain. ${ }^{7]}$ Modification of traditional processes is known to lower losses and increase nutritional quality. [3]

Food fermentation in Africa is usually through a spontaneous process, i.e. relying on microorganisms from the environment and crop microflora as inoculum, chapter 2. This process is not always safe and can result in product failure, hence the need for pure starter cultures. Moreover, traditional sources of microbial inoculum are becoming scarce, such as the root (Rhynchosia heterophylla) required for the production of a fermented beverage, called munkoyo, in southern Africa ${ }^{[8]}$, while modern agronomic practices, such as the use of Aflasafe ${ }^{\mathrm{TM}}$ (a biocontrol product to deter aflatoxigenic fungi through competitive ecological exclusion) in maize could change the microflora that is 
responsible for spontaneous fermentation. To address the variability and/or scarcity of inoculum in Africa, affordable starter culture practices, such as backslopping of material from a previous batch (containing carefully selected microorganisms) can be promoted in local communities. Since Africans are familiar with the use of yeast starter culture for baking as well as the use of roots or malt as inoculum, the introduction of starter cultures for fermentation of traditional food is feasible.

\subsection{Diffusion and adoption of new maize varieties in Africa}

In view of the importance of maize in the diet of Africans and the resources spent on maize development, the impact and effectiveness of breeding activities need critical evaluation. Walker et al. [9] in their report on "Diffusion and Impact of Improved Varieties in Africa (DIIVA)" showed that more scientists are assigned to maize than to any other crop in Africa, i.e. maize breeding is on top of the agenda, particularly by international research centres such as IITA and CIMMYT. Given the current climate change, considerable resources are allocated to developing improved varieties that withstand pests, diseases, heat and drought situations as well as close the wide yield gaps in Africa. This is a worthy track of investment from the perspective of a plant breeder or an agronomist. From a multidisciplinary perspective, food and consumer scientists would advocate broadening the scope to gain more impact. Breeding efforts often take a long time to achieve tangible results, thus prioritizing the screening and distribution of existing cultivars with preferred end user attributes seems an approach that deserves more attention. Regarding the current predominance of trait-based breeding, chapter 3 makes the case for an increased focus on end user quality characteristics in maize breeding programs. However, the allocation of resources to breeding activities would most practically be based on relative costs and benefits of individual quality traits. A cost-benefit analysis (CBA) of the suggested traits was not provided in the chapter but we recognize that $\mathrm{CBA}$ is useful for decision-makers and any actionable step forward. The main concept of chapter $\mathbf{3}$ is highlighted in figure 3.1. Consumer preference is an important factor that should be prioritized in maize improvement since high agronomic performance alone has not maximally attracted farmers towards the improved varieties. For instance, the statistic that most private bred varieties were dent maize when the dominant preference of the consumers is for flint maize, is indicative that breeders assumed that higher yield potential of the dents would supersede any preference for flint but this was not the case. ${ }^{[10]}$ The decision on where breeders should focus is driven by regional preferences, with some preferring whole or ground maize and others preferring refined maize flour (especially urban dwellers).

Furthermore, green maize breaks the hunger period and is a favourite dish all over the continent. However, unfortunately, maize is solely bred and grown for the end use grain 
product, i.e. dry milling. Green maize research is yet to gain traction in Africa. Moreover, dual-purpose maize is gradually gaining attention among breeders and farmers in Africa, especially in Kenya. Farmers grow these varieties for their added advantage as cattle fodder. Trade-offs with yield and other quality characteristics are important constraints in the development of new varieties, chapter 3. Generally, during plant breeding, in a situation where there is a trade-off between nutritional quality traits such as increase in lysine, tryptophan, zinc, iron, $\beta$-carotene or processing quality and agronomic performances such as yield, the agronomy wins. However, in the long-term, the wishes and preferences of the street vendors or mothers who make ugali, sadza, kenkey etc. from the crop will eventually win. Therefore, the decision on trade-offs should be carefully considered using participatory plant selection and breeding processes, involving breeders, farmers, retailers, processors, street vendors and households.

The issue of maize colour preferences highlighted in chapter $\mathbf{3}$ is an ongoing debate; less nutritious white varieties are preferred over high nutritious yellow/orange varieties. It begs the question: Ceteris paribus, would there be a preference for colour? Available evidence suggests that colour is a binding criterion but provision of nutritional information and value-added products can shift preferences. $\left.{ }^{[11-13,14}, 15\right]$ The authors reported that consumers need a price reduction of about $40 \%$ in Kenya to accept yellow maize. Therefore, consumers' willingness to only switch at a high discount indicates a strong preference for white maize.

Although our research focused on maize, it is important to state that the lack of diet diversification is the main culprit of malnutrition in SSA. Therefore, allocation of resources to highly nutritious underutilized crops such as bambara groundnut, cowpea, bean, pearl millet, sorghum as well as fruit and "lost indigenous" African vegetables which are usually climate-smart and crucial to local food security will greatly complement the efforts in maize breeding. This can go hand in hand with the provision of nutritional awareness, which has been proven to help in local communities in SSA.[1117]

\subsection{Acceptance of improved maize varieties: does aroma contribute?}

Flavour or aroma is a key driver of consumer preference and adoption of improved or nutritionally superior maize varieties. In chapter 4 we found vast differences in volatile organic compounds (VOC) among different maize varieties using PTRMS and GCMS analysis, figure 8.1. The reported differences in aroma profile of nutritionally unique groups (provitamin A maize, quality protein maize, yellow and white maize) suggest that aroma could contribute to consumer preference. 

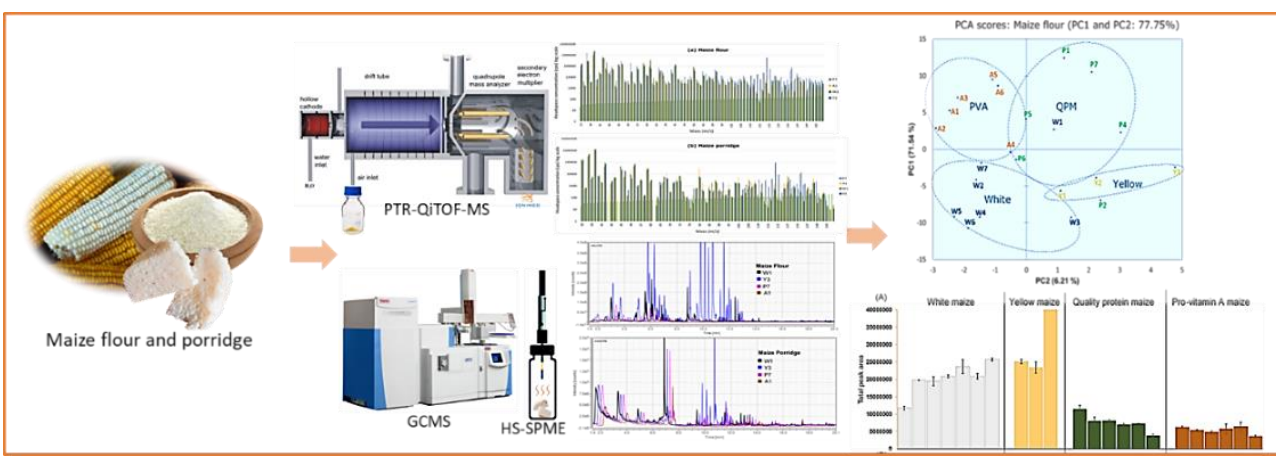

Figure 8.1: Graphical representation of PTRMS and GCMS sampling methods

To find the association of VOC with consumer perception, comprehensive sensory data on African consumer perception is essential. Since African maize consumers are biased towards the white maize, a sensory analysis must be done primarily with this in mind. Methods such as blindfolding, the addition of odourless food colourant or use of coloured lighting in the sensory room can be considered, figure 8.2. The downside of the blindfolding of the panellist is the amount of extra work and time that needs to be invested in the sensory test (which may cause sensory fatigue). Changing room colour may influence perception since some respondents might associate a certain colour to a specific aroma attribute.

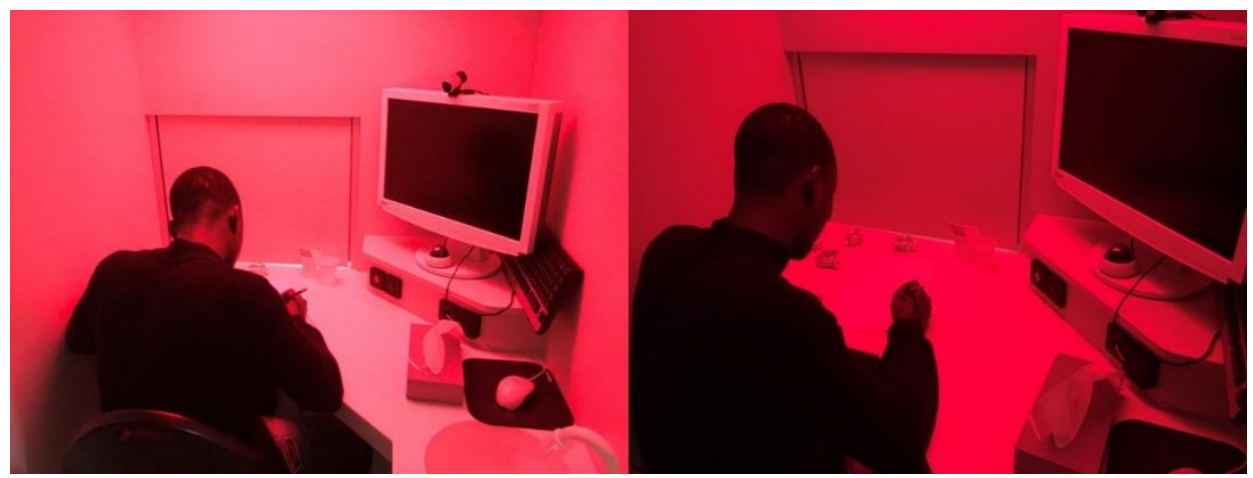

Figure 8.2: An African participant in a sensory booth.

All things considered, sensory analysis must be done with local African consumers since preliminary analysis with Africans in the diaspora showed no significant difference in sensory parameters tested - sweet aroma, overall liking of aroma, sweetness, bitter flavour, sour flavour, flavour intensity and overall liking of flavour, figure 8.3. The association between maize sensory perception and instrumental data could not be found 
in the current research but can be achieved using trained panellists from different countries in SSA combined with PTR - or GC - olfactometry. Improving maize aroma is a challenging task since aromas are yet to be properly understood and classified, but our research in chapter 4 gives information useful for further classification.

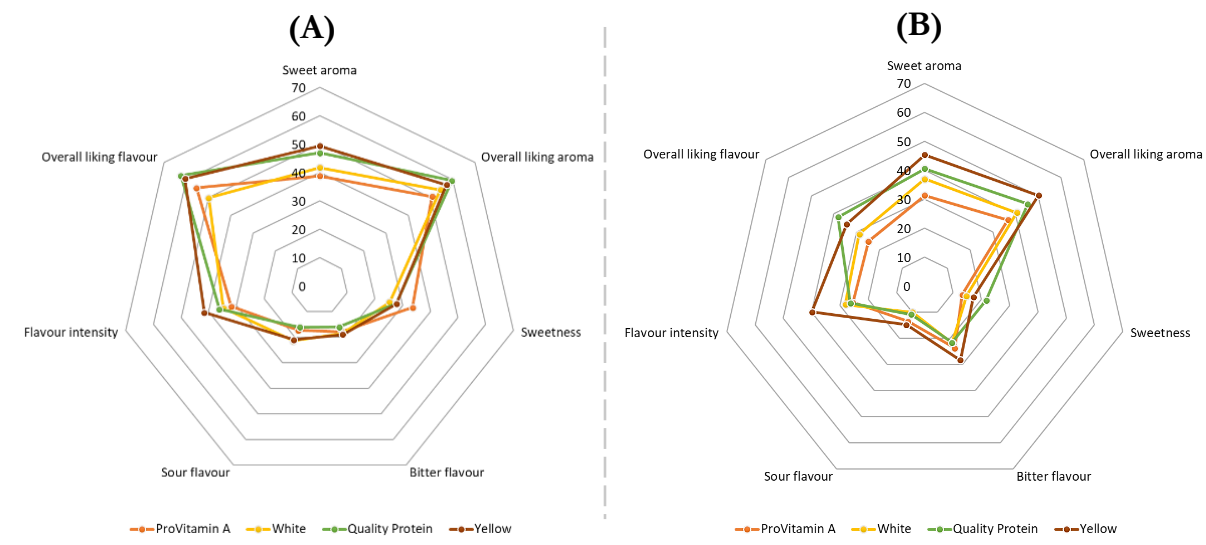

Figure 8.3: Sensory attributes of four maize porridges (Provitamin A variety, white maize variety, quality protein variety and yellow maize variety) rated by a Sub-Saharan African group (A) and Control group (B). No significant differences $(p<0.05)$. Sub Saharan African group $(n=21)$ and control group $(\mathrm{n}=15)$.

\subsection{Nixtamalization using available local African alkaline salt - Kaun}

In chapter 2, we emphasised the importance of nixtamalization to maize product diversification and nutritional improvement in Africa. Nixtamalization is a technique in which maize is cooked in water containing calcium hydroxide, $\mathrm{Ca}(\mathrm{OH})_{2}$. The usefulness of the method in bread making was tested in chapter 6 . One of the main constraints to the thriving of the nixtamalization technique in Africa is the availability of calcium hydroxide - $\mathrm{Ca}(\mathrm{OH})_{2}$ (a potent alkaline salt for the method). Besides, calcium in the $\mathrm{Ca}(\mathrm{OH})_{2}$ has been suggested to have an inhibitory effect on the bioavailability of iron and zinc. ${ }^{[18]}$ Calcium competes with iron and zinc for binding sites on phytate (IP6) to form insoluble calcium-IP6-iron/zinc complexes, which limit bioavailability.[18] Kaun $\left(\mathrm{Na}_{2} \mathrm{CO}_{3} \cdot \mathrm{NaHCO}_{3} \cdot 2 \mathrm{H}_{2} \mathrm{O}\right)$ is an affordable and readily available rock salt that occurs naturally in most parts of Africa, which could be a good alternative to $\mathrm{Ca}(\mathrm{OH})_{2}$. Kaun is used for several traditional dishes in SSA to reduce cooking time and improve flavour and texture, but not yet for maize processing. 
Table 8.1: Mineral composition of Kaun salt (local African rock salt)

\begin{tabular}{|c|c|c|c|}
\hline & Kaun Salt 1 & Kaun Salt 2 & Kaun Salt 3 \\
\hline \multicolumn{4}{|c|}{$[\mathrm{mg} / \mathrm{kg}]^{*}$} \\
\hline $\mathrm{Fe}$ & 211 & 150 & 28.2 \\
\hline $\mathbf{K}$ & 32831 & 16478 & 8323 \\
\hline Mn & 30.40 & 25.9 & 3.49 \\
\hline $\mathrm{Na}$ & 192534 & 245522 & 293413 \\
\hline $\mathrm{Zn}$ & 1.05 & 0.23 & 0.68 \\
\hline \multicolumn{4}{|c|}{$[\mu \mathrm{g} / \mathrm{kg}]^{* *}$} \\
\hline As & 6215 & 2644 & 1972 \\
\hline Cd & 23.10 & 11.50 & 18 \\
\hline $\mathrm{Cu}$ & 1514 & 748 & 208 \\
\hline $\mathrm{Ni}$ & 1583 & 1195 & 240 \\
\hline $\mathrm{Pb}$ & 819 & 694 & 295 \\
\hline
\end{tabular}

Kaun 1, 2 \& 3 were obtained from Accra-Ghana, Ibadan-Nigeria, Ilorin-Nigeria, respectively.

* Measured by ICP-AES ** Measured by ICP-MS

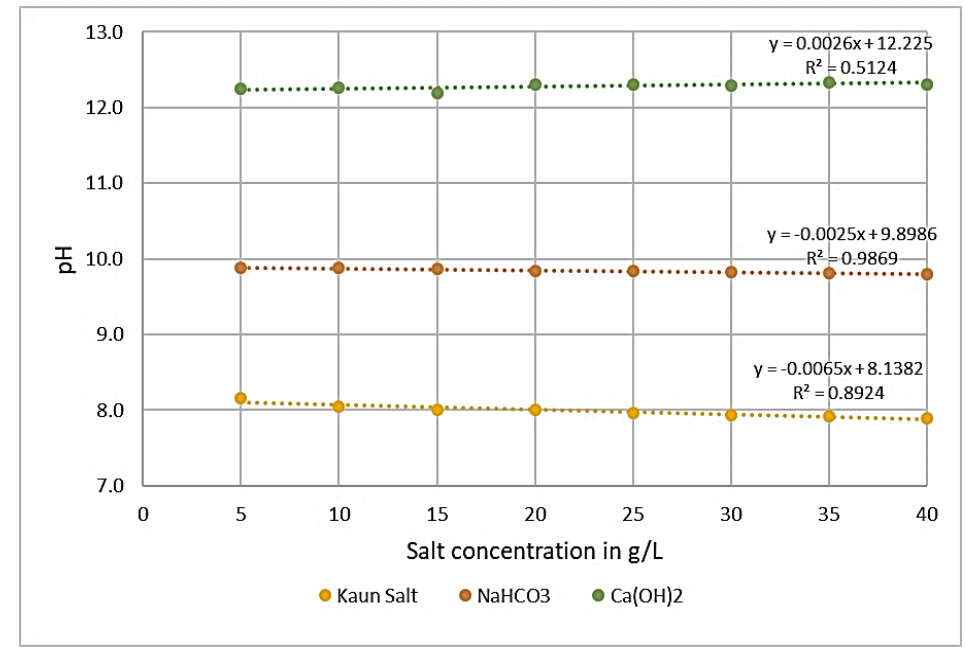

Figure 8.4: Linear curves and fit of the correlation between Kaun salt, $\mathrm{Ca}(\mathrm{OH})_{2}$ and $\mathrm{NaHCO}_{3}$ concentration in $\mathrm{g} / \mathrm{L}$ and the $\mathrm{pH}$ of the solution. 
Kaun is usually sold in its raw form and thus the mineral content was determined to understand the level of purity, table 8.1. Considering that about $3 \%$ is used for nixtamalization, i.e. $30 \mathrm{~g}$ per $1 \mathrm{~kg}$ maize, the heavy metals found in the salt are low and may not pose any health risk, particularly because the salt is mostly washed off after soaking. In all the Kaun salts, $\mathrm{Fe}$ and $\mathrm{K}$ differ significantly but $\mathrm{Na}$ and $\mathrm{Zn}$ did not differ significantly $(\mathrm{p} \leq 0.05)$. Comparing Kaun salt to other common alkaline salts, a Tukey HSD test showed that the average $\mathrm{pH}$ of a Kaun solution (8), $\mathrm{NaHCO}_{3}$ solution (10) and $\mathrm{Ca}(\mathrm{OH})_{2}$ solution $(12)$ differed significantly $(\mathrm{p}<0.01)$ from each other, figure 8.4. High $\mathrm{pH}(>11)$ is required for the desired physical and chemical changes in maize during alkaline cooking, ${ }^{[19]}$ implying that Kaun salt is not strong enough to give the needed changes in the kernel as per nixtamalization technique.

\subsection{Future perspectives: emphasizing the opportunities in Africa's maize value chain}

\subsubsection{Nixtamalized products}

In Mexico, where maize originates, more than $70 \%$ of processed maize is produced using the thermoalkaline method known as nixtamalization. This process has been used for centuries and is the basis of a large diversity of maize-based foods. In Mexico alone more than 300 foods (including masa flour, tortilla, chips, hominy, pazole, atoles, taco shells, tastados, sopapilla, menudo, tastados) are produced with this method, the most common one being the tortilla. ${ }^{[20]}$ For more than 500 years since maize was introduced to Africa, nixtamalization was not known on the continent. However, a form of alkaline cooking is practised in Africa, whereby maize kernels are boiled in water with or without the addition of wood ash. For instance, processing of ogui (an intermediate product for akassa, akpan, koko) in Benin requires preheating in water;[21] the only processing step different from the Mesoamerican technique is the absence of an alkaline ingredient (calcium hydroxide) [22], figure 8.5. Similarly, the Kalenjin people in Kenya prepare githeri by boiling a mixture of maize and beans in wood ash (as alkaline source). The inclusion of ash is believed to improve the taste compared to boiling in plain water. [20] Furthermore, the nixtamalization technique was recently demonstrated for the first time in Africa by CIMMYT and was well received by local communities in Kenya and Ghana.[23] In August 2019, Wageningen University organized an INREF workshop on alkaline cooking for Sub-Saharan Africa in Zambia to get the viewpoints of experts from the represented countries - Zimbabwe, Zambia and Benin. During the workshop, the experts agreed that the alkaline cooking technique combined with fermentation and using a nutrient-dense crop could improve the maize value chain and encourage diversification of products for enhancing the nutritional and socioeconomic status of Africans. Nevertheless, up until now the technique has not been taken up anywhere in 
Africa. Therefore, it is important to identify the appropriate channel to disseminate the processing technology.

The acceptance of the method in Africa seems very feasible through the adoption of local recipes using a consumer-oriented approach. Nixtamalization of maize improves nutritional composition, processing quality, protein and starch functionality, flavour, aroma, and significantly reduces mycotoxin contamination. ${ }^{[20]}$ Nixtamalization has been shown to reduce aflatoxin contamination in maize through extraction and hydrolysis. ${ }^{24}$, 25] This simple processing method can help to reduce the burden of aflatoxin contamination, which is still a huge problem in Africa. Street food vendors can be very effective intermediaries to promote the use of the method. This will serve as an opportunity to spread, scale-up and sustain the innovations. Interestingly, since maize is similar to other indigenous staple crops such as millet and sorghum, the method could be deployed for the benefit of these indigenous crops, which have over the years received less attention. Maize value creation will result in a direct reduction of postharvest losses and create market access for farmers as well as create job opportunities to mitigate migration pressure towards urbanization or the search of "greener pastures" abroad, which is currently a major issue in SSA.

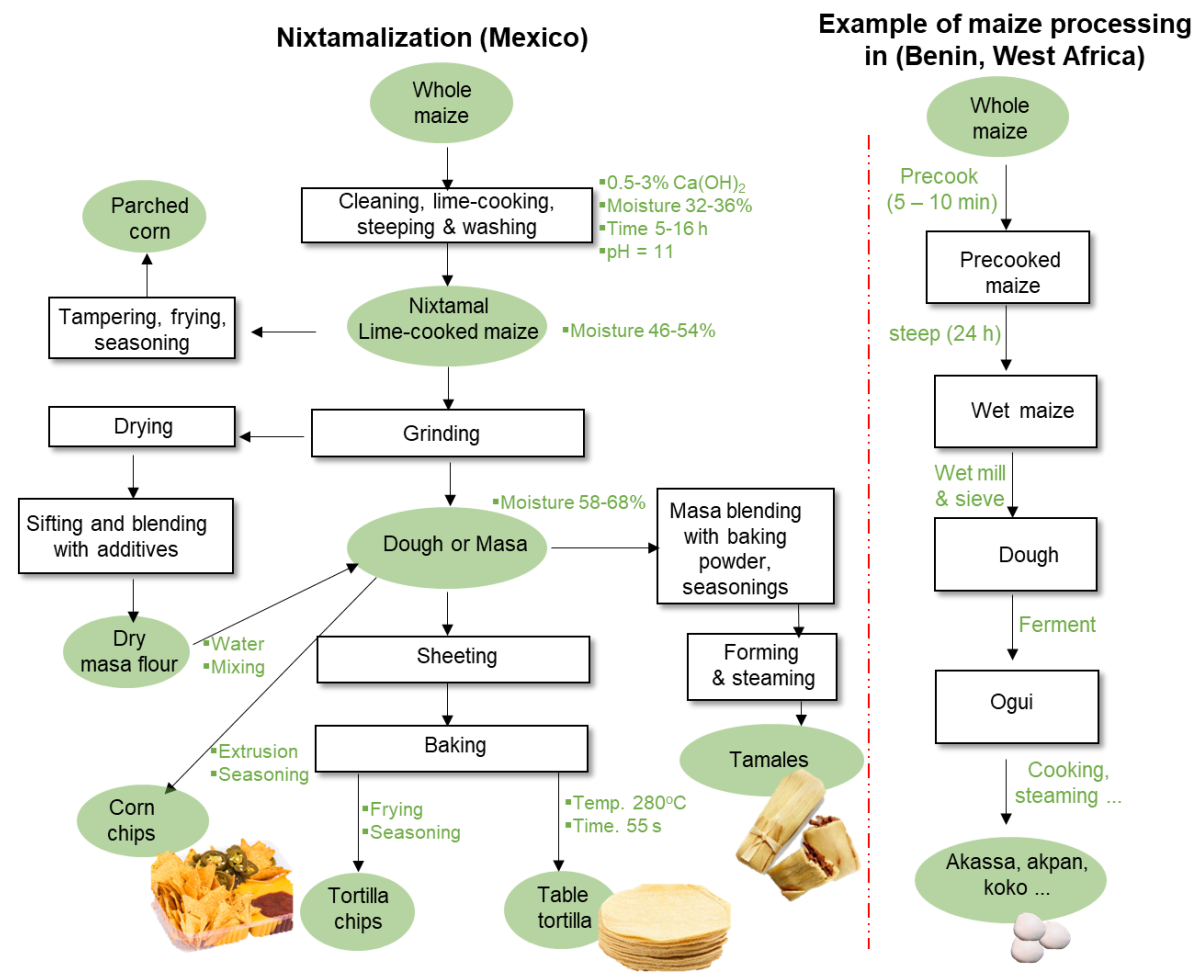

Figure 8.5: Similarities between maize processing in Mexico and a typical traditional food in Benin. 
Nixtamalization is not without its own challenges. Processors in Mexico have been reported to use non-food grade sources of salts, which could cause contamination of food and the environment. Similarly, large volumes of water are required for the nixtamalization process; cooking and washing 1,000 kg maize takes 3,000 - 10,000 L of water. ${ }^{[26]}$ Management of wastewater generated is still a major issue in Mexico, hence wastewater management must be carefully considered before implementing the technique in SSA. It is worthy of note that in Mexico several alternative solutions that require less water have been developed, e.g. the use of microwave technology, extrusion cooking, steam, ultrasonic-assisted techniques and ohmic heating, termed Ecological Nixtamalización Process (ENP).[26]

\subsubsection{Composite flour for bread making}

Policymakers in African countries have over the years advocated the incorporation of local ingredients to make composite flour for bakery use since wheat is not sufficiently grown on the continent. Unfortunately, the policy has not been successful because of issues related to poor shelf life and baking properties, food safety, a decrease of nutritional value and sensory properties due to the inclusion of flours made from cassava, maize, millet, sorghum and other staple crops.[27] Since SSA produces almost enough maize to meet domestic demands, improvement of the functional properties of maize flour could enhance its use for bread making, thereby reducing the dependence on wheat and even promote the use of other indigenous crops such as millet and sorghum. Gluten-free bread has poor texture and taste, short shelf-life, low volume and stales fast. ${ }^{[28]}$ However, using an appropriate technological approach, acceptable bread could be produced using composite flour containing wheat flour and other crops or total replacement of wheat. This proportion of inclusion of $10-20 \%$ non-wheat flour fits with the level accepted by government policies of countries in Africa.

The functional properties and nutritional value of the composite flour can be improved by the inclusion of protein from crops like peanut, sesame seed, sunflower seed, soybeans, cowpea, melon seed, winged bean, bambara groundnut, chickpea, lentil seed, shea nut and sweet potato flour. Composite flours with improved protein, vitamin and mineral content can serve a dual purpose - for bakery use and complementary infant foods. With the use of suitable additives - emulsifiers, hydrocolloids and binding agents and the right flour milling conditions, the viscoelastic and sensory properties of the dough can be enhanced. The inclusion of these additives helps to keep the protein and starch together chemically and mechanically in a spongy structure that is strong enough to hold the air produced by yeast. Different additives or gluten replacers are available and applied in the gluten-free bread industry but it is important to focus on those that are feasible for use by households, street vendors and local companies, to avoid issues 
with reliance on import market and higher costs of bread. Additives such as extracted gum from locust beans, soy lecithin, egg, lard, lamb fat, deodorized shea fat and margarine are effective and easily accessible binding agents that can be used in a composite flour to improve the rheological properties suitable for bread making. Furthermore, pre-gelatinized cereal flour and composite flour made by inclusion of malted grains have been shown to improve dough and bread qualities. [29-31] Likewise, sourdough flour obtained from fermentation using selected mixtures of bacterial strains has been shown to improve maize bread quality. ${ }^{[32]}$ However, in our experiment in Chapter 6, nixtamalized flour did not enhance bread volume and texture, figure 8.6. Therefore, more research work is required to ascertain its application. Acidification of the sourdough during fermentation improves the swelling or water-binding properties of starch and the functionality of protein to enhance the texture of the gluten-free bread.[33] Sourdough improves nutritional quality, i.e. increases mineral bioavailability due to a decrease in the phytate content. Likewise, the low $\mathrm{pH}$ helps to extend shelflife. [32]

Considering that the inclusion of exotic additives may incur a higher cost of bread, pregelatinization, malting, fermentation and addition of local ingredients could play a significant role in improving the quality of maize bread without significantly affecting the cost. With appropriate food processing technology, there are huge opportunities in bread production from composite flour, especially using crops and ingredients sufficiently available in SSA, where the populace mostly depends on imported wheat.

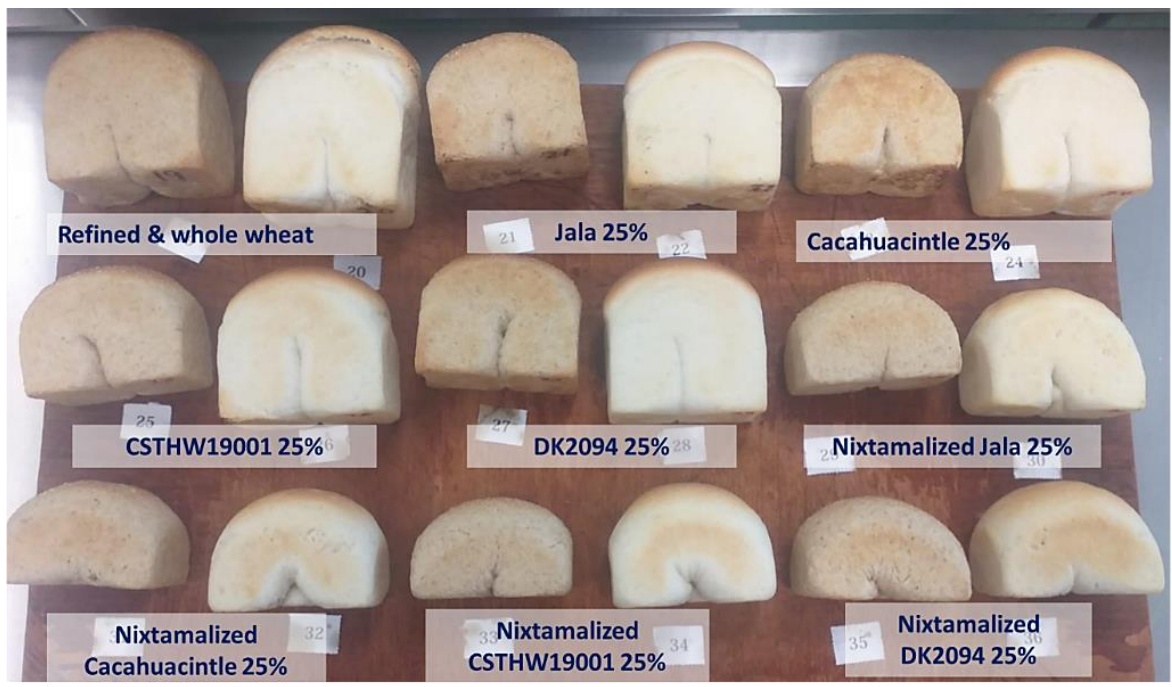

Figure 8.6: Effect of the addition of nixtamalized maize flour on the volume and texture of wheat bread. The bread fomulations contain $25 \%$ native maize flour or nixtamalized maize flour and $75 \%$ refined or whole wheat. Cacahuacintle and jala are maize landraces from Mexico while DK2094 and CSTHW19001 hybrid maize from CIMMYT station in Mexico. The wheat is high Zn variety produced at CIMMYT, Ciudad Obregon, Mexico. 


\subsubsection{Composite flour for complementary foods}

Given the existing rate of malnutrition in Africa, there is a huge potential for the production of composite flours for complementary foods from mixtures of locally available cereals, legumes, nuts and fruits. To augment the poor protein quality of maize, soy-ogi (a blend of soya bean and maize) was developed. [34] Soy-ogi was reported to be low cost and nutritionally sufficient when compared to commercial weaning foods Incaparina, Pro-Sutro, Incaparinaf, etc. The Nigerian government endorsed soy-ogi as a complete protein food for children. ${ }^{[35]}$ However, soy-ogi is yet to thrive due to strong competition from other products and lack of willingness to scale up the production. ${ }^{[36]}$ A modified maize dough (called eko ilera) was prepared by the addition of toasted cowpea flour, red palm oil and sugar, thereby increasing the energy density from 38 to $85 \mathrm{kcal}$ and the protein from 0.8 to $2.0 \mathrm{~g}$ per $100 \mathrm{~g} .{ }^{[37]}$ Seventeen percent of the mothers who participated in the trial adopted the recipe. Similarly, a complimentary food known as Weanimix was developed by the United Nations Children's Fund (UNICEF) and the Ghanaian government. Weanimix is made from 75 - 80\% maize, 10 - 15\% soya bean or cowpeas and 10\% groundnuts. The energy and protein density of Weanimix is much higher than that of maize dough. However, it had high phytate and fibre, and was low in vitamins and riboflavin. ${ }^{34]}$ A modified Weanimix was made by the inclusion of fish powder. The iron content almost doubled, but this did not improve the iron status of infants. ${ }^{[34]}$ It was suggested that the inclusion of alfalfa could boost the nutrient content of the recipe. [38] In another trial, an increase in the crude protein in kenkey from $11 \%$ to $12 \%$ was found after the addition of $20 \%$ cowpea (Vigna unguiculata) to the maize dough.[39] The kenkey that was enriched with cowpea was relatively well accepted by consumers. ${ }^{[39]}$ In Eastern Africa, soya bean was included in the production of ugali. ${ }^{[40]}$ When compared to maize-based ugali, the soya-maize based ugali had an increase in protein and available lysine from $13 \%$ to $20 \%$ and 2.6 to $5.1 \mathrm{~g} / 16 \mathrm{~g} \mathrm{~N}$, respectively, with no obvious effect on taste and digestibility. Other cereal with legume/nut/fruit/vegetables (even cereal with insect) blends have been tested and found to be better than available single protein sources. $[38,41-43]$ Data on home use of the blends are not available but the aforementioned studies show that many opportunities abound in the maize value chain for making of complementary foods.

\subsubsection{Local manufacturing of breakfast and ready-to-eat foods}

Breakfast foods are crucial in every society, especially for school children. The growing trend of development in Africa further strengthens the need to tap into this opportunity since the demand for convenient, shelf-stable, quick and energy saving food is on the rise. The ease of preparing flake foods makes these a common favourite breakfast food in the growing cities. Flake foods are produced by pre-cooking maize in steam and then pressing the maize kernels into flakes. The production process of popular breakfast 
food such as cornflakes is relatively "simple", i.e. cooked corn is milled, passed through a roller with several rounds of drying, then toasted and sprayed with sugar/salt and a nutrient premix before packing in a moisture-proof container. ${ }^{[44]}$ Similarly, extruded products are pre-cooked dry coarse maize flour mixed with additional ingredients and passed through perforated plates (extruder). Despite the ease of processing these products, the sector remains untapped to its full potential in many countries in Africa, especially for the benefit of street vendors. The finished products are largely imported from outside the continent.

Besides, partially or completely cooked traditional cereal products in Africa can be transformed into acceptable shelf-stable breakfast foods that will only take a few minutes of boiling or the addition of hot water to prepare, thus decreasing cooking time and fuel requirements. For instance, maize dough dumplings such as donkunu, gwate and ablo (Chapter 3, table 8.4 and 8.6) can be converted through controlled drying, rolling and toasting to make granules, flakes and couscous, making them shelf-stable breakfast and ready-to-eat foods.

\subsubsection{Starter cultures for bio-enrichment}

Large parts of SSA depend on cereal crops as their staple foods. Unfortunately, the nutritional quality of these crops is poor. ${ }^{[45]}$ In normal maize varieties, zein and glutelin are the main proteins in the kernel. Both proteins are deficient in the essential amino acids lysine and tryptophan; consequently, the protein quality is poor.[45, 46] Likewise, maize products contain low amounts of vitamins since they are mostly lost during processing. ${ }^{[45]}$

Several methods have been used to improve the protein quality of maize. These include, for instance, endogenous fortification using conventional breeding, transgenic breeding, targeted agronomic practices (application of soil fertilizer or foliar sprays) and exogenous fortification using nutrient premixes, blending of nutrient-dense crops and fermentation. Though endogenous fortification has achieved notable success in severe malnourished communities, the approach faces several challenges, e.g. low adoption, climate change and the fact that the increase in nutrient density through plant breeding is often negatively correlated with agronomic properties - yield, pest/disease resistance etc. ${ }^{[47]}$ Since fermentation is used for many foods in SSA, a sustainable increase in the nutritional value of food products can be achieved by improving starter cultures for fermentation. This will reduce the need for the expensive exogenous fortification methods currently practised. Thereby increasing wider coverage and reducing the incidence of malnutrition in Africa. 
Several bio-enrichment methods have been developed to substitute for the expensive chemical production of amino acids and vitamins. ${ }^{[48-50]}$ To improve the protein quality of maize sourdough, microbial in situ bio-enrichment such as the application of high amino acid excreting microorganisms has been used. ${ }^{[51,52]}$ Naturally, microorganisms regulate the amount of nutrients produced, i.e. synthesize only what is required for growth. However, spontaneous mutant microorganisms with defective feedback inhibition or repressor systems have been shown to overproduce essential amino acids and vitamins. ${ }^{[50,51]}$

Sybesma et al. [50] isolated Lactococcus lactis able to secrete both vitamin $\mathrm{B} 9$ and vitamin $\mathrm{B}_{2}$ in in situ fermentation of food. Several vitamin overproducing organisms have been developed. ${ }^{[48]}$ Microbial sources for the production of lycopene, $\beta$-carotene, lutein and zeaxanthin have been reported. ${ }^{[53]}$ These organisms have the potential for the development of low cost and environmental friendly vitamin-enriched food products. Since mineral deficiency remains a major public health issue in SSA, selection of organisms that are capable of degrading antinutrients is also desirable. ${ }^{[54]}$ Furthermore, cereal associated bacteria are known to produce exopolysaccharides (EPS) in large quantities. ${ }^{[55,56]}$ EPS can serve as hydrocolloids to enhance textural properties of glutenfree bread such as specific volume, gas retention, crumb structure, taste as well as reduce hardness and staling rate. EPS is also good for gut health, i.e. prebiotic, and enhances the immune system. ${ }^{[57]}$

Identification and selection of natural, spontaneously nutrient, enzyme and polymer overproducing mutant microorganisms for starter culture production should be prioritized over genetic or metabolic engineering, to avoid legislative setbacks. Selected strains from culture collections of traditionally fermented foods usually have 'generally regarded as safe' (GRAS) status and can be simply adapted for local fermentation to improve nutritional value and maintain sensory and textural properties. ${ }^{[48]}$ The spontaneous mutants could be incorporated as starter culture into natural maize-based food fermentation to augment for the deficient nutrients as well as help to speed up fermentation time, prevent fermentation failure and enhance end-product quality consistency. This innovative and "green" bio-enrichment approach, which has gained little or no attention in Africa, can be used to improve the nutrients that are naturally deficient in crops and also enhance digestion of indigestible crop parts. Depending on the starter culture composition and the cultivation conditions, maize-based foods can be adapted to favour the production of the target nutrient in situ. Starter cultures developed for this purpose need to be fit for use in local communities, work with sustainable energy sources, independent of harsh climatic conditions and be environment friendly. 


\subsubsection{Other opportunities: canned whole maize, wet-milled products and animal feed}

Canned whole maize is produced from green maize, i.e. maize harvested before physiological maturity when it is still green, or from specific sweet maize varieties with natural green maize properties. Green maize helps to close the hunger gap in SSA and is a very important form of maize consumption in Africa.[58] Besides, it is consumed as a whole, thus avoiding nutrient losses associated with refined maize products. Despite the significance of green maize as a means to provide financial security (especially for local women) and its impact on nutrition, it is not available all year round, only during the harvest period. Canning of green maize provides an opportunity to make it available throughout the year, and will also reduce exposure to aflatoxin contamination, which is a major problem with mature kennels dried on the farm. Likewise, both cooked and precooked green maize on the cob can be vacuum packed to obtain a much longer shelf life. Furthermore, current developments in African society, i.e. increasing numbers of cinemas, tourist sites and parks, drive the demand for popcorn, which is a snack usually associated with these environments. Popcorn production still depends on the importation of the appropriate maize variety. It is an important opportunity in the maize value chain with great chances of enhancing the socioeconomic status of street food vendors.

Wet milling, i.e. the process of extracting maize components such as protein, starch, oil, and fibre, is not common in Africa (except in South Africa) and is a long-term opportunity. As society develops, becomes more industrialized and food secured, there will be an increasing need for these maize components as ingredients for pharmaceutical, cosmetic, food and feed industries. Although this research focuses on maize for human consumption, animal feed is an emerging focus in Africa, consequent to the rise in income levels and its significant correlation with meat consumption. Meat consumption in developed countries commonly stagnates or decreases but developing countries (including African countries) are experiencing a growing trend in meat consumption. The OECD and FAO estimated that more than $80 \%$ of the additional meat consumption will come from developing countries. ${ }^{[59]}$ The growing trend in livestock farming, especially poultry in Africa, suggests a continuous rise in the use of maize for feed. This implies that in the near future a large amount of maize will be cultivated (mostly at commercial scale) for animal feed production, as currently is the case in Europe and America. 


\subsubsection{Forward-thinking: people $\&$ planet}

\subsubsection{Less visible hunger, more hidden hunger in the world}

Humans, as the most adaptive and successful species, have come a very long way in terms of providing the basic needs of life, i.e. water, food, shelter, safety and dignity. We have developed resilience and capacities to navigate through countless apocalyptic prognoses and incidents that threatened our existence. About five decades ago, some parts of the world (mostly in Asia and Africa) were marked for extinction due to severe hunger; video streams of starving children were the state of affairs. Then came light at the end of the tunnel - "the green revolution" through the relentless work of scientists around the world, particularly Norman Borlaug. Their miracle crops saved humanity from the doomsday. Recent progress in breeding technology, not to mention the renowned CRISPR-Cas9[60], will foster further development of more miracle crops. Likewise, the advancements in food processing, safety, quality and design will immensely contribute to food and nutrient security. Humanity is now in a better place, the global agri-food system can provide for everybody in the presence of stable social conditions and sustainable distribution channels. As Harari ${ }^{[61]}$ well put it "more people die from eating too much than eating too little these days". Willett et al. ${ }^{[62]}$ in the EATLancet Commission report corroborated the aforesaid.

Globally, the number of people having enough to eat has increased significantly but having enough food does not automatically mean access to a nutritious, healthy and balanced diet. Thus nutrient insecurity, commonly termed "hidden hunger", remains a global public health issue, especially in SSA. Most people in SSA may get their daily calories but many still lack essential minerals (zinc and iron) and vitamins (vitamin A) and suffer from a double burden of malnutrition - undernutrition vs overweight. According to the recent annual report of FAO et al. [63] SSA is still experiencing a rise in hunger with lack of diet diversification being the major culprit, despite the efforts and the progress to achieve Zero Hunger. Hidden hunger stunts the future of children across the globe and grips people in an endless cycle of poverty. Strengthening initiatives such as dietary supplementation, exogenous fortification, endogenous fortification, food nutrient retention methods and particularly food product diversification strategies meant to eradicate visible and hidden hunger at all levels of society, are highly recommended.

\subsubsection{Future perspectives: theory of change}

Maize quality is affected by not just the genetic factors but also by crop management practices and most importantly post-harvest activities until utilization, figure 8.7. Therefore, it is important to integrate every element in the value chain to achieve the best outcome for maize consumers, i.e. system thinking. The problem of feeding the 
current and future population is complex, implying that all solutions need to be brought together in one basket in a holistic manner to tackle the impending food and nutrition insecurity. Sustainable intensification (growing more with little) is a common strategy being promoted but it may centre attention around the crop production system while certainly many food security issues could be solved by paying equal attention to the entire agri-food system. Reducing post-harvest food and nutrient losses in SSA, most of which are associated with storage problems and inefficient food processing, will significantly support nutrient supply.

Sustainable intensification is only effective when the entire value chain is strengthened to prevent losses. This will require a paradigm shift using a system thinking approach, i.e. covering the crop system plus the food system. While the plant breeders ensure the release of nutrient-dense varieties, food scientists and other disciplines must work handin-hand with local stakeholders, especially the consumers, to ensure the adequate use of the crops. Any form of disintegration of cooperation between the stakeholders can negate the efforts of crop improvement. 


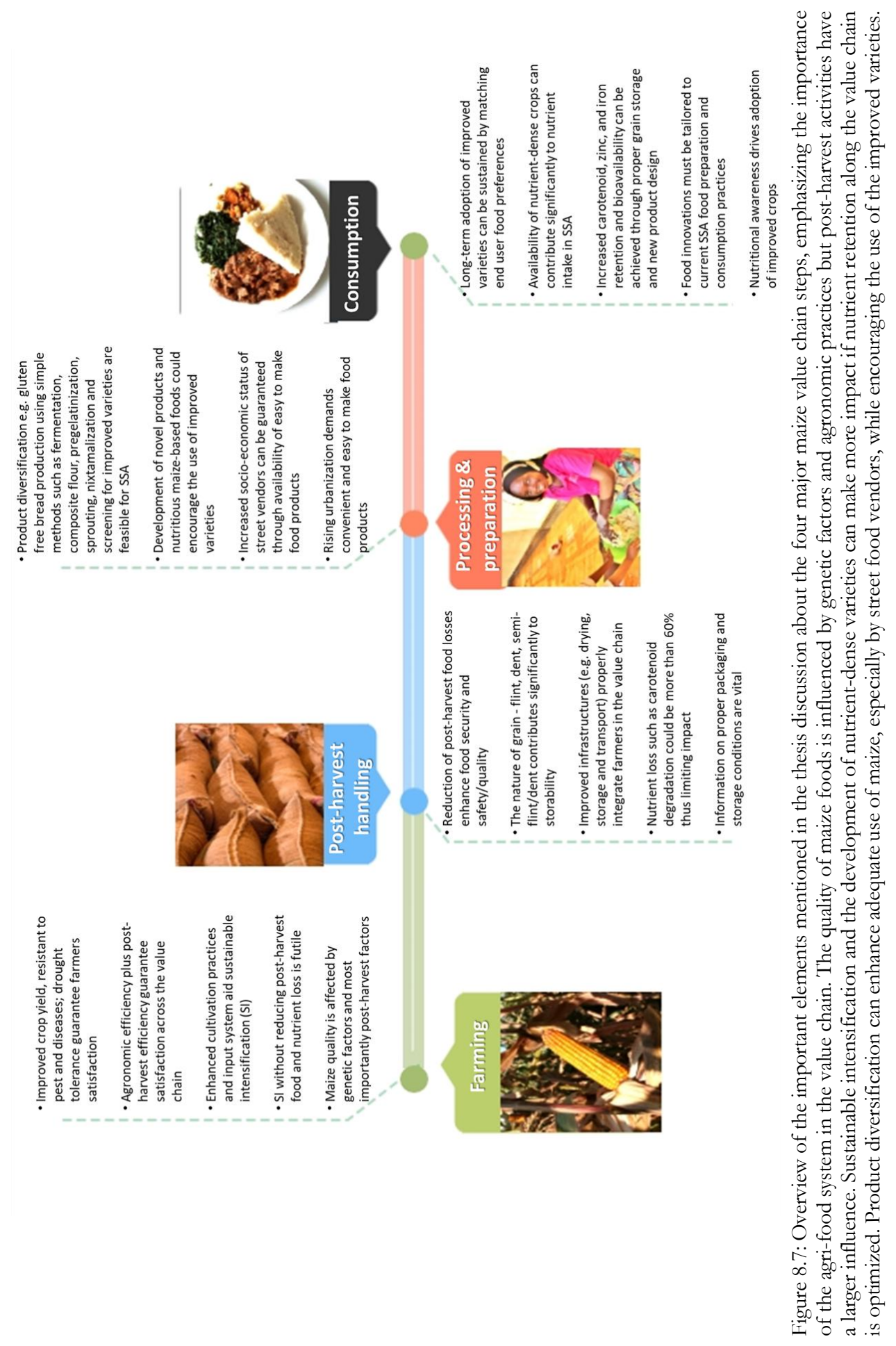


The trend in population growth, rapid urbanization and income rise have increasingly led to shifts in consumption towards convenient foods such as bread and snacks, which are produced from wheat, not sufficiently grown in SSA. If the trend in the dependence on wheat importation is not curtailed, SSA food demands will continue to rely on import markets at the expense of socio-economic development. Improvement of the functional properties of climate-smart indigenous crops to serve as an alternative to wheat is crucial.

Furthermore, the limited value addition to staple crops reduces market access. Street foods constitute the largest part of daily urban food consumption in Africa. However, the roles of street food vendors in food nutrition security and socio-economic development of the continent have not received sufficient attention. Considering the importance of street foods, innovative food science and technology solutions to improve their safety, nutritional, sensory, shelf life and convenience qualities are necessary.

\subsubsection{Concluding remarks}

There are strong indications that interventions in the crop production system alone are not sufficient to meet the nutritional needs of Africans. This is particularly because of the substantial nutrient losses and inefficient use of the major crops. Thus suggesting the need to innovate complementing solutions through crop value chains to deal with the impending food security challenges. To ensure food and nutrition security, the agrifood systems of staple crops must be more efficiently coordinated, thereby creating innovations to feed more people. Value creation (enhancing product diversification, quality, safety, sensory quality as well as the nutritional value of the end product) is critical to unlock untapped potentials of staple crops. Value addition to the maize crop will contribute to all Sustainable Development Goals (SDGs). Acceptability of improved varieties can be encouraged and sustained by the development of novel nutrient-rich and easy-to-make products, especially products targeting the street food sector. 


\section{References}

1. Ekpa O, Palacios-Rojas N, Kruseman G, Fogliano V, Linnemann AR. Sub-Saharan African Maize-Based Foods - Processing Practices, Challenges and Opportunities. Food Reviews International. 2019:1-31.

2. Oke O. Chemical studies on the Nigerian foodstuff" ogi". Food technology. 1967;21:202-4.

3. Oyarekua M, Eleyinmi A. Comparative evaluation of the nutritional quality of corn, sorghum and millet ogi prepared by a modified traditional technique. Journal of Food Agriculture and environment. 2004;2:94-9.

4. Hounhouigan D, Nout M, Nago C, Houben J, Rombouts F. Changes in the physicochemical properties of maize during natural fermentation of mawe. Journal of Cereal Science. 1993;17(3):291-300.

5. Aremu C. Nutrient composition of corn OGI prepared by a slightly modified traditional technique. Food chemistry. 1993;46(3):231-3.

6. Adeniji AO, Potter nN. Properties of OGI powders made from normal, fortified and Opaque-2 corn. Journal of Food Science. 1978;43(5):1571-4.

7. Burt AJ, Grainger CM, Young JC, Shelp BJ, Lee EA. Impact of postharvest handling on carotenoid concentration and composition in high-carotenoid maize (Zea mays L.) kernels. Journal of agricultural and food chemistry. 2010;58(14):8286-92.

8. Phiri S. Spontaneous fermentation of Munkoyo: a cereal-based beverage in Zambia: Wageningen University; 2019.

9. Walker T, Alene A, Ndjeunga J, Labarta R, Yigezu Y, Diagne A, et al. Measuring the effectiveness of crop improvement research in Sub-Saharan Africa from the perspectives of varietal output, adoption, and change: 20 crops, 30 countries, and 1150 cultivars in farmers' fields. Synthesis Report for Objectives. 2014;1.

10. Hassan RM, Mekuria M, Mwangi W. Maize Breeding Research in Eastern and Southern Africa: Current Status and Impact of Past Investments Made by the Public and Private Sectors, 1966-97: CIMMYT; 2001.

11. De Groote H, Kimenju SC. Comparing consumer preferences for color and nutritional quality in maize: Application of a semi-double-bound logistic model on urban consumers in Kenya. Food Policy. 2008;33(4):362-70.

12. De Groote H, Kimenju SC. Consumer preferences for maize products in urban Kenya. Food and nutrition bulletin. 2012;33(2):99-110.

13. Muzhingi T, Langyintuo AS, Malaba LC, Banziger M. Consumer acceptability of yellow maize products in Zimbabwe. Food Policy. 2008;33(4):352-61.

14. Pillay K, Derera J, Siwela M, Veldman FJ. Consumer acceptance of yellow, provitamin A-biofortified maize in KwaZulu-Natal: original research. South African Journal of Clinical Nutrition. 2011;24(4):186-91.

15. Stevens R, Winter-Nelson A. Consumer acceptance of provitamin A-biofortified maize in Maputo, Mozambique. Food Policy. 2008;33(4):341-51.

16. Pixley K, Rojas NP, Babu R, Mutale R, Surles R, Simpungwe E. Biofortification of maize with provitamin A carotenoids. Carotenoids and Human Health: Springer; 2013. p. 271-92. 
17. Khumalo TP, Schönfeldt HC, Vermeulen H. Consumer acceptability and perceptions of maize meal in Giyani, South Africa. Development Southern Africa.

2011;28(2):271-81.

18. Platt S, Clydesdale F. Effects of iron alone and in combination with calcium, zinc and copper on the mineral-binding capacity of wheat bran. Journal of food protection. 1986;49(1):37-41.

19. Santiago-Ramos D, de Dios Figueroa-Cárdenas J, Mariscal-Moreno RM, EscalanteAburto A, Ponce-García N, Véles-Medina JJ. Physical and chemical changes undergone by pericarp and endosperm during corn nixtamalization-A review. Journal of Cereal Science. 2018;81:108-17.

20. Palacios-Rojas N, Vázquez G, Rodriguez ME, Carvajal M, Molina A, RosalesNolasco A, et al. Lime cooking process: nixtamalization from Mexico to the world. 2016.

21. Nago MC, Hounhouigan JD, Akissoe N, Zanou E, Mestres C. Characterization of the Beninese traditional ogi, a fermented maize slurry: physicochemical and microbiological aspects. International journal of food science $\&$ technology. 1998;33(3):307-15.

22. Fandohan P, Zoumenou D, Hounhouigan DJ, Marasas WFO, Wingfield MJ, Hell K. Fate of aflatoxins and fumonisins during the processing of maize into food products in Benin. International Journal of Food Microbiology. 2005;98(3):249-59.

23. Wawa B. Kenyan maize nutrition and safety get boost from Ancient Mexican technique CIMMYT2016 [updated May 6, 2016. Available from: https://www.cimmyt.org/kenyan-maize-nutrition-and-safety-get-a-boost-fromancient-mexican-technique/.

24. Voss K, Ryu D, Jackson L, Riley R, Gelineau-van Waes J. Reduction of fumonisin toxicity by extrusion and nixtamalization (alkaline cooking). Journal of agricultural and food chemistry. 2017;65(33):7088-96.

25. Elias-Orozco R, Castellanos-Nava A, Gaytan-Martinez M, Figueroa-Cárdenas J, Loarca-Pina G. Comparison of nixtamalization and extrusion processes for a reduction in aflatoxin content. Food Additives \& Contaminants. 2002;19(9):878-85.

26. Ramírez-Araujo H, Gaytán-Martínez M, Reyes-Vega M. Alternative technologies to the traditional nixtamalization process. Trends in food science \& technology. 2018.

27. Abass A, Awoyale W, Alenkhe B, Malu N, Asiru B, Manyong V, et al. Can food technology innovation change the status of a food security crop? A review of cassava transformation into "bread" in Africa. Food Reviews International. 2018;34(1):87102.

28. Kohajdová Z, Karovicova J, Schmidt S. Significance of emulsifiers and hydrocolloids in bakery industry. Acta Chimica Slovaca. 2009;2(1):46-61.

29. Nkhabutlane P, du Rand GE, de Kock HL. Quality characterization of wheat, maize and sorghum steamed breads from Lesotho. Journal of the Science of Food and Agriculture. 2014;94(10):2104-17. 
30. Brites C, Trigo MJ, Santos C, Collar C, Rosell CM. Maize-based gluten-free bread: influence of processing parameters on sensory and instrumental quality. Food and Bioprocess Technology. 2010;3(5):707-15.

31. Watanabe M, Maeda T, Tsukahara K, Kayahara H, Morita N. Application of pregerminated brown rice for breadmaking. Cereal Chemistry. 2004;81(4):450-5.

32. Falade AT, Buys EM, Taylor JR. Effect of Different Non-Wheat Bread Making Methods on the Quality of Maize Bread. Journal of Food Technology. 2017;15(1):1-6.

33. Sly AC, Taylor J, Taylor JR. Improvement of zein dough characteristics using dilute organic acids. Journal of Cereal Science. 2014;60(1):157-63.

34. Lartey A, Manu A, Brown KH, Peerson JM, Dewey KG. A randomized, communitybased trial of the effects of improved, centrally processed complementary foods on growth and micronutrient status of Ghanaian infants from 6 to 12 mo of age. The American journal of clinical nutrition. 1999;70(3):391-404.

35. Akinrele I, Edwards CC. An assessment of the nutritive value of a maize-soya mixture,'Soy-Ogi', as a weaning food in Nigeria. British Journal of Nutrition. 1971;26(02):177-85.

36. Steinkraus K. Industrialization of indigenous fermented foods, revised and expanded: CRC Press; 2004.

37. Guptill KS, Esrey SA, Oni GA, Brown KH. Evaluation of a face-to-face weaning food intervention in Kwara State, Nigeria: Knowledge, trial, and adoption of a homeprepared weaning food. Social Science \& Medicine. 1993;36(5):665-72.

38. Onofiok N, Nnanyelugo D. Weaning foods in West Africa: Nutritional problems and possible solutions. Food and Nutrition Bulletin. 1998;19(1):27-33.

39. Nche P, Nout M, Rombouts F. The effect of cowpea supplementation on the quality of kenkey, a traditional Ghanaian fermented maize food. Journal of cereal science. 1994;19(2):191-7.

40. Nyotu H, Alli I, Paquette G. Soy supplementation of a maize based Kenyan food (ugali). Journal of food Science. 1986;51(5):1204-7.

41. Mbata I, Ikenebomeh M, Ahonkhai I. Improving the quality and nutritional status of maize fermented meal by fortification with bambara nut. The International Journal of Microbiology. 2006;2(2).

42. Oyarekua M. Evaluation of the nutritional and microbiological status of co-fermented cereals/cowpea 'OGI'. Agriculture and Biology Journal of North America. 2011;2(1):61-73.

43. Adeoti O, Elutilo O, Babalola J, Jimoh K, Azeez L, Rafiu K. Proximate, Mineral, Amino Acid and Fatty Acid Compositions of Maize Tuwo-Cirina Forda Flour Blends. . Greener Journal of Biological Sciences. 2013;3(4):165-71.

44. Delcour J, Hoseney RC. Principles of cereal science and technology authors provide insight into the current state of cereal processing. Cereal Foods World. 2010;55(1):212.

45. Nuss ET, Tanumihardjo SA. Quality protein maize for Africa: closing the protein inadequacy gap in vulnerable populations. Advances in Nutrition: An International Review Journal. 2011;2(3):217-24. 
46. Qi GH, Diao Q-Y, Tu Y, Wu S-G, Zhang S-H, editors. Nutritional evaluation and utilization of quality protein maize (QPM) in animal feed. FAO expert consultation and workshop, Bangkok, Thailand; 2004.

47. Ekpa O, Palacios-Rojas N, Kruseman G, Fogliano V, Linnemann AR. Sub-Saharan African maize-based foods: Technological perspectives to increase the food and nutrition security impacts of maize breeding programmes. Global Food Security. 2018;17:48-56.

48. Burgess CM, Smid EJ, van Sinderen D. Bacterial vitamin B2, B11 and B12 overproduction: an overview. International journal of food microbiology. 2009;133(12):1-7.

49. Adebawo O, Ruiz-Barba JL, Warner PJ, Oguntimein GB. Regulation of aspartokinase in Lactobacillus plantarum. Journal of applied microbiology. 1997;82(2):191-6.

50. Sybesma W, Burgess C, Starrenburg M, van Sinderen D, Hugenholtz J. Multivitamin production in Lactococcus lactis using metabolic engineering. Metabolic engineering. 2004;6(2):109-15.

51. Adebawo O, Akingbala J, Ruiz-Barba JL, Osilesi O. Utilization of high lysineproducing strains of Lactobacillus plantarum as starter culture for nutritional improvement of ogi. World Journal of Microbiology and Biotechnology. 2000;16(5):451-5.

52. Odunfa S, Adeniran S, Teniola O, Nordstrom J. Evaluation of lysine and methionine production in some lactobacilli and yeasts from Ogi. International journal of food microbiology. 2001;63(1):159-63.

53. Borowitzka MA. Carotenoid production using microorganisms. Single cell oils: Elsevier; 2010. p. 225-40.

54. Hellström AM, Vázques-Juárez R, Svanberg U, Andlid TA. Biodiversity and phytase capacity of yeasts isolated from Tanzanian togwa. International journal of food microbiology. 2010;136(3):352-8.

55. Hüttner EK, Dal Bello F, Arendt EK. Identification of lactic acid bacteria isolated from oat sourdoughs and investigation into their potential for the improvement of oat bread quality. European Food Research and Technology. 2010;230(6):849-57.

56. Schwab C, Mastrangelo M, Corsetti A, Gänzle M. Formation of oligosaccharides and polysaccharides by Lactobacillus reuteri LTH5448 and Weissella cibaria 10M in sorghum sourdoughs. Cereal Chemistry. 2008;85(5):679-84.

57. Ruas-Madiedo P. Methods for the screening, isolation, and characterization of exopolysaccharides produced by lactic acid bacteria. J Dairy Sci. 2005;88:853-66.

58. Alamu O, Maziya-Dixon B, Olaofe O, Menkir A. Varietal and harvesting time effects on physical characteristics and sensory properties of roasted fresh yellow maize hybrids. IOSR Journal of Applied Chemistry (IOSR-JAC). 2015;8(2):55-63.

59. OECD-FAO. OECD/Food and Agriculture Organization of the United Nations (2014), OECD-FAO Agricultural Outlook. (OECD/FAO); 2014.

60. Razzaq A, Saleem F, Kanwal M, Mustafa G, Yousaf S, Arshad I, et al. Modern trends in plant genome editing: an inclusive review of the CRISPR/Cas9 toolbox.

International journal of molecular sciences. 2019;20(16):4045. 
61. Harari YN. Homo Deus: A brief history of tomorrow: Random House; 2016.

62. Willett W, Rockström J, Loken B, Springmann M, Lang T, Vermeulen S, et al. Food in the Anthropocene: the EAT-Lancet Commission on healthy diets from sustainable food systems. The Lancet. 2019;393(10170):447-92.

63. FAO, IFAD, UNICEF, WFP, WHO. a. The State of Food Security and Nutrition in the World 2019. Safeguarding against economic slowdowns and downturns. Rome, FAO. 2019;Licence: CC BY-NC-SA 3.0 IGO. 


\subsubsection{General summary}

Feeding 2.4 billion mouths in Africa by 2050 will require all hands on deck as the demand for cereals may triple. Viable options to feeding Africa include measures with respect to (a) food technology, e.g. improved utilization of the available crops and their by-products, (b) plant breeding, e.g. through bio-fortification, and (c) agronomy, e.g. yield improvement and sustainable crop intensification. Although the latter two options have received most research traction, the current cereal yields in sub-Saharan Africa (SSA) is about $20 \%$ of its potential. Crop intensification has huge economic and environmental implications while biofortified crops have not received the expected adoption. This reinforces the importance of strategies aimed at optimizing crop utilization such as the prevention of food and nutrient losses as well as enhancing product diversification from existing climate-resilient crops to feed the ever-rising population. Matching consumer preferences and enhancing the ease of processing of maize into different food types will support better use, with positive consequences on reducing malnutrition and alleviating poverty.

Many high potential maize products that are localized or confined to particular communities can be scaled up across the continent and beyond for prosperity, as elaborated in chapter 2 . This will require standardization of the processing conditions for effective monitoring and evaluation. Curbing nutrient loss during post-harvest handling of maize will enhance the nutritional status of Africans relying on maize as a staple crop. Furthermore, research on more effective ways to enhance the protein quality i.e. tryptophan and lysine as well as vitamin content of maize-based foods especially through novel fermentation technique is important. Novel fermentation techniques such as the use of microbial fortification or bio-enrichment using high lysine producing microorganism could help to ameliorate the poor protein quality of maize foods. This was briefly highlighted in the pilot test carried out with three strains of bacteria in this thesis discussion. Microbial fortification has potential to produce healthy maize food with quality protein but must be through methods that are feasible for use, safe, meet organoleptic preferences of consumers, work under sustainable energy sources, independent of the harsh climatic condition and environmental friendly.

Chapter 3 stressed that tackling malnutrition in Africa requires a holistic strategy that stretches across the entire agricultural value chain - Crop-to-Health strategy i.e. from agronomy to beyond plate. Maize value chain improvement with a keen consideration of end user preferences will have a broader impact on the target population. Matching the flavour and taste preference, and enhancing the ease of processing of maize into different food types will guarantee a better consumption of maize in the future, with a better contribution to reducing malnutrition. Therefore, an adequate understanding of 
the needs of the consumers and incorporating it into breeding programs will help to properly harness research resources, increase adoption of new varieties, improves nutrition and also protects the traditions of the local communities. Six clusters of maize breeding objectives were identified in chapter 3. We develop a framework which identifies the relationship between the breeding objectives and how it impacts farmers, food processors and consumers to achieve sustainable food security. This will help breeders to examine in detail how to establish those priorities.

In aroma analysis presented in chapter 4 and 5, PTRMS gives signals of the headspace while GCMS gives signals of headspace/fibre system hence signal differences in both instruments were found. PTRMS was very useful to give a quick "snapshot" of differences among maize varieties while GCMS was efficient for the identification of VOCs. Generally, vast volatile differences were found in maize genotypes which could help to further improve the flavour of the crop. PTR-QiTOF-MS used for the first time on maize successfully clustered the 22 maize varieties in four nutritionally distinct categories while 69 volatile compounds were identified for quality protein maize, provitamin A maize, white and yellow maize. The nutritional contribution of biofortified maize varieties is significantly limited by loss of the provitamin A content even at the earliest stage of post-harvest handling such as storage; more deteriorations of nutrient occur after processing, as shown in chapter 5. Furthermore, the carotenoidrich varieties are prone to aroma deterioration during storage which may negatively influence consumer perception.

Chapter 6 showed significant differences in maize genotypes (landraces and hydrides) for bread making performance. Suitable maize flour can be obtained for gluten free bread through selection of appropriate genotypes. Similarly, sourdough technology can help to further improve the functional properties of the flour for better bread-making performance, as observed in chapter 7. Fermentation is a common practice for maize food in SSA and cereal associated bacteria are known to produce exopolysaccharides (EPS) in large quantities which can enhance dough quality. Screening for EPS producing bacteria in ogi and munkoyo generated $10 \%$ producers and $22 \%$ producers respectively, chapter 7. Isolated EPS producing lactic acid bacteria were identified using morphological, biochemical and microscopic observations as $W$. confusa, a common EPS producer. EPS can serve as hydrocolloids to enhance textural properties of gluten-free bread such as specific volume, gas retention, crumb structure, taste as well as reduce hardness and staling rate. Availability of suitable maize flour for bread making could replace or reduce Africa's reliance on wheat for bread making which would certainly improve the socioeconomic status of people. 


\section{Acknowledgement}

It's been a long ride - no GPS, no google maps, just go go go, you never know where the road leads. It was never an easy ride. Bumps upon bumps but I have paid my dues. I couldn't have done it without the help of many people.

\section{"If I have seen farther, it is by standing on the shoulders of giants"}

\section{(Sir Isaac Newton)}

I acknowledge all previous work upon which I have incrementally built my work. Special thanks to my giant supervisors whose shoulders I have confidently stood in the past four years - Prof Vincenzo Fogliano, Dr Anita Linnemann, Dr Stefano Renzetti, Dr Natalia Palacios and Dr Gideon Kruseman. You helped me to evolve in research and as a total person. Vincenzo and Anita, thank you for believing in me. I will forever be indebted to the opportunity you gave me. Vincenzo, thank you for always giving vital inputs, comments, suggestions and advice which helped to improve my research and personal capabilities. Anita, you go above and beyond to inspire and guide me both in research and personal life. The weekly meeting with you was anti-stress, anti-anxiety and anti-negativities. Many thanks!

Special thanks to the students I was privileged to supervise their BSc/MSc thesis or internship - Aniek de Vos, Marijn van den Dikkenberg, Charles Antwi, Hortense Carrot, Mira Theunissen, Nadine Uwobasa, Trine Hojgaard, Hongeun Choi, Fleur de Groot, Nicole Medema, Linarty Linarty, Shuan Peng, Chatpavee Wongsirichat and Esteban Gutierrez. Thanks for the support in laboratory work. Words cannot express my appreciation for your contribution to this research and my personal growth as a supervisor. I am always buzzing with joy every time I see you around. The kind of happiness I get from hearing that you are doing very well in your career is unexplainable. I wish you all the best!

Many thanks to the highly esteemed FQD lab technicians - Geert, Erik, Charlotte, Xandra, Frans and Mike for the wonderful support. Geert I will always appreciate your great support in GCMS analysis. Hmm, Erik, your dedication is awesome. I think there should be a reality TV show for you - "The Incredible Mr Erik". It's amazing how many questions you answer per day! Charlotte, I have learnt a lot from you. Thanks! Frans, thanks for keeping us safe.

Cheers to all my colleagues for the great time we have had together. I will forever exercise the lessons I have learnt from every one of you. The FQD office culture is amazing! Many thanks to Kimberley, Corine and Lysanne for your support in 
administration processes. Kimberley and Corine, I will always appreciate your prompt booking of my defence. Thanks to Pieternel Luning for giving me a strong foundation during my MSc thesis and internship. Many thanks to Sara Erasmus and Sine Yener for their technical support in PTR-MS analyses. Isabelle Silvis and Valentin Acierno, thanks for the lessons during my traineeship at RIKILT.

Many thanks to the staff of CIMMYT (Mexico) maize and wheat quality laboratory for technical assistance and great hospitality during my stay in Mexico - Alejandra, Dionisio, Bertha, Ruben, Irving, Miguel \& German, Aldo, Aide, Luisa, Dr Carlos, Anayeli, Ana, Gabriel, Arturo, Leticia, Cynthia, Hector and Orlando.

To all UCAS board member 2018/2019 - Emily Ongus, Abiola Adebayo, Oluwaseun Akinlade, Lordina Eshun and Spencer Matiki thank you for the successful tenure. I wouldn't have done anything without you beside me. Being the president of UCAS shaped my leadership skills. Emily, your work ethic is superb. You will change the world! Abiola, your dedication is out of the world. I can't thank you enough! Many thanks to Sawo, Cynthia, Taofiq, Fredy, Mukoma, Catherine and Wushama for keeping the momentum despite the challenges posed by the lockdown. Many thanks to CTA team particularly Judith Francis for the excellent support during One World Week event. Jennie van der Mheen, you have been a great support. Thanks! Astrid van den Heuvel, you are wonderful!

My career started at Standards Organisation of Nigeria (SON) where I met amazing people, some of who shaped my career through actions, words and kindness. Special appreciation to Mrs Idakwo Rabi for the great support during my service year. I thank Mrs Oyenike Owoyele, Mr Ikhenebome David, Mr Stephen Attahiru, Mr Adetoyi Adeyinka, Mr Akinleye Adebayo Felix, Mr Roger John, Mr Jimoh Gambari, Mr Bwallam Baunis, Mrs Adaeze Ruth Adebisi, Mr Alex Odiba, Mr Ibrahim Abdullahi, Mr Auwal Isa Mamman, Mrs Augustina Chinyereugo, Mrs Aderonke Apim, Deaconess Arannilewa Comfort, Mr Bashir Shehu Gwandu and Mr Lucky Akoma. Sorry, no order of ranking applied and pardon me if I address you wrongly. I guess some $\mathrm{Mr} \& \mathrm{Mrs}$ on the list are Dr or Prof now. I appreciate you all and hope our path cross again.

Many thanks to Mrs Ndidi Nwuneli and Mr Mezuo Nwuneli. You taught me passion and values, both of which have kept me sailing through every life obstacles. I so much respect and look up to you. Mr Segun Adebanji, the few minutes I spent with you through AiMP mentorship programme shaped my thinking system a lot. Thanks for supporting my trip. Pst. John Enelamah keep the ball rolling. You are raising a generation of people with great integrity. Keep changing the world. 
A special thanks to my paranymphs Sara Erasmus and Nur Alim Bahmid for all the effort put into my PhD defence. I will be forever grateful.

To AGP church, the 5 years with you was a great blessing. Thanks, Pst. Farai, Pst. Busi, Pst. Adesuwa, my sure oga (Ikenna), Elton, Biaty and all AGP members. ICF church and Ede connect group, thanks for receiving me and Laura with both hands. One love to Naija connect Wageningen - you have been my home away from home.

Uche Okafor and Mashood Giwa, you are childhood friends that stood out for me in days of needs during my undergraduate. I hope I can repay you one day in many folds. Thank you from the bottom of my heart. Mrs Martha Anyanwu and Mrs Idowu Sanni, thanks for your support and friendship. I appreciate you!

To my Dad and Mom, thanks for making me believe that education is the greatest inheritance you can give me. My inheritance is well received in perfect condition, thanks! I have broken the formidable rooftop and I believe many in the family and elsewhere will follow suit. Dad, you have always said you will sell everything you have to send your children to school if situation demands. Now I know why! Education is way cheaper than ignorance. A wise investment, bravo! Mom, even though circumstance did not allow you to get the education your brilliant mind deserves, you insisted that I register for pre-university courses which gave me access to study Biochemistry while I was fruitlessly applying to study medicine. Your decision shaped my life. Here I am, a doctor of food, not medicine. Anyway, food is medicine. Next time you ask me for a drug prescription (as usual) I will prescribe nice fruit and vegetables :) . Dad and Mom, you have educated my mind and heart, the world will be a better place for it. You can trust me on that. May you live long in sound health to enjoy the fruits of your labour.

To my siblings - Sunday, Enemona, Ojoma, Faith, Solomon, Ojima and Favour thank you for all your supports. Thanks to Bekky, Joel and Eliot! I am grateful to Adesuwa for her motherly support in The Netherlands. To Mr \& Mrs Joseph Isaiah Edogbo who were instrumental to my undergraduate admission and guidance, thanks and may heaven reward you greatly.

Mr \& Mrs Pol, bedankt voor het accepteren van mij in jullie mooie familie. Ik bewonder uw onbaatzuchtige steun. Veel dank aan Machlien, Joost, Elles, Ruth, Sarah, Johan, Marcus, Daniel, Mieke, Jiska en de nieuwste baby in de familie, Femke. Dank u wel oma Pol! Bedankt voor uw liefde en warm welkom elke keer weer. 
My sweetheart Laura - we started this journey together. You have been my source of inspiration and strength. Coffee and love taste best when hot, keep the flame burning! Who knows, maybe one day you might want to do your PhD too. I will be right behind you like a rock. Dank je wel, lieverd! We made it!

And last but never the least, my unborn children. The hope of giving you and your generation a better life kept me going. Thanks! I wish I can put your names here but you are still X or Y chromosomes apart. I understand that the world can be a stressful and tiring place so I want to use this once-in-a-lifetime opportunity to write you a short note. Don't forget to be a child because there won't be a replay button. Do not be too anxious about the future, the future will take care of itself. Put all your worry on me (and your mom), it's our job to worry for you while you enjoy life. When you are weak, remember I said you are the strongest person I will ever meet. When anxious, remember I said anxiousness causes a problem that was not there in the first place. When facing challenges, remember I said Ojo gives hardest battles to the strongest soldiers. Yes, you are a gladiator! When bad times come, remember I said this too shall pass (be patient). When you do wrong, remember I said don't be too hard on yourself, we are so imperfect being. The past is out of your control, moving forward is within your control. Move on and do good for humanity. You only live once so treat yourself good, be silly, eat well, travel far and wide, take risk, do sport for fun, do the unthinkable, attempt the impossible, break limits, be kind, be awkward, say what you think, write what you think, learn and write computer coding (AI will rule your generation!), make mistakes and learn, fail forward, fail cheap, give people chances, see good in others, value others, don't compare yourself to others, value yourself, don't give up to the low life bully (and don't ever be a bully!), embrace your stunningly gorgeous colour, embrace your kinky cute hair, laugh it out, cry it out, have a cause greater than yourself, be yourself, be patient, believe, forgive, trust, care and love unconditionally. There's no time for anything else. Time will never be right for anything anyway! I wish you a lifetime of happiness!

Finally, if I omitted you in this acknowledgement, I apologize for that. A Nigerian proverb says "It takes a whole village to raise a child" - you are a bonafide member of the village that raised me well. Please trust that my appreciation of you is not less than those stated above! 


\section{About the Author}

Onu Ekpa was born in Nigeria on October $30^{\text {th }}, 1986$. He obtained a bachelor's degree in Biochemistry from the University of Ilorin (Nigeria). Afterwards, he worked in the food industry for four years before progressing with his studies. While working in the food industry, he managed the relocation of the company to her permanent site as well as upgraded the quality control department and initiated product line extension. He managed

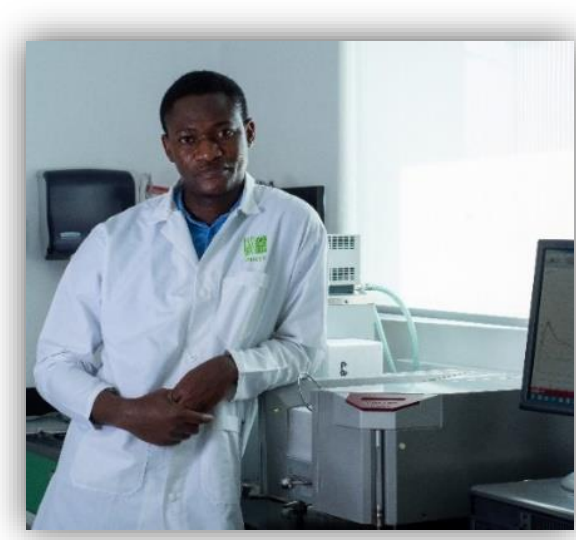
the development, reformulation and registration of five food products that are still doing very well in the market after six years. He obtained a master's degree in Food Quality Management at Wageningen University. During his master thesis, he assessed factors influencing the control of raw milk safety in Kenya and the roles of inclusive business model. While his $\mathrm{PhD}$ thesis presented here assessed different ways to improve the shelf life, nutritional value and diversification of maize-based foods. He supervised courses such as case studies product quality, and advanced fermentation science. He also supervised diverse topics of masters/bachelor theses and internship students of a wide range of background, personalities and nationalities. In 2018, Onu founded an agribusiness - Eion Ltd in Nigeria to boost protein supply. He was the president of UCAS - United Community of African Student, Wageningen from 2018 - 2019. He has functioned in reputable organizations such as SON (Nigeria), Aace Foods Ltd (Nigeria), RIKILT (Nederland), Bio Food Products (Kenya), CIMMYT (Mexico) and WUR (Nederland).

Onu's ultimate vision is to empower people through the development and management of ground-breaking products and services. Onu enjoys reading, writing, playing football and travelling.

What next on Onu's career bucket list? Exciting job, MBA, master computer coding and serial entrepreneurship.We can do a lot together, stay in touch: ekpa.onun@gmail.com.

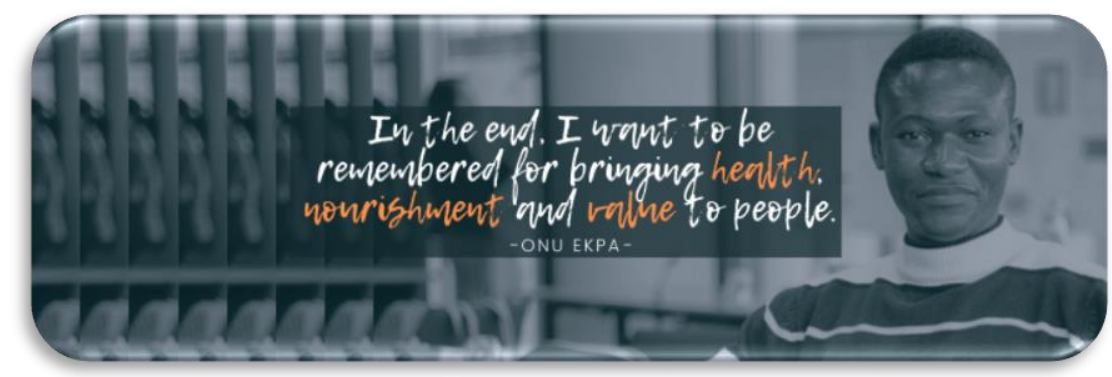




\section{List of publications}

- Ekpa O, Palacios-Rojas N, Kruseman G, Fogliano V, Linnemann AR. SubSaharan African maize-based foods: Technological perspectives to increase the food and nutrition security impacts of maize breeding programmes. Global Food Security. 2018;17:48-56.

- Ekpa O, Palacios-Rojas N, Kruseman G, Fogliano V, Linnemann AR. SubSaharan African Maize-Based Foods - Processing Practices, Challenges and Opportunities. Food Reviews International. 2019:1-31.

- $\quad$ Ekpa, O., Palacios-Rojas, N., Rosales, A., Renzetti, S., Fogliano, V., \& Linnemann, A. R. (2020). Genotype selection influences the quality of glutenfree bread from maize. LWT, 109214.

- Identification of the volatile profiles of 22 traditional and newly bred maize varieties and their porridges by PTR-QiTOF-MS and HS-SPME/GC-MS. (submitted)

- Carotenoid stability and aroma retention during the post-harvest storage of biofortified maize. (submitted)

- Influence of exopolysaccharides produced by lactic acid bacteria on the quality of maize bread. (submitted) 


\section{Overview of training activities}

\begin{tabular}{|c|c|c|}
\hline Courses & $\begin{array}{l}\text { Graduate } \\
\text { school/Institute }\end{array}$ & Year \\
\hline \multicolumn{3}{|c|}{ Category A: Discipline specific activities } \\
\hline Advanced food analysis (The Netherlands) & VLAG & 2017 \\
\hline Healthy food design (The Netherlands) & VLAG & 2018 \\
\hline $\begin{array}{l}\text { Healthy and sustainable diets: synergies and trade- } \\
\text { offs (The Netherlands) }\end{array}$ & VLAG & 2019 \\
\hline $\begin{array}{l}\text { Evaluation of grain, flour and bread quality using } \\
\text { maize landraces (Mexico) }{ }^{b}\end{array}$ & $\begin{array}{l}\text { FQD/CIMMYT } \\
\text { Academy }\end{array}$ & 2019 \\
\hline Rheology: The do's and don'ts (The Netherlands) & VLAG & 2019 \\
\hline $\begin{array}{l}\text { SDG-Conference 'Towards Zero Hunger: } \\
\text { Partnerships for Impact (The Netherlands) }\end{array}$ & WUR & 2018 \\
\hline Symposium Population Dynamics (The Netherlands) ${ }^{b}$ & SKOV & 2019 \\
\hline $\begin{array}{l}\text { 18th European Young Cereal } \\
\text { Scientists and Technologists Workshop (Italy) }{ }^{b}\end{array}$ & $\begin{array}{l}\text { Università di } \\
\text { Camerino }\end{array}$ & 2019 \\
\hline $\begin{array}{l}\text { Workshop on WOTRO-INREF-alkaline cooking } \\
\text { (Zambia)c }\end{array}$ & WUR/CUT & 2019 \\
\hline $\begin{array}{l}\text { EFFoST - European Federation of Food Science } \\
\text { and Technology conference (The Netherlands) }{ }^{a}\end{array}$ & WUR & 2019 \\
\hline $\begin{array}{l}\text { Virtual 15th Plant-Based Foods \& Proteins Summit. } \\
\text { (online) }\end{array}$ & Bridge2food & 2020 \\
\hline $\begin{array}{l}\text { Discovery Days: Virtual insights into the } \\
\text { digitization in the process industry. (online) }\end{array}$ & CSB & 2020 \\
\hline Future Food for a Sustainable Planet. (online) & QAAFI & 2020 \\
\hline
\end{tabular}

\section{Category B: General courses}

\begin{tabular}{|l|l|c|}
\hline Data Management Planning (The Netherlands) & WGS & 2017 \\
\hline $\begin{array}{l}\text { Introduction to R for Statistical Analysis (The } \\
\text { Netherlands) }\end{array}$ & VLAG & 2017 \\
\hline Applied Statistics (The Netherlands) & VLAG & 2017 \\
\hline Chemometrics (The Netherlands) & VLAG & 2017 \\
\hline Scientific Writing (The Netherlands) & WGS & 2017 \\
\hline $\begin{array}{l}\text { Philosophy and Ethics of Food science and } \\
\text { technology. } \\
\text { (The Netherlands) }\end{array}$ & WGS & 2018 \\
\hline \multicolumn{1}{|c|}{ Category C: Optional } & 2016 \\
\hline VLAG Proposal (The Netherlands) & VLAG & 2018 \\
\hline Global Food Science Student Competition (China)
\end{tabular}




\begin{tabular}{|l|l|l|}
\hline Tropentag 2018 (Student Reporter) (Belgium) ${ }^{b}$ & Ghent University & 2018 \\
\hline $\begin{array}{l}\text { Dutch Nigerian Student Business Challenge } \\
\text { (Nigeria) }\end{array}$ & $\begin{array}{l}\text { Delft University of } \\
\text { Technology }\end{array}$ & 2018 \\
\hline PhD Trip (Australia) ${ }^{b}$ & FQD & 2018 \\
\hline $\begin{array}{l}\text { African Union Research Grant 2018 Open call for } \\
\text { proposal }\end{array}$ & FQD & 2018 \\
\hline PhD Supervision & VLAG PhD council & 2019 \\
\hline Business foundations courses. (online) & $\begin{array}{l}\text { Quantic school of } \\
\text { business and } \\
\text { technology }\end{array}$ & 2020 \\
\hline Six sigma white and yellow belt. (online) & VMEdu & 2020 \\
\hline Food defence awareness. (online) & FSPCA & 2020 \\
\hline
\end{tabular}

a Poster presentation

b Oral presentation

c Organizing committee 
The research described in this thesis was financially supported by Food Quality and Design Group, Wageningen University, the Netherlands.

Financial support from Wageningen University for printing this thesis is gratefully acknowledged.

Cover design and layout by Onu Ekpa

This thesis was printed by Digiforce || ProefschriftMaken 

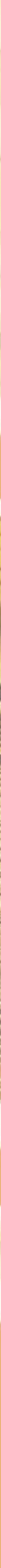